Ewald Werthmöller

Räumliche Identität als Aufgabenfeld des Städte-
und Regionenmarketing 
Ewald Werthmöller

\section{Räumliche Identität als Aufgabenfeld des Städte- und Regionenmarketing}

Angesichts der wachsenden Intensität des interkommunalen Wettbewerbs kommt dem Städte- und Regionenmarketing in Wissenschaft und Praxis wachsende Aufmerksamkeit zu. Die vorliegende Arbeit verfolgt das Ziel, die Bewußtwerdung und kommunikative Herausstellung räumlicher Identität als wesentliche Voraussetzung für die Profilierung im Wettbewerbsumfeld deutlich zu machen. Der Konkretisierung des Begriffsverständnisses räumlicher Identität liegt eine Zweisamkeit zugrunde, welche zwischen der Identität der Person und der Identität des Raumes unterscheidet. Darauf aufbauend werden Erfolgsvoraussetzungen für das Städte- und Regionenmarketing dargelegt. Ergänzend zur theoretischen Diskussion erfolgt eine Überprüfung von Teilaspekten räumlicher Identität auf der Basis einer empirischen Studie.

Ewald Werthmöller wurde 1958 in Düsseldorf geboren. Nach der Ausbildung zum Bankkaufmann folgte das Studium der Betriebswirtschaftslehre an der Universität Münster. Während der Promotion war er als wissenschaftlicher Assistent am Institut für Marketing der Universität Münster tätig. 
Räumliche Identität als Aufgabenfeld des Städte- und Regionenmarketing Ein Beitrag zur Fundierung des Placemarketing 


\section{Schriften zu Marketind und Manasement}

Herausgegebenvon Prof.Dr.Dr.h.c. Heribert Meffert

\section{Band 24}

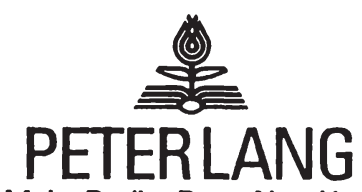

Frankfurtam Main.Berlin. Bern.New York. Paris. Wien 


\section{EwaldWerthmöller}

\section{Räumliche Identität als Aufgabenfeld des Städte-und \\ Regionenmarketing}

Ein Beitrag zurFundierung des Placemarketing

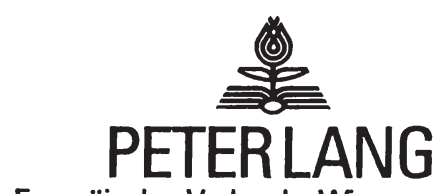

EuropäischerVerlag derWissenschaften 
Die Deutsche Bibliothek - CIP-Einheitsaufnahme

Werthmöller, Ewald:

Räumliche Identität als Aufgabenfeld des Städte- und Regionenmarketing : ein Beitrag zur Fundierung des Placemarketing / Ewald Werthmöller. - Frankfurt am Main ; Berlin ; Bern ; New York ; Paris ; Wien : Lang, 1995

(Schriften zu Marketing und Management ; Bd. 24)

Zugl.: Münster (Westfalen), Univ., Diss., 1994

ISBN 3-631-48218-3

\section{NE: GT}

Open Access: The online version of this publication is published on www.peterlang.com and www.econstor.eu under the international Creative Commons License CC-BY 4.0. Learn more on how you can use and share this work: http://creativecommons.org/ licenses/by/4.0.

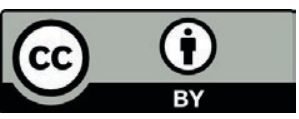

This book is available Open Access thanks to the kind support of ZBW - Leibniz-Informationszentrum Wirtschaft.

D 6

ISSN 0176-2729

ISBN 3-631-48218-3

ISBN 978-3-631-75084-1 (eBook)

(C) Peter Lang GmbH

Europäischer Verlag der Wissenschaften

Frankfurt am Main 1995

Alle Rechte vorbehalten.

Das Werk einschließlich aller seiner Teile ist urheberrechtlich geschützt. Jede Verwertung außerhalb der engen Grenzen des Urheberrechtsgesetzes ist ohne Zustimmung des Verlages unzulässig und strafbar. Das gilt insbesondere für Vervielfältigungen, Übersetzungen, Mikroverfilmungen und die Einspeicherung und Verarbeitung in elektronischen Systemen.

Printed in Germany $1234 \quad 67$ 
Vorwort des Herausgebers

In einer zeit weitreichender wirtschaftlicher und gesellschaftlicher Veränderungen sehen sich Städte und Regionen Herausforderungen ausgesetzt, die als typische Fragestellungen des Marketing anzusehen sind. Im Zuge dieser Entwicklungen wird dem städte- und Regionenmarketing in wissenschaft und Praxis ein verstärktes Interesse zuteil. Eine Vielzahl von geplanten und realisierten Marketingkonzepten belegt eindrucksvoll den hohen Stellenwert, welcher dem Placemarketing gerade von kommunalen Entscheidungsträgern zugewiesen wird.

Der Wunsch nach Wachstum, Stabilität und Attraktivität hat Kommunen seit jeher zu vielfältigen, nicht selten unkoordinierten Einzelaktionen mit schwerpunktsetzung auf Werbung und $P R$ veranlaßt. Vereinzelte Ansatzpunkte sind beispielsweise in den Konzeptionen zur Vermarktung von Gewerbestandorten (Standort-Marketing), dem Tourismus-Marketing bis hin zum Marketing für die öffentliche Verwaltung oder kommunale Institutionen $\mathrm{zu}$ beobachten.

Aus heutiger sicht ist eine Schwerpunktsetzung auf einige wenige Handlungsfelder jedoch mit Schwächen behaftet. Grundlage eines Marketingkonzeptes für Städte und Regionen ist ein ganzheitlicher Denkansatz, der die konsequente Planung, Steuerung und Kontrolle der Beziehungen einer Kommune mit ihren unterschiedlichen Anspruchsgruppen beinhaltet. Dazu ist es erforderlich, alle vorhandenen Ansätze zu integrieren. Mit der Kanalisierung dieser Stoßrichtungen durch die schaffung einer einheitlichen räumlichen Identität wird im Endergebnis eine klare Positionierung der stadt oder Region im Wettbewerbsumfeld angestrebt.

Räumliche Identität wird in Wissenschaft und Praxis zunehmend als wichtiges Gestaltungsziel des städte- und Regionenmarketing betrachtet. Bislang existiert ein wider- 
spruchsfreies Begriffsverständnis jedoch nur im Ansatz. In der vorliegenden Untersuchung wird das $\mathrm{Ziel}$ verfolgt, den Bedeutungsinhalt räumlicher Identität aus der Beliebigkeit herauszulösen und den Stellenwert räumlicher Identität als konzeptionelle Klammer eines integrierten Städte- und Regionenmarketing darzustellen.

Im theoretischen Hauptteil der Arbeit werden zunächst bestehende Konzepte aufgegriffen, welche in ein eigenständiges Verständnis räumlicher Identität aus Marketingsicht einfliessen. Zu diesem Zweck wählt der Verfasser einen interdisziplinären Ansatz, der ausgewählte Forschungsbemiihungen sozialwissenschaftlicher Nachbardisziplinen berücksichtigt. Der Heimatbegriff sowie die geographische Regionalbewußtseinsforschung finden dabei ebenso Berücksichtigung wie psychologische und soziologische Identitätsauffassungen.

Auf dieser konzeptionellen Basis aufbauend, wird ein zweiseitiges Begriffsverständnis räumlicher Identität gewählt. In einem ersten Bedeutungskontext wird räumliche Identität als Beziehungsaspekt $z$ wischen Mensch und seiner räumlichen Umwelt konzipiert, welcher in der Identifizierung von und der Identifikation mit (räumliche Verbundenheit, räumliches Zugehörigkeitsgefühl) einer Stadt oder Region Ausdruck findet. Der zweite Bedeutungskontext stellt den Raum selbst als objekt der Identitätszuschreibung in den Vordergrund. Eine Stadt oder Region verfügt über räumliche Identität, sofern sie sich von anderen Städten und Regionen unterscheidet. In dieser verwendungsrichtung stellt die Unverwechselbarkeit, Einzigartigkeit oder Besonderheit einer Stadt oder Region wichtige Konnotationen räumlicher Identität dar.

Im Rahmen der empirischen überprüfung räumlicher Identität entwickelt der Autor Ansatzpunkte zu einem hypothesengeleiteten Analyseansatz. Dieser Ansatz gibt insbesondere 
Aufschluß über die Wirkungsbeziehungen und den Erklärungsgehalt der einbezogenen Bestimmungsfaktoren. Im einzelnen werden Identitätstypen abgeleitet und die erfaßten Beziehungsstrukturen auf Plausibilität überprüt. Ein besonderes Augenmerk wird auf mögliche Unterschiede räumlicher Identität in Abhängigkeit von der Größe des betrachteten Raumausschnittes gelegt. Die Ergebnisse der Untersuchung bestätigen größtenteils die vermuteten Zusammenhänge. Dabei wird deutlich, daß die Wohndauer und der Bildungsstand die Identifikation mit einer vorgegebenen räumlichen Bezugsgröße maßgeblich beeinflußt. Desweiteren wird eine Schwerpunktlegung räumlicher Identifikationen auf kleinere räumliche Einheiten beobachtet.

Im abschließenden Teil werden Implikationen für die Praxis des Städte- und Regionenmarketing abgeleitet. Dabei steht die Darstellung zentraler Erfolgsvoraussetzungen eines integrierten Städte- und Regionenmarketing im Vordergrund.

Insgesamt gelingt es dem Verfasser, das komplexe Thema zu strukturieren. Unter sorgfältiger Auswertung verschiedener wissenschaftlicher Nachbardisziplinen wird die Bedeutung räumlicher Identität aus Marketingsicht aufgezeigt. Die trotz der datenbezogenen Auswertungsgrenzen empirisch gehaltvolle Arbeit vermittelt dabei unter Darlegung der Prämissen wertvolle Anregungen für die weiterführende wissenschaftliche Diskussion und die praktische Planung auf dem Gebiet des Placemarketing.

Münster, im Juli 1994

Heribert Meffert 
Ewald Werthmöller and Universität Münster - 978-3-631-75084-1 Downloaded from PubFactory at 01/11/2019 08:31:35AM via free access 
Vorwort des Verfassers

Das Marketing von Städten und Regionen gewinnt in Theorie und Praxis zunehmend an Bedeutung. Dabei steht der wachsenden Aufmerksamkeit die immer noch stiefmüterliche wissenschaftliche Forschung entgegen. Gleichwohl zeigt die große Akzeptanz in der Praxis, daß der Nutzenbeitrag des städte- und Regionenmarketing weitestgehend unstrittig ist.

Die vorliegende Arbeit hat sich zum ziel gesetzt, zum Abbau dieses Forschungsdefizits beizutragen. Ausgehend von einer begrifflichen Abgrenzung des Städte- und Regionenmarketing von ähnlichen Begriffen wird räumliche Identität als wesentlicher Gestaltungsparameter des Marketing für Städte und Regionen herausgestellt. Grundlage dazu ist ein ganzheitlicher Denkansatz, der die konsequente Planung, Steuerung und Kontrolle der Beziehungen einer Kommune mit ihren unterschiedlichen Anspruchsgruppen beinhaltet. Mit der Kanalisierung des Instrumenteeinsatzes durch die orientierung an einer einheitlichen räumlichen Identität wird im Endergebnis eine klare Positionierung der stadt oder Region im Wettbewerbsumfeld angestrebt.

Bei der Fertigstellung der Arbeit unterstützten mich verschiedene Personen. Meinem akademischen Lehrer Prof. Dr. Dr. h.c. Heribert Meffert gilt mein besonderer Dank, der die Anregung für die Themenstellung gab und die Fertigstellung der Arbeit umfassend förderte. Prof. Dr. Rainer Thoss sei für die übernahme des Zweitgutachtens gedankt.

Dank gilt weiterhin den Kolleginnen und Kollegen am Institut für Marketing, die mich unterstützt haben. Besondere Erwähnung gebührt Herrn Dr. Manfred Kirchgeorg für seine Anregungen in jeder Phase der Arbeit. Herrn Dr. Christoph Burmann danke ich für seine umfassende Diskussionsbereit- 
schaft und viele wertvolle Tips insbesondere in den letzten wochen vor der Fertigstellung.

Darüber hinaus möchte ich einen harten Kern weiterer Personen hervorheben, welche die ganze zeit über mitgezittert haben: Herr Dipl.Kfm. Felix Leis, den ich seit unserer gemeinsamen Ausbildungszeit bei der Deutschen Bank und während des Studiums als kompetenten und unterhaltsamen Gesprächspartner schätze. Dies gilt auch für Herrn Dipl.Kfm. Dietmar Hölscher, der sich immer wieder geduldig über meine Forschungsfortschritte informieren ließ.

Weiterhin möchte ich Herrn Friedhelm Ruppel erwähnen, der meinen alten "Chrombomber" in den vergangenen Jahren unermuidlich repariert hat. Ungeachtet der mit der Instandhaltung verbundenen finanziellen Belastungsproben, hat er einen gewissen Beitrag $z u$ meiner emotionalen Stabilität geleistet.

Schließlich danke ich meinen Eltern und meiner "großen" Schwester Ulla, die mich in allen Phasen der Ausbildung geduldig unterstützt haben und damit die Grundlage für die Fertigstellung der Arbeit schafften.

Münster, im Juli 1994

Ewald Werthmöller 


\section{INHALTSVERZEICHNIS}

A. RÄUMLICHE IDENTITÄT ALS PROBLEM DES STÄDTE- UND REGIONENMARKETING ...................... 1

1. Interkommunaler Wettbewerb als Auslöser für das Marketing von Städten und Regionen ............... 1

2. Stellenwert räumlicher Identität für das Marketing von Städten und Regionen ................. 5

3. Begriff und ziele des städte- und Regionenmarketing ................................. 14

4. Abgrenzung des Städte- und Regionenmarketing von

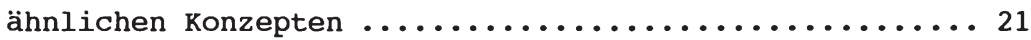

5. Ziel und Gang der Untersuchung ................. 30

B. THEORETISCHE GRUNDLAGEN RÄUMLICHER IDENTITÄT . . . . . . 35

1. Forschungsansätze räumlicher Identität ........... 35

1.1 Relevanz sozialwissenschaftlicher Identitätsauffassungen für die räumliche Identi-

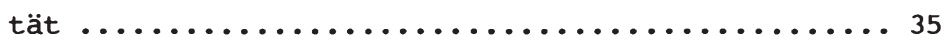

1.11 Generelle Verwendungsweisen des Identitätsbegriffes .................. 37

1.12 Merkmale und Gemeinsamkeiten des sozialwissenschaftlichen Identitätsverständnisses

1.2 Räumliche Identität als Spezialfall der sozialwissenschaftlichen Identitätsforschung ..... 47

1.21 Räumliche Identität als Identität der

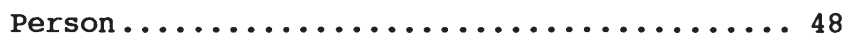

1.22 Räumliche Identität als Identität des Raumes ........................... 54

1.3 Forschungsansätze räumlicher Identität ........ 56

1.31 Heimat....................... 57

1.32 Regionalbewußtsein................. 60

1.33 Implikationen für das Marketing......... 71 
2. Zentrale Faktoren räumlicher Identität .......... 76

2.1 Träger räumlicher Identität .............. 78

2.2 Systematisierung räumlicher Bezugsgrößen in

einer Hierarchie räumlicher Maßstabsebenen ......83

2.21 Vertikale systematisierung räumlicher Bezugsgrößen..................... 84

2.22 Horizontale systematisierung räumlicher Bezugsgrößen................. 90

2.23 Abgrenzung räumlicher Bezugsgrößen als Grundlage für die Gestaltung räumli-

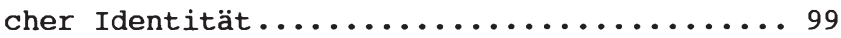

2.3 Inhalte räumlicher Identität .............. 101

3. Ansatzpunkte zur Operationalisierung räumlicher

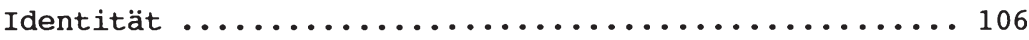

3.1 Methodische Prämissen für die Operationalisierung räumlicher Identität ............ 106

3.2 Wahrnehmungsebenen räumlicher Identität ....... 113

3.3 Einflußgrößen und Bestimmungsfaktoren räum-

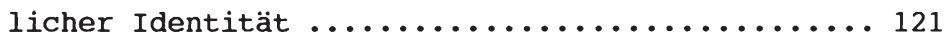

3.31 Maßstabsbezogene Einflußgrößen......... 123

3.32 Angebotsbezogene Einflußgrößen......... 129

3.33 Personenbezogene Einflußgrößen......... 132

C. EMPIRISCHE ANALYSE UND GESTALTUNG VON TEILASPEKTEN RÄUMLICHER IDENTITÄT IM RAHMEN DES STÄDTEUND REGIONENMARKETING ....................... 135

1. Empirische Analyse räumlicher Identität ......... 135 1.1 Design der Untersuchung und Methoden der

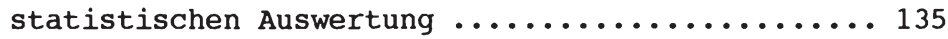

1.2 Analyse der Ausprägungsformen räumlicher Identifikationen auf verschiedenen Maßstabs-

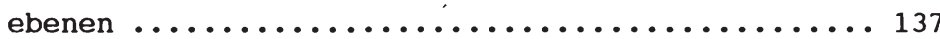

1.21 Ableitung genereller Muster räumlicher Identifikationen .................... 138

1.22 Typologie räumlicher Identifikationen..... 142 
1.3 Personenbezogene Bestimmungsfaktoren .......... 145

1.31 Einfluß der Wohndauer................ 145

1.32 Einfluß des Geburtsortes.............. 149

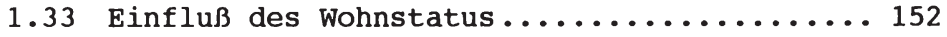

1.34 Einfluß des sozio-ökonomischen Status ...... 154

1.4 Raumbezogene Bestimmungsfaktoren ............ 159

1.41 Wirkung auf die Identifikation mit dem Wohnort (Mikromaßstab) ............... 160

1.42 Wirkung auf die Identifikation mit der Region (Mesomaßstab) ................ 162

1.5 Zusammenfassende würdigung der empirischen Ergebnisse ......................... 164

2. Implikationen für das städte- und Regionenmarke-

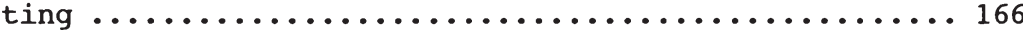

2.1 Stellenwert eines integrierten städte- und

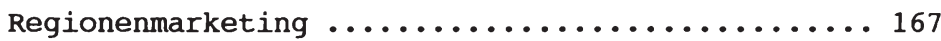

2.2 Erfolgsvoraussetzungen für die Institutionalisierung eines integrierten städte- und Re-

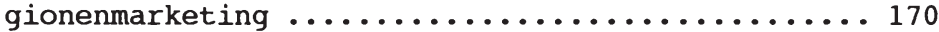

2.21 Partnerschaftliche Zusammenarbeit privater und öffentlicher Akteure......... 171

2.22 Placemanagement als Durchsetzungsor-

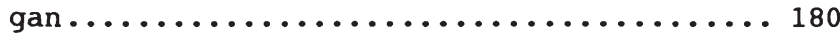

2.3 Prozeßschema zur Identitätsentwicklung ........ 186

2.4 Erfolgsvoraussetzungen für die Identitäts-

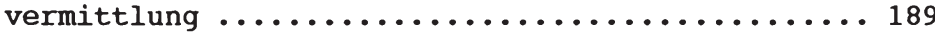

2.41 Singularität der Identitätsbausteine..... 192

2.42 Authentizität der Identitätsvermitt-

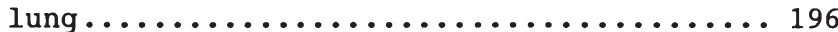

D. SCHLUßBETRACHTUNG ...................... 201

1. Zusammenfassende Würdigung der Untersuchungser-

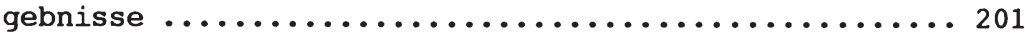

2. Ansatzpunkte für die weitere Forschung ........... 203 LITERATURVERZEICHNIS ...................... 207 


\section{ABBILDUNGSVERZEICHNIS}

Abb. 1: Erwartungen an das Stadtmarketing............ 13

Abb. 2: Begriffsabgrenzung des Placemarketing........ 23

$\mathrm{Abb}$. 3: Definition des Begriffes Stadtmarketing....... 29

Abb. 4: Systematisierung sozialwissenschaftlicher Identitätsauffassungen................ 38

Abb. 5: Ansatzpunkte zur Präzisierung räumlicher Identität......................... 55

Abb. 6: Intensitätsstufen von Regionalbewußtsein......66

Abb. 7: Paradigma für die Analyse räumlicher Identität....................... 77

Abb. 8: Identitätsträger räumlicher Identität........80

Abb. 9: Systematisierung der Komponenten räumli-

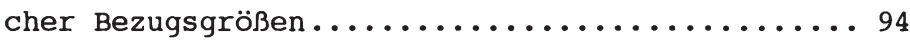

Abb.10: Inhalte räumlicher Identität............. 102

Abb.11: Gegenüberstellung positivistischer und naturalistischer Grundannahmen............ 108

Abb.12: Analyseraster räumlicher Identität......... 110

Abb.13: Einflußgrößen räumlicher Identität.......... 122

Abb.14: Erfahrungsgrundlagen räumlicher Identität in Abhängigkeit von der räumlichen Maß-

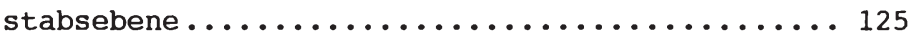

Abb.15: Erfassung räumlicher Identität auf verschiedenen räumlichen Maßstabsbereichen....... 138

Abb.16: Identifikationsanker der Bürger des Mün-

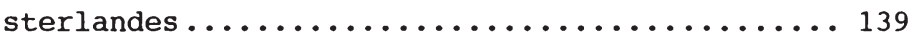

Abb.17: Faktoranalytisch verdichtete räumliche $\mathrm{Zu}-$ gehörigkeitsgefühle................. 141

Abb.18: Clusterbildung nach räumlichen Zugehörig-

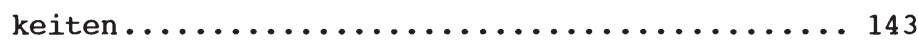

Abb.19: Organisatorische Rahmenbedingungen für das Städte- und Regionenmarketing............ 170

Abb.20: Akteure/Interessen im kommunalen Bereich: das "politisch administrative system

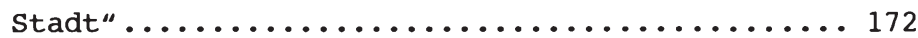

Abb.21: Funktionen des Placemanagement............ 181 
Abb.22: Phasenschema des Placemanagement.

Abb.23: Allgemeines Prozeßschema zur Identitätsentwicklung........................ 187

Abb.24: Spannungsfeld der Gestaltung räumlicher Identität......................... 190

Abb.25: Typologie räumlicher Identitätsfaktoren....... 194

Abb.26: Wirkung räumlicher Identität in Abhängigkeit vom Authentizitätsgrad der übermittelten Botschaftsinhalte............... 198 


\section{XVI}

\section{TABELLENVERZEICHNIS}

Tab. 1: Analyse räumlicher Identität differenziert nach Wohndauergruppen................. 146

Tab. 2: Analyse räumlicher Identität differenziert nach Wohndauergruppen und clusterzugehö-

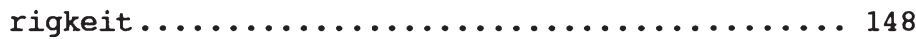

Tab. 3: Analyse räumlicher Identität differenziert

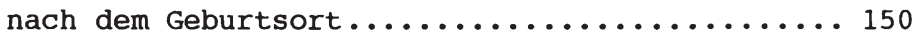

Tab. 4: Analyse räumlicher Identität differenziert nach Geburtsort und Clusterzugehörigkeit...... 151

Tab. 5: Analyse räumlicher Identität differenziert

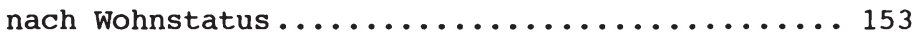

Tab. 6: Analyse räumlicher Identität differenziert nach Wohnstatus und clusterzugehörigkeit...... 154

Tab. 7: Analyse räumlicher Identität differenziert nach Bildungsstand................... 155

Tab. 8: Analyse räumlicher Identität differenziert nach Clusterzugehörigkeit und Bildungs-

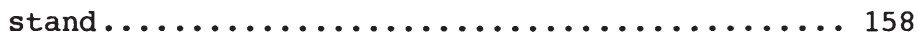

Tab. 9: Wirkung inhaltlicher Besonderheiten auf die Identifikation mit dem wohnort......... 161

Tab.10: Wirkung inhaltlicher Besonderheiten auf die Identifikation mit der Region.......... 163 
VERZEICHNIS DER ABKÜRZUNGEN

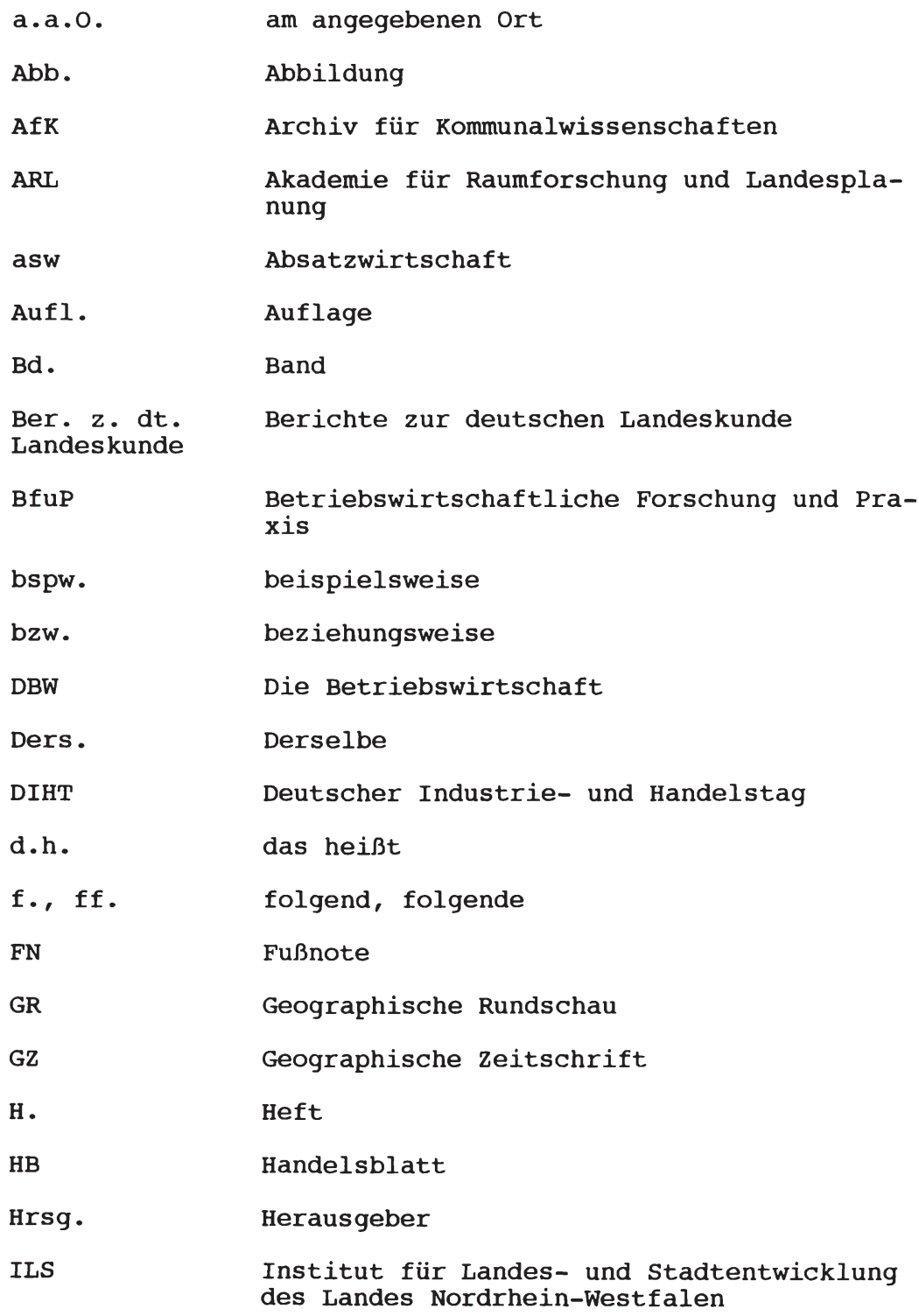




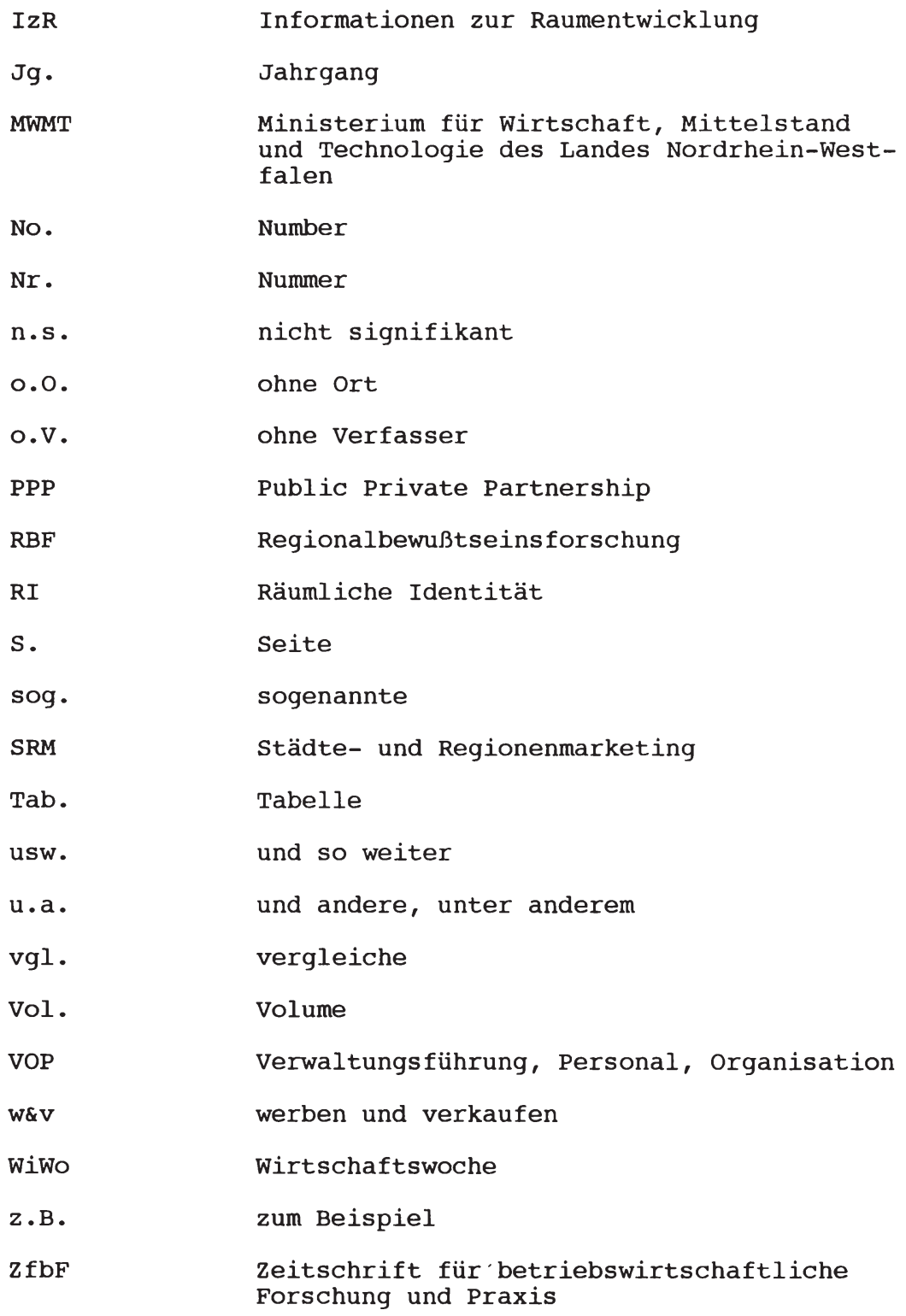


A. Räumliche Identität als Problem des städteund Regionenmarketing

\section{Interkommunaler Wettbewerb als Auslöser für das Marketing von städte und Regionen}

Angesichts der fortschreitenden Dynamik der politisch-gesellschaftlichen, ökologischen, technologischen und wirtschaftlichen Entwicklungstrends sehen sich nicht nur Unternehmen, sondern auch städte und Regionen einem kontinuierlichen Anpassungsdruck und wachsenden Wettbewerbsherausforderungen ausgesetzt.1 Die nachhaltige Veränderung der Rahmenbedingungen findet beispielsweise im Europäischen Binnenmarkt, den „Neuen Bundesländern“, der zunehmenden öffnung Osteuropas aber auch in einem wachsenden Demokratiebewußtsein der Bürger oder einem veränderten Freizeitverhalten der Bevölkerung Ausdruck. Städte und Regionen müssen sich auf diesen Wandel einstellen und Konzepte für eine Neupositionierung in einem veränderten Umfeld entwickeln.

Den Wettbewerb um qualifizierte Arbeitskräfte, Investoren oder Touristen, in dem städte und Regionen ihre Vorzüge herausstellen, hat es immer gegeben. 2 vergleichweise neu ist jedoch die Diskussion, ob die übernahme von Denkweisen und Konzepten aus der Unternehmenspraxis die Chancen im kommunalen Wettbewerb verbessern kann. Die Diskussion über sinnvolle Einsatzfelder moderner Managementmethoden reicht von der öffentlichen Verwaltung, die beispielsweise durch

1 Die Veränderung der verschiedenen Kontextfaktoren hat Auswirkungen auf die Wahl der Instrumente, Methoden und Einsatzbereiche des Marketing. Vgl. dazu: Meffert, H., Erfolgreiches Marketing in den neunziger Jahren, in: Atag Ernst \& Young (Hrsg.), Marketing im Umbruch, Referate anläßlich der Dolder-Tagung v. 23.05.1991 in zürich.

2 Vgl. Afheldt, H., Städte im Wettbewerb, in: Stadtbauwelt 1970 , s. 100 ff.. 
den Einsatz von Lean-Management effizienter gestaltet werden soll, bis hin zu ganzheitlichen Kommunikationskonzepten, welche nach dem Beispiel erfolgreicher Großunternehmen, eine zielgruppengerechte selbstdarstellung von städten und Regionen im Wettbewerbsumfeld zum Inhalt haben. 3 Im Zuge dieser überlegungen wird die Frage aufgeworfen, inwiefern das ursprünglich auf kommerzielle Unternehmensbereiche bezogene konzept des Marketing auf Problemstellungen von Städten und Regionen übertragen werden kann. Es verwundert daher nicht, wenn zunehmend die Forderung nach Marketing im kommunalen Bereich, nach Städtemarketing, nach standort-oder Regionenmarketing erhoben wird. 4

Die Profilierung von Städten und Regionen durch den Einsatz von Marketing wird insbesondere von der ortsansässigen wirtschaft begrüßt. Spätestens seit der Einführung von "Made in Germany" ist die Transferwirkung von Standortwerbung auf die Qualitätswahrnehmung inländischer Produkte bekannt. 5 Das Verhältnis zwischen Stadt/Region und Wirtschaft ist dabei interdependent: Einerseits werden die Standorte von den ortsansässigen Unternehmen geprägt. So werden viele städte und Regionen mit bestimmten Unternehmen oder ganzen Wirtschaftszweigen assoziiert. 6 Anderer-

3 Vgl. Reichard, C., Kommunales Management im internationalen Vergleich, in: Der städtetag, 12/1992, S. 843-848.

4 Vgl. Meffert, H., Städtemarketing - Pflicht oder Kür?, in: Arbeitsgemeinschaft Stadtvisionen (Hrsg.), Dokumentation des symposiums "stadtvisionen", v. 2./3. März 1989 in Münster, S. 1 .

5 Vgl. Stilcken, R., Rationale Argumente verlieren immer mehr an Kraft, in: Blick durch die wirtschaft, Nr. 204 , v. 20.10.1989, S. 7 .

6 Wolfsburg und stuttgart (Automobile), Solingen (Schneidewerkzeuge), Schweinfurt (Kugellager), oder das Ruhrgebiet (Montanindustrie) werden häufig mit bestimmten Industriezweigen in Verbindung gebracht. Wie 
seits werden Unternehmen durch ihre Standorte mitgeprägt, mitentwickelt, mitgefördert aber auch behindert. So stellt beispielsweise das stadt-oder Regionenimage ein wichtiges Entscheidungskriterium bei der Arbeitsplatzsuche von Hochschulabsolventen dar. 7 Regionale Präferenzen werden dabei nachhaltig durch den wohn-, Freizeit-, Sozial-, Arbeitsund öffentlichkeitswert des betreffenden Raumes beeinflußt. 8

Das Wettbewerbsumfeld in dem sich städte und Regionen bewegen, geht über den Kirchturmhorizont von Gemeinde und Nachbargemeinde weit hinaus. Angesichts der wachsenden Mobilität immer breiter werdender Bevölkerungskreise, der zunehmenden Internationalisierung und Globalisierung vieler Unternehmen sowie der Verfügbarkeit weltumspannender Kommunikations- und Distributionssysteme müssen die Wettbewerbsbeziehungen in einem länderübergreifenden Nordsuid- und West-Ost-Raster analysiert werden:

- Im Inland wird langfristig eine Wettbewerbsverschärfung zwischen Regionen in Ost und west prognostiziert, welche bestehende wirtschaftliche Disparitäten zwischen Nord und süd ergänzt. Ein Grund dafür ist beispiels-

schwierig es ist, ein einmal verfestigtes Image $\mathrm{zu}$ verändern, wird im Ruhrgebiet deutlich. Obwohl nur noch 9 \& der Beschäftigten in den Bereichen Kohle und Stahl beschäftigt sind, wird die Region nach wie vor als Montanregion, als "Krisenregion" bzw. mit "Dreck, Kohle und stahl" nachhaltig verknüpt. Dies belegt eine jüngst abgeschlossene Befragung (Herbst 1993) bei 2.600 Menschen in ganz Deutschland. Die Studie belegt weiterhin, daß die im Ruhrgebiet objektiv gegebenen, positiven Fakten insbesondere im Wahrnehmungsbild von Auswärtigen ignoriert werden. Vgl. Onkelbach, H., Das Image voller Kohlenstaub, in: Rheinische Post, Nr. 93 v. 22.04 .1994 .

Vgl. Campillo-Lundbeck, S., standortmarketing gegen Imagedefizite, in: HORIZONT, Nr. $46 \mathrm{v} \cdot 19.11 .1993, \mathrm{~S}$. 89.

8 Vgl. Bergler, R., Der Standort als Imagefaktor, Manuskript, 0.0. 1991, S. 11 . 
weise die Umlenkung von Fördermitteln und Investitionen in die neuen Bundesländer. 9

- In Europa bilden sich nach Auffassung von Regionalexperten zwei verdichtete wachstumszentren heraus, die in der Form einer Nord-Süd-Achse ("Banane") und einer West-Ost-Achse ("Sunbelt") durch Europa verlaufen.10 Mitunter wird ein Zukunftsszenario gezeichnet, welches für die starken Regionen im zentrum Europas einen Wachstumsboom prognostiziert, während die ohnehin schwachen Regionen weiter an wirtschaftlicher Bedeutung einbüßen werden. 11

Schließlich darf der interkommunale Wettbewerb nicht ausschließlich unter dem Gesichtspunkt wirtschaftlicher Fakten betrachtet wird. Die interkommunalen Wettbewerbsbeziehungen beziehen grundsätzlich alle Leistungsfelder ein. Die wachsende Beliebtheit von städterankings ("Hitlisten"), welche sich in der Wirtschafts- und Boulevardpresse gleichermaßen großer Beliebtheit erfreuen, sind ein Hinweis für das breite Interesse der Öffentlichkeit an allen möglichen Attraktionspotentialen einer stadt oder Region. 12

9 Vgl. Heinacher, P., NRW: Wettbewerb zwischen den Regionen deutlich spürbar, in: HB Nr. $55 \mathrm{v} \cdot 19.3 .1991$.

10 Mit der sogenannten "Banane" wird Europas am dichtesten besiedelter Raum umschrieben, der sich von Südengland über die Rhein- und Rhône-Schiene bis hin in die Lombardei erstreckt, mit London und Mailand als Endpunkten und Frankfurt im zentrum. Im rechten winkel zur Nord-Süd-Achse bildet sich mit dem "Sunbelt" eine Ost-West-Schiene am Mittelmeer heraus - von der Toskana uber Mailand und Lyon bis Barcelona und weiter nach Valencia. Vgl. o.v., Die neuen Stars der alten Welt, in: Manager Magazin 3/1990, S. $207 \mathrm{f}$.

$11 \mathrm{Vgl}$. Ebenda.

12 Vgl. Lackner, W., Städte-Ranking: Ein Instrument kommunaler Wirtschaftsförderung, in: Der städtetag, $6 / 1992$, S. $471 \mathrm{f}$. 
2. Stellenwert räumlicher Identität für das Marketing von städten und Regionen

Die aus den fortschreitenden Veränderungen der Rahmenbedingungen entstehenden Anpassungserfordernisse fördern ein Umdenken der für die Prosperität einer stadt oder Region verantwortlichen Entscheidungsträger. So ist vielerorts bereits eine umfassende Bereitschaft privater und öffentlicher Akteure zu beobachten, die internen Stärken zu bündeln und sich abzeichnende Chancen in einem immer dynamischer werdenden wettbewerbsumfeld durch ein gemeinsam abgestimmtes Handeln effizienter zu nutzen.

Dies trifft insbesondere auf die Regionen zu. So läßt der fortschreitende Wandel der Kontextfaktoren die Kritik an der Effizienz auf zentraler Ebene formulierter Förderziele aufkommen.13 Im Zuge der Diskussion über eine "Regionalisierung der Regionalpolitik" werden in verschiedenen Bundesländern verstärkt die regionalen Akteure in die Formulierung, Planung und Umsetzung regionaler Programme eingebunden. So wird beispielsweise mit der im Jahre 1989 in Nordrhein-westfalen initiierten "Zukunftsinitiative für die Regionen Nordrhein-Westfalens"

13 Die im Jahre 1970 eingefürte Gemeinschaftsaufgabe "Verbesserung der regionalen Wirtschaftsstruktur" geht von der Prämisse aus, daß der Staat über zentrale Gestaltungsmöglichkeiten bei der Steuerung regionaler Entwicklungsprozesse verfügt. In der wissenschaftlichen Diskussion wird bemängelt, daß die "Gemeinschaftsaufgabe" aufgrund ihres interventionistischen Charakters ("Einheitsrezeptur") den Problemeinschätzungen der Bevölkerung nur unzureichend Rechnung trägt. Stattdessen wird die Forderung erhoben, die sogenannten "endogenen Potentiale" für die Regionalentwickung verstärkt $z$ u nutzen. Vgl. Klemmer, P., Die Gemeinschaftsaufgabe "Verbesserung der regionalen Wirtschaftsstruktur". Zwischenbilanz einer Erscheinungsform des kooperativen Föderalismus, in: Konrad Adenauer Stiftung (Hrsg.), Dezentralisierung des politischen Handelns III. Konzeption und Handlungsfelder, Melle 1987, S. 320. 
(ZIN) auch das $\mathrm{ziel}$ verfolgt, den regionalen Dialog $\mathrm{zu}$ intensivieren und die Attraktivität der Regionen stärker als bisher in die selbstverantwortung der regionalen Akteure zu legen. 14

Unabhängig von der Einbindung in die regionale wirtschaftspolitik und unabhängig von der Inanspruchnahme von Fördermitteln gilt eine intensive kooperation vor ort zunehmend als wichtiger Erfolgsfaktor im interkommunalen Wettbewerb. Die Notwendigkeit zur zusammenarbeit in bestimmten Handlungsfeldern wird in diesem Zusammenhang von Städten und Regionen gleichermaßen gesehen. Dazu müssen alle maßgeblichen gesellschaftlichen Gruppen einer stadt oder Region mit der zielvorstellung an einen Tisch gebracht werden, einen Konsens über die grundsätzlich zu verfolgenden Entwicklungsziele für den Referenzraum $z u$ erarbeiten. 15 Zahlreiche Praxisbeispiele sind ein Hinweis dafür, daß der Wunsch zur Zusammenarbeit an Popularität gewinnt (z.B. MediaPark in Köln).16 Insbesondere unter dem Eindruck des europäischen Binnenmarktes sind in den letzten Jahren eine Vielzahl von Initiativen entstanden oder im Entstehen begriffen, welche auf einem gemeinsam getragenen Selbstverständnis aufbauend, ein abgestimmtes Han-

14 Die fünfzehn ZIN-Regionen in Nordrhein-Westfalen haben die Aufgabe, "ihre regionale Entwicklung verstärkt in regionaler selbstverwaltung zu gestalten. Gefordert sind Eigeninitiative, Kreativität und regionale Kooperationen. Dies soll insbesondere im Rahmen von regionalen Entwicklungskonzepten geschehen."Vgl. MWMT, Handlungsempfehlungen regionale Entwicklungskonzepte $(26.11 .1990)$, S. 1 .

15 Vgl. Krafft, A., Ulrich, G., Chancen und Risiken regionaler Selbstorganisation, Opladen 1993, S. 11.

16 Vgl. Kamps, M., private und öffentliche Partner, in: Der städtetag, 2/1992, S. 156 f.; Heinz, W., Partnerschaftsprojekte für die Stadtentwicklung - Lehren und Thesen, in: Der Städtetag, 3/1993, S. 210-213.; Helms . V., Public Private Partnership heißt das neue Stichwort, in: HB Nr. 222 v. 16.11.1993, S. B3. 
deln privater und öffentlicher Entscheider in verschiedensten Handlungsfeldern zum Inhalt haben. 17 Die Planung und Umsetzung von Marketingkonzepten für städte und Regionen im allgemeinen und die zielgerichtete Beeinflussung räumlicher Identität (Stadtidentität oder Regionalbewußtsein) im besonderen repräsentieren mögliche Handlungsfelder derartiger Kooperationen. 18

Angesichts der Heterogenität der Interessen, welche die verschiedenen privaten und öffentlichen Gruppen einer stadt oder Region zwangsläufig in die Zusammenarbeit einbringen, sind Zielkonflikte vielfach unvermeidlich. Eine reibungslose Konsensbildung erscheint aus diesem Grund eher die Ausnahme als die Regel zu sein. Der Wille zur zusammenarbeit und die Kompromißbereitschaft der beteiligten Akteure sind daher von entscheidender Bedeutung für die Verabschiedung und Umsetzung gemeinsam getragener ziele.

Eine Harmonisierung divergierender zukunftsentwürfe erscheint insbesondere dann erfolgversprechend $z u$ sein, wenn sich die involvierten gesellschaftlichen Gruppen mit dem Referenzraum identifizieren. 19 Die beispielsweise in einem

17 Regionale Kooperationsmodelle, welche eine Zusammenarbeit im Regional- und standortmarketing zum Inhalt haben, sind beispielsweise in Trier ("Initiativkreis Trier") und im Großraum Hannover gebildet worden. Vgl. o.V., Der Binnenmarkt zwingt Deutschlands Regionen zur stärkeren Zusammenarbeit, in: HB v. 21./22.02.1992, S. 6.; vgl. dazu auch o.V., "Neue Hanse Interregio" soll die Anliegen der Nordseeanrainer in Brüssel vertreten, in: HB v. 08.04.1992.; Mombaur, P.M., Europäischer Binnenmarkt: Kommunalpolitik und Wirtschaftspolitik im Wettbewerb der Standort, in: Städte- und Gemeinderat. Sonderdruck 4, 1989, S. 19-21.

18 Vgl. Campillo-Lundbeck, S., Standortmarketing gegen Imagedefizite, a.a.0., S. 89.; Kral, F., Die Metropole kann ihre Probleme nur gemeinsam mit der gesamten Region lösen, in: HB Nr. 123 v. 29./30.06.1990, S. 27.

19 So wird beispielsweise in den "Handlungsempfehlungen" des MWMT darauf hingewiesen, daß die gemeinsame Er- 
räumlichen Zugehörigkeits- oder Verbundenheitsgefühl sich widerspiegelnde Identifikation mit dem gemeinsamen Lebensraum trägt dazu bei, in zentralen Fragen Einzelinteressen zurückzustellen. Insofern kommt der Identifikation mit dem Referenzraum eine wichtige Koordinierungsfunktion zu. Eine weitere Funktion läßt sich aus den Zielen der örtlichen Wirtschaftsförderungsämter und -gesellschaften ableiten, welche sich im Zeichen veränderter ökonomischer Rahmenbedingungen zunehmend auf die Wahrnehmung und Förderung der örtlichen Entwicklungspotentiale (Bestandspflege) konzentrieren. 20 Es ist anzunehmen, daß ortsansässige Unternehmen, welche durch eine ausgeprägte Verbundenheit mit dem Referenzraum geprägt sind, diesen nicht ohne weiteres verlassen werden.

Das Marketing für Städte und Regionen ist in diesem Zusammenhang aufgefordert, auf die Identifikation der zielkreise einzuwirken. Eine zentrale interne zielgruppe stellt in diesem Zusammenhang die Bevölkerung dar.21 Als Ergebnis des gesellschaftlichen Wertewandels werden von seiten der Bürger zunehmend Mitwirkungsmöglichkeiten am kommunalen Geschehen eingefordert. Insbesondere für die städte bedeutet dies, die Rolle des einzelnen Bürgers nicht länger auf die Rolle eines „Bedenkenträgers“ zu reduzieren, wie dies in den verschiedenen Formen sogenannter

stellung von Entwicklungskonzepten a ch zur "Identifikation der Bürger und Bürgerinnen mit ihrer Region" betragen können. Vgl. MWMT, Handlungsempfehlungen regionale Entwicklungskonzepte (26.11.1990), S. 2 .

20 Vgl. Heuer, H., Instrumente kommunaler Gewerbepolitik. Ergebnisse empirischer Erhebungen, Stuttgart 1985, S. 151.; Krafft, A., Ullrich, G., Chancen und Risiken regionaler Selbstorganisation, a.a.0., S. 20 .

21 Vgl. Böltz, C., City-Marketing. Eine stadt wird verkauft, in: Bauwelt, H.24, 1988, S. 996. 
Bürgerbeteiligung immer noch der Fall ist.22 Es müssen vielmehr angemessene Partizipationsmodelle Anwendung finden, die ein Engagement der Bewohner bereits im Stadium der Zielfindung gestatten. Andernfalls wird das Aufkommen einer "Not-invented-here"-Stimmung bei den Betroffenen geradezu herausgefordert. Im Extrem können derartige Reaktanzgefühle im organisierten Protest gegen Entwicklungsziele münden.

Die Identifikation mit einer stadt oder Region durch die ortsansässigen privaten und öffentlichen Entscheider und die Bewohner läßt sich als erster Bedeutungskontext räumlicher Identität auffassen. Räumliche Identität hat somit zunächst eine auf Personen (oder Gruppen) bezogene Bedeutung, indem damit ein Beziehungsaspekt zwischen dem Menschen und seiner näheren oder weiteren räumlichen Umwelt herausgegriffen wird. In dieser ersten Begriffsverwendung wird räumliche Identität als mentale Größe in "den Köpfen" von Personen und Gruppen interpretiert, welche sich beispielsweise in positiv empfundener zugehörigkeit oder Aversion (Identifikation) niederschlägt und möglicherweise ein raumbezogenes Handeln zur Folge hat. Die Bandbreite eines derartigen Handelns reicht vom Engagement in räumlich ausgerichteten Kooperationsformen bis hin zur Mitgliedschaft in Heimatvereinen. Darüber hinaus lassen sich die verschiedenen Ausprägungsformen des Mobilitätsverhaltens als weitere Ausprägungsformen exemplarisch aufzählen.

In der zweiten Begriffsverwendung hat räumliche Identität eine unmittelbar auf die bestimmte stadt oder Region bezogene Bedeutung: Danach haben nicht nur Personen räumliche Identität, sondern jede stadt oder Region ist eine räumliche Identität. In Analogie zu unternehmensbezogenen Identitätsauffassungen ist $z u$ vermuten, daß Städte und Re-

22 Vgl. Rammstein, o., Bürgerbeteiligung und Bürgerinitiativen, Villingen-Schwenningen 1977. 
gionen insbesondere dann als Austauschpartner für vielfältige kommerzielle und nicht-kommerzielle Transaktionen ausgewählt werden, sofern sie von ihren zielkreisen als unverwechselbare, einzigartige oder typische Ganzheit identifiziert werden können.23 Die Identifizierbarkeit einer Stadt oder Region als Ganzheit, welche beispielsweise in ihrer wahrgenommenen Besonderheit, Einzigartigkeit oder Individualität zum Ausdruck kommt, markiert damit den zweiten Bedeutungskontext räumlicher Identität.

Je prägnanter die räumliche Identität des Referenzraumes ausgebildet ist, umso eindeutiger ist die Unterscheidbarkeit gegenüber konkurrierenden städten und Regionen gegeben. Während bei kleineren Städten ("Kurorte“) oder Regionen mit ausgeprägter wirtschaftlicher Monostruktur ("Alpen-Skigebiet") kaum Zweifel bestehen, anhand welcher Merkmale die räumliche Identität festgestellt werden kann, ist dies bei einer "großen" stadt oder Region bedeutend komplizierter. Insbesondere dann, wenn mit wachsender Größe die Funktionsvielfalt steigt und der Referenzraum nebeneinander alles mögliche sein kann: Bischofssitz, Industrie- und Modezentrum, Vergnügungs-, Bier-, Theaterund Museen,- Verkehrs- und Messeplatz.24 Es verwundert deshalb nicht, wenn die Schaffung einer unverwechselbaren Identität oder die Notwendigkeit einer "Corporate Identity“ bzw. einer „Place Identity“ als Gestaltungsziel kommunaler Entscheidungsträger an Bedeutung gewinnt. 25

23 Vgl. dazu beispielsweise Heinen, E., Identität: Ein bisher vernachlässigtes Element des zielsystems der Unternehmung, a.a.0., S. 129, in: Wirtschaftstheorie und Wirtschaftspolitik, Gedenkschrift für E. Preiser, hrsg. v. Mückl, W., Ott, A. E., Passau 1981, S. 125 ff..

24 Vgl. Scheele, W., Von der Städtewerbung zur kommunalen Corporate Identity: ein weiter Weg, in: Jahrbuch der Werbung, 0.0. 1986, S. 55 .

25 Vgl. Heuer, H., Imagepflege und Standortmarketing werden wieder $\mathrm{zu}$ wichtigen Handlungsfeldern der Kommunen, 
Eine ausgeprägte räumliche Identität ist ganz besonders solchen Städten und Regionen zu eigen, welche über einen Bedeutungsüberschuß26 in verschiedenen Leistungsfeldern verfügen. So ist beispielsweise die stadt Frankfurt sehr erfolgreich in ihrem Bemühen, europäische und internationale Entscheidungszentralen - vornehmlich im Finanzbereich - für sich zu gewinnen. Der jüngst erfolgte zuschlag für Frankfurt als Sitz des Europäischen währungsinstituts und der künftigen Europäischen Zentralbank wird vor diesem Hintergrund als strategisch wichtiger Erfolg im Standortwettbewerb gewertet. 27 Dieser Erfolg ist sicherlich auch darauf zurückzuführen, daß Frankfurt seit geraumer zeit national und international als Bankenstadt und Finanzzentrum identifiziert wird. Eine räumliche Identität sein bedeutet somit, internen und externen zielgruppen sowie der allgemeinen öffentlichkeit eine wichtige qualitative ori-

in: HB Nr. 225 v. 23.11.1988, S. 28.; Lalli, M., Plöger, W., Corporate Identity für Städte. Ergebnisse einer bundesweiten Gesamterhebung, Heidelberg 1990, s. $24 \mathrm{ff}$. .

26 Der Begriff Bedeutungsüberschuß verweist darauf, daß es zentrale orte gibt, die andere, nicht zentrale orte, mit versorgen. Im einzelnen läßt sich die sogenannte Arbeitsplatzzentralität unterscheiden: Orte, die mehr Arbeitsplätze anbieten, als für die ortsbevölkerung notwendig ist; Handelszentralität: Orte, die mehr oder qualitativ hochwertigerere Geschäfte anbieten als die Siedlungen des Umlandes; Dienstleistungszentralität: Orte, die öffentliche und private Einrichtungen unterhalten, deren Geltungs- bzw. Zuständigkeitsbereich oder Einzugsbereich über die ortsgrenze hinausreicht. Vgl. Benzing, A., Verwaltungsgeographie, Köln 1978, S. 93 ff. Wittkämper schlägt vor, die Erlebniszentralität als weitere spielart hinzuzufügen: Orte, die eine Erlebnisbandbreite anbieten, die von anderen Städten nicht geleistet werden kann. Vgl. Wittkämper, G.W., Die Rolle der Städte im neuen Jahrtausend. "Stadtvisionen". Stadtstrategien und Städtemarketing in der zukunft, in: Eröffnungsvortrag auf dem Symposium "Stadtvisionen". Stadtstrategien und Städtemarketing in der Zukunft, am 2./3. März 1989 im Historischen Rathaus zu Münster, S. 27.

27 Vgl. Eick, G., Der Rhein-Main-Regon fehlen bisher noch gemeinsame Ziele und ein politisches Dach, in: HB, Nr. 233 v. 2.12.1993, S. B11. 
entierungshilfe zur Verfügung zu stellen. Die beispielsweise in der Umgangssprache mitunter verwendete Umschreibung von Frankfurt als "Bankfurt” oder "Mainhattan” unterstreicht diese Einschätzung.

Häufig ist eine einzelne Stadt oder Region zu klein oder zu unbedeutend, um als eigenständiger Marktpartner identifiziert werden zu können. Defizite in der Identifizierbarkeit haben schwerwiegende Folgen, weil damit die chancen im Städtewettbewerb bzw. in der "Olympiade der Regionen"28 sinken. Die Gefahr als potentieller Austauschpartner ins Hintertreffen zu geraten ist umso größer, wenn das Wettbewerbsumfeld in einem europäischen oder internationalem Maßstab betrachtet wird.29 In diesem kontext ist häufig bereits der Vorrat an Fläche bedeutsam, um im Wettbewerbsumfeld bzw. "auf der Landkarte“ wahrgenommen zu werden. So verwundert es nicht, daß mitunter die vermutung geäußert wird, daß in dem häufig zitierten "Europa der Regionen" mit Ausnahme der großen Metropolen vornehmlich Regionen wahrgenommen werden, die bestimmten Größenkriterien genügen. 30

Die Herausforderung, den wachsenden Wettbewerbsherausforderungen und den wünschen und Bedürfnissen der Bewohner Rechnung zu tragen, findet Ausdruck in den Ergebnissen einer jüngst veröffentlichten Studie der Kienbaum-Unterneh-

28 Vgl. O.V., Die neuen Stars der alten Welt, a.a.o, s. 204 ff..

29 o.V. Schleswig-Holstein: Wirtschaftliche und technologische Planungen sollen verzahnt werden, in: HB $v$. $11 . / 12.10 .1991$, S. 7 .

30 Die Regionen müssen einerseits groß genug sein, um eine gezielte Beeinflussung der regionalen Entwicklungspotentiale zu ermöglichen und andererseits dürfen sie eine bestimmte Größe nicht uberschreiten, damit die Kooperation der beteiligten Akteure gewährleistet bleibt. Vgl. Krafft, A., Ulrich, G., Chancen und Risiken regionaler Selbstorganisation, a.a.0, S. 49. 
mensberatung. 31 Die studie belegt, daß mit dem Einsatz von Marketing in städten und Regionen gleichermaßen nach innen- und außengerichtete Erwartungen verbunden werden. Aus Abbildung 1 läßt sich entnehmen, welche $\mathrm{ziele}$ mit dem Einsatz von stadt- und Regionalmarketing in der Hauptsache verknüpft werden:

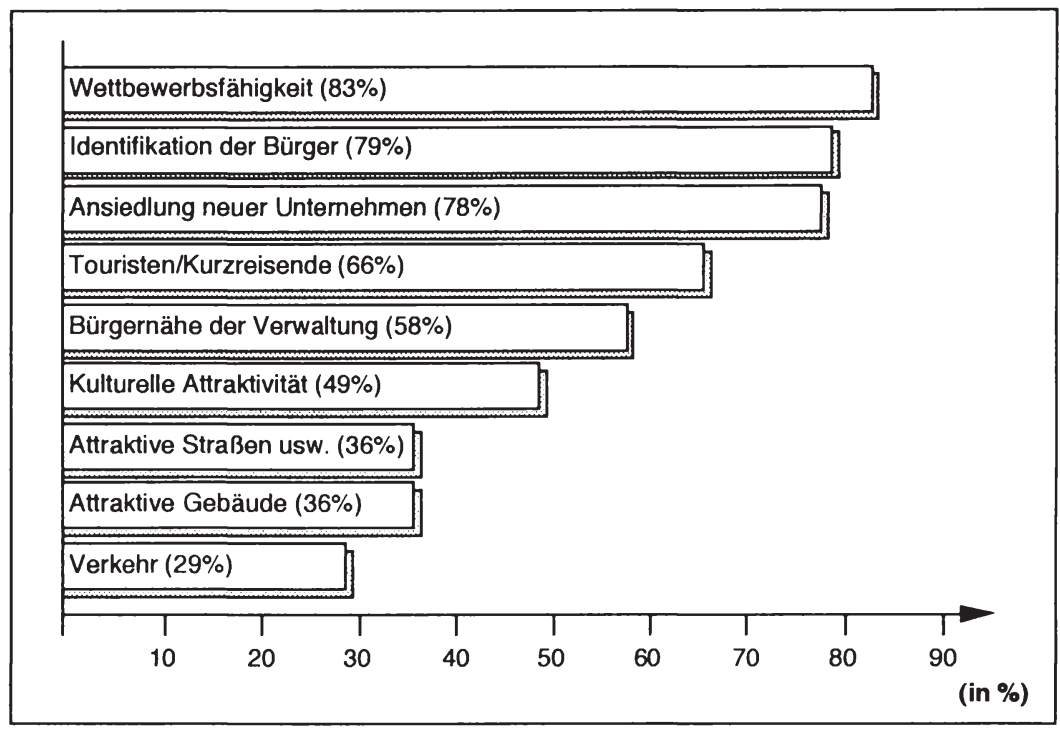

Abb. 1: Erwartungen an das stadtmarketing Quelle: Schückhaus, U., u.a., Stadt- und Regionalmarketing, a.a.0., s. 30 .

- Verbesserung/Erhaltung der Wettbewerbsfähigkeit der angesiedelten Dienstleistungs- und Industrieunternehmen (83\%)

31 Nach ihren derzeitigen Marketingaktivitäten befragt wurden kreisfreie städte und Kreise. Der Fragebogen wurde von 77 städten und Kreisen beantwortet (Rücklaufquote 33\%). Vgl. Schückhaus, U., Graf, H.-A., Dormeier, C., stadt- und Regionalmarketing. Einsatzmöglichkeiten und Nutzen, Kienbaum-Unternehmensberatung $\mathrm{GmbH}$, Düsseldorf 1992, s. 8 . 
- Verbesserung der Identifikation der Bürger mit dem Standort (79\%)

- Ansiedlung neuer Unternehmen (78\%)

- Schaffung eines überregionalen Bekanntheitsgrades (75\%)

Zusammenfassend wird deutlich, daß der Handlungsbedarf der Kommunen wächst, einerseits auf die Identifikation der zielkreise mit dem Referenzraum einzuwirken und andererseits die Identifizierbarkeit der stadt oder Region im Innen- und Außenverhältnis sicherzustellen. Beide Ziele lassen sich in der Forderung nach der Beeinflussung räumlicher Identität zusammenführen. Als Rahmenkonzept zur Erreichung dieser $\mathrm{zielvorgabe}$ bietet $\mathrm{sich}$ der Einsatz von Marketing an.

Angesichts der Neuartigkeit des Forschungsfeldes für die Marketingwissenschaft ist es zunächst erforderlich, eine konsensfähige Definition des Städte- und Regionenmarketing (SRM) zu entwickeln.

\section{Begriff und ziele des städte- und Regionenmar- keting}

Marketing wird heute allgemein als Mittel zur stimulierung und Förderung von Austauschprozessen zwischen Anbieterund Nachfragerinteressen verstanden, unabhängig davon, ob kommerzielle oder nichtkommerzielle ziele verfolgt werden. Auf dieser Grundlage wird das Marketingdenken zunehmend auch auf städte und Regionen ubertragen. Obgleich ein wissenschaftlich geschlossenes Konzept zum Städte- und Regionenmarketing noch nicht vorliegt, zeichnen sich zwei unterschiedliche Forschungsschwerpunkte ab. Eine erste Forschungsrichtung konzentriert sich auf das Marketing für einzelne Städte ("Städte- oder Stadtmarketing“) bzw. Teilaspekte davon. Die zweite Gruppe erweitert das Untersuchungsgebiet auf geographisch, wirtschaftlich und/oder po- 
litisch zusammenhängende Regionen ("Regionen- oder Regionalmarketing“) .32

Ausgehend von der generischen und zugleich weitesten Marketingdefinition läßt sich das städtemarketing ${ }^{33}$ wie folgt definieren:

\begin{abstract}
"Städtemarketing umfaßt die Analyse, die Planung und die Kontrolle von Programmen, deren Zweck es ist, erwünschte Austauschvorgänge mit ausgewählten Märkten bzw. Zielgruppen zu bewirken." 34
\end{abstract}

Dazu ist es erforderlich,

"die Meinungen, die Einstellungen und Verhaltensweisen externer und interner zielgruppen durch ein geeignetes Maßnahmenbündel zu beeinflussen, ..."35

Ein erfolgreiches städte- und Regionenmarketing (SRM) setzt die Berücksichtigung der Bedürfnisse, Wünsche und Probleme tatsächlicher und potentieller Austauschpartner voraus, welche im "Produkt" Stadt oder Region Niederschlag finden müssen. In diesem Sinne wird auch beim SRM die Produktpolitik treffend als das "Herz des Marketing" bezeichnet. 36

32 Vgl. Meffert, H., Regionenmarketing Münsterland. Ansatzpunkte auf der Grundlage einer empirischen Untersuchung, Münster 1991, S. 2 .

33 Die analoge übertragung auf das Regionenmarketing ist angesichts der Weite der zugrundeliegenden Marketingdefinition zulässig.

34 Vgl. Meffert, H., städtemarketing - Pflicht oder Kür, a.a.0., s. 2 .

35 Ebenda, S. 4.

36 Vgl. Meffert, H., Marketing. Grundlagen der Absatzpolitik, Wiesbaden 1986 , S. 361 . 
Die allgemeinen Grundprinzipien, welche sich im klassischen Markenartikelmarketing herausgebildet haben, lassen sich auch für das SRM anwenden. Es sind dies die folgenden fün Aspekte: 37

1. Der Philosophieaspekt, d.h. Probleme, Wünsche und Bedürfnisse interner und externer zielgruppen sind an den Anfang aller überlegungen zu stellen.

2. Ein kundengerechtes Verhalten setzt Informationen über die Bedürfnisse, Wünsche, Probleme und Ängste der betroffenen Personengruppen (z.B. Bewohner, ortsansässige Gewerbebetriebe, Besucher) voraus.

3. Der strategie- und Aktionsaspekt, d.h. die erwünschten Reaktionen der Märkte erfordern einen längerfristigen Verhaltensplan und den planmäßigen Einsatz aller Instrumente des Marketing-Mix.

4. Das Denken in zielgruppen, d.h. daß SRM erfordert die Anwendung des Prinzips der differenzierten Marktbearbeitung.

5. Das Marketing muß nach einer koordinierten Planung vorgehen.

Mit Blick auf die allgemeinen Grundprinzipien des SRM werden wesentliche Gemeinsamkeiten zum kommerziellen Marketing deutlich. Unterschiede lassen sich in der schwerpunktsetzung und in der Zielgruppenauswahl feststellen:

- Von zentraler Bedeutung im SRM ist die Konsensbildung der im Referenzraum involvierten Interessen(träger), um

37 Vgl. Meffert, H., Marketing. Grundlagen der Absatzpolitik, Wiesbaden 1986, S. 31 f.; Ders., Städtemarketing - Pflicht oder Kür, a.a.0., s. 2 . 
darauf aufbauend ein harmonisch abgestimmtes Handeln zu ermöglichen. Ein besonderer Stellenwert kommt dabei der Institutionalisierung eines Dialogs politischer und privater Entscheider $\mathrm{zu} .38$ Derartige Kooperationsformen werden meist als sogenannte "Public Private Partnerships" (PPP) bezeichnet. Ausgehend von dieser Harmonisierungsfunktion ist das SRM mit einem "Konflikt-Management" vergleichbar. 39

- Im Gegensatz zu einem Unternehmen, welches nach frei wählbaren Effizienzkriterien seine Marktsegmente auswählt, müssen in einem SRM-Konzept alle Bewohnergruppen gedanklich einbezogen werden. 40 Dies ist insbesondere darauf zurückzuführen, daß die Träger des SRM im Innenverhältnis gleichzeitig auch wichtige zielgruppen darstellen.

Das städtemarketing ist auf grundsätzlich alle Leistungsfelder einer stadt mit dem ziel ausgerichtet, das Gesamtangebot der Stadt bei internen und externen $\mathrm{ziel-}$ gruppen möglichst transparent und positiv darzustellen.41 Im Gegensatz zu traditionellen Vorgehensweisen (z.B. Werbegemeinschaften), ist das Städtemarketing durch einen in-

38 Der Interessenausgleich wird nicht nur durch die häufig divergierenden Orientierungen von privaten und öffentlichen Entscheidern kompliziert. Hinzu kommt, daß jeder Bewohner gleichzeitig Mitglied in verschiedenen Interessengruppen ist. Vgl. Honert, S., stadtmarketing und Stadtmanagement, in: Der Städtetag, 44. Jg., 1991, H. 6 , S. 397 .

39 Töpfer, A., Stadtmarketing, Eine neue Herausforderung an Kommunen (Teil 2), in: VOP, 1/1992, s. 26.

40 vgl. Töpfer, A., Stadtmarketing, a.a.o., s. 344.

41 Vgl. Meffert, H., Städtemarketing - Pflicht oder Kür?, a.a.0., S. 1 ff.; Töpfer, A., Stadtmarketing, Eine neue Herausforderung an Kommunen (Teil 1), in: VOP, 6/1991, S. $339 \mathrm{ff} .$, Ders., Stadtmarketing, Eine neue Herausforderung an Kommunen (Teil 2), a.a.O., 1/1992, S. 22 ff.. 
tegrativen Ansatz gekennzeichnet. Entscheidender Erfolgsfaktor ist die Anpassung des Städtemarketing an die Situation der Stadt sowie der Interessenausgleich aller relevanten gesellschaftlichen Gruppen. 42

Mitunter stößt das Städtemarketing bei politischen Entscheidungsträgern auf Vorbehalte:

- Assoziationen mit Werbung für Seife oder Waschmittel lassen die Vermutung entstehen, Städtemarketing beinhalte nicht mehr als eine oberflächliche "Vermarktung" und sei lediglich ein moderner Ausdruck für hinlänglich bekannte Werbemaßnahmen. 43

- Weitere Vorbehalte finden in der Befürchtung Ausdruck, die übertragung einer in privatwirtschaftlichen Unternehmen beheimateten Denkweise auf städte oder Regionen könne eine Dominanz wirtschaftlicher Gesichtspunkte nach sich ziehen. 44

- Von besonderer Tragweite ist der Vorwurf, mit der Implementierung des Städtemarketing sei der versuch verknüpft, ein „Nebenparlament” zu etablieren, welches den

42 Vgl. Erlebach, D., Schückhaus, U., Rüstzeug. Stadtmarketing und die zukunft der Kommunen, in: Der Gemeinderat, $2 / 1994$, S. 16 .

43 Vgl. Meffert, H., Pflicht oder Kür?, a.a.O., S. 1.

44 In extremen Positionen wird Marketing als Versuch mißverstanden, die Kompetenzen gewählter politischer Repräsentanten aufzuweichen, indem beispielsweise der Stadtverwaltung ein Gremium mit Marketingfachleuten zur Seite gestellt wird. Vgl. Kemming, H., Zur Gestaltung von Stadtmarketing - Orientierungen für die Praxis, a.a.0., S. 13.; 0.v., Stadtmarketing - mehr als Mode?, in: Der Städtetag, 1/1992, S. 1 (Leitartikel). 
legitimierten städtischen Entscheidungsträgern Kompetenzen streitig macht. 45

Die Existenz von Vorbehalten gegenüber dem Marketingeinsatz unterstreicht die Notwendigkeit, dem Marketing nach außen ein Marketing nach innen vorzuschalten, um eine größtmögliche Akzeptanz aller relevanten Interessengruppen zu erzielen. 46

Das Regionenmarketing wird in der wissenschaftlichen Diskussion meist im Kontext von Marketingkonzepten für die Wirtschafts- oder Tourismusförderung verwendet. 47 Diese Spielarten des Regionenmarketing sind somit im Hinblick auf ein spezifisches Handlungsfeld - z.B. Wirtschaftsförderung, Tourismus - als integrative Konzepte $\mathrm{zu}$ bezeichnen. In diesen traditionellen Ansätzen fehlt die Berücksichtigung von Interdependenzen $z w i s c h e n$ verschiedenen Handlungsfeldern. So darf beispielsweise ein Regionenmarketing-Konzept zur Akquisition neuer Unternehmen nicht ausschließlich auf "harte" wirtschaftliche standortfaktoren ausgerichtet sein. Jeder potentielle Unternehmer muß

45 Diese Befürchtung wird mit dem auf Rat und Verwaltung entstehenden Entscheidungsdruck begründet, der entsteht, wenn die maßgeblichen gesellschaftlichen Gruppen $z \cdot B$. einer stadt nicht mehr einzeln und unkoordiniert auftreten, sondern ihre Interessen bündeln und gemeinsam artikulieren. Mitunter wird diese abgestimmte Vorgehensweise als "positive Bürgerinitiative” umschrieben. Vgl. Honert, S., stadtmarketing in Langenfeld, in: stadtmarketing in der Diskussion, ILS (Hrsg.), Dortmund 1991, S. 64 .

46 Vgl. dazu Kap. C.2.21.

47 Vgl. Tietz, B., Regional- und Kommunalmarketing, Bericht über ein Forschungsprogramm, in: Marketing ZFP, H. 2, Mai 1981, S. 129 ff.; Meissner, H.-G., Grundprobleme eines regionalen Marketing der Industrieregion Ruhr, Vortrag im Rahmen des wissenschaftlichen Kolloquiums aus Anlaß des 60. Geburtstages von Prof. Dr. H.-G. Meissner am 6.10.1989.; Hänni, H.D., Regionales Tourismus-Marketing, Bern 1984 . 
gleichermaßen als Konsument verschiedenster Leistungsangebote betrachtet werden, welche von dem betreffenden Standort vorgehalten werden (z.B. Freizeit- und Bildungsangebote usw.).

Die vergleichsweise nachgeordnete Relevanz des Regionenmarketing als umfassender, alle Leistungsfelder einer Region berücksichtigender Ansatz, ist insbesondere darauf zurückzuführen, daß die Unterschiede zwischen dem Städteund dem Regionenmarketing fließend sind. So ist ein enger Zusammenhang zwischen stadt und Region zwangsläufig gegeben, weil jede stadt als Element einer - wie auch immer abgegrenzten - übergeordneten Region aufzufassen ist.48 In Wissenschaft und Praxis finden sich eine Vielzahl von Begriffen, die sich auf das Marketing für städte und Regionen oder auf bestimmte Teilaspekte (z.B. die Stadtverwaltung) beziehen. Dabei werden unterschiedliche Sachverhalte z.T. mit dem gleichen Begriff belegt. So wird beispielsweise der in zahlreichen veröffentlichungen und in der Praxis verwendete Terminus "Stadtmarketing" häufig mit dem enger gefaßten Innenstadt- und Citymarketing gleichgesetzt. 49

Angesichts der Parallelen zwischen dem Städte- und dem Regionenmarketing wird in dieser Untersuchung der Terminus Placemarketing 50 als Synonym für das SRM verwendet. Da-

48 Häufig stellen Städte einen Bezug zur umliegenden Region her, um angesichts der sich verschärfenden Konkurrenzlage ihr Marktpotential zu vergrößern. Es handelt sich dabei jedoch weniger um eine spielart des Regionenmarketing als vielmehr um eine Ausweitung des städtemarketing, indem die stadt konsequent synergien zwischen Stadt und Umland nutzt.

49 Zur inhaltlichen Gleichsetzung von Stadt- und Citybzw. Innenstadtmarketing vgl. DIHT, Modernes Stadtmarketing. Attraktive Innenstadt, Bonn 1989.

$50 \mathrm{Vgl}$. Meffert, H., Regionenmarketing Münsterland, a.a.o., s. 2 . 
bei wird der Tatsache Rechnung getragen, daß die Gemeinsamkeiten zwischen Städten und Regionen im Hinblick auf die zu lösenden Problemkreise größer sind als die Unterschiede. Im einzelnen lassen sich die folgenden fünf allgemeinen Herausforderungen aufzählen, denen sich städte und Regionen gleichermaßen konfrontiert sehen: 51

- Marketingdenken nach innen verankern,

- Bedarfsfelder frühzeitig erkennen,

- Selbstverständnis der Stadt/Region klären,

- Zielprioritäten festlegen,

- Konsens und Maßnahmenkontinuität sicherstellen.

Angesichts der Unschärfe in der Begriffsverwendung ist eine präzise Abgrenzung des SRM bzw. des Placemarketing von ähnlichen Konzepten zwingend erforderlich.

\section{Abgrenzung des städte- und Regionenmarketing von ähnlichen Konzepten}

Die wesentlichen konzeptionellen Ansatzpunkte zum SRM sind in der Abbildung 2 zusammengestellt. Im wesentlichen lassen sich drei verschiedene Ansatzpunkte voneinander unterschieden:

- Das kommunale Marketing. Dazu zählt das Marketing für Kommunalverwaltungen, das Marketing für öffentliche Unternehmen, sowie das Marketing für öffentliche Güter.

- Das City- oder Innenstadtmarketing als spezifisches Marketing für den lokalen Einzelhandel bzw. zur Belebung der Innenstädte.

51 Vgl. Meffert, H., Städtemarketing - Pflicht oder Kür?, a.a.o., s. 7 . 
- Das städte- und Regionenmarketing (SRM) bzw. das Placemarketing als ganzheitlicher Marketingansatz für alle Leistungsfelder einer Stadt oder Region.

Das Marketing für Kommunalverwaltungen ist Ausdruck für die Abkehr von einer binnenorientierten Sichtweise der verwaltung. 52 Der Anspruch besteht darin, den Bürger nicht länger als "Antragsteller", sondern als „Kunde“ eines öffentlichen Dienstleistungsunternehmens zu begreifen. Diese Ausrichtung wird durch ein konsequent umweltgerichtetes Handeln $z u$ erreichen versucht, welches die Ausgestaltung der kommunalen Dienstleistungen so weit als möglich an den Wünschen und Bedürfnissen der Bürger ausrichtet. 53 wichtige ziele sind demgemäß die steigerung der Bürgeridentifikation sowie Imageverbesserungen, welche durch Verbesserungen in der Leistungserbringung (z.B. durch flexible Öffnungszeiten oder die Einrichtung von "Bürgerämtern" usw.) erreicht werden sollen. 54

52 Vgl. Eichhorn, P., Buchholz, W., Marketing in öffentlichen Verwaltungen, in: Bfup, 35. Jg., 1983, Nr. 3, S. $209 \mathrm{ff}$; 0.V., Kommt Marketing ins Rathaus?, in: asw, 8/1989, S. $36 \mathrm{ff}$.; Wagner, G.R., Kommunales Marketing, in: Verwaltungsrundschau, H.7, 1984, S. 225 ff.; o.v., Kommunales Marketing, in: Der Städtetag, 8/1989, S. 526 f.

$53 \mathrm{Vgl}$. Homann, K., Marketing in Kommunalverwaltungen, in: Marketing in Kommunalverwaltungen, Schriftenreihe des Instituts für Marketing der Universität Dortmund, Homann, K., Meissner, H.G. (Hrsg.), H. 4, Dortmund 1986 , s. $30 \mathrm{f}$.

54 Zur verstärkten Ausrichtung des Verwaltungshandelns an die Beduirfnisse der Bürger vgl. Schnoor, H., Bürgernähe als Aufgabe von Politik und Verwaltung, in: Marketing in Kommunalverwaltungen, a.a.O.; Vgl. Braun, G.R., Töpfer, E. (Hrsg.), Marketing im kommunalen Bereich - Der Bürger als "Kunde" seiner Gemeinde, Stuttgart 1989.; Homann, K., Mehr Bürgernähe in Kommunalverwaltungen durch Marketing, in: Der Städtetag, 1986, S. $607 \mathrm{ff.}$ 


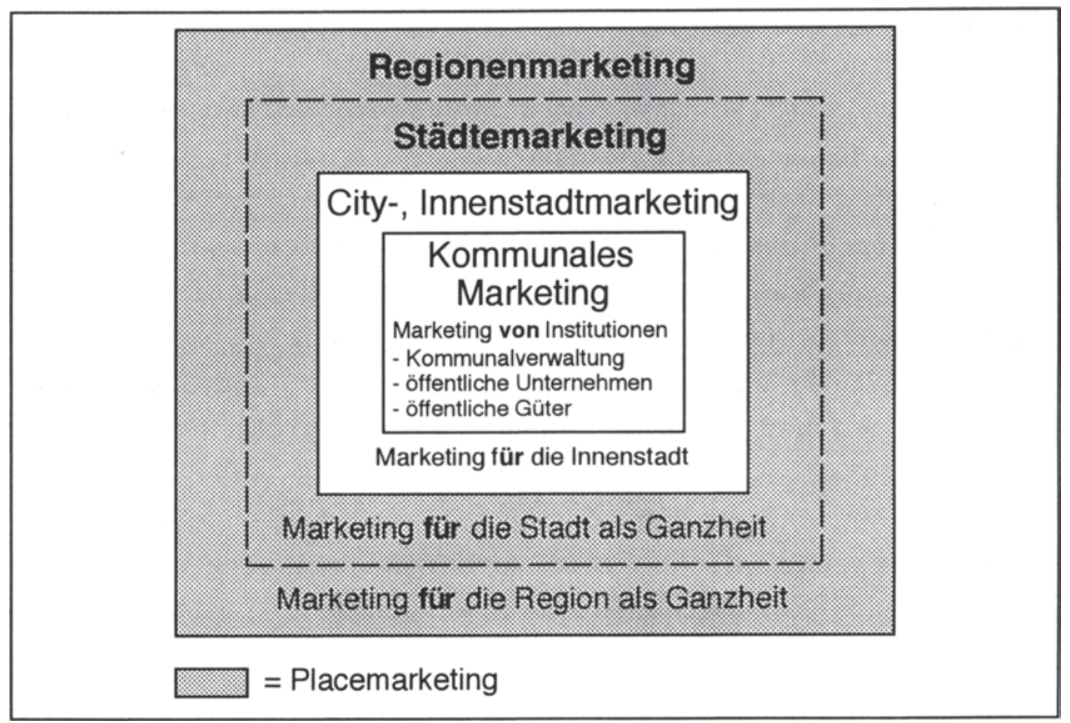

Abb. 2: Begriffsabgrenzung des Placemarketing

Von diesen primär auf das Verwaltungsgeschehen öffentlicher Institutionen ausgerichteten Konzepten ist das Marketing für öffentliche Betriebe zu unterscheiden. 55 Dazu zählen beispielsweise die öffentlichen Betriebe der Ver- und Entsorgung (z.B. Gas- und Wasserwerke, Müllab-

55 Vgl. Raffée, H., Marketing in öffentlichen Betrieben, in: Marketing im Wandel, Hrsg.: Meffert, H., Schriftenreihe Unternehmensführung und Marketing, Meffert, H., Steffenhager, H., Freter, H. (Hrsg.), Bd. 13, Wiesbaden 1980, S. 201 ff., Stauss, B., Grundlagen des Marketing öffentlicher Unternehmen, Baden-Baden 1987.; Eiteneyer, H., Meissner, H.G., Marketing öffentlicher Unternehmungen, Schriftenreihe des Lehrstuhls für Marketing der Universität Dortmund, Dortmund 1978.; Eiteneyer, H., Social Marketing-Unternehmensphilosophie öffentlicher Unternehmen, in: ZfbF, H. 5, 1977, S. 303 ff.; Hesse, J., Zum Marketingverständnis öffentlicher Unternehmen, in: Jahrbuch der Absatz und Verbrauchsforschung, Gesellschaft für Konsum-, Markt- und Absatzforschung (Hrsg.), Berlin 1981. 
fuhr) 56 , öffentliche Verkehrsbetriebe (z.B. Busverkehr, UBahnen, Flughäfen), öffentliche Betriebe im sektor Kultur und Freizeit (z.B. Theater und Museen, Volkshochschulen, Frei- und Hallenbäder, Tierparks).57 Im Gegensatz zu privatwirtschaftlich organisierten Unternehmen tritt der Gewinn als primäres ziel hinter die Berücksichtigung des Gemeinwohls zurück. 58 Das primäre Ziel des Marketing für öffentliche Unternehmen besteht vielmehr darin, den öffentlichen Auftrag sowie die Legitimität des Handelns besser darzustellen und damit einen Schritt in Richtung größerer Verbrauchernähe zu gehen.59 Mit Hinweis auf ihr meist räumlich begrenztes Angebotsmonopol und fehlende substitutionskonkurrenz weisen viele versorgungsunternehmen jedoch die Notwendigkeit eines derartigen Marketing mitunter zurück. 60

In engem Zusammenhang mit dem Marketing für öffentliche Betriebe und dem Marketing für öffentliche Verwaltungen ist das Marketing für öffentlich Güter zu betrachten, welches - je nach Produkt - einem dieser beiden Bereiche zugeordnet werden kann. Im Mittelpunkt der Marketingaktivitäten stehen Güter, welche die Privatwirtschaft nicht ausreichend zur Verfügung stellen würde, nicht zur Verfü-

56 Vgl. Cadosch, W., Marketingstrategien für öffentliche Energieversorgungsunternehmen, Berlin, Stuttgart 1982.

57 Vgl. Stauss, B., Grundlagen des Marketing öffentlicher Unternehmen, Baden-Baden 1987 . ; Eiteneyer, H., Meissner, H.G., Marketing öffentlicher Unternehmungen, a.a.O.; Eiteneyer, H., Social Marketing-Unternehmensphilosophie öffentlicher Unternehmen, in: BfuP, H. 5, 1977 , s. 303 ff..

58 Vgl. Eiteneyer, H., Social Marketing-Unternehmensphilosophie öffentlicher Unternehmungen, a.a.0., S. 304 .

59 Vgl. Eiteneyer, H., Social-Marketing-Unternehmensphilosophie, a.a.0, S. 303 ff..

60 Vgl. Röber, M., Marketing - ein Konzept für öffentliche Betriebe?, Berlin 1988, s. 56. 
gung stellen kann (z.B. Polizei) bzw. für die keine Bereitschaft zur $\mathrm{z}$ ahlung eines Leistungsentgelts besteht (z.B. saubere Luft). Wesentlicher Bestandteil des zielkataloges muß die Schaffung von verständnis und Vertrauen auch für unpopuläre Maßnahmen im Dienste der Öffentlichkeit sein.

Den verschiedenen Spielarten des kommunalen Marketing ist gemeinsam, daß sie nicht explizit auf die stadt oder Region, sondern auf eine öffentliche Aufgabe ausgerichtet sind. Die Tätigkeit dieser Institutionen beeinflußt zwar das Vorstellungsbild, welches die interne öffentlichkeit von ihrer Kommune zeichnet; die profilierung der Stadt/Region ist im Zielkatalog der betreffenden Organisation jedoch nicht enthalten. Die Tätigkeit kommunaler Institutionen muß somit zusammenfassend als eine Marketingaufgabe aufgefaßt werden, welche die Bereiche des nichtkommerziellen 61 und des öffentlichen 62 Marketing berührt.

Dieses Marketing von kommunalen Institutionen und öffentlichen Unternehmen ist ein eigenständiger objektbereich des Marketing, der vom Marketing für eine Innenstadt, Gesamtstadt, oder Region $\mathrm{zu}$ unterscheiden ist. 63

61 Vgl. Kotler, P., Marketing für Nonprofit-Organisationen, Stuttgart 1978.; Hasitschka, W., Hruschka, H., Nonprofit-Marketing, München 1982.; Raffée, H., Wiedmann, K.-P., Nicht-kommerzielles Marketing - ein Grenzbereich des Marketing, in: BFuP, 35. Jg., 1983, Nr. 3, S. 185 ff..

62 Vgl. Kotler, P., Marketing für den öffentlichen Bereich, in: DBW, 39/1979, S. 421-430.

63 Diese beiden grundsätzlich zu unterscheidenden Ansätze sind jedoch miteinander verbunden, weil das Marketing für eine stadt oder Region wesentlich vom Marketing der einzelnen kommunalen Institutionen abhängig ist, welche für den betreffenden Raum zuständig sind. Vgl. Töpfer, A., Braun, G. E., Ansatzpunkte für Marketing im kommunalen Bereich, in: Braun, G.E., Töpfer, A. (Hrsg.), Marketing im kommunalen Bereich - Der Bürger als "Kunde" seiner Gemeinde, a.a.0., s. $10 \mathrm{f}$. 
Angesichts des Bedeutungsverlusts großstädtischer Innenstädte für die versorgung der Bevölkerung und der Akzeptanz großflächiger Einzelhandelsbetriebe in den städtischen Randgebieten, hat das city- oder Innenstadtmarketing zur Behebung von Attraktivitätsdefiziten der Innenstädte an Bedeutung gewonnen. 64 Dieses spezielle Marketing für die Innenstadt deckt ausdrücklich nur spezifische Produktfacetten der Gesamtstadt $a b$, welche mit dem örtlichen Einzelhandel in Verbindung stehen. Als Träger eines Citymarketing-Konzeptes kommen insbesondere kommunale Behörden, Werbe- und Aktionsgemeinschaften des Handels bzw. des Dienstleistungssektors sowie sonstige Interessenvereinigungen dieser Branchen (örtliche Einzelhandelsverbände, Industrie- und Handelskammern usw.) in Frage.65 Das Citymarketing ist in der Praxis besonders weit verbreitet, so daß mittlerweile eine Reihe von Erfahrungsberichten vorliegen. 66

64 Vgl. Tietz, B., Rothhaar, P., City Studie - Marktbearbeitung und Management für die stadt - Neue Konzepte für Einzelhandels- und Dienstleistungsbetriebe, Landsberg/Lech 1991.; Jacobs, S., City-Marketing. Die Anwendung der Marketing-Technologie zur Erhöhung der Einkaufsattraktivität von Innenstädten, in: Marketing ZFP, H. 2, II. Quartal 1991, S. 121-130.; 0.V., Innenstadt zieht an, in: asw $8 / 87$, s. 26-35.; o.v., CityMarketing für eine stadt, in: w\&v, Nr. 44, 25. Jg. (1988), S. 30 ff.; Hartzfeld, U., Junker, R., City-Management - Anything goes?, in: Raumplanung, $H$. 45, 1989, S. 116-119.; Hartzfeld, U., Reetz, C., Stadtmarketing oder Bürgermitwirkung. Stadtentwicklung in der Innenstadt - ein Resumee, in: Raumplanung, H. 50, 1990 , S. 175-177.

Vgl. Jacobs, S., City-Marketing. a.a.O., S. 122 .

66 Vgl. ILS (Hrsg.), Stadtmarketing in der Diskussion, Fallbeispiele aus NRW, Duisburg 1991.; Uhlmann, J., City-Marketing Velbert. Gemeinsame Arbeit mit Beteiligten und Betroffenen, in: Experimenteller Wohnungsund Städtebau, November 1991, S. 29 ff.; DIHT, Modernes Stadtmarketing. Attraktive Innenstadt, a.a.0. 
Ähnlich dem Citymarketing, das mit der Schwerpunktsetzung auf den lokalen Einzelhandel nur einige wenige Leistungsfelder bedient, deckt das standortmarketing nur einen kleinen Teilbereich möglicher Funktionen eines Gesamtraums ab. Im einzelnen beinhaltet das standortmarketing die laufende Beobachtung und Analyse des Marktes für Industrie- und Gewerbestandorte sowie eine gezielte, systematische und planmäßige Ausrichtung der standortaktivitäten auf die gegenwärtigen Bedürfnisse und Erwartungen der vorhandenen und potentiellen Investoren mit dem ziel, die Entwicklung einer Gemeinde oder Region voranzutreiben. 67 Dabei geht es primär darum, einen Interessenausgleich zwischen dem Standortanbieter und ansässigen oder potentiellen Unternehmen herbeizuführen. 68 standort-Anbieter sind städte und Gemeinden, Regionen mit gemeinsamer wirtschaftsförderung und Grundstückseigentum. 69 wichtige ziele sind die Entwicklung der Gewerbesteuer, die Belegung von freien Industrieflächen, und die Anzahl der vorhandenen Arbeitsplätze.

67 In Anlehnung an Nieland, M., Standort-Marketing, in: Konzeptionen zur Industrieansiedlung, Siedlungsverband Ruhrkohlebezirk (Hrsg.), Essen 1977, S. $17 \mathrm{ff.;} \mathrm{vgl.}$ auch Kolz, H., Essling, H., Standort-Marketing - ein Konzept zur kommunalen Wirtschaftsförderung, in: Der Städtetag, $10 / 86$, S. $677 \mathrm{ff}$.; Hammann, P. , Ansätze zu einem Marketing fur kommunale standorte, in: Arbeitspapiere zum Marketing Nr. 15, Ruhr-Universität Bochum, Seminar für angewandte Wirtschaftslehre, Bochum 1986.; Zimmermann, K., Wirtschaftsförderung als Aufgabe des kommunalen Marketing, in: Kommunalwirtschaft, $\mathrm{Nr} .11$, 1976 , S. $341 \mathrm{ff}$; Steinmetz, F., Standortmarketing aber wie?, in: Der Städtetag, H. 3, 1986, S. 100 .

68 Vgl. Meissner, H.-G., Marketing für die kommunale wirtschaftsförderung, in: Städte- und Gemeinderat, $7 / 1987$, S. 196 .

69 Vgl. Kolz, H., Essling, H., Standort-Marketing - ein Konzept zur kommunalen Wirtschaftsförderung, a.a.0., S. 677 . 
Zentraler Gestaltungsbereich des Standortmarketing ist das Angebot und die Qualität von Gewerbegrundstücken. 70 Neben der Standortqualität stellen Fördermaßnahmen (Finanz- und Sachzuwendungen, Konditionen bei der überlassung von Gewerbegrundstücken und Infrastruktureinrichtungen), der persönliche Einsatz der Wirtschaftsförderer sowie Öffentlichkeits- und Ansiedlungswerbung (Publikationen, Anzeigen, Vorträge, Messestände usw.) wichtige Instrumente dar. 71

Die Ausweitung des Städtemarketing auf grundsätzlich alle Funktionsbereiche einer stadt stellt den wesentlichen inhaltlichen Unterschied zum City- oder Innenstadt- sowie zum Standortmarketing dar. Formale Gemeinsamkeiten aller Konzepte lassen sich hinsichtlich der Kooperations- und Konsensschaffungserfordernisse der involvierten Entscheidungsträger aufzeigen.

Im Rahmen einer empirischen Untersuchung der Kienbaum-Unternehmensberatung wurde der Frage nachgegangen, welche Definitionen des SRM in der Praxis vorherrschen. Dazu wurden verschiedene Antwortmöglichkeiten vorgegeben, die jeweils einen bestimmten Aspekt des SRM herausgreifen. Aus einer vorgegebenen Antwortliste wurden die folgenden Definitionen genannt (vgl. Abbildung 3):72

70 In den letzten Jahren gewinnen insbesondere auf junge Unternehmen ausgerichtete, vorgefertigte, StandortProblemlösungen wie Technologieparks, Industrieparks und Gewerbehöfe an Bedeutung. Vgl. Hennicke, H., Tengler, H., Industrie- und Gewerbepark als Instrument der kommunalen Wirtschaftsförderung, Stuttgart 1986.

71 Vgl. Kolz, H., Essling, H., Standort-Marketing - ein Konzept zur kommunalen Wirtschaftsförderung, a.a.0., S. $679 \mathrm{f}$.

72 Vgl. Schückhaus, U., u.a., Stadt- und Regionalmarketing, a.a.o, s. 24 . 


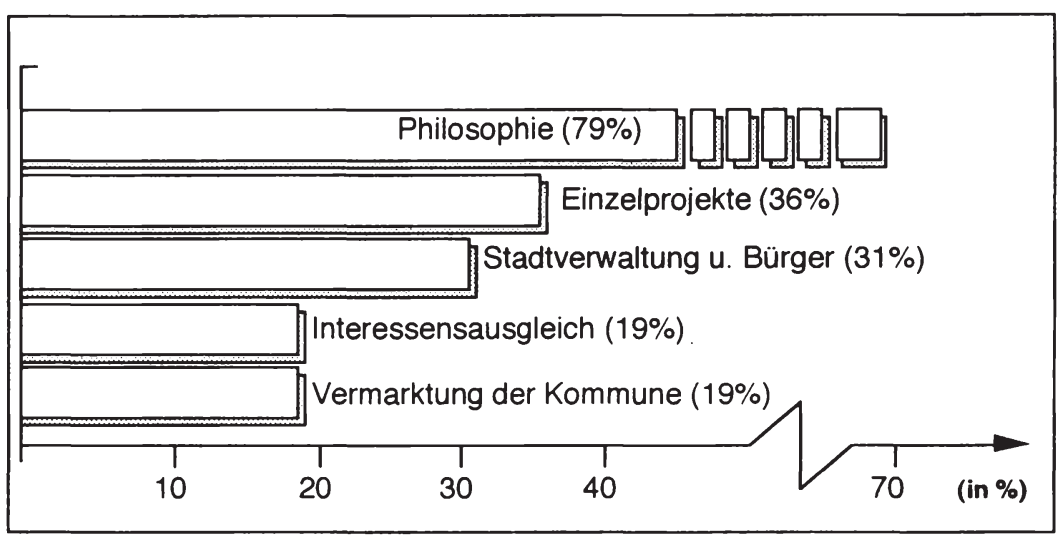

Abb. 3: Definitionen des Begriffes Stadtmarketing Quelle: Schückhaus, U., u.a., Stadt- und Regionalmarketing, a.a.0., s. 24 .

- Philosophie (79\%): Nach Auffassung von 79\% der Befragten, ist städtemarketing eine Philosophie im Rahmen eines ganzheitlichen Konzepts, das die Inhalte, das Verfahren sowie die Vermittlung nach innen und außen umfaßt.

- Einzelprojekte (36\%): Städtemarketing ist eine Werbeund Verkaufsstrategie zur medienwirksamen Vermarktung kommunaler Einzelprojekte.

- Stadtverwaltung und Bürger (31\%): Städtemarketing ist eine auf die Verbesserung der Beziehungen zwischen stadtverwaltung und Bürger abgestellt Strategie.

- Interessensausgleich (19\%): Städtemarketing ist ein Verfahren zur zielfindung in einer/einem stadt/Kreis mit Hilfe des Interessenausgleichs.

- Vermarktung der Kommune (198): Städtemarketing ist eine Werbe- und Verkaufsstrategie zur medienwirksamen vermarktung der Kommune. 
Die Ergebnisse belegen, daß SRM größtenteils als Philosophie im Rahmen einer ganzheitlichen Vorgehensweise verstanden wird. Damit deckt sich die Auffassung des SRM in einem wesentlichen Punkt mit theoretischen Forderungen. Die Interpretation als ganzheitliches Konzept steht jedoch in widerspruch zur praktischen Durchführung, welche vornehmlich durch Einzelaktivitäten gekennzeichnet ist. 73 Diese Zurückhaltung ist möglicherweise mit einer rezessionsbedingten Verschärfung der Haushaltslage zu begründen, welche viele kommunen dazu zwingt, ihre Kommunikationsetats zu kürzen. 74

\section{Ziel und Gang der Untersuchung}

Ausgehend von der zentralen Bedeutung, welche dem Identitätsbegriff in Wissenschaft und Praxis im Rahmen des Städte- und Regionenmarketing eingeräumt wird, besteht die generelle zielsetzung der Arbeit darin, einen Beitrag zur theoretischen Fundierung räumlicher Identität aus Marketingsicht zu leisten.

Die wissenschaftliche $\mathrm{Zielsetzung} \mathrm{der} \mathrm{Arbeit} \mathrm{untergliedert}$ sich in eine theoretisch-begriffliche, eine methodische sowie in eine praxisorientierte Zielsetzung. Auf diese Weise wird gleichzeitig der Gang der Untersuchung vorgezeichnet:

73 So haben lediglich $17 \%$ der Befragten eine ganzheitliche Marketingkonzeption erarbeitet, während $52 \%$ eine ganzheitliche Marketingkonzeption planen. Die durchgeführten Marketingkonzepte beziehen sich überwiegend auf städtische/regionale Téilbereiche. Vgl. Schückhaus, U., u.a., Stadt- und Regionenmarketing, a.a.o., S. 25 .

74 Vgl. O.V., Kommunen fürchten um Etats der Imagewerbung, in: HORIZONT, Nr. $28 / 93$, S. 1,9 . 
Das theoretisch-begriffliche ziel bezieht sich auf die Konkretisierung des Identitätsbegriffes in Bezug auf Städte und Regionen. Weil vergleichbare Untersuchungen in der Betriebswirtschaftslehre fehlen, ist ein interdisziplinärer Ansatz erforderlich, der zentrale Forschungsansätze der sozialwissenschaftlichen Identitätsforschung im allgemeinen und der Beziehung zwischen dem Menschen und seiner räumlichen Umwelt im besonderen berücksichtigt. Das methodische $\mathrm{ziel}$ bezieht sich auf die empirische überprüfung räumlicher Identität, wobei das räumliche zugehörigkeitsgefühl in Abhängigkeit von personenbezogenen (z.B. demographischer) und raumbezogenen (z.B. räumlicher Maßstabsbereich: Wohnort, Region, Europa usw.) Bestimmungsgrößen untersucht wird. Auf dem entwickelten verständnis räumlicher Identität aufbauend werden darüber hinaus generelle Erfolgsvoraussetzungen für das städte- und Regionenmarketing sowie Implikationen für das Management von Städten und Regionen aufgezeigt.

In Kapitel B. steht zunächst ein überblick über die zentralen verwendungsweisen des Identitätsbegriffes in den sozialwissenschaften im Vordergrund. Weil die Identitätsforschung kein originäres Forschungsfeld der Betriebswirtschaftslehre bzw. der Marketingwissenschaft darstellt, wird dazu ein interdisziplinärer Ansatz gewählt, welcher eine schwerpunktlegung auf die Begriffsverwendung der Identität einer Person legt. Mit diesem überblick über die allgemeine Identitätsforschung wird die Grundlage für die weitere Diskussion räumlicher Identität gelegt.

I $m$ nächsten Untersuchungsschritt B.1.2 werden konzeptionelle Ansatzpunkte verschiedener Wissenschaftsdisziplinen vorgestellt, welche übereinstimmend die Beziehung des Menschen zu seiner näheren und weiteren räumlichen Umwelt zum Inhalt 
haben und damit erste Hinweise zur Konkretisierung räumlicher Identität liefern können. Die wesentlichen Bedeutungsinhalte des keiner bestimmten Wissenschaftsdisziplin eindeutig zurechenbaren Heimatbegriffes sowie der von den Befurwortern und K r i $t$ i k r n d e r sogenannten geographischen Regionalbewußtseinsforschung verwendete Terminus "Regionalbewußtsein" werden exemplarisch vorgestellt. Anschließend wird die Frage diskutiert, inwiefern die aus $\mathrm{d}$ e $\mathrm{m} \quad \mathrm{B} l \mathrm{i} \mathrm{c} \mathrm{k}$ w $\mathrm{i} \mathrm{n}$ e 1 sozialwissenschaftlicher Nachbardisziplinen vorgenommenen Konkretisierungen räumlicher Identität geeignet sind, Impulse für die Konkretisierung räumlicher Identität aus Marketingsicht zu geben.

In einem nächsten Teilkapitel wird räumliche Identität als spielart der sozialwissenschaftlichen Identitätsforschung konzipiert. Die Entwicklung eines zweiseitigen Begriffsverständnisses räumlicher Identität, welches räumliche Identität in Abhängigkeit von der Betrachtungsperspektive als

- Identität der Person, bzw. als

- Identität des Raumes

konzipiert, schließt das erste Teilkapitel B.1 ab.

A u s g he nd von der zweiseitigkeit des Begriffsverständnisses räumlicher Identität wird dem Untersuchungsabschnitt B.2 ein Paradigma vorangestellt, welches die wesentlichen Arbeitsschritte des Teilkapitels vorzeichnet. Auf diese Weise wird zum Ausdruck gebracht, daß räumliche Identität zwingend an die Existenz von Personen und Gruppen gebunden ist, welche eine Beziehung zu ihrer räumlichen Umwelt (z.B. eine Stadt oder Region) 
herstellen. In diesem zusammenhang lassen sich verschiedene Typen von Identitätsträgern grundsätzlich voneinander abgrenzen. Darüber hinaus setzt jede Untersuchung räumlicher Identität zwingend die Existenz einer räumlicher Bezugsgröße voraus, auf die räumliche Identität bezogen ist. Zu diesem Zweck wird ein Kontinuum räumlicher Maßstabsbereiche herausgearbeitet, welches das gesamte spektrum alternativ möglicher räumlicher Bezugsgrößen abbildet. Ausgehend von der These, daß räumliche Identität nicht auf Flächen, sondern - im weitesten Sinne - auf inhaltliche Besonderheiten ausgerichtet ist, wird dazu schließlich ein systematisierungsvorschlag aufgezeigt.

Im dritten Teilkapitel B. 3 werden Ansatzpunkte zur operationalisierung räumlicher Identität aufgezeigt. Ausgehend von den methodischen Prämissen, welche jede Untersuchung räumlicher Identität bestimmen, wird zunächst räumliche Identität als abhängige variable operationalisiert. Eine ausführliche Diskussion der Bestimmungsfaktoren räumlicher Identität stellen die Grundlage zur Ableitung von Hypothesen bzgl. der Wirkung der Einflußgrößen dar. Dabei wird eine Unterteilung $\mathrm{zw}$ ischen personenbezogenen und raumbezogenen Bestimmungsfaktoren vorgenommen. Ein Bezugsrahmen für die empirische Analyse räumlicher Identität schließen den BTeil der Untersuchung ab.

In Teil C werden zunächst Teilaspekte räumlicher Identität, aufbauend auf einer Darstellung des Untersuchungsdesigns, empirisch überprüf. Dabei wird das Verständnis räumlicher Identität als Identität der Person zugrunde gelegt. Die Ausgestaltung des Fragebogens macht es erforderlich, räumliche Identität (abhängige Variable) als Zugehörigkeitsgefühl zu konzipieren. Dabei wird der Einfluß verschiedener räumlicher Maßstabsebenen und der Einfluß personenbezogener Bestimmungsfaktoren auf die 
Ausprägung des räumlichen Zugehörigkeitsgefühls gemessen. Eine zusammenfassende Würdigung der empirischen Ergebnisse schließt den Teil C.1 der Arbeit ab.

In den folgenden Untersuchungsschritten werden Ansatzpunkte zur praktischen Relevanz räumicher Identität als Aspekt des Städte- und Regionenmarketing aufgezeigt. Dabei werden zunächst die organisatorischen Rahmenbedingungen, we lche eine wesent 1 iche Erfolgsvoraussetzung für die erfolgreiche Durchführung eines städte- und Regionenmarketing darstellen, a ufgezeigt. Ein besonderer stellenwert kommt Kooperationsformen privater und öffentlicher Akteure in der Form von Public Private Partnerships zu. Darüber hinaus werden die zentralen Aufgabenfelder des Placemanagements dargelegt. Abschließend werden weitere Erfolgsvoraussetzungen formuliert, welche für die konkrete Ausgestaltung von Marketingkonzepten für städte und Regionen bedeutsam sind. Dabei wird der zentrale Stellenwert des Wirklichkeitsbezuges der ibermittelten Botschaftsinhalte (Authentizität) sowie der Individualität der übermittelten räumlichen Besonderheiten (Singularität) herausgearbeitet.

In der Schlußbetrachtung in Teil D erfolgt eine zusammenfassende Darstellung der Untersuchungsergebnisse sowie eine Diskussion der Ansatzpunkte fur die weiterfuhrende Forschung. 
B .

1 .

$1 \cdot 1$

Theoretische Grundlagen räumlicher Identität

Forschungsansätze räumlicher Identität

Relevanz sozialwissenschaftlicher Identitätsauffassungen für die räumliche Identität

Das sozialwissenschaftliche Identitätsverständnis ist durch keine allgemein anerkannte Begriffsdefinition gekennzeichnet. 75 Die Verwendung des Identitätsbegriffes in einer Vielzahl unterschiedlicher Wissenschaftsdisziplinen sowie in der Alltagssprache führt häufig zu Begriffsverwirrungen, wenn unterschiedliche Sachverhalte mit dem gleichen Begriff belegt werden. 76 Die Antwort darauf, was unter Identität $\mathrm{zu}$ verstehen ist, hängt deshalb maßgeblich von der Art des Untersuchungsobjektes und der wissenschaftlichen Forschungsperspektive ab. Angesichts der Unschärfe des Begriffsverständnisses muß eine wissenschaftIiche Arbeit über Identität deshalb Bedeutungsschwerpunkte setzen, und sich darauf beschränken, die wesentlichen,

75 Vgl. Frey, H.P., Haußer, K., Entwicklungslinien sozialwissenschaftlicher Identitätsforschung, in: H.-P. Frey, K. Haußer (Hrsg.), Identität. Entwicklungslinien psychologischer und soziologischer Forschung, Stuttgart 1987, S. 17 .

76 In der Soziologie wird der Identitätsbegriff beispielsweise zur Beschreibung typischer Muster sozialer Rollen eines Individuums verwendet; persönlichkeitspsychologisch wird unter Identität die Bedeutung eines zusammenhängenden Selbstkonzeptes verstanden, Moraltheologen und Philosophen verstehen unter Identität eine Reihe unveränderter persönlicher Werthaltungen und ethischer Prinzipien, während die Psychiatrie mit Identität die Intaktheit der Organisationsleistungen des Nervensystems bezeichnet. Vgl. Conzen, P., E. H. Erikson und die Psychoanalyse. Systematische Gesamtdarstellung seiner theoretischen und klinischen Positionen, Heidelberg 1989, s. 72 . 
notwendigermaßen partiell stilisierten Grundannahmen und Definitionen herauszuarbeiten. 77

Mit den Begriffen Individualität, Einzigartigkeit, Unterscheidbarkeit, Unverwechselbarkeit oder dem Begriffspaar "Gleichheit und Differenz" wird der semantische Raum jener Konnotationen abgesteckt, welche das sozialwissenschaftliche Identitätsverständnis kennzeichnen. Als objekt dessen Identität im sinne der oben beispielhaft aufgezählten Schlagworte festgestellt werden soll, kommt ein Gegenstand, eine Person, Gruppe oder eine organisation usw. grundsätzlich in Betracht.78 Im Rahmen der Betriebswirtschaftslehre wird daruber hinaus ganzen Unternehmen (Unternehmensidentität, "Corporate Identity"), oder Produkten (Markenartikel) eine Identität zugeschrieben.79 Gleichermaßen ist es möglich, einem beliebigen Raum (z.B. einem straßenzug, stadtteil, Nachbarschaft oder einer Stadt oder Region) eine Identität zuzuweisen.

77 Vgl. Kammerer, J., Beitrag der Produktpolitik zur Corporate Identity, München 1988, S. 59.

78 In einem übertragenen wortsinn läßt sich die umgangssprachliche Interpretation des Identitätsbegriffes mit einer Polizeikontrolle vergleichen, die anhand der überprüfung von Ausweispapieren die eindeutige Identifizierung des jeweiligen Gegenübers zum $\mathrm{ziel}$ hat. Auf diese Weise wird aber nicht nur die übereinstimmung der betreffenden Person mit den Angaben im Identitätspapier festgestellt. Gleichheit bedeutet zugleich Differenz, weil sich die solchermaßen identifizierte Person zwangsläufig hinsichtlich der eingetragenen Merkmale von allen anderen Personen unterscheiden muß.

79 Vgl. Birkigt, K., stadler, M.M., Corporate Identity Grundlagen, in: Birkigt, K., Stadler, M.M., Funck, H.J., Corporate Identity. Grundlagen Funktionen Fallbeispiele, Landsberg am Lech 1988, S. 23 ff.. 
1.11 Generelle Verwendungsweisen des Identitätsbegriffes

Die Beschränkung auf die zentralen Eckpunkte des sozialwissenschaftlichen Identitätsverständnisses läßt eine Dreiteilung der Begriffsverwendung erkennen. Als Analyseraster zur Gegenüberstellung und Abgrenzung verschiedener Identitätsauffassungen ist die Trennung zwischen dem subjekt (Wer identifiziert?) und dem objekt (Was wird identifiziert?) der Identitätsfeststellung hilfreich: 80

- Im Falle der Selbstidentifizierung stimmen subjekt und objekt überein. Eine Person stellt Identität über sich selbst her. Identität wird somit aus der Innenperspektive festgestellt, indem eine Person im Rahmen eines selbstreflexiven Bewußtwerdungsaktes Identität über sich herstellt.

- Fremdidentifizierung liegt vor, sofern subjekt und Objekt der Identitätsfeststellung nicht in einer Person zusammenfallen. Identität wird somit aus der Außenperspektive hergestellt, indem eine bestimmte Person von anderen Personen z.B. als groß oder klein, alt oder jung aber auch als Bewohner einer bestimmten stadt identifiziert wird.

Der Identitätsbegriff wird in Bezug auf Individuen und Gruppen verwendet. So ist es beispielsweise möglich, daß eine Person sich selbst u.a. als Mitglied einer Gruppe beschreibt ( "Wir von der Deutschen Bank", "Wir im Münsterland“), der sie sich verbunden fühlt. Analog wird eine bestimmte Person aus der Außenperspektive möglicherweise als Mitglied bestimmter Gruppen identifiziert.

80 Vgl. Frey, H.P., Haußer, K., Entwicklungslinien sozialwissenschaftlicher Identitätsforschung, a.a.o., S. 6,17 . 
Auf Grundlage der Unterscheidung zwischen der Perspektive aus der die Identität eines objektes festgestellt wird (Innen- und Außenperspektive) und dem Objekt der Identitätszuschreibung (Person oder Gruppe), läßt sich ein Raster genereller Verwendungsweisen des Identitätsbegriffes in den Sozialwissenschaften aufspannen (vgl. Abbildung 4).

\begin{tabular}{|c|l|l|}
\hline Objekt & Serspektive & Fremdidentifizierung \\
\hline Individuum & $\begin{array}{l}\text { Persönliche Identität } \\
\text { Ich-Identität (Erikson) }\end{array}$ & Soziale Identität \\
\hline Gruppe & $\begin{array}{l}\text { Gruppenidentität } \\
\text { (Mitglied) }\end{array}$ & $\begin{array}{l}\text { Gruppenidentität } \\
\text { (Nicht-Mitglied) }\end{array}$ \\
\hline
\end{tabular}

Abb. 4: Systematisierung sozialwissenschaftlicher Identitätsauffassungen

Persönliche Identität bedeutet, daß eine Person sich selbst eine Identität zuschreibt.81 Diese Sichtweise entspricht dem eigentlichen Schwerpunkt der psychologischen und soziologischen Identitätsforschung. Identität wird als selbstreflexiver Prozeß eines Individuums verstanden, d.h. Subjekt und objekt der Identifizierung sind einer Person vereint. Plastisch läßt sich persönliche Identität durch

81 Der Begriff "persönliche Identität" oder "Ich-Identität" geht auf E.H. Erikson zurück. Durch seine Schriften wurden die Begriffe Identität und Identitätskrise $\mathrm{zu}$ herausragenden Themen der modernen Psychologie und darüber hinaus $z u$ Modewörtern in der breiten Offentlichkeit. Vgl. Conzen, P., E.H. Erikson und die Psychoanalyse, a.a.0, S. 74. In der Betriebswirtschaftslehre wird auf das Identitätsverständnis von Erikson explizit als theoretisches Geruist zur Beschreibung der Identität von Unternehmen (Corporate Identity) Bezug genommen. Vgl. Birkigt, K., Stadler, M.M., Corporate Identity - Grundlagen, a.a.0., S. 23. 
die Fragen: "Wer bin ich?" und "Wer bin ich in den Augen anderer?" umschreiben.

Im Gegensatz zur persönlichen Identität in der subjekt und objekt der Identifizierung in einer Person zusammenfallen ( "Ich-Identität"), verweist die Gruppenidentität a uf Gruppen, Organisationen, Schichten, Klassen, Kulturen usw. als Objekt der Identifizierung. Objekt der Identifizierung ist somit nicht eine einzige Person (die sich selbst identifiziert), sondern ein Sozialgebilde 82 . Subjekt sind Personen, die das jeweilige Sozialsystem durch Beschreibungen kenntlich machen, entweder als Angehöriger dieses systems ( "Wir") oder als Außenstehende ("Sie”).83

Jeder Einzelne wird im Laufe seines Lebens in eine Vielzahl verschiedenster Kollektive integriert. Dazu zählt die Familie, gesellschaftliche Institutionen (z.B. Unternehmen, Kegelclub, Heimatverein usw.), das Volk, die Glaubensgemeinschaft usw.. Wenn sich der Einzelne als Teil einer solchen gewachsenen oder künstlich hergestellten Gemeinschaft begreift, ist Identität bzw. Gruppenidentität gleichbedeutend mit einem Zugehörigkeits- oder Verbundenheitsgefühl zur betreffenden Gruppe.

Der Terminus Gruppenidentität wird darüber hinaus mit Blick auf die Gruppe als Ganzes verwendet. In diesem Verständnis bezeichnet der Begriff generell die Wesensmerkmale einer Gruppe, die konstant bleiben, obwohl die Gruppenmitglieder variieren. Eine Nation, eine politische Partei, ein Unternehmen, eine stadt oder Region bleibt gleich, selbst wenn alle Mitglieder durch andere ersetzt

82 Im weiteren Verlauf dieser Untersuchung werden die Begriffe Sozialgebilde, soziales Gebilde, Sozialsystem und Kollektiv synonym verwendet.

83 Vgl. Frey, H.P., Haußer, K., Entwicklungslinien sozialwissenschaftlicher Identitätsforschung, a.a.o., S. 4. 
werden.84 Die Identität der Gruppe beruht auf dem Konsens über zentrale Werte und Normen, die von den Mitgliedern geteilt und internalisiert werden ("shared values").

Dieser Satz an Werten und Normen ist anschaulich mit einem gemeinsamen "Wissensvorrat" vergleichbar, auf den alle Gruppenmitglieder zugreifen. In diesem Sinne kommt der Gruppenidentität gleichzeitig eine wichtige Abgrenzungsfunktion zu: Wer die zentralen Normen und Werte der Gruppe nicht mitträgt, der ist "anders" und kann sich nicht mit dem Pronomen "Wir" als Gruppenmitglied ausgeben. 85

Gruppenidentität hat zusammenfassend eine zweifache Bedeutung:

- Aus einem individualen Betrachtungswinkel betrachtet, bezeichnet Gruppenidentität das Zugehörigkeits- oder Verbundenheitsgefühl des Einzelnen $z u$ einer bestimmten Gruppe und die Identifikation mit den durch die betreffende Gruppe repräsentierten Werten und Normen.

- In der zweiten Verwendungsrichtung wird der individuelle Blickwinkel verlassen und das Sozialgebilde als Ganzes als Identität aufgefaßt. Gruppenidentität wird in diesem Bedeutungskontext gleichgesetzt mit der Gesamtheit der Werte und Normen, welche eine bestimmte Gruppe charakterisiert und zusammenhält.

84 Eine Gruppe kann folgendermaßen ihre Identität wahren: 1. durch eine gewisse Variationsbreite beim Festlegen der Regeln und Standards; 2. durch Selektivität bei der Aufnahme von neuen Mitgliedern; 3. durch Übertragung der eigenen Ideologie auf die neuen Mitglieder (z.B. durch Schulung, Erziehung usw.). Vgl. De Levita, D.J., Der Begriff der Identität, Frankfurt 1971, S. $67 \mathrm{f} ., 70,88,190$.

85 Vgl. Weber, J., Unternehmensidentität und unternehmenspolitische Rahmenplanung, Planungs- und Organisationswissenschaftliche Schriften, Nr. 42, München 1985 , S. 133 . 
In der dritten Verwendungsrichtung wird der sozialwissenschaftliche Identitätsbegriff als ein von außen zugeschriebener Merkmalskomplex interpretiert. Objekt der sozialen Identität ist eine Person, subjekt sind andere Personen. 86 Im Gegensatz zur persönlichen Identität, in der subjekt und objekt in einer Person zusammenfallen, wird somit einer Person von einer (oder mehreren) anderen Person(en) eine Identität gewissermaßen „von außen“ zugewiesen. Diese Identifizierung erfolgt auf Grundlage einer Kombination von Merkmalen und Rollenerwartungen, die dem Individuum in einem sozialen system zugeschrieben werden.87 Im einfachsten Fall geschieht dies durch Benennen. Darüber hinaus läßt sich eine Person auf der Grundlage ihrer Zugehörigkeit zu einer bestimmten Gruppe (Bewohner der Stadt x), Nationalität, Schicht-oder Berufszugehörigkeit, ethnische zugehörigkeit usw. identifizieren.

\subsection{Merkmale und Gemeinsamkeiten des sozial- wissenschaftlichen Identitätsverständnis- ses}

Unabhängig davon, ob das sozialwissenschaftliche Identitätsverständnis als persönliche Identität, Gruppenidentität oder soziale Identität konkretisiert wird, lassen sich charakteristische Merkmale des Identitätsbegriffes aufzeigen, welche für jede Verwendungsrichtung gleichermaBen bestimmend sind. Dazu zählen im einzelnen die Merkmale:

86 Vgl. Frey, H.P., Haußer, K., Entwicklungslinien sozialwissenschaftlicher Identitätsforschung, a.a.o., s. 3 .

87 In der Literatur wird diese Verwendungsrichtung des Identitätsbegriffes als soziale, öffentliche oder "situierte" Identität bezeichnet. 
1. Wechselseitigkeit,

2. Kontinuität und Konsistenz, sowie

3. Individualität.

Das Kriterium der Wechselseitigkeit bringt zum Ausdruck, daß persönliche Identität nicht ohne die Vorstellung von "anderen" auskommt, welche das Individuum in seiner Identität anerkennen. Identität kann sich somit nur in der Gemeinschaft mit anderen ausbilden.88 Identität läßt sich als etwas umschreiben, was eine bestimmte Person gegenüber anderen Personen präsentiert, und das umgekehrt andere Personen gegenüber Dritten darstellen. Insofern kann Identität nur so lange Bedeutung haben, wie die Person unter anderen Menschen lebt. In Situationen, die völlig isoliert gegenüber Einflüssen von außen sind, entstünde für das Individuum nicht die Notwendigkeit, seine Identität zu entwickeln.89 Seit den Anfängen der sozialwissenschaftlichen Identitätsforschung wird dieses als wechselseitigkeit oder Reziprozität bezeichnete Kriterium zur Beschreibung des Gesellschaftsbezuges von Identität herangezogen.90

88 Die Wechselbeziehung zwischen Mensch und Gesellschaft stellt einen "dialektischen Kreislauf" dar, welcher nach Auffassung von Frey/Hausser als "Paradigma der Identitätsforschung" angesehen werden kann. Vgl. Frey, H.P., Haußer, K., Entwicklungslinien sozialwissenschaftlicher Identitätsforschung, a.a.0., S. 17 .

89 Die hervorragende Bedeutung von Wechselseitigkeit als Merkmal von Identität beschreibt besonders plastisch De Levita: "Wir möchten den Leser daran erinnern, daß diese, anderen' für den Identitätsbegriff unerläßlich sind, und daß Identität für Robinson Crusoe nichts bedeuten würde." Nach De Levita verfügt eine Person somit nur dann über Identität, sofern sie Mitglied in einer Gruppe ist. Vgl. De Levita, D.J., Der Begriff der Identität, Frankfurt 1971, S. 67 f.

90 Die Trennung der Perspektiven wird James (1890) zugeschrieben, der zwischen dem "pure ego", dem subjekt der Reflexion, und dem "me" dem objekt der Reflexion differenziert. Beides zusammen nennt er das selbst. Das Selbst besteht aus drei Komponenten: Das materielle Selbst, das geistige Selbst (psychische Funktio- 
Der Gesellschaftsbezug findet darüber hinaus in der Auswahl jener Merkmale Niederschlag, welche eine Person zur Beschreibung der eigenen Identität oder zur Feststellung der Identität Dritter verwendet. So wählen Personen zur Beschreibung ihrer persönlichen Identität häufig solche Merkmale aus, die auf ihre Position in der Gesellschaft und ihrer zentralen Interaktionsfelder Bezug nehmen.91 Familie, Ausbildungssystem, Arbeitswelt, Freizeit sind einige Beispiele dafür. Diese Merkmale werden als Identitätsfaktoren bezeichnet. Dabei gilt: "Alles, was eine Person ist, besitzt oder woran sie teilhat, kann ein Identitätsfaktor werden."92 Identitätsfaktoren lassen sich als zugeschrieben, erworben und übernommen klassifizieren: 93

- Zugeschriebene Identitätsfaktoren sind nicht wählbar. Alter, Geschlecht, bestimmte Körpermerkmale, Eltern, Rasse, Nationalität sind Beispiele dafür.

nen u. Fähigkeiten) und schließlich das soziale Selbst. Vgl. De Levita, D.J., Der Begriff der Identität, a.a.0., S. 45. In ähnlicher Weise wird in dem von G.H. Mead entwickelten Symbolischen Interaktionismus das "Selbst" eines Individuums konzipiert. In Meads Begriffssystem besteht das "Selbst" eines Individuums aus den Elementen "I" und "me". Für den Teil des "Selbst", der aus der Summe der Erwartungen anderer Personen ("generalized others") resultiert, gebraucht Mead den Begriff des "me". Das "me" ist gleichsam Sprachrohr der Gesellschaft im "Selbst". Das "I" bezieht sich auf die Einstellungen und Verhaltensweisen von Individuen, deren Entstehung allein aus Interaktionserfahrung nicht geklärt werden können. Vgl. Reinhard, W., Die Identität von Organisationen, Bonn 1983, S. 76 .

91 Vgl. Frey, H.P., Haußer, K., Entwicklungslinien sozialwissenschaftlicher Identitätsforschung, a.a.o., s. 15 .

92 Vgl. De Levita, D.J., Der Begriff der Identität, a.a.O., S. 190 .

93 Die Systematisierung der Identitätsfaktoren ist an die Klassifikation von Rollen angelehnt, welche ebenfalls in zugeschrieben, erworben und übernommen aufgeteilt werden. Vgl. De Levita, D.J., Der Begriff der Identität, a.a.0., s. 45 . 
- Demgegenüber sind erworbene Identitätsfaktoren wählbar bzw. durch Eigenleistung zu erreichen. Beruf, Titel, Mitgliedschaft in Gruppen lassen sich hier nennen.

- Übernommene Identitätsfaktoren kommen durch Rollentransaktionen zustande und führen zu Rollenübereinkünften.

Mit dem Aspekt der Kontinuität wird die Beibehaltung der grundlegenden Eigenschaften einer Person oder Gruppe im Zeitablauf als wesentlich hervorgehoben. Identität bedeutet in dieser Verwendungsrichtung, daß sich eine Person in wesentlichen Merkmalen nicht verändert. Eine Person ist in jedem Augenblick einer Fülle von biologischen Prozessen unterworfen. Im strengen sinn ist ein und dieselbe Person einen Moment später nicht mehr identisch. Trotzdem besteht kein Zweifel darüber, daß ein Mensch von der Geburt, über die Kindheit, bis hin zum Erwachsenenstadium als ein und derselbe identifiziert werden kann. Sich verändern heißt zwar, anders werden, sich vom vorhergehenden unterscheiden, aber die Person als solche bleibt dieselbe. Es existiert offensichtlich ein stabiler Identitäts-Kern, der es gestattet, eine Person - aber auch physische Gegenstände trotz andauernden Wandels im zeitablauf, als identisch zu betrachten. 94

94 Der Kontinuitätsaspekt verweist auf die Aristoteles zugeschriebene Unterscheidung zwischen essentiellen und akzidentiellen Eigenschaften. Damit wird eine Trennung zwischen dem "Entstehen und Vergehen" einerseits und der bloßen "Veränderung" andererseits vollzogen. Die essentiellen Eigenschaften bestimmen das Wesen des Gegenstandes, sie definieren das "Wassein", als was der Gegenstand existiert. Verliert der Gegenstand sein Wesen, vergeht er. Die akzidentiellen Eigenschaften eines Gegenstandes können sich demgegenüber beliebig verändern, ohne daß die Einheit des Gegenstandes verloren geht. Der Gegenstand verändert sich lediglich, ohne daß er aufhört, zu existieren. Ein Tisch, der grün angemalt wird, behält seine Identität, weil er sich lediglich akzidentiell verändert. Ein Tisch, der verbrannt wird, hat dagegen auf- 
Während Kontinuität die Unveränderlichkeit wesentlicher Eigenschaften im Zeitablauf zum Inhalt hat, verweist der Aspekt der Konsistenz auf den Zusammenhang von Merkmalen $z u$ einem gegebenen Zeitpunkt hin. Dazu ist die Angabe von Bezugsgrößen erforderlich, die aufzeigen, welche Elemente stimmig sind.

Das Kriterium der Individualität schließlich entspricht weitgehend dem umgangssprachlichen Identitätsverständnis, welches die Einzigartigkeit eines objekts zum Inhalt hat. Der Aspekt der Einzigartigkeit kann in verschiedenen Weisen aufgefaßt werden: 95

- Es gibt nur ein Individuum, das bestimmte besondere Kennzeichen aufweist.

- Es gibt viele, durchaus nicht allein einem betreffenden Individuum eigene Fakten, welche insgesamt zu einer einmaligen Kombination zusammenfließen, und das Individuum von allen anderen unterscheidbar machen.

- Schließlich sind die Individuen in ihrem innersten wesen und nicht nur auf der Ebene identifizierbarer Merkmale einzig.

Bisweilen wird Identität in der Form von Individualität oder Einzigartigkeit als normative Forderung an das Individuum aufgefaßt, jene Eigenschaften $z u$ betonen, $z u$ ent-

gehört zu existieren. Er hat sich substantiell verändert. Vgl. Böhm, B., Identität und Identifikation. Zur Persistenz physikalischer Gegenstände, Frankfurt/Mn. u.a. 1989 , s. $48 \mathrm{f}$.

95 Vgl. Goffmann, K., Stigma. über Techniken der Bewältigung beschädigter Identität, Frankfurt 1967, S. 125 . 
wickeln und herauszuarbeiten, welche die betreffende Person einmalig machen. 96

In der Betriebswirtschaftslehre wird häufig ein Analogieschluß zwischen der Identität von Individuen auf die von Unternehmen gezogen. So liegt beispielsweise dem Corporate Identity-Konzept eine umfassende Analogie zwischen der menschlichen Persönlichkeit bzw. der "Ich-Identität" und der Identität eines Unternehmens zugrunde.97 Ausgehend von einem abgeschwächten Identitätsverständnis lassen sich darüber hinaus einzelne konstitutive Elemente des Identitätsbegriffes - Wechselseitigkeit, Kontinuität, Konsistenz und Individualität - auf Unternehmen beziehen. So beinhaltet eine Vielzahl der Ansätzen aus dem Umfeld der strategischen Unternehmensführung implizit oder explizit Teilaspekte des Identitätsbegriffes. 98

96 Vgl. Frey, H.P., Haußer, K., Entwicklungslinien sozialwissenschaftlicher Identitätsforschung, a.a.0., s. 9.

97 Vgl. Birkigt, K., Stadler, M.M., Corporate Identity Grundlagen, a.a.O., S. 23 ff. Die Zulässigkeit des Analogieschlusses ist seit Beginn der Diskussion über Corporate Identity immer wieder in $\mathrm{Z}$ weifel gezogen worden. Zur Unzulässigkeit der Gleichsetzung vgl. insbesondere Tafertshofer, A., Corporate Identity. Magische Formel als Unternehmensideologie, in: Die Unternehmung, $36 . \mathrm{Jg} ., \mathrm{Nr} .1,1982, \mathrm{~S} .11 \mathrm{ff}$. Einen vermittelnden Standpunkt nimmt Achterholt ein, der den vergleich zwischen der menschlichen Persönlichkeit und einem Unternehmen aus methodologischer Sicht ablehnt. In einem metaphorischen Sinne ist eine Analogiesetzung jedoch zulässig. Vgl. Achterholt, G., Corporate Identity: in 10 Arbeitsschritten die eigene Identität finden und umsetzen, Wiesbaden 1988, S. 32 .

98 Die Forderung nach Individualität oder Einzigartigkeit findet beispielsweise in dem zentralen strategischen Prinzip der Differenzierung gegenüber dem Wettbewerb und in der Schaffung von Wettbewerbsvorteilen Ausdruck. Die Konsistenzforderung läßt sich aus vielen Ansätzen der strategischen Unternehmensführung herauslesen. Häufig stellt Konsistenz sogar einen zentralen Baustein derartiger Konzepte dar, ohne explizit mit dem Identitätsbegriff verknüpft $\mathrm{zu}$ werden. Die Forde- 

sozialwissenschaftlichen Identitätsforschung

Ausgehend von den generellen Verwendungsweisen des Identitätsbegriffes in den Sozialwissenschaften läßt sich eine Präzisierung räumlicher Identität vornehmen. Dabei wird räumliche Identität einerseits in einer personenbezogenen Perspektive und andererseits in einer auf einen Raum (z.B. eine Stadt oder Region) bezogenen Perspektive betrachtet:

In der personenbezogenen Perspektive hat die Person eine räumliche Identität, indem sie sich beispielsweise mit einer bestimmten stadt oder Region verbunden/zugehörig fühlt bzw. mit einer bestimmten stadt oder Region assoziierte Merkmale als Bestandteil ihrer persönlichen Identität, ihrer Gruppenidentität oder einer sozialen Identität wahrnimmt. In der raumbezogenen Perspektive wird der Identitätsbegriff in Bezug auf eine Stadt oder Region angewendet und dem betreffenden Raum selbst eine Identität zugewiesen. In diesem Bedeutungskontext ist die Stadt oder Region eine räumliche Identität.

rung nach einem "fit" zwischen Unternehmen und Umwelt oder zwischen Unternehmenskultur und Strategie lassen sich als Beispiele anführen. Besonders populär ist das 7-S-Konzept von McKinsey. Das 7-S-Modell weist auf die Notwendigkeit hin, alle "S" eines Unternehmens (strategy, structure, systems, style, staff, skills) optimal zu nutzen und aufeinander abzustimmen. Schließlich kommt den sogenannten "Konsistenz-Ansätzen" in der Organisationstheorie ein besonderer stellenwert $\mathrm{zu}$. Diese Ansätze zeichnen sich durch die Betonung von Synthese und Gestalt als wichtige Erfolgsfaktoren von Organisationen aus. Zu den Konsistenz-Ansätzen vgl. Staehle, W., Management, 6. Aufl., München 1991, S. 58-64. 
1.21 Räumliche Identität als Identität der Person

Der personenbezogenen Perspektive liegt der Gedanke zugrunde, daß die Identität einer Person - persönliche Identität, Gruppenidentität, soziale Identität - auf der Grundlage einer Reihe von Merkmalen ("Identitätsfaktoren") festgestellt wird. Es ist zu vermuten, daß eine Person zur Beschreibung ihrer Identität oder zur Feststellung der Identität Dritter neben zentralen Identitätsfaktoren (z.B. Alter, Geschlecht, Beruf usw.) gleichermaßen ihre Beziehung zu spezifischen Raumausschnitten (z.B. Geburtsort, Wohnort, bevorzugtes Urlaubsziel usw.) einfließen läßt. Vor diesem Hintergrund läßt sich räumliche Identität als eine spezifische substruktur oder Teilidentität der Identität einer Person auffassen.

Wenn der Aspekt räumlicher Identifikation (räumliches $\mathrm{zu-}$ gehörigkeits- oder Verbundenheitsgefühl) als Erklärungsbestandteil räumlicher Identität herausgegriffen wird, lassen sich tendenziell psychologische oder soziologische Erklärungsansätze einander gegenüberstellen. Extreme psychologische Erklärungsansätze gehen von der Notwendigkeit einer gefühlsmäßigen Bindung an den Raum aus. Häufig wird ein "territorialer Instinkt" als Mechanismus herangezogen, uber den die Bindung von Personen an bestimmte Raumausschnitte erklärbar sei.99 Es wird somit eine mechanischkausaler Zwang zur Identifikation bei Vorliegen bestimmter

99 Vgl. den überblick in Gerson, K., u.a., Attachment to place, in: Fischer, C.S., Networks and places, New York 1977, S. 140 und die dort angegebene Literatur.; Proshansky, H.M. , Fabian, A.K., Kaminoff, R., Placeidentity: Physical world socialization of the self, in: Journal of Environmental Psychology, 3/1983, S. 83. Mitunter wird räumliche Identität als "Grundbeduirfnis" aufgefaßt, welche durch Mitgestaltung der Umwelt erreichbar ist. Vgl. Mai, U., Gedanken über räumliche Identität, in: Zeitschrift für Wirtschaftsgeographie, H.1.2.1989, S. $12 \mathrm{ff}$.. 
Stimulus-Kombinationen unterstellt. Demgegenüber wird in den soziologischen Ansätzen der räumliche Bezug uberwiegend durch die Qualität und den Umfang von Sozialbeziehungen erklärt. 100

In der Nachbarschaftsforschung werden mitunter ökonomische Ansätze (Entscheidungsmodelle) diskutiert.101 In diesen Modellen werden Nachbarschaftsbindungen als Folge von als Belohnung und Bestrafung erlebten Erfahrungen innerhalb des Referenzraumes interpretiert. Im Gegensatz zu psychologischen oder soziologischen Modellen, welche die Entstehung räumlicher Bindungen gewissermaßen "automatisch" zu erklären versuchen, begreifen ökonomische Modelle räumliche Bindungen als Kosten/Nutzen-Kalkül. In einem "ChoiceConstraint"-Modell werden Raumausschnitte als komplexes Angebot verschiedener Identifikationsmöglichkeiten aufgefaßt. Aus diesem Angebot potentieller Identifikationen wählt der Einzelne diejenigen Merkmale aus, für die der Nutzen am höchsten und die Kosten relativ am geringsten sind. Dies geschieht jeweils unter Berücksichtigung spezifischer constraints (z.B. Ressourcen, Lebenszyklusphase, Qualitäten des Raumausschnittes u.a.). Identitätsträger werden in diesen Modellen somit als bewußt handelnde Subjekte aufgefaßt, welche die Entscheidung treffen, sich in jeweils spezifischer Hinsicht mit bestimmten räumlich gebundenen Merkmalen zu identifizieren.

Die Wahl des Modelltyps hat Auswirkungen auf die Spezifizierung des Konstrukts. In psychologischen und soziologischen Modellen werden räumliche Bindungen meist unidimensional (holistisch) gemessen, indem die probanden auf ei-

$100 \mathrm{Vgl}$. dazu beispielsweise Treinen, H., symbolische Ortsbezogenheit. Eine soziologische Untersuchung zum Heimatproblem, in: Atteslander, P., Hamm, B. (Hrsg.): Materialien zur Siedlungssoziologie, 1974, S. 234-259.

101 Vgl. Gerson, K., u.a., Attachment to place, a.a.o., s. 147. 
ner Skala pauschal den Grad ihrer zustimmung bzw. Ablehnung zum Referenzraum ausdrücken. Demgegenüber wird in Choice-Constraint-Modellen räumliche Identität als multidimensionales konstrukt begriffen. Danach existiert eine vielzahl unterschiedlicher und voneinander unabhängiger Möglichkeiten, sich an einen Referenzraum zu binden. 102 Der Terminus "Bindung" (Attachment-to-place) ist nicht zwangsläufig als affektiv empfundene Bindung $z u$ verstehen. Es ist beispielsweise möglich, sich mit einer Nachbarschaft verbunden $\mathrm{zu}$ fühlen, ohne diese zu mögen.103 Im wesentlichen wird deshalb zwischen einem affektiven ortsbezug und einem funktionalen Ortsbezug unterschieden. Ein affektiver ortsbezug findet in einer affektiv empfundenen Zugehörigkeit oder Ablehnung Ausdruck. Demgegenüber ist ein funktionaler ortsbezug auf spezifische Sachbezüge ausgerichtet. Diese können formaler Art sein (z.B. Bindung an Institutionen, Arbeitsplatz usw.) oder als freiwillige Bindungen auf Sozialbeziehungen bezogen sein (z.B. Bindung an Freunde und Bekannte). Diese Bezüge sind prinzipiell austauschbar, weil sie nicht an den Referenzraum gebunden sein müssen, und grundsätzlich überall eingegangen werden können. 104

Eine weitere Präzisierung dieser personenbezogenen Perspektive räumlicher Identität läßt sich erzielen, wenn umweltpsychologische Forschungsansätze ergänzend berücksichtigt werden. Die Umweltpsychologie105 ist für einen Theo-

102 Vgl. Gerson, K., u.a., Attachment to place, a.a.o., s. $142-144$.

103 Vgl. Hunter, A., Symbolic communities, a.a.o., s. 143.

$104 \mathrm{Vgl}$. Esser, H., Lokale Identifikation im Ruhrgebiet, Zur allgemeinen Erklärung einer spezifischen Angelegenheit, in: IzR, 3/1987, S. 110.

105 Die Umweltpsychologie oder ökologische Psychologie befaßt sich mit der "dynamischen Wechselwirkung" zwischen dem Menschen und seiner Umwelt. Dabei steht die Frage nach dem Einfluß der Umwelt (unabhängige Va- 
rieimport besonders geeignet, weil sie - neben anderen Fragestellungen - den Stellenwert materieller Umwelt für die persönliche Identität ("Place-identity") untersucht.106 Für das vorliegende Untersuchungsinteresse ist in diesem Zusammenhang die Aufspaltung räumlicher Identität in zwei Teilprozesse hilfreich:107

riable) auf das individuelle Wahrnehmen, Erleben und Verhalten (abhängige Variable) im Vordergrund. Während in den Sozialwissenschaften lange zeit die soziale Umwelt im Blickpunkt des Interesses stand, wird in der Umweltpsychologie ein umfassender Umweltbegriff verwendet, der die soziale und physische Umwelt des Menschen umfaßt. Vgl. Kroeber-Riel, W., Konsumentenverhalten, München 1990, S. $423 \mathrm{ff}$.

106 place-identity wird als substruktur der "self-identity" einer Person aufgefaßt, die folgendermaßen zusammengesetzt ist: "Place-identity (...) consisting of broadly conceived, cognitions, about the physical world in which the individual lives. These cognitions represent memories, ideas, feelings, attitudes, values, preferences, meanings, and conceptions of behaviour and experience which relate to the variety and complexity of physical settings that define the dayto-day existence of every human being." Vgl. Proshansky, H.M., Fabian, A.K., Kaminoff, R. Place-identity: Physical world socialization of the self, a.a.0., s. 59 .

107 Vgl. Schneider, G., Graumann, C.F., Städtische Umwelt: Identität und Identifikation, in: M. Kampen (Hrsg.), Environment and human action, Berlin 1986, S. 237 . Eine vergleichbare Begriffsverwendung wird auch in der Geographie diskutiert, wenn vorgeschlagen wird, die kognitiven und die "Selbst-bezogenen" Aspekte der Umweltinteraktion als grundsätzlich verschiedenartige und eigenständige Dimensionen raumbezogener Bewußtseinsinhalte anzusehen. Vgl. Weichhart, P. Raumbezogene Identität, Bausteine $z u$ einer Theorie räumlichsozialer Kognition und Identifikation, Stuttgart 1990, S. $20 \mathrm{ff}$.. Am Beispiel von Stadtteilen geht Göschel von einer Doppelseitigkeit "lokaler Identität" aus, indem er zwischen der Identität des Lokalen und der Identifikation mit dem Lokalen unterscheidet. Vgl. Göschel, A., Lokale Identität 1984, S. 1. Der Geograph E. Relph unterscheidet zwischen der "identity of a place" und der "identity with a place". Vgl. Relph, E. Place and placelessness, a.a.O., S. 49. Aus soziologischer sicht unterscheidet Hunter zwischen "identification with a community" und "identification 
- D i e Identifizierung von verweist a u f die "psychologische Repräsentation" z.B. einer stadt im Wahrnehmungsbild eines Betrachters, und rückt damit die kognitiven Aspekte der Beziehung zwischen dem Menschen und seiner räumlichen Umwelt (z.B. Nachbarschaft, Stadt, Region) in den Mittelpunkt. 108

- Bei der Identifikation mit wird die Perspektive gewechselt. Nicht der als kognitive struktur repräsentierte Raum steht im Vordergrund, sondern die Identität einer Person, welche sich einer bestimmten räumlichen Bezugsgröße ( $z$.B. einer stadt) gegenüber verbunden fühlt und diese Zugehörigkeit in ihr selbstkonzept 109 und damit „als Teil ihrer selbst“ einbezieht.110

of the community" Vgl. Hunter, A., Symbolic Communities, Chicago 1974, S. 95.

108 I n dieser Teilbedeutung räumlicher Identität (Weichhart: "raumbezogene Identität") ist "die subjektiv oder gruppenspezifisch wahrgenommene Identität eines Raumausschnittes und damit auch seine Abgrenzung gegenüber der mentalen/ideologischen Repräsentation anderer Gebiete angesprochen". Vgl. Weichhart und die dort angegebene Literatur: Weichhart, P., Raumbezogene Identität, a.a.0., s. 20 .

109 Das Selbstkonzept „ist die Vorstellung, die jemand von sich selbst hat." Allen Ansätzen der Selbstkonzeptforschung ist gemeinsam, denselben stimulus, der zur Reflexion über sich auffordert, zu verwenden. Dazu zählen Antworten auf die Frage: Wer bin ich? Was bin ich? Wie bin ich? Mögliche Antwortkategorien sind beispielsweise: (1.) quasi objektive selbstbeschreibung ("Ich bin groß gewachsen"), (2.) Selbstbewertungen dieser Beschreibungen, (3.) selbstwertgefüle ("Ich bin stolz auf mich"), (4. Selbstideale) ("Ich wäre gern ...") Vgl. Krappmann, L., Soziologische Dimensionen der Identität, Stuttgart 1978, S. 24.; Vgl. Frey, H.P., Haußer, K., Entwicklungslinien sozialwissenschaftlicher Identitätsforschung, a.a.0., s. 8 .

110 Räumliche Identität (Weichhart: „raumbezogene Identität") ist in dieser Teilbedeutung $z u$ verstehen "als gedankliche Repräsentation und emotional-affektive Bewertung jener Ausschnitte aus der Umwelt, die ein Individuum in sein selbstkonzept einbezieht, als Teil 
Der besondere Beitrag der Umweltpsychologie besteht darin, die Prozesse zur Herausbildung räumlicher Identität deutlich herauszustellen. Eine Person hat somit eine räumliche Identität, welche in die Teilprozesse der Identifizierung von und der Identifikation mit aufgespalten werden kann.

Darüber hinaus ist $\mathrm{zu}$ unterscheiden, ob räumliche Identität als holistisches oder mehrdimensionales Konstrukt aufgefaßt wird.111 Eine detaillierte Unterteilung räumlicher Identität in affektive und neutrale räumliche Bindungen erlaubt Aussagen darüber, ob die Zugehörigkeit ursächlich mit dem Referenzraum verbunden ist, oder aber auf Merkmalen beruht, welche grundsätzlich von jedem anderen Raum auch vorgehalten werden. Für das Marketing sind in diesem Zusammenhang insbesondere jene Faktoren bedeutsam, welche von konkurrierenden städten und Regionen nicht kopierbar sind. 112 Aus theoretischer sicht ist somit eine mehrdimensionale Konstrukterfassung anzustreben.

seiner selbst wahrnimmt."Vgl. Weichhart, P., Raumbezogene Identität, a.a.0., s. 23 .

111 Der Umweltpsychologe Lalli entwickelt ein Meßkonzept zur überprüfung "stadtbezogener Identität". Auf insgesamt füf Unterskalen werden dabei die folgenden Aspekte "stadtbezogener Identität" erfaßt: (1.) Außendarstellung: Der bewertende Vergleich zwischen der eigenen stadt und anderen orten und die wahrgenommene Einzigartigkeit und Besonderheit der Stadt; (2.) Allgemeine Identifikation: Das Heimatgefühl und Sich-zuHause fuihlen in der Stadt; (3.) Aktuelle Vertrautheit: Die aktuelle Vertrautheit mit der städtischen Umwelt, das Gefühl, dazuzugehören: (4.) Vergangenheitsbezug: Die Verbindung zwischen der eigenen Geschichte und der stadt, die symbolisierung der eigenen Erfahrungen: (5.) Zukunftsorientierung: Die wahrgenommene Bedeutung der stadt für die eigene zukunft, das committment "bleiben zu wollen". Vgl. Lalli, M., Stadtbezogene Identität. Theoretische Präzisierung und empirische Operationalisierung, Darmstadt 1989, S. 26.

112 Die Schaffung einer prägnanten räumlichen Identität im Wahrnehmungsbild interner und externer zielgruppen erfordert die kommunikative Herausstellung solcher Identitätsfaktoren, welche einzigartig und nicht kopierbar sind (Singularität). Zur Singularität von Identitäts- 
Räumliche Identität hat jedoch nicht nur eine auf bestimmte Personen bezogene Bedeutung, sondern bezieht sich in einem zweiten Bedeutungskontext auf den Raum selbst, der - einer natürlichen Person vergleichbar - über eine räumliche Identität verfügt. Unter diesem Blickwinkel betrachtet ist $z$.B. eine bestimmte stadt oder Region eine räumliche Identität.

1.22 Räumliche Identität als Identität des Raumes

Im allgemeinen Sprachgebrauch ist es üblich, von der stadt oder von der Region zu sprechen. Es wird gewissermaßen unterstellt, daß ein beliebiger Raumausschnitt eigenständig denken, fühlen und handeln kann und somit (in einem übertragenen sinne) als "Individuum", "Wesen" oder "Persönlichkeit" aufgefaßt werden darf.113 Die Individualisierung und die Beschreibung eines Raumes auf Grundlage individualpsychologischer Merkmale (z.B. Wechselseitigkeit, Kontinuität und Konsistenz, Individualität) ist jedoch methodologisch unzulässig und darf nur zur Gewinnung eines Denkmusters bzw. als Metapher erfolgen.114

Wenn ein Raumausschnitt in einem metaphorischen sinne als eigenständiges "Individuum" aufgefaßt werden darf, muß er auch in dem Maße über eine soziale Identität verfügen, wie er von Personen wahrgenommen wird. Genauso wie eine natür-

faktoren als Erfolgsvoraussetzung für das SRM vgl. Kap. C.2.41.

113 Im allgemeinen sprachgebrauch ist es üblich, einer stadt oder Region Individualeigenschaften zuzuweisen (z.B. "Bonn verhandelt mit Washington" anstatt Kohl verhandelt mit Clinton).

114 Eine Metapher bezeichnet das "Sehen" der einen "Sache" unter dem Blickwinkel einer anderen zur Gewinnung von neuen Einsichten. Vgl. Gloor, R., Die Rolle der Metapher in der Betriebswirtschaftslehre, Bern 1987. 
I iche Person auf Grundlage spezifischer Merkmale (Körpergröße, Alter, Ausbildung usw.) aus der Außenperspektive identifiziert wird, entspricht die soziale Identität eines Raumes den unverwechselbaren und typischen Eigenschaften, welche ihm von außen zugewiesen werden.

Die beiden Bedeutungskontexte räumlicher Identität lassen sich zusammenfassend in der Abbildung 5 einander gegeniberstellen.

\begin{tabular}{|c|c|c|c|}
\hline$\underbrace{\begin{array}{c}\text { Identitäts } \\
\text { konzept }\end{array}}_{\text {Objekt }}$ & $\begin{array}{l}\text { Persönliche } \\
\text { Identität }\end{array}$ & Gruppenidentität & $\begin{array}{l}\text { Soziale } \\
\text { Identität }\end{array}$ \\
\hline $\begin{array}{l}\text { Person } \\
{\left[\begin{array}{l}\text { Person "hat" } \\
\text { räumliche } \\
\text { Identität }\end{array}\right]}\end{array}$ & $\begin{array}{l}\text { Räumliche Identität } \\
\text { als Substruktur der } \\
\text { persönlichen Iden- } \\
\text { tität oder als räum- } \\
\text { liche Verbundenheit/ } \\
\text { Zugehörigkeit } 1\end{array}$ & $\begin{array}{l}\text { Räumliche Identität } \\
\text { als Bestandteil des } \\
\text { Zusammengehörig- } \\
\text { keitsgefühls einer } \\
\text { Gruppe }\end{array}$ & 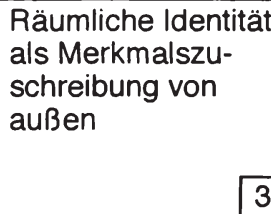 \\
\hline $\begin{array}{l}\text { Raum } \\
{\left[\begin{array}{l}\text { Raum "ist" } \\
\text { räumliche } \\
\text { Identität }\end{array}\right.}\end{array}$ & $\begin{array}{l}\text { Räumliche Identität } \\
\text { als Denkmuster/ } \\
\text { Metapher (Raum } \\
\text { als "Individuum") }\end{array}$ & & $\begin{array}{l}\text { Räumliche Identität } \\
\text { als Merkmalszu- } \\
\text { schreibung in der } \\
\text { Form von } \\
\text { Vorstellungsbildern } \\
\text { u. Images }\end{array}$ \\
\hline
\end{tabular}

Abb. 5: Ansatzpunkte zur Präzisierung räumlicher Identität

Die jeweilige Verwendungsrichtung des sozialwissenschaftlichen Identitätsverständnisses (persönliche Identität, Gruppenidentität, soziale Identität) läßt sich dabei als eine erste Dimension auffassen. Die zweite Dimension wird durch das objekt bestimmt, dessen Identität festgestellt werden soll (Person oder Raum). Die Felder 1-3 in der Abbildung 5 repräsentieren unmittelbare Anwendungsfelder der sozialwissenschaftlichen Identitätsforschung. Räumliche Identität wird dort als substruktur oder Teilidentität der umfassenden Identität einer Person interpretiert. Bei $\mathrm{zu}-$ grundelegung eines pragmatischen Begriffsverständnisses läßt sich räumliche Identität darüber hinaus als räumli- 
ches Verbundenheits- oder Zugehörigkeitsgefühl auffassen. Feld 4 repräsentiert eine Verständnis räumlicher Identität, welches in einem ubertragenen sinne unterstellt, daß $z$.B. eine Stadt oder Region als "Individuum" oder eigenständige "Persönlichkeit” aufgefaßt werden kann. Wenn dieses Bild aufgegriffen wird, läßt sich dem so definierten "Individuum" auch eine soziale Identität (Feld 5) zuweisen. Dies bedeutet, daß eine bestimmte stadt oder Region auf der Grundlage besonders charakteristischer Merkmale identifiziert wird.

\subsection{Forschungsansätze räumlicher Identität}

Entstehungsursachen und Ausprägungsformen räumlicher Identität finden in zahlreichen Wissenschaftsdisziplinen unter Verwendung verschiedener Begriffe Beachtung. Dem breiten Spektrum verschiedener Ansätze und Begriffe aus der Sozialgeographie, Geographie, Psychologie, Umweltpsychologie, Soziologie bis hin zur Kulturanthropologie und den Politikwissenschaften ist gemeinsam, jeweils spezifische Aspekte der Beziehung zwischen dem Menschen und seiner näheren und weiteren räumlichen Umwelt als Forschungsgegenstand herauszugreifen. Alle Ansätze gehen darüber hinaus von der Voraussetzung aus, daß Personen eine räumliche Identität haben. Die Heterogenität der verwendeten Begriffe wie Heimat, emotionale oder symbolische ortsbezogenheit, Territorialität, Regional-oder Raumbewußtsein, Regionalismus oder lokale oder regionale Identität verdeutlicht, daß dem für die vorliegende Untersuchung gewählten Terminus "räumliche Identität" in diesem Zusammenhang nur die Funktion einer begrifflichen Klammer zukommen kann. 


\subsection{Heimat}

Auf allgemeinster Ebene läßt sich die Beziehung zwischen dem Menschen und seiner näheren und weiteren räumlichen Umwelt mit dem Heimatbegriff umschreiben.115 Heimat bedeutet zunächst Geburts- oder Herkunftsort,116 während mit dem Heimatgefühl auf die Gesamtheit der emotionalen und affektiven Bindungen des Menschen meist an den engeren Lebensraum verwiesen wird. Auf jeden Fall ist Heimat ein subjektiver Faktor. 117

In modernen Definitionen wird Heimat nicht länger als passiv empfunden interpretiert. Stattdessen wird die aktive Rolle des Einzelnen in den Vordergrund gestellt: Danach ist eine Heimatgefühl stiftende Identifikation mit einem Raum nicht ein und für allemal gegeben, sondern Gegenstand ständigen Bemühens.118 Heimat bildet sich dabei in einem ständigen Kreislauf von subjektiver Erwartung gegenüber der räumlichen Umwelt und tatsächlicher Bedürfnis- und Sicherheitserfüllung durch diese aus. Solange dieser Prozeß

115 Die Heimatforschung ist bevorzugtes Forschungsgebiet der Kulturanthropologie und der Volkskunde. Fragen nach der ideologieanfälligen Geschichte des Heimatbegriffs oder des Heimatverlusts, das "Heimweh"-Phänomen bis hin $\mathrm{zu}$ heimatfördernden oder -verhindernden $\mathrm{Pla}-$ nungen in den Gemeinden lassen sich beispielhaft als Forschungsgegenstand kennzeichnen. Vgl. z.B. Greverus, I.-M, Auf der Suche nach Heimat, München 1979.

116 vgl. Becker, H., Keim, K.D., Wahrnehmung in der städtischen Umwelt - möglicher Impuls für kollektives Handeln, Berlin 1978, s. 90.

117 Vgl. Hasse, J., „Regionale Identität”. Zur Reichweite verschiedener wissenschaftstheoretischer Begriffe auf ein zwiespältiges Phänomen, Mitteilungen des Arbeitskreises für Neue Methoden in der Regionalforschung (AMR-Info), 18/1988, S. 32 .

118 Vgl. Hilgers, W.W., Lebensraum, Sozialisation und Identitätsbildung. Sozialökologische sowie umweltpsychologische Erklärungsansätze zur symbolischen Ortsbezogenheit, Düsseldorf 1990, S. 16. 
als "Heile Welt" erfahren wird, d.h. als ein Verhaltenssicherheit und Stabilität widerspiegelnder Bereich wahrgenommen wird, ist Heimat kaum oder gar nicht bewußt. 119

Als Folgeerscheinung einer gestörten Mensch-Umwelt-Beziehung wird Heimat als Flucht- oder Widerstandsphänomen konzipiert. Der erstgenannte Aspekt findet beispielsweise Ausdruck in der Pflege einer "Volkstanz-Heimat", womit das Festhalten an vermeintlich traditionsreichen strukturen verstanden wird, die jedoch in wirklichkeit ortsbezogene Authentizität vermissen lassen.120 Meist geht es darum, in vordergründiger Weise Tourismuspotentiale zu erschließen, ohne die tatsächlichen örtlichen Gegebenheiten (z.B. Traditionen) zu berücksichtigen. Heimat wird als "Identitätsund Sinnprothese"121 mißbraucht, welche kaum geeignet ist, psychologische sicherheit zu vermitteln.

Heimat als widerstand ist demgegenüber mit dem $\mathrm{Ziel}$ verknüpft, durch ein abgestimmtes Handeln der Betroffenen, der Einflußnahme übergeordneter Entscheidungszentralen entgegenzutreten.122 In diesem Verständnis ist Heimat Ausdrucksform zahlreicher Regionalismusbewegungen sowie ziel kleiner und großer Bürgerinitiativen:

119 Vgl. Hasse, J., Krüger, R., Raumentwicklung und Identitätsbildung in der nordwestdeutschen Küstenregion. Wahrnehmungsgeographische Untersuchung zur räumlichen Umweltqualität und ihrer Verbesserung, oldenburg 1984, S. $6 \mathrm{ff}$.

$120 \mathrm{Vgl}$. Habermas, J., Moderne und postmoderne Architektur, in: Theorie des kommunikativen Handelns, Frankfurt 1981, S. 26 (zit. in: Hasse, J., Regionale Identität, a.a.o., s. 35.)

121 Vgl. Hasse, J., Regionale Identität, a.a.o., s. 31 .

122 Vgl. Hasse, J., "Regionale Identität”, a.a.o., S. 35 $\mathrm{f}$. 
- Der in vielen Staaten der Erde zu beobachtende Regionalismus 123 wird als Gegenposition $z$ u einer zentralistischen staatsgewalt betrachtet. Die Bandbreite der Bedeutungsinhalte von Regionalismus reichen von Autonomiebestrebungen, wie sie beispielsweise die zentralistisch regierten Staaten Spanien und Europa zu bewältigen haben, bis hinab zu grenzüberschreitenden Kooperationen in Sachfragen, die von regionalen Gebietskörperschaften, Kommunen oder Ländern durchgeführt werden.124

- Eine "neue räumliche Sensibilität” wird in der Bürgerinitiativbewegung und anderen Mitwirkungs- und Protestpotentialen gesehen.125 Als Auslöser für die Artikulation gemeinsamer Interessen in der Form von Bürgerinitiativen wird gleichermaßen ein "Ohnmachtsgefühl“ verantwortlich gemacht, welches in der tatsächlichen oder vermeintlichen Einflußnahme übergeordneter Entscheiderzentralen begründet liegt: Der Protest gegen den Bau einer Kernkraftwerks, einer Autobahn, eines

123 Regionalismus 1 äßt sich umschreiben als "oppositionelle Politisierung von kulturellen, politischen und/oder wirtschaftlichen Zentralisierungsprozessen, die eine Konkurrenz zwischen einem subnationalen und einem gesamtstaatlichen Bezugsrahmen gesellschaftlicher Aktivitäten begründen." Vgl. Gerdes, D., Regionalismus und Politikwissenschaft. Zur Wiederentdeckung von "Territorialität" als innenpolitischer Konfliktdimension, in: GR 39 (1987), H. 10, S. 527 . Die Regionalismusforschung ist bevorzugter Forschungsgegenstand von Politologie und Soziologie. Ein überblick uber verschiedene Definitionen findet sich in: Gerdes, D., Regionalismus und Politikwissenschaft, a.a.O., S. $526 \mathrm{ff.}$; Vgl. auch Regionalismus aus soziologischer Sicht: Pieper, R., Region und Regionalismus, in: GR, Bd. 39, H. 10, 1987, S. $534 \mathrm{ff} .$.

$124 \mathrm{Vgl}$. Fichtner, U., Regionale Identität am Südlichen oberrhein - Zur Leistungsfähigkeit eines verhaltenstheoretischen Ansatzes, in: Ber. z. dt. Landeskunde, Bd. $62, \mathrm{H} .1,1988$, S. 112 .

$125 \mathrm{Vgl}$. Mai, U., Gedanken über räumliche Identität, in: zeitschrift für Wirtschaftsgeographie, H. 1/2, 1989, s. $15 \mathrm{f}$. 
Golfplatzes bis hin zur jüngst gegründeten und auf Anhieb erfolgreichen "Statt-Partei" in Hamburg, sind Beispiele hierfür.

\subsection{Regionalbewußtsein}

Im Zuge der "Renaissance des Heimatbegriffs"126 befaßt sich auch die Geographie mit räumlichen Bindungen des Menschen im Rahmen der sogenannten "geographischen Regionalbewußtseinsforschung” (RBF).127 Die zur Behandlung derartiger Fragestellungen zunächst gewählten Begriffe "Territorialität" und "regionale Identität"128 werden auf Vorschlag der Initiatoren der RBF (Blotevogel, Heinritz, Popp) durch den Terminus „Regionalbewußtsein“ ersetzt. Da-

126 Zur Wiederentdeckung des Heimatphänomenes vgl. die Literaturverweise bei Endruweit, G., Raumbewußtsein bei Bürgern und öffentlichkeit als Planungsbedingung, in: ARL (Hrsg.), Aktuelle Probleme der Raumordnung. Raumbewußtsein, Verrechtlichung, Raumordnungsverfahren, Arbeitsmaterialien Nr. 66, Hannover 1983, S. 30.

127 Vgl. Blotevogel, H.H., Heinritz, G., Popp, H., Regionalbewußtsein. Bemerkungen zum Leitbegriff einer Tagung, in: Ber. z. dt. Landeskunde, H.1, 1986, S. 103114.; Dies., Regionalbewußtsein - Überlegungen zu eine $r$ geographisch-landeskundlichen Forschungsinitiative, in: IzR, H. 7/8, 1987, S. 409-418.; Dies. "Regionalbewußtsein". Zum Stand der Diskussion um einen Stein des Anstosses, in: GZ, Jg. 77, H.2, 1989, S . 65-88. Mit der Grïndung eines Arbeitskreises "Regionalbewußtsein und Landeskunde" Anfang der 80er Jahre erfolgte eine Institutionalisierung der "geographischen Regionalbewußtseinsforschung". Im Zuge der Diskussion zum Thema sind eine Reihe von Tagungen, Projekten und Lehrveranstaltungen abgehalten worden. Für einen überblick über die Aktivitäten im Rahmen der Regionalbewußtseinsforschung vgl. Weichhart, P., Raumbezogene Identität, a.a.0., s. 5 .

128 Der Begriff "Identité régionale" als übergeordnete Sammelbezeichnung für unterschiedliche Ansätze zu dieser Thematik ist beispielsweise auch im französischen Sprachgebrauch seit längerer zeit verbreitet. Vgl. Bassand, M., L identité régionale. Regionale Identität, Saint-Saphorin 1981 . 
mit wird bezweckt, etwaige Mißverständnisse, welche in der Unschärfe, Heterogenität und des umfassenden Anspruches des Identitätsbegriffes begründet liegen, $\mathrm{zu}$ vermeiden.129 Regionalbewußtsein fungiert in der Folge als Leitbegriff des gleichnamigen Forschungsprojektes und als Gegenstand einer ganzen Reihe von konzeptionellen und empirischen Untersuchungen.

Eine einheitliche Begriffsverwendung hat sich jedoch nicht durchgesetzt. So werden neben "Regionalbewußtsein" auch d i e B e g r if $\mathrm{f}$ e "raumbezogenes Bewußtsein", "Raumbewußtsein”,130 „raumbezogene Identität"131 oder "regionale Identität"132 verwendet.

Der Erforschung von Regionalbewußtsein liegen eine Reihe von generellen Annahmen zugrunde, nämlich, daß:

- es Bewußtsein gibt,

- es einen Träger in menschlichen Individuen besitzt,

129 Vgl. Blotevogel, H.H., Heinritz, G., Popp, H., Regionalbewußtsein - Überlegungen zu einer geographischlandeskundlichen Forschungsinitiative, a.a.0, S. 409.

130 Vgl. Drinkmann, E., Mobilität und Raumbewußtsein, Untersuchungen am Beispiel der Pfarrerschaft der Evangelisch Lutherischen Kirche in Bayern, München 1991, S. 23.; Endruweit, G. , Raumbewußtsein bei Bürgern und öffentlichkeit als Planungsbedingung, in: ARL (Hrsg.), Aktuelle Probleme der Raumordnung. Raumbewußtsein, a.a.o., s. $22 \mathrm{ff.}$

131 Um das Gesamtspektrum räumlicher Bindungen auf allen räumlichen Maßstabsebenen zu berücksichtigen, verwendet Weichhart die Begriffe "raumbezogene Identität" und "räumliche Identität". Vgl. Weichhart, P., Raumbezogene Identität, a.a.0., s. 14 .

132 Vgl. dazu bspw. Kerscher, U., Raumabstraktionen und regionale Identität: Eine Analyse der regionalen Identitätsmanagements im Gebiet zwischen Augsburg und München, Kallmünz 1992., S. 12.; Fichtner, U., Regionale Identität am Südlichen oberrhein - zur Leistungsfähigkeit eines verhaltenstheoretischen Ansatzes, a.a.0.. 
- es verbalisierbar ist,

- es sich auf Räume beziehen kann,

- man verortete Regionen herauslösen kann.133

Die schwerpunktsetzung auf die Region wird primär mit forschungspragmatischen Erwägungen begründet, weil auf diese Weise eine größtmögliche vergleichbarkeit verschiedener Forschungsbemuihungen gewährleistet ist.134 Zwei weitere Gründe belegen nach Auffassung der Initiatoren der RBF sowohl das legitime Interesse an der Erforschung von Regionalbewußtsein als auch die besondere Hervorhebung der regionalen Ebene: 135

- Der Region komme als ort künftiger Lebensgestaltung ein besonders hoher stellenwert $\mathrm{zu}$, weil viele wichtigen gesellschaftlichen Aufgaben weder auf der Ebene des Zentralstaates noch auf der lokalen Ebene alleine wirksam lösbar seien. Darüber hinaus wird der Region ein hohes Maß an sozialer Kohäsion zugeschrieben, welche "aus gemeinsamer Tradition, gleichen Lebensumständen oder äußerer Bedrohung und Fremdbestimmtheit hervorgehen kann.

- Schließlich könne die Erfassung des Regionalbewußtseins der Bevölkerung Grundlage einer kulturgeographischen Raumgliederung "von unten" sein. Eine derartige Regionsabgrenzung stößt bei den Betroffenen möglicherweise auf höhere Akzeptanz als Aufteilungen, welche von Pla-

133 Vgl. Pohl, J., Regionalbewußtsein im Friaul, Habilitationsschrift im Druck, 1993.

134 Vgl. Blotevogel, H.H., Heinritz, G., Popp, H., "Regionalbewußtsein". Zum Stand der Diskussion um einen Stein des Anstosses, a.a.0., S. $70 \mathrm{f}$.

135 Vgl. Blotevogel, H.H., Heinritz, G., Popp, H., Regionalbewußtsein - überlegungen zu einer geographischlandeskundlichen Forschungsinitiative, a.a.0, S. 410. 
nungsinstitutionen "von oben" nach normativen Kriterien vorgenommen werden.

Die Sinnfälligkeit der schwerpunktmäßigen Betrachtung räumlicher Bindungen auf Ebene der Region ist vielfach auf Kritik gestoßen. So konnte beispielsweise in empirischen Untersuchungen wiederholt nachgewiesen werden, daß der kleinräumige Maßstabsbereich einbezogen werden muß, um die Bindungswirkungen z.B. auf der Ebene der Region zu erklären. 136

Unabhängig davon, welcher Terminus verwendet wird, herrscht Konsens in der Interpretation des $z u$ beschreibenden oder zu erklärenden Phänomens. Regionalbewußtsein wird entweder als raumbezogene Einstellung 137 (individueller Zugang) 138 oder als Gesamtheit raumbezogener Einstellungen

136 Vgl. Aring, J., u.a., ,... daß die Wahrnehmung wichtiger ist als die Realität?" Zur Krisenbewältigung und Regionalentwicklung im Ruhrgebiet, in: Ber. $z$. dt. Landeskunde, Bd. 63, H.2, 1989, S. 513-536.; Wolf, K., Otto, G., u.a., Das Hessische Ried. Name und Abgrenzung einer hessischen Landschaft im Regionalbewußtsein ihrer Bevölkerung, in: Ber. z. dt. Landeskunde, Bd. 63, H.2, 1989, S. 610 .

137 zum Begriff der Einstellung als Prädisposition eines Konsumenten zur Reaktion auf Reize vgl. Meffert, $H$. Marketingforschung und Käuferverhalten, Wiesbaden 1992, S. 55 ff.; zu Einstellungen als Grundlage für kognitive und konative Prozesse vgl. Kroeber-Riel, W., Konsumentenverhalten, 4. Aufl., München 1990, S. 4954, S. 162 ff.; Müller-Hagedorn, L., Das Konsumentenverhalten - Grundlagen für die Marktforschung, Wiesbaden 1986 , s. $79 \mathrm{ff}$., S. $182 \mathrm{ff}$.; Trommsdorff, V., Konsumentenverhalten, Stuttgart 1989, S. $121 \mathrm{ff.}$.

138 Auf der Individualebene umschreibt Regionalbewußtsein das "Bewußtsein der zugehörigkeit zu einem bestimmten Raum". Dabei wird vorgeschlagen, die Intensität des Gefühls vom Inhalt der Raumvorstellung (z.B. die mit einem bestimmten Raum verbundenen Assoziationen) zu trennen. Vgl. Blotevogel, H.H., Heinritz, G., Popp, $\mathrm{H}$., Regionalbewußtsein - überlegungen zu einer geographisch-landeskundlichen Forschungsinitiative, a.a.o, S. $409 \mathrm{f}$. 
(kollektiver Zugang)139 konzipiert.140 Das Einstellungskonstrukt wird dabei in eine kognitive, affektive und in eine konative Komponente aufgegliedert. Die einzelnen Bestandteile von Regionalbewußtsein lassen darauf aufbauend wie folgt umschreiben: 141

- Die Wahrnehmung der Region (kognitive Dimension) ist ausgerichtet auf physisch-räumliche (z.B. landschaftliche) Objekte und Merkmale, Grenzen, symbole, Organisationen (z.B. Behörden, Verbände, Zeitungen usw.), regionale Geschichte und Traditionen, Ereignisse, Entwicklungsprobleme und die mentale Raumrepräsentation in der Form von inneren Bildern bzw. sogenannter "Mental maps". Die Wahrnehmung der Region und damit die Abgrenzung von anderen Regionen beruht insbesondere auf vergleichendem Denken.142 Im Mittelpunkt des Forschungsin-

139 Auf der Kollektivebene entspricht Regionalbewußtsein der "Gesamtheit raumbezogener Einstellungen und Identifikationen, fokussiert auf eine mittlere Maßstabsebene." Vgl. Blotevogel, H.H., Heinritz, G., Popp, H., "Regionalbewußtsein". Zum Stand der Diskussion um einen Stein des Anstosses, a.a.0., S. $70 \mathrm{f}$.

140 Die grundsätzliche offenheit, Regionalbewußtsein als individuales oder kollektives Phänomen $\mathrm{zu}$ interpretieren, markiert einen wesentlichen Unterschied zum Heimatbegriff, der durchweg als individueller Bewußtseinsinhalt verstanden wird.

141 Vgl. Blotevogel, H.H., Heinritz, G., Popp, н., "Regionalbewußtsein". Zum Stand der Diskussion um einen Stein des Anstosses, a.a.0., S. $71 \mathrm{f}$; vgl. auch Meier-Dallach, H.-P., Regionalbewußtsein, soziale Schichtung und politische Kultur. Forschungsaspekte und methodologische Aspekte, in: IzR, H. 7/8.1987, S. $378 \mathrm{ff}$. .

142 Vgl. Meier-Dallach, H.-P., u.a., Regionalbewußtsein, soziale Schichtung und politische Kultur. Forschungsergebnisse und methodolgische Aspekte, in: IzR, H.7, 1987, S. 380.; Flemming, M., Regionalbewußtsein und regionale Identität in der Region Franken/Baden-Würtemberg, in: Arbeitsmaterialien zur Raumordnung, H.43, Regionales Bewußtsein und regionale Identität als Voraussetzung der Regionalpolitik, Bayreuth 1985, S. 8. 
teresses steht häufig die Frage, in welchem Umfang Administrativräume ("Planungsregionen“) mit den subjektiv erlebten Grenzen der Bevölkerung übereinstimmen. 143

- Die regionale Verbundenheit oder das Heimatgefühl (affektive Dimension) umfaßt die emotionale Besetzung von Regionselementen (z.B. Landschaft, Symbole usw.), die Identifikation mit der Region als Ganzheit sowie den Grad der Erfüllung von Bedürfnissen bzw. Ansprüchen innerhalb des Referenzraumes.

- Die regionalen Handlungsorientierungen gegenüber der Region (konative Dimension) äußern sich beispielsweise in der Mitwirkung in Vereinen, politischen Parteien oder Kirchen usw.. Von dieser räumlich neutralen Integration in regionale Gruppen und Netzwerke ist das Engagement für Institutionen mit explizit explizit regionsbezogener Zielsetzung (Heimatverein, Naturschutzverband usw.) zu unterscheiden. Schließlich stellt die Mobilitätsbereitschaft eine weitere wichtige Ausprägungsform regionaler Handlungsorientierungen und einen möglichen Wirkungsaspekt kognitiver und affektiver Raumbindungen dar. 144

Die drei Komponenten des Einstellungskonstruktes werden in der RBF als stufen zunehmender Intensität interpretiert. 145 Abbildung 6 verdeutlicht, daß ein wissen um die

$143 \mathrm{Vgl}$. Flemming, M., Regionalbewußtsein und regionale Identität in der Region Franken/Baden-Würtemberg, a.a.0., s. 8 .

$144 \mathrm{Vgl}$. Drinkmann, E., Mobilität und Raumbewußtsein, a.a.0., s. 21 ff..

145 Vgl. Schöller, P., Traditionsbezogene räumliche verbundenheit als Problem der Landeskunde, in: Ber. $z$. dt. Landeskunde, Bd. 58, H. 1, 1984, S. 31 ff. Der Gedanke von Schöller wurde von der Regionalbewußtseinsforschung weitergeführt. Vgl. Blotevogel, H.H., Heinritz, G., Popp, H., Regionalbewußtsein - Überlegungen 
regionalen Eigenarten des eigenen Lebensraumes und der in ihm lebenden Menschen nicht mit einer affektiven Bindung an die betreffende Region geknüpft sein muß. Und schließlich muß die affektive Bindung an die Region nicht notwen -

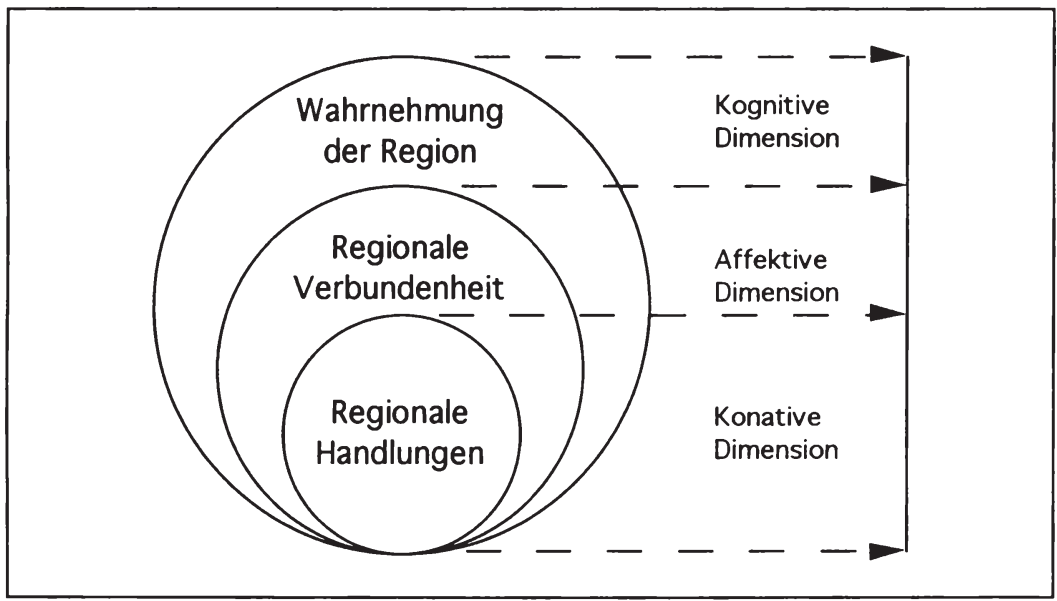

Abb. 6: Intensitätsstufen von Regionalbewußtsein

Quelle: In Anlehnung an Blotevogel H.H.. u.a., Regionalbewußtsein, a.a.0., s. 415 .

digerweise mit einer Artikulation der regionalen Zugehörigkeit einhergehen, wie sie sich beispielsweise in der Mitgliedschaft in regionsgebundenen Institutionen oder in der Unterstützung von bestimmten Bürgerinitiativ- oder Regionalismusbewegungen dokumentiert.146 Umgekehrt setzt

z u einer geographisch-landeskundlichen Forschungsinitiative, a.a.0., S. $414 \mathrm{ff}$.. Eine vergleichbare Systematisierung nimmt der Soziologie Meier-Dallach vor. Er unterscheidet zwischen verschiedenen Intensitätsabstufungen von Regionalismus. Vgl. Meier-Dallach, H.P., Räumliche Identität - Regionalistische Bewegung und Politik, in: IzR, H. 5, 1980, S. $301 \mathrm{ff} .$.

146 Die partnerschaftliche Zusammenarbeit privater und öffentlicher Akteure in der Form einer Public Private Partnership (PPP) mit dem $\mathrm{ziel}$, ein gemeinsam verabschiedetes SRM-Konzept umzusetzen, läßt sich als eine weitere mögliche Ausprägungsform regionaler Handlungs- 
aber ein aktiver Zugehörigkeitswille eine affektive Bindung voraus, welche wiederum auf ein wissen über die regionalen Eigenarten aufbaut (vgl. Abbildung 6).

Ausgehend von der grundsätzlichen definitorischen Bestimmung von Regionalbewußtsein lassen sich die folgenden Kriterien aufzählen, anhand der Regionalbewußtsein veranschaulicht werden kann: 147

\section{- Maßstab:}

Regionalbewußtsein variiert in Abhängigkeit von der räumlichen Maßstabsebene. So unterscheiden die Initiatoren der RBF zwischen einem Lokalbewußtsein (z.B. Zugehörigkeitsbewußtsein zu einer bestimmten stadt), dem Nationalbewußtsein (z.B. Zugehörigkeitsbewußtsein $z u$ einem Staat mit den extremen Ausprägungsformen des $\mathrm{Pa}-$ triotismus oder des Nationalismus) und einer sogenannten "mittleren Maßstabsebene", welche die Zugehörigkeit $\mathrm{zu}$ einer Region abbildet. 148

\section{- Grenzen und innere struktur:}

Die Intensität von Regionalbewußtsein hängt vom geographischen Standpunkt eines Befragten ab (z.B. Wohnort, Arbeitsplatz). Unterschiede werden insbesondere zwischen Bewohnern vermutet, welche im zentrum und in der Peripherie einer Region ansässig sind. Dies kann dazu führen, daß beispielsweise im Grenzbereich eine Art "Doppelbewußtsein" auftritt, weil sich die dort lebenden Menschen sowohl der einen als auch der anderen Region zugehörig empfinden. Es kann aber auch ein toter

orientierungen auffassen. $\mathrm{Zu}$ möglichen Ausgestaltungsformen einer PPP vgl. Kap. C.3.

147 Vgl. Blotevogel, H.H., Heinritz, G., Popp, H., Regionalbewußtsein - Überlegungen zu einer geographischlandeskundlichen Forschungsinitiative, a.a.0., S. 409 ff..

148 Vgl. dazu Kap. B2.21. 
Winkel, ein "Niemandsland“ zurückbleiben, wenn sich Bewohner weder der einen noch der anderen Region zurechnen. 149

- zeit:

Regionale Zugehörigkeiten sind häufig traditionell verankert. Von besonderem Interesse sind Veränderungen von Regionalbewußtsein, welche ihre Ursachen in der Gegenwart haben (z.B. Auswirkungen der europäischen Integration, der Gemeindegebietsreform oder der Einfluß von Werbung und Medien auf die Ausprägung von Regionalbewußtsein).

- Soziale Differenzierung des Regionalbewußtseins: Regionalbewußtsein ist nicht allein räumlich bestimmt, sondern variiert in Abhängigkeit demographischer Merkmale.

Mitunter wird die Frage nach den Auslösern von Regionalbewußtsein aufgeworfen, wobei häufig eine fatalistische Perspektive eingenommen wird: Regionale Fremdbestimmtheit150, Gefährdung, Angst, Verlustgefahr, Ohnmacht, Katastrophen (z.B. Flutkatastrophen, Erbeben)151, Maßnah-

149 Zugehörigkeitsüberschneidungen sind nicht auf die Grenzbereiche benachbarter Regionen beschränkt. Überschneidungen sind denkbar, wenn auf ein und demselben Raum in verschieden Handlungskontexten verwiesen wird. Vgl. Blotevogel, H.H., Heinritz, G., Popp, H., Regionalbewußtsein - überlegungen $\mathrm{zu}$ einer geographischlandeskundlichen Forschungsinitiative, a.a.o., S. 412.

150 Geipel, R., Regionale Fremdbestimmtheit als Auslöser territorialer Bewußtwerdungsprozesse, in: Ber. $z$. dt. Landeskunde, B. 58 , H. 1, 1984, S. 37 ff..

151 Den zentralen Stellenwert von Katastrophen bzw. einer „Einflußnahme von außen" auf die Entwicklung von räumlichen Einstellungen bzw. räumlichen Handlungsorientierungen belegen auch jüngste Beispiele. So haben beispielsweise die in den letzten Monaten in kurzer Folge eingetroffenen Naturkatastrophen im Großraum von Los Angeles (Erdbeben, Überschwemmungen) zu einer Ver- 
men im Bereich sogenannter "Sperriger Infrastruktur" (Großbauvorhaben wie Flughäfen, Autobahnen, Kraftwerke) 152 usw. werden als zentrale Auslöser für das Entstehen von Regionalbewußtsein benannt. Die Konfrontation mit "kultureller Andersartigkeit etwa in Grenzsäumen“ oder politische und wirtschaftliche "Fremdbestimmung” lassen sich als weitere Ursachen hinzufügen. 153

Veröffentlichungen, welche die gezielte schaffung und Förderung von Regionalbewußtsein zum Inhalt haben, sind vergleichsweise selten.154 Kritiker der RBF befüchten sogar, daß mit der Erforschung von Regionalbewußtsein das ziel verfolgt werden könnte, politischen Instanzen Möglichkeiten zur Manipulation regionalen Bewußtseins und

lagerung zahlreicher Produktionsbetriebe in den Bundesstaat Arizona geführt. Vgl. Deysson, C., Licht ausknipsen, in: WIWO, Nr. 12 v. 18.3.1994, S. $36 \mathrm{ff.}$

152 Vgl. Hasse, J., Krüger, R., Raumentwicklung und Identitätsbildung in der nordwestdeutschen Küstenregion. a.a.O.; Hagen, D., Hasse, J., Krüger, R., Bestand und Veränderungstendenzen räumlicher Identität (Heimatbewußtsein) angesichts bevorstehender Umweltveränderungen durch den Neubau eines seedeichs innerhalb der Ortslage des Sielhafendorfs Ditzum, Oldenburg 1984 .

153 Vgl. Meier-Dallach, H.-P., Räumliche Identität, a.a.o, S. 301 ff..

154 In einer der geographischen Regionalbewußtseinsforschung zurechenbaren empirischen Untersuchung wird die Diffusion von Raumnamen ( Raumabstraktionen“) als Grundlage für die Schaffung bzw. Manipulierung regionalen Bewußtseins im Rahmen eines regionalen Identitätsmanagements untersucht. Als Fazit konnte festgestellt werden, daß die von den Kritikern der Regionalbewußtseinsforschung wahrgenommene Gefahr, Regionalbewußtsein könne von politischen Instanzen für ihre jeweiligen $\mathrm{Zwecke}$ mißbraucht werden, nicht nachweisbar ist. Vgl. Kerscher, U., Raumabstraktionen und regionale Identität, a.a.o., s. 12 . 
eine damit verbesserte steuerbarkeit der von ihnen "regierten Massen" an die Hand zu geben. 155

Ein wachsendes Interesse an Regionalbewußtsein ist in Regionalpolitik und Regionalforschung z.B. als Strategieelement "endogener Raumentwicklung" zu beobachten.156 Der Grundgedanke dieser auch als "regional angepaßte Entwicklung", "Regionalisierung der Regionalpolitik" bezeichneten regionszentrierten Konzepte besteht im Prinzip darin,

- die ökonomisch-technologischen Entwicklungsfaktoren einer Region nicht auf "harte" Faktoren zu begrenzen, sondern um "weiche" Standortfaktoren, (z.B. Selbstvertrauen in die Entwicklungsfähigkeit der Region) zu ergänzen.157 In engem Zusammenhang damit wird die Forderung erhoben,

- die politischen und planerischen Aktivitäten zur Regionalentwicklung vermehrt auf die Ebene von Regionen $z u$ verlagern (Dezentralisierung).

Die geforderte planerische und politische selbständigkeit der Regionen setzt eine Konsensbildung bzw. ein homogenes und damit widerspruchsfreies Regionalbewußtsein der von den Planungen unmittelbar Betroffenen zwingend voraus, um

155 vgl. Hard, G. , "Bewußtseinsräume“. Interpretationen zu geographischen "Versuchen, regionales Bewusstsein zu erforschen, GZ, Jg. 75, H.3, 1987, S. 146.

156 Vgl. Wood, G., Regionalbewußtsein im Ruhrgebiet in der Berichterstattung regionaler Tageszeitungen, in: Bericht zur deutschen Landeskunde, Bd.63, H. 2, 1989, S. 538.; Helbrecht, I., Danielzyk, R., Butzin, B., Wahrnehmungsmuster und Bewußtseinsformen als qualitative Faktoren der Regionalentwicklung: Fallstudie Ruhrgebiet, in: Raumforschung und Raumordnung, H.4, 1991, S. 229.

$157 \mathrm{Vgl}$. Wood, G., Regionalbewußtsein im Ruhrgebiet in der Berichterstattung regionaler Tageszeitungen, a.a.o., S. 538 . 
beispielsweise Apathien oder offenen Widerstand gegenüber Planungsvorhaben abzubauen bzw. gar nicht erst entstehen zu lassen. 158 zur steigerung der planungspolitischen Effizienz wird aus diesem Grund die umfassende Einbeziehung der Bevölkerung in die Gestaltung der regionalen Entwicklung befürwortet. $159 \mathrm{zu}$ diesem Zweck müssen die Wahrnehmungen und Orientierungen der Bevölkerung berücksichtigt werden. In diesem Zusammenhang stellt sich die Frage, ob Regionalbewußtsein überhaupt manipulierbar oder gar "machbar" ist, und in welchem Ausmaß dies der Fall sein kann.

\subsection{Implikationen für das Marketing}

Die Idee, Regionalbewußtsein als raumbezogene Einstellung zu konzipieren, verschafft der Marketingwissenschaft keine wesentlich neuen Impulse für die eigene Forschung. Im Gegensatz zur Geographie, welche sich erst allmählich für Wahrnehmungsphänomene öffnet, verfügt das Einstellungskonstrukt in der Marketingwissenschaft uber eine lange Tradition, und düfte in allen seinen wesentlichen Facetten diskutiert sein. Für das Marketing ist demgegenüber die

158 Für Planungsprojekte, welche aufgrund ihrer struktur, Standorte und Nutzungen einer Informationspolitik bedürfen, wird der Einsatz von Marketing als Mittel zur Akzeptanzschaffung diskutiert. Träger des Marketing sind beispielsweise Institutionen wie Regionale Planungsverbände oder Regionalplanungsstellen. Als denkbare Planungsprojekte lassen sich beispielhaft aufzählen: Maßnahmen mit negativem Wirkungsspektrum (z.B. Kraftwerke), Standortalternativen bei sperriger Infrastruktur, bei flächenintensiven planungen ( $\mathrm{z}$.B. von Golfplätzen), bei Maßnahmen mit geringer Interessenvertretung. Vgl. Maier, J., Troeger-Weiss, G., Marketing in der räumlichen Planung. Ansätze und Wege zu einer marktorientierten Regional- und Kommunalplanung/-politik, Akademie für Raumforschung und Landesplanung (ARL), Hannover 1990, S. 14 .

$159 \mathrm{Vgl}$. Helbrecht, I., Danielzyk, R., Butzin, B., Wahrnehmungsmuster und Bewußtseinsformen als qualitative Faktoren der Regionalentwicklung, a.a.0., s. 230 . 
innergeographische Kontroverse über „Unsinn oder Sinn"160 der Erforschung räumlicher Zugehörigkeiten, welche sich in der Abgrenzung von Regionalbewußtseinsräumen entzündet hat, aufschlußreich. Ausgehend von den Veröffentlichungen der Initiatoren des Forschungszweiges ist die Sinnfälligkeit der Erforschung räumlicher Bindungen in teilweise kontroversen stellungnahmen geographischer Fachvertreter immer wieder grundsätzlich in Frage gestellt worden.161

Der Hauptkritikpunkt an der geographischen RBF gipfelt in dem Vorwurf, mit der Erforschung von räumlichen Zugehörigkeiten einer „Verräumlichung nichträumlicher Phänomene“ 162 Vorschub zu leisten.163 Es handele sich um einen Sonder-

160 Vgl. Bahrenberg, G., Unsinn oder Sinn des Regionalismus in der Geographie, in: Gz, Jg. 75, H.3, 1987, S. $149 \mathrm{ff.}$.

161 Eine nachdrücklich ablehnende Haltung wird beispielsweise von den folgenden Autoren eingenommen: Hard, G., "Bewusstseinsräume", a.a.O., S. $127 \mathrm{ff}$., Ders., Das Regionalbewußtsein im spiegel der regionalistischen Utopie, in: IzR, H.7/8, 1987, S. 419 ff.; Bahrenberg, G., Unsinn oder Sinn des Regionalismus in der Geographie, a.a.O., Aschauer, W., Zum Nutzen von "Ethnizität" und "Regional-" oder "Heimatbewußtsein" als Erklärungsansatz geographischer Theoriebildung, wien 1990 , S. 3 ff..

162 Vgl. Hard, G., Das Regionalbewußtsein im spiegel der regionalistischen Utopie, a.a.0., S. 426.

163 In der Raumforschung wird generell die Gefahr gesehen, die räumliche Dimension eines Phänomens wichtiger zu nehmen als alle anderen Dimensionen. Vor diesem Hintergrund wird häufig die Frage aufgeworfen, ob nicht soziale Differenzierungen wie z.B. Alter, Geschlecht oder Schicht/Klasse viel entscheidender für die Ausbildung kollektiver Identitäten sind als die regionale zugehörigkeit. Vgl. Meier-Dallach, H.-P., Soziale Strukturen und räumliches Bewußtsein, Bern, Stuttgart 1985, S. 2 [Anm. 2].; Danielzyk, R., Wiegandt, C.-C., Regionales Alltagsbewußtsein als Faktor der Regionalentwicklung? Untersuchungen im Emsland, in: IzR, H. $7 / 8,1987$, S. 442.; In seiner Untersuchung uber die historische Entwicklung der Ruhrgebietsidentität stellt Rohe fest, daß es nicht nur eine Konkurrenz von räumlichen Identitätsebenen, sondern auch von räumli- 
fall der "Verwandlung abstrakter sprachverhalte in Sachverhalte." (Ontologisierung).164 Sollte dieser Vorwurf gerechtfertigt sein, und die Erforschung von Regionalbewußtsein ein zweckloses Unterfangen darstellen, läuft die Marketingwissenschaft Gefahr, möglicherweise den gleichen "Fehler" zu begehen.

Der Grundgedanke der Kritik besteht darin, daß heutzutage angesichts weltweiter Verflechtungen in allen nur denkbaren Lebensbereichen, eigenständige, physisch abgrenzbare Regionen obsolet geworden sind.165 Die Vorwüfe gipfeln in der These, daß heute keine räumlich organisierte Gesellschaft (sogenannte segmentär gegliederte Gesellschaft) mehr existiert, sondern nur noch die moderne, funktional gegliederte Einheitsgesellschaft.166 Die Weltgesellschaft muß auf Grundlage weltumspannender Kommunikationssysteme analysiert werden. Wenn es jedoch keine räumlich abgrenzbaren Regionalgesellschaften mehr gibt, kann es auch kein Regionalbewußtsein geben. Das als "Regionalbewußtsein" bezeichnete Phänomen ist vielmehr auf Kommunikationssysteme ausgerichtet, welche beispielsweise durch die von N. Luhmann stammende Typisierung in die Medien Geld, Macht,

chen und nichträumlichen Identitätsmustern gibt. Vgl. Rohe, K., Regionalkultur, regionale Identität und Regionalismus im Ruhrgebiet, in: Lipp, w. (Hrsg.), Industriegesellschaft und Regionalkultur, Köln, Berlin, Bonn, München 1984, S. 134 .

164 Vgl. Hard, G., „Bewußtseinsräume”, a.a.O., S. 135.

165 Zur Frage inwieweit Räume als "organische Ganzheiten" oder "Individuen" in einem metaphorischen oder pragmatischen Sinn aufgefaßt werden dürfen vgl. Kap. 2.2.

166 Der übergang von der segmentär gegliederten Gesellschaft ("Regionalgesellschaft") zur weltweit gültigen, funktional gegliederten Einheitsgesellschaft basiert auf der systemtheorie von N. Luhmann. Vgl. dazu den überblick in Vgl. Pohl, J., Regionalbewußtsein im Friaul, a.a.o.. 
Liebe/Vertrauen repräsentiert werden.167 Diese Kommunikationssysteme haben keine physisch-räumliche Existenz. Das beispielsweise einer Region gegenüber geäußerte Zugehörigkeitsgefühl ist nicht "räumlich", sondern situationsspezifisch auf unterschiedliche Kommunikationssysteme bezogen, welche lediglich räumlich verschlüsselt sind.168

Der im Zuge der Entwicklung $z u$ einer weltweit gültigen „Einheitsgesellschaft" zum Ausdruck kommende Bedeutungsverlust räumlicher Grenzen ist durchaus mit Fragestellungen vergleichbar, welche in der Marketingwissenschaft im Rahmen der Globalisierungsdiskussion aufgeworfen werden. Ausgehend von der Feststellung, daß sich die Konsumentenwïnsche - zumindest bezüglich bestimmter produktgruppen weltweit angleichen, stehen Unternehmen vor der Frage, inwieweit die Berücksichtigung lokaler Besonderheiten durch eine globale Vorgehensweise ersetzt werden kann.169 In der Terminologie der Kritiker an der RBF läßt sich somit auch am Beispiel ökonomischer Prozesse ein übergang von der

167 Das Medium Geld konstituiert das Teilsystem Wirtschaft. Die Medien Macht und Recht sind Basis für das Teilsystem Politik. Liebe/Vertrauen soll Basis für Familie sein, Ästhetik die von Kunst, Glaube die von Religion usw. Wahrheit und Reputation sind konstitutiv für das Teilsystem Wissenschaft.

168 In einem vermittelnden Standpunkt werden Regionen als segmentäre Einheiten innerhalb funktionaler und enträumlichter Kontexte begriffen. Danach können Regionen ihr Profil und ihre Existenz nur dadurch gewinnen oder präsentieren, daß sie als sinnkontexte wahrgenommen werden, in denen 'eigensinnige' Regeln gelten und erlebbar sind. Von daher sind Regionen, die diese identitätsrelevante Eigenschaft besitzen, als segmentäre Kulturen zu bezeichnen. Vgl. Schulze, H.-J., Regionale Identität Erwachsener. Voraussetzungen und empirische Befunde, in: Raumforschung und Raumplanung, H.5/6, 1989, S. 319 .

$169 \mathrm{Vgl}$. Meffert, H., Marketing-Management. Analyse Strategie - Implementierung, Wiesbaden 1994, S. 20, $265 \mathrm{ff.;}$ Ders., Strategische Unternehmensfuhrung und Marketing. Beiträge zur marktorientierten Unternehmenspolitik, Wiesbaden 1988, S. 269. 
segmentären Gesellschaft in eine "Weltgesellschaft" beobachten.

Die Globalisierungsdebatte hat jedoch gleichermaßen aufgezeigt, daß ein völliger Verzicht auf lokale Besonderheiten in der Marktbearbeitung nicht möglich ist. Es ist vielmehr erforderlich, einen sinnvollen Ausgleich zwischen der Berücksichtigung lokaler Gegebenheiten und dem wunsch nach internationaler standardisierung $\mathrm{zu}$ finden. 170

Vor diesem Hintergrund erscheint eine Negierung von "Regionalbewußtseinsräumen“, wie sie von den Gegnern der RBF vorgenommen wird, überspitzt. Damit soll nicht bezweifelt werden, daß sich eine vielzahl austauschbarer räumlicher Orientierungen nachweisen lassen, welche nahezu jede Stadt oder Region auszeichnen. Trotzdem ist $z u$ vermuten, daß jede Stadt oder Region uber Attribute und Besonderheiten verfügt, über die eine konkurrierende stadt nicht verfuigt.

Die innergeographische Kontroverse zur RBF unterstreicht die möglicherweise triviale Erkenntnis, daß räumliche Identität situationsspezifisch unterschiedlich interpretiert werden muß. Wenn beispielsweise die Verbundenheit $\mathrm{zu}$ einer Stadt oder Region im Rahmen einer empirischen Untersuchung erhoben wird, ergibt sich zwangsläufig die Frage, worauf sich die von den Probanden möglicherweise geäußerte Zugehörigkeit oder Aversion tatsächlich bezieht. In diesem Zusammenhang ist der Auffassung zuzustimmen, daß die beispielsweise gegenüber dem Stimulus "Name der Stadt xy" geäußerte zuwendung oder Aversion zunächst nichts anderes ist als ein räumlicher kode, der spezifische Inhalte verschlüsselt. Das gegenüber einer stadt oder Region geäußerte Zugehörigkeitsgefühl, welches beispielsweise auf

$170 \mathrm{Vgl}$. Meffert, H., Strategische Unternehmensführung und Marketing, a.a.0., s. 274 f. 
einer Likert-Skala den höchsten Sympathiewert (oder Aversionswert) zum Ausdruck bringt, ist somit dahingehend zu untersuchen, welche Faktoren für das Urteil tatsächlich ausschlaggebend gewesen sind. So ist es beispielsweise denkbar, daß für den Einen die Lärmbelästigung in der Großstadt und für einen anderen das mangelnde kulturelle Angebot im Referenzraum die ablehnende Haltung begründet.

Daraus ergibt sich zwangsläufig die Frage, was einen "Ort” ausmacht, bzw. was unter "Raum” zu verstehen ist. Die Definition des Raumes bzw. die Definition räumlicher Bezugsgrößen ist jedoch kompliziert, weil aufgrund selektiver Wahrnehmungen für jede Person situationsspezifisch andere räumliche Merkmale relevant sind, und jede person somit andere Sinnbezüge mit einer räumlichen Bezugsgröße verbindet. So wird möglicherweise ein Pendler den Standort seiner Arbeit mit in die Definition des ortes einbeziehen, während ein Student die Universität als "ortsrelevant" betrachtet. 171

2 .

Zentrale Faktoren räumlicher Identität

Das Zusammenspiel zwischen Identitätsträgern, räumlichen Bezugsgrößen und den beispielsweise mit einer räumlichen Bezugsgröße assoziierten Inhalten wird in Abbildung 7 anhand eines Paradigmas strukturiert. Gedanklicher Ausgangspunkt ist das auf die Person als objekt ausgerichtete Verständnis räumlicher Identität, welches zwischen den Teilprozessen der Identifizierung von und der Identifikation mit (räumlicher Umwelt) unterscheidet.

171 Vgl. dazu Kap. B.2.2. 

Wer? (Identitätsträger)
identifiziert ("Identifizierung von")
welche räumliche Bezugsgröße?
wodurch? (Inhalte)

und:

Wer? (Identitätsträger)

identifiziert sich mit ("Identifikation mit")

welcher räumlichen Bezugsgröße?

womit? (Inhalte)

Abb. 7: Paradigma für die Analyse räumlicher Identität

Die beiden Prozesse müssen nicht zwangsläufig durchlaufen werden: Die Identifizierung stellt zwar eine notwendige Voraussetzung für die Identifikation dar. Jedoch muß die Identifizierung von (räumlicher Umwelt) nicht zwangsläufig zur Identifikation mit führen. Wenn ein bestimmter Raum beispielsweise als "Messestadt" identifiziert wird, muß der Wahrnehmende dieser stadt gegenüber nicht zwangsläufig eine Gefühlshaltung in der Form von Zuneigung oder Aversion entgegenbringen.

Von dieser Zweiseitigkeit des Begriffsverständnisses räumlicher Identität ausgehend, muß zunächst die Frage beantwortet werden, welche Personen und Gruppen grundsätzlich als Identitätsträger in Frage kommen. Damit wird berücksichtigt, daß die Identität z.B. einer stadt oder Region nicht gleichgewichtig von Bewohnern und Auswärtigen festgestellt werden kann. Im Anschluß daran stellt sich die Frage, welche räumliche Bezugsgrößen als Projektionsfläche räumlicher Identität grundsätzlich zu unterscheiden sind. Damit wird ein Kontinuum räumlicher Maßstabsbereiche angesprochen, welches sich von einem kleinräumigen Mikro- 
maßstab bis hin zu einer großflächigen Makroebene erstreckt. Weil räumliche Identität nicht primär auf physische Merkmale (z.B. eine Fläche), sondern auf inhaltliche Besonderheiten ausgerichtet ist, schließt sich die Frage an, welche Inhalte mit den jeweiligen räumlichen Bezugsgrößen verknüpft werden.

\subsection{Träger räumlicher Identität}

In der Abbildung 8 werden exemplarisch 3 Typen verschiedener Identitätsträger einander gegenübergestellt, welche jeweils durch spezifische Wahrnehmungsmuster gekennzeichnet sind. Um zu einer handhabbaren Anzahl von Analyseeinheiten zu gelangen, wird in der Innenperspektive eine Beschränkung auf Bewohner und Entscheider vorgenommen, die Außenperspektive wird pauschal durch Auswärtige repräsentiert. Dabei werden mögliche Unterschiede in der Ausprägung räumlicher Identität durch Diskrepanzen (sog • "gaps") versinnbildlicht.

In der Innenperspektive läßt sich ein gap zwischen Bewohnern und Entscheidern annehmen (gapl).172 Darüber hinaus

172 Die Ursachen und Ausprägungsformen derartiger Abweichungen werden insbesondere von geographischen Autoren behandelt: Im Mittelpunkt steht dabei die überwindung der Widersprüchlichkeit von funktionsorientierter Experten- und vertrauter Alltagswelt. Aring u.a. sowie andere sozialgeographische Autoren verweisen häufig auf Habermas, der ein gesellschaftskritisches Bild der Postmoderne zeichnet, welches in der Entkopplungsthese zwischen "System und Lebenswelt" Ausdruck findet. Danach treten in der Gegenwart zunehmend Diskrepanzen auf zwischen den Subsystemen der Wirtschaft und der bürokratischen staatsverwaltung einerseits, und den Lebenssphären der öffentlichkeit (der Privatleute und der Staatsbürger mit Familie, Nachbarschaft usw.) andererseits. In einem lebensweltlichen Regions-bzw. Raumbegriff steht nach Auffassung dieser Autoren die Zentrierung um den Mittelpunkt des eigenen Ich im Zentrum des Raumerlebens. Demgegenüber sind die Raumori- 
ist $z u$ vermuten, daß Auswärtige ein anderes Bild von einer Stadt/Region zeichnen als die die Bewohner.

Neben den unterschiedlichen Interessenlagen von Bewohnern und Entscheidern werden unterschiedliche Arten des wissens als wesentlicher Ursachenfaktor für Diskrepanzen in der Innenperspektive betrachtet. Für den Bewohner ist das im Alltag eingespielte Verhältnis zum ihn umgebenden Lebensraum handlungsleitend, daß weitgehend unbewußt existiert und häufig habitualisiert und damit gewissermaßen ohne Nachdenken und Aufmerksamkeit abläuft.173 Eine Abkehr von diesem häufig unterhalb der Bewußtseinsschwelle angesiedelten Raumbezug setzt einen fülbaren Anlaß voraus, die Beziehung zum Raum zu überdenken. Veränderungen in den sozioökonomischen Lebensbedingungen, der bebauten und natürlichen Umwelt, Veränderungen der persönlichen Lebenssituationen des Menschen lassen sich als mögliche Ursachen beispielhaft aufführen.174 während somit die räumliche Umwelt für den einzelnen Bewohner in einer intakten Mensch-Umwelt-Beziehung meist gar nicht oder nur schwach reflektiert wird, ist der Raumbezug der Experten explizit auf eine Veränderung des Raumes ausgerichtet.

entierungen von Experten im Raster eines $\mathrm{x} / \mathrm{y}$-Koordinatensystems angeordnet. Vgl. Aring u.a., Krisenregion Ruhrgebiet, in: Wahrnehmungsgeographische Studien zur Regionalentwicklung, Nr. 8, 1989. S. 122. Vgl. dazu auch: Blotevogel, H.H., "Regionalbewußtsein". Zum Stand der Diskussion um einen Stein des Anstosses, a.a.O., S. $68 \mathrm{ff.;}$ Wood, G., Regionalbewußtsein im Ruhrgebiet in der Berichterstattung regionaler Tageszeitungen, a.a.0., s. $537 \mathrm{ff..}$

$173 \mathrm{Vgl}$. Wirth, A., Bewahrung lokalen Bewußtseins bei Umsiedlungsmaßnahmen im rheinischen Braunkohlerevier, in: IzR, H.10, 1981, S. $157 \mathrm{ff}$.

$174 \mathrm{Vgl}$. Hasse, J., Krüger, R., Raumentwicklung und Identitätsbildung in der nordwestdeutschen Küstenregion, a.a.0., s. 7 . 


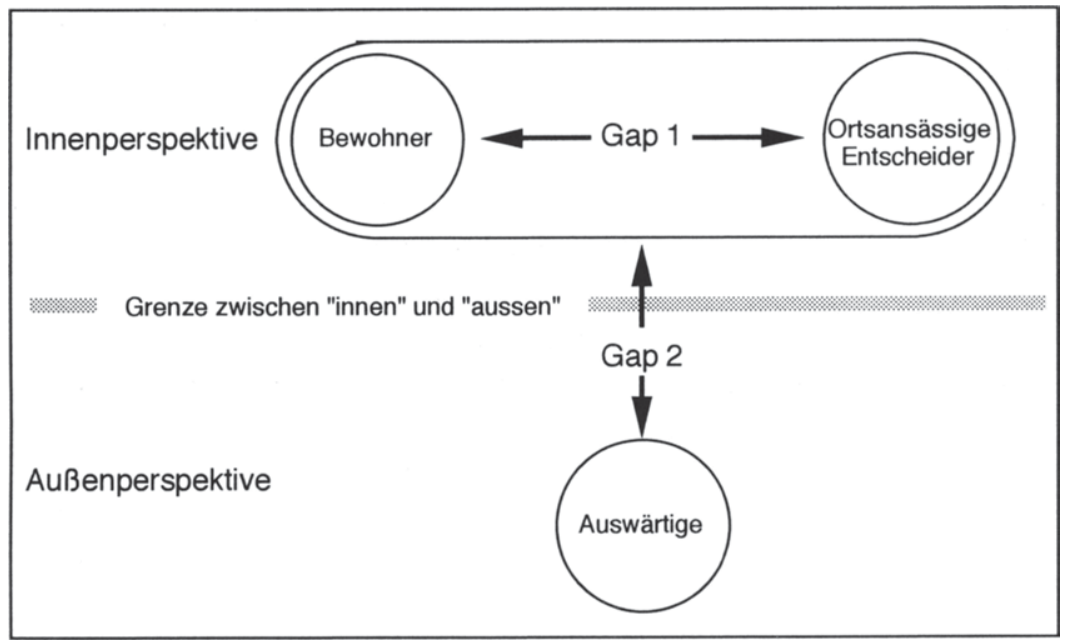

Abb. 8: Identitätsträger räumlicher Identität

Die Unterschiede zwischen Innen- und Außenperspektive sind in Gap2 zusammengefaßt. Als Auswärtige sind sowohl Personen und Gruppen aufzufassen, welche eine betreffende stadt oder Region noch nie persönlich aufgesucht haben, als auch verschiedende Formen von Pendlern. Neben Berufspendlern zählen dazu eine Reihe von mehr oder weniger zufällig und zyklisch auftretenden Besuchern, welche eine stadt oder Region situativ zur Befriedigung ganz bestimmter Beduirfnisse, zu ganz bestimmten Formen des Konsums oder von Erlebnissen aufsuchen ("flukturierende Öffentlichkeit“).175 Diese Personen und Gruppen unterscheiden sich von den Bewohnern allein schon aufgrund ihre geringen zeitlichen Aufenthaltsdauer und der eingeschränkten Bandbreite der im Referenzraum befriedigten Bedürfnisse. Die Qualität der persönlichen Erfahrungsgrundlage ist deshalb eine wesentliche Ursache für Wahrnehmungsabweichungen zwischen Selbst- und Fremdidentifizierung.

$175 \mathrm{Vgl}$. Meier-Dallach, H.-P., Was macht die Identität einer Stadt aus?, Zürich 1990, S. 5. 
Die unmittelbare Beteiligung eines Bewohners in die Lebensvollzüge eines Raumes hat zwangsläufig ein von Auswärtigen abweichendes Informationsverhalten sowie bessere Informationschancen zur Folge. Die Raumkenntnis von Auswärtigen basiert im wesentlichen auf veröffentlichten Informationen, wobei mitunter das - mehr oder weniger verzerrte - räumliche Image internalisiert wird.176 Demgegenüber können die Bewohner in der Regel auf ein weitläufiges Netz informeller Netzwerke zugreifen. Weil die Bewohner von den raumbezogenen Entscheidungen unmittelbar betroffen sind, ist darüber hinaus ein höherer Intensitätsgrad bei der Informationssuche zu erwarten.

Weitere Unterschiede zwischen den Gruppen sind auf abweichende raumbezogene Intentionen zurückzuführen. Auswärtige suchen eine bestimmte stadt oder Region aus einem ganz bestimmten Grund auf und nehmen dabei spezifische Aspekte selektiv wahr. So werden Kurzzeitbesucher ihr Besuchsziel möglicherweise als Arrangement verschiedener sehenswürdigkeiten betrachten, während Durchreisende (z.B. Lastwagenfahrer, Flugzeugcrews) oder Berufspendler primär die Verkehrssituation im Auge haben. Demgegenüber verknüpft ein Bewohner mit dem ihn umgebenden Lebensraum ein ganzes Bündel verschiedener Intentionen (z.B. wohnen, arbeiten, sich erholen usw.), deren Erfüllung ein wesentlichen Faktor seiner Lebensqualität darstellt.

Zweifelsohne lassen sich auch vielfältige übereinstimmungen zwischen den Bedürfnissen von Bewohnern und Auswärtigen vermuten, welche allesamt in ein und derselben stadt oder Region befriedigt werden. Der Erlebniskauf in einer attraktiven Innenstadtpassage oder der Besuch eines regionalen Freizeitparks spricht langjährige Bewohner oder Kurzurlauber vermutlich gleichermaßen positiv an. Diese Konvergenzen spiegeln jedoch nur vordergründig eine überein-

176 Vgl. dazu Kap. B.3.2.

Ewald Werthmöller and Universität Münster - 978-3-631-75084-1

Downloaded from PubFactory at 01/11/2019 08:31:35AM 
stimmung zwischen den verschiedenen Gruppen wider. Im Gegensatz zu den flukturierenden Besucherströmen von außerhalb tragen die Bewohner maßgeblich die kosten, welche mit der Bereitstellung dieser Einrichtungen verbunden sind. Dies ist beispielsweise der Fall, wenn die verkehrliche Infrastruktur kontinuierlich umfunktioniert wird, um die Besucherströme besser in die stadt/Region hinein und wieder hinaus leiten $z u$ können. In den stadtzentren gewinnen deshalb aus sicht der Bewohner die Verkehrs- und Umweltkosten zunehmend an Gewicht.

Mit Blick auf die von den Bewohnern zu tragenden Kosten muß auch die von örtlichen Entscheidern wünschenswerte Ansiedlung von Unternehmen und uberregional bedeutsamen Institutionen zwiespältig beurteilt werden. Dem Zuwachs an Gewerbesteuereinnahmen und der Chance eines positiven Imagetransfers zwischen den akquierierten organisationen und der betreffenden stadt oder Region stehen nicht selten explodierende Boden- und Mietpreise sowie wachsende $\mathrm{Z}$ insbelastungen gegenüber.

Zusammenfassend wird deutlich, daß verschiedene Identitätsträger ein und denselben Raum in Abhängigkeit von ihren mit dem Raum verbundenen Intentionen unterschiedlich wahrnehmen. So ist plausibel anzunehmen, daß die Identifikation der Bewohner maßgeblich davon abhängt, ob im Referenzraum die Bandbreite der sogenannten Daseinsgrundfunktionen (in Gemeinschaft leben, wohnen, arbeiten, sich versorgen, sich bilden, Freizeitverhalten) quantitativ und qualitativ ausreichend zur Verfügung steht.177 Die Da-

177 Unter Grundfunktionen, Grunddaseinsfunktionen oder Daseinsgrundfunktionen werden in der Sozialgeographie solche grundlegenden menschlichen Daseinsäußerungen, Aktivitäten und Tätigkeiten verstanden, die allen sozialen Schichten immanent, massenstatistisch erfaßbar, räumlich und zeitlich meßbar sind und sich raumwirksam ausprägen. Vgl. Maier, J., Sozialgeographie, Braunschweig 1977, S. 100.; Birkenhauer, J., Die Daseins- 
seinsgrundfunktionen werden mitunter als objektive Lebensbedingungen aufgefaßt, die der wahrnehmung und Bewertung durch die Bevölkerung unterliegen. Die Einstellung zum Lebensraum ergibt sich als Funktion der Daseinsgrundfunktionen und wird als Indiz für die örtliche Lebensqualität herangezogen.178 Demgegenüber sind die räumlichen Identifikationen Auswärtiger vornehmlich punktuell ausgeprägt. In Abhängigkeit von den jeweiligen raumbezogenen Intentionen (z.B. Shopping, Kultur, Freizeit usw.) findet keine Identifikation mit der Stadt als Ganzheit, sondern mit spezifischen Leistungs- und Attraktionspotentialen der betreffenden Stadt oder Region statt. 179

$2 \cdot 2$

systematisierung räumlicher Bezugsgrößen in einer Hierarchie räumlicher Maßstabsebenen

In der Marketingwissenschaft ist eine Fundierung des Raumbegriffes bislang nicht erforderlich gewesen, weil dort

grundfunktionen und die Frage einer "curricularen Plattform" für das Schulfach Geographie, in: GR, $26 / 1974$, S. 499 ff..

178 Die Verknüpfung zwischen den Daseinsgrundfunktionen und dem Grad der "Ortsverbundenheit“ verdeutlicht, daß die Einstellung zum Lebensraum in erheblichem Umfang von den objektiv gegebenen Realitäten im Referenzraum abhängt. Vgl. Schmied, W., Ortsverbundenheit - eine Triebkraft für die Entwicklung ländlicher Räume?, in: IzR, H.3, 1987, S. 131 .

179 Die Selektivität Auswärtiger, welche spezifische Merkmale des Referenzraumes als Identifikationsbasis herausgreifen, läßt sich anschaulich auf Grundlage der am Beispiel der Nachbarschaftsforschung dargestellten "choice-constraint-Modelle" veranschaulichen. Auswärtige genießen das Privileg, ihre Raumbezüge auf jene Attraktionspotentiale und Leistungsfelder einer Stadt/Region zu beziehen, welche einen besonders hohen Nutzen bereitstellen. Die mit der Inanspruchnahme dieser Identifikationsangebote verbundenen Kosten (z.B. Lärm, Verkehr, Kriminalität usw.) werden demgegenüber den Bewohnern aufgebürdet. Vgl. dazu Kap. B.1.21. 
Raum jeweils im Zusammenhang mit anderen Fragestellungen behandelt wird und lediglich als Hintergrundvariable bedeutsam ist. 180 so verwundert es nicht, daß im Marketing ein unexpliziertes, der Umgangssprache entlehntes, Raumverständnis typisch ist.

Im Gegensatz zu betriebswirtschaftlichen Arbeiten, welche auf eine Präzisierung des Raumbegriffes verzichten können, muß eine Untersuchung ubber räumliche Identität dem Raumbegriff zwangsläufig einen größeren stellenwert einräumen. Dies erscheint schon allein deshalb erforderlich zu sein, weil in der vorliegenden Untersuchung keine Unternehmen, sondern Räume (Städte und Regionen) als Gegenstandsbereich und objekt von Identitätszuschreibungen behandelt werden.

\subsection{Vertikale systematisierung räumlicher Be- zugsgrößen}

Prozesse im Rahmen der Identifizierung von und der Identifikation mit räumlicher Umwelt setzen die Existenz einer räumlichen Bezugsgröße voraus, welche als solche zunächst bezeichnet werden muß und auf die die Identitätszuschreibungen projiziert werden. Dabei muß jede mögliche räumli-

180 Diese Vernachlässigung des Raumbegriffes bedeutet jedoch nicht, daß Raum im Marketing vollständig bedeutungslos ist. So wird beispielsweise im Handelsmarketing die Frage aufgeworfen, inwiefern sich die räumliche Gestaltung eines Geschäftes und die davon abhängige Ladenatmosphäre auf das Einkaufsverhalten der Konsumenten auswirkt. Diese "Atmosphärendimension“ der Verkaufsstättengestaltung wird angesichts des Bedeutungszuwachses hedonistischer Grundorientierungen der Konsumenten immer wichtiger. Es konnte beispielsweise empirisch nachgewiesen werden, da $\beta$ e ine "übersichtliche Ladenraumgestaltung" (in Verbindung mit einer "erfrischenden Farbzusammenstellung im Laden") einen maßgeblichen Einfluß auf die wahrgenommene Erlebnisorientierung der Konsumenten ausübt. Vgl. Heinemann, G., Betriebstypenprofilierung und Erlebnishandel, Wiesbaden 1989, S. 172 ff.. 
che Bezugsgröße vor dem Hintergrund einer Hierarchie räumlicher Maßstabsbereiche abgestuft betrachtet werden.

Im Hinblick auf seine flächenhafte Ausdehnung entsteht Raum auf verschiedenen Maßstabsebenen. Die einzelnen Maßstabsebenen bilden in ihrem Zusammenspiel ein Kontinuum räumlicher Bezugsgrößen, welches sich von der Wohnung, über die Straße, Stadt, Region in vielen Zwischenstufen bis hin zur Nation erstreckt und im Extrem den gesamten Globus umfaßt. Jeder dieser Raumausschnitte ist als Element eines umfassenden Systems konzentrischer Kreise aufzufassen, wobei jeder kleinere Raumausschnitt gleichzeitig Bestandteil eines größeren Raumes ist. So ist beispielsweise eine Stadt Bestandteil einer oder mehrerer ubbergeordneter Regionen. Gleichzeitig setzt sich die stadt aus mehreren Stadtteilen, Nachbarschaften, Straßenzügen usw. zusammen, welche möglicherweise situationsspezifisch als eigenständige räumliche Bezugsgrößen Geltung erlangen.

Um die Fülle möglicher Maßstabsebenen auf eine handhabbare Zahl von Analyseeinheiten zu beschränken, wird zwischen einem Mikro-, Meso- und Makromaßstab unterschieden. In Abhängigkeit von der Größe des Areals und menschlicher Interaktionsreichweiten läßt sich diese Dreiteilung folgenermaßen umschreiben: 181

- Der Mikromaßstab bezeichnet einen flächenhaft abgegrenzten Raumausschnitt, von dem anzunehmen ist, daß ihn ein Individuum aus persönlicher Erfahrung kennen kann. Damit sind insbesondere fußläufig erschließbare Wohnumfelder, Innenstadtbezirke, Freizeiträume usw. gemeint.

181 Vgl. Tzschaschel, S., Geographische Forschung auf der Individualebene, Münchener Geographische Schriften, München 1986, S. 20 f. 
- Mit dem Mesomaßstab werden Raumausschnitte bezeichnet, die vom Individuum aufgrund ihrer Größe nur in Teilbereichen aus persönlicher Erfahrung bekannt sind.182 Aus sicht des Individuums kommt deshalb der symbolisch übermittelten Kommunikation ( $z$. B. über Massenmedien) ein zentraler stellenwert als Informationsquelle über den Raum zu.

- Die Abgrenzung zwischen Meso- und Makromaßstab ist fließend. Der Makromaßstab bezieht sich auf eine großräumige Betrachtung. Die Kenntnis von Individuen beschränkt sich auf einzelne strecken und wenige Punkte (Orte, kleine Regionen) oder ist eine mittelbare Kenntnis.

Wenn die Hierarchie räumlicher Maßstabsebenen aus dem Blickwinkel einer sich im Raum bewegenden Person betrachtet wird, werden mehrere räumliche Maßstabsebenen gleichzeitig relevant. 183 Je nach Handlungskontext verwendet eine bestimmte Person sowohl die Nachbarschaft, die stadt

182 Städte und Regionen lassen sich der Mesoebene zuordnen. Es wird vorgeschlagen, den regionalen Maßstab durch den Ausschnitt der sozialen Welt zu begrenzen, in dem das persönliche Interaktionsfeld überschritten ist, aber die Ebene des politischen systems noch nicht erreicht ist. Vgl. Pohl, J., Regionalbewußtsein im Friaul, a.a.o.

183 Den Maßstabsebenen lassen sich bevorzugte Forschungsschwerpunkte verschiedener Wissenschaftsdisziplinen zuordnen. So beschäftigt sich die (Umwelt)psychologie vorrangig mit dem Mikromaßstab. Der Mesomaßstab wird insbesondere von der Geographie bearbeitet. Die Nation ist insbesondere Gegenstand soziologischer und politologischer Untersuchungen. In der vorliegenden Untersuchung wird mit der selektion von städten und Regionen eine Focussierung auf den Mesomaßstab vorgenommen. Dabei darf jedoch nicht unberücksichtigt bleiben, daß Identitätswirkungen auf niedrigereren Hierarchieebenen (z.B. auf der Ebene des Wohnortes) möglicherweise bedeutsam für die Entstehung und Aufrechterhaltung räumlicher Identität auf Ebene der Stadt oder Region sind. 
oder Region, als auch z.B. nationale oder europäische zugehörigkeiten als relevante Aspekte zur Umschreibung ihrer räumlichen Identität. Es ist somit möglich, daß die Identität einer Person zwischen den verschiedenen räumlichen Maßstabsbereichen "oszillieren" kann.184

Ausgehend von der Zweiteilung räumlicher Identität in die Identifizierung von und die Identifikation mit läßt sich die Relevanz verschiedener Maßstabsbereiche für die räumliche Identität einer Person (Identität des Subjektes) differenziert beschreiben:

- Die Identifizierung von räumlicher Umwelt erstreckt sich in Abhängigkeit vom jeweiligen Handlungskontext grundsätzlich auf jeden denkbaren Maßstabsbereich. Ein Raumausschnitt wird identifiziert und damit im Wahnehmungsbild des Beobachters von allen anderen Räumen unterschieden.

- Bei der Identifikation mit ist eine differenziertere Betrachtung erforderlich. Dies erscheint sinnvoll, weil Identifizierung nicht zwangsläufig Identifikation zur Folge haben muß. Nicht jeder Raumausschnitt, sondern nur ganz bestimmten Räumen wird ein Zugehörigkeitsoder Verbundenheitsgefühl entgegengebracht. Darüber hinaus wird nicht jeder Raumausschnitt als Bestandteil der persönlichen Identität oder als verbindendes Element einer Gruppenidentität bedeutsam.

In Abhängigkeit vom jeweiligen Handlungskontext sind Loyalitätskonflikte zwischen verschiedenen räumlichen Maßstabsebenen oder verschiedenen Räumen derselben Maßstabse-

$184 \mathrm{Vgl}$. Weichhart, P., Raumbezogene Identität, a.a.O., s. 76.; Krupat, E., A place for place identity, in: Journal of Environmental Psychology, 3/1983, S. 343. 
bene (z.B. konkurrierende städte) denkbar.185 Darüber hinaus unterscheiden sich die verschiedenen räumlichen Hierarchieebenen hinsichtlich ihrer wichtigkeit für den Einzelnen.186 so ist beispielsweise die Beziehung zwischen dem Menschen und seiner unmittelbaren räumlichen Umgebung von der Beziehung zur Gesamtstadt oder zur Nation zu unterscheiden. 187 Aus der Identifikation mit dem Stadtviertel muß beispielsweise nicht zwangsläufig die Identifikation mit der Gesamtstadt resultieren. Möglicherweise ist das Gegenteil zutreffend: Vielleicht ergibt sich das Verbundenheitsgefühl mit der Gesamtstadt aus den positiven Erfahrungen in der Nachbarschaft. So ist beispielsweise denkbar, daß das der Gesamtstadt gegenüber geäußerte Zugehörigkeitsgefühl in Wirklichkeit nur auf einen kleinen Teilbereich innerhalb der stadt bezogen ist. 188 Es konnte

185 Die situations - und kontextspezifische Akzentuierung unterschiedlicher Bezugsobjekte räumlicher Identität läßt sich an einem Fußballbeispiel anschaulich erläutern: "Beim Match des lokalen Fußballclubs gegen den Verein des Nachbarviertels wird sich der Zuseher als loyaler Viertelsbewohner fühlen, der gegen "die anderen" pfeift, spielt die Nationalmannschaft, dann wechselt die Bezugsebene, und die nationale Identität tritt (...) in den Vordergrund. Mit der Änderung der Situation wechselt die symbolische Bezugsgruppe, verändern sich Rollen und Erwartungshaltungen." Vgl. Weichhart, P., Raumbezogene Identität, a.a.0., s. 77.

$186 \mathrm{Vgl}$. Weichhart, P., Raumbezogene Identität, a.a.o., s. 77 .

187 Vgl. Pohl, J., Regionalbewußtsein im Friaul, a.a.o.; Russel, J.A., Ward, L.M., Environmental Psychology, in: Annual Review of Psychology, 33/1982, S. 654 .

188 Angesichts der Interdependenzen zwischen den verschiedenen Maßstabsbereichen sollte im Rahmen einer empirischen Analyse räumlicher Identität ein detailliertes Meßinstrumentarium entwickelt werden, das diese überschneidungen berücksichtigt. Diese Vorgehensweise ist erforderlich, um die Herstellung meßtechnischer Artefakte $\mathrm{zu}$ vermeiden. Auf die Gefahren, welche mit einem simplifizierenden Meßkonzept verbunden sind, weisen insbesondere die Kritiker der RBF hin. Vgl. Hard, G., „Bewusstseinsräume“, a.a.0., S. 134, FN 14 . 
beispielsweise wiederholt nachgewiesen werden, daß der kleinräumige Maßstab vom Individuum als primäre Referenzgröße seiner räumlichen Bindungen betrachtet wird. Der Wohnstandort und die unmittelbare Wohnumgebung, und gerade noch das weitere Wohnviertel sind als "subjektive Mitte der Welt" der eigentlich entscheidende Maßstabsbereich, auf den individuelle Identifikationsprozesse ausgerichtet sind. 189

Demgegenüber kommt den regionalen und überregionalen Maßstabsebenen eine vergleichsweise nachrangige Bedeutung als Projektionsfläche räumlicher Identität zu. Daraus folgt, daß eine Untersuchung der Prozesse auf den größeren Maßstabsbereichen nur sinnvoll interpretiert und verstanden werden kann, sofern die dahinterstehenden Bindungswirkungen auf der lokalen Maßstabsebene angemessen berücksichtigt werden. 190

189 Vgl. Weichhart, P., Raumbezogene Identität, a.a.o., s. 77. Vgl. dazu auch die empirischen Ergebnisse der vorliegenden Untersuchung in Kap. C.1.3.

190 Es konnte nachgewiesen werden, daß die Bedeutsamkeit eines bestimmten Maßstabsbereiches maßgeblich von den Inhalten der Identität abhängt. So unterscheidet beispielsweise eine geographische Forschergruppe in ihrer empirischen Untersuchung zwischen einem "Naturraum", "Siedlungsraum" und einem "Sozialraum" als möglichen Inhalten von Regionalbewußtsein. Dabei konnte nachgewiesen werden, daß die einzelnen Inhalte unterschiedliche Bezüge $z u$ den Maßstabsebenen aufweisen. So zeichnet sich beispielsweise der Sozialraum im Hessischen Ried durch eine stark lokale Ausprägung aus, während die naturräumlichen Gegebenheiten des Referenzraumes eine großräumige Abgrenzung bedeutsam erscheinen lassen. Vgl. Wolf, K., Otto, G., u.a., Das Hessische Ried. Name und Abgrenzung einer hessischen Landschaft im Regionalbewußtsein ihrer Bevölkerung, a.a.O., S. 587 ff.. 


\subsection{Horizontale systematisierung räumlicher Bezugsgrößen}

Die Systematisierung räumlicher Bezugsgrößen in eine Hierarchie ineinandergeschachtelter Maßstabsebenen stellt ein überwiegend quantitatives Kriterium dar, welches Raumausschnitte in Abhängigkeit ihrer flächenhaften Ausdehnung klassifiziert. Der qualitative Aspekt räumlicher Bezugsgrößen und damit die Frage, worauf sich der Einzelne bezieht, wenn er sich z.B. als Bewohner eines bestimmten stadtteils, als "Münsteraner", "Duisburger" oder "Rheinländer" oder als "Europäer" zu erkennen gibt, bleibt dabei zunächst unbeantwortet.191

Erste Ansatzpunkte zur Präzisierung des Begriffsverständnisses lassen sich der Geographie entnehmen. In der chorischen Raumvorstellung der Geographie wird Raum als etwas umfassendes betrachtet, in dem unterschiedliche Inhalte einbezogen sind.192 Damit wird im wesentlichen auf die im alltäglichen sprachgebrauch gängige Auffassung von Raum als einem Stück Land mit festen Grenzen verwiesen. Dieses Landstück gehört jemandem als Eigentum oder es untersteht einer Behörde als Zuständigkeitsbereich. Die Reihe solcher Landstücke erstreckt sich von Grundstücken über Kommunen, Kreise, Provinzen und andere Gebietskörperschaften bis hin zum souveränen Staat und zur UN-Organisation.193 Diese Raumvorstellung wird vereinzelt mit einem Behälter 194

191 zur systematisierung möglicher Inhalte räumlicher Identität vgl. Kap. B2.4.

192 Vgl. Bartels, D., Schwierigkeiten mit dem Raumbegriff in der Geographie, in: Geographica Helvetica 1974, Beiheft zu Nr. $2 / 3$, s. 9 ff..

193 Vgl. Ritter, W., Allgemeine Wirtschaftsgeographie. Eine systemtheoretisch orientierte Einführung, München 1991, S. 11 .

194 Vgl. Bartels, D., Schwierigkeiten mit dem Raumbegriff in der Geographie, a.a.0., S. $13 \mathrm{f}$. 
verglichen, der nahezu beliebig mit unterschiedlichen Dingen wie beispielsweise Bergen, Flüssen, Siedlungen, politischen Grenzen, rechtlichen Geltungsbereichen oder sogar sozialen und psychischen Phänomenen (z.B. Regionalbewußtsein) usw. angefüllt ist.

Wenn diese Raumvorstellung als Denkmuster aufgegriffen wird, ist auf jeder einzelnen räumlichen Maßstabsebene grundsätzlich zwischen drei komponenten räumlicher Bezugsgrößen zu unterscheiden:

- Jede räumliche Bezugsgröße basiert auf einem bestimmten Areal, welches als physische Bezugsbasis einem bestimmten flächenhaften Ausschnitt auf der Erdoberfläche entspricht. Mit dem Areal verbundene objekte wie z.B. landschaftliche und bauliche Gegebenheiten stellen gleichermaßen die materielle Basis z.B. einer Stadt oder Region dar. 195

- Darüber hinaus läßt sich ein Raum als komplexes soziales system (Sozialgebilde) auffassen, welches eine Vielzahl von Funktionen und Aktivitäten ausübt.196

- Eine weitere Kategorie räumlicher Bezugsgrößen stellen symbole dar.197 symbole zeichnen sich dadurch aus, die

195 Die flächenhafte Ausdehnung des Areals stellt gleichzeitig das Kriterium zur Aufteilung des Raumes in einen Mikro- Meso- und Makromaßstab dar.

196 Der räumlichen Maßstabsebene "Wohnung" läßt sich beispielsweise das Sozialsystem "Familie", dem Wohnviertel das Sozialgebilde "Nachbarschaft” zuordnen. Demgegenüber repräsentieren z.B. "die Deutschen", "die Europäer" oder die "Amerikaner", auf der Makroebene das "Volk".

197 Vereinzelt wird vermutet, daß bereits die Kenntnis von Ortssymbolen z.B. bei den Bewohnern einer Stadt Identifikation zur Folge hat. Es entsteht ein ortsbezogenes "Wir-Bewußtsein", das aus den gemeinsamen Handlungssituationen erwächst. Vgl. Ruhl, G., Das Image 
Vielschichtigkeit raumbezogener Wahrnehmungs- und Erlebnismöglichkeiten „zusammenzufassen”.198 Dem Namen der betreffenden räumlichen Bezugsgröße kommt in diesem Zusammenhang eine herausragende Funktion zu.199 Grundsätzlich lassen sich mit dem Ortsnamen zwei Bedeutungsinhalte symbolisieren: Einerseits ruft der Name eine Vorstellung vom Raum als Ganzheit hervor. Andererseits repräsentiert der Ortsname spezifische Attribute innerhalb des betreffenden Raumes (physische Merkmale, Funktionen/Aktivitäten, bestimmte Personen oder atmosphärische Qualitäten, Gerüche usw.).200 Insgesamt betrach-

von München als Faktor für den zuzug, in: Münchener Geographische Hefte Nr. 35, Kallmünz/Regensburg 1971, S. 34 .

198 "Often we have only to mention the name of major city, San Francisco, London, Jerusalem, and a particular scene will be brought to mind." Vgl. Canter, D., The psychology of place, New York 1977, S. 123. Insbesondere städten wird ein breites spektrum verschiedener Namen zugewiesen. Diese Bezeichnungen symbolisieren häufig bestimmte (Fehl)entwicklungen oder Stadtvisionen: Metropolis, Megalopolis, Profitopolis, FuturopoI is, Ökoopolis, Heliopolis, Allergolopolis, "High Crime". Es gibt die Gartenstadt, Parkstadt, Trabantenstadt, Satellitenstadt, Stahlstadt, Atomstadt usw.. Vgl. Glaser, H., Die Kulturstat und die Zukunft der Industriegesellschaft, wien 1991, s. $30 \mathrm{f}$.

199 Zur Symbolisierungsfunktion des ortsnamens vgl. beispielsweise Treinen, H., symbolische Ortsbezogenheit, a.a.0.; Hunter, A., Symbolic communities, a.a.o., s. 67. Der Name einer Region bzw. das Wissen um den Namen einer Region wird als Indiz für eine deutliche Ausprägung von Regionalbewußtsein angesehen. Vgl. Wolf, K., u.a., Das Hessische Ried, a.a.0., S. 593. Die Existenz eines Orts- bzw. Raumnamens stellt darüber hinaus eine wichtige Voraussetzung für die Verbreitung, Steuerung und Manipulation "regionaler Identität" im Rahmen eines "Identitätsmanagements" dar. Vgl. Kerscher, U., Raumabstraktionen und regionale Identität, a.a.o., s. 12.

200 Vgl. Ashworth, G.J., Voogd, H., Selling the city, London, New York 1990, S. 66. 
tet, prägt der Name in entscheidendem Maße die Identität einer Stadt oder Region. 201

Weitere wichtige symbole sind beispielsweise prägnante Landschafts- oder Architekturzeichen sowie verbale Zeichen (z.B. Slogans). 202

Die in der Abbildung 9 dargestellten Komponenten räumlicher Bezugsgrößen unterscheiden sich hinsichtlich ihrer inhaltlichen Reichweite. Wenn die Abbildung von oben nach unten gelesen wird, strahlt die symbolische Ebene sowohl auf das Sozialgebilde als auch auf das Areal ab. Damit soll zum Ausdruck gebracht werden, daß z.B. dem Ortsnamen "Münster", dem Autokennzeichen "MS" oder bestimmten Gebäuden und Wahrzeichen (z.B. Dom, Lambertikirche, Prinzipalmarkt, „Kiepenkerl“) nicht nur eine Kennzeichnungs-, sondern auch eine symbolfunktion zukommt, indem bestimmte Vorstellungen, Images, Vorurteile, Stereotypen usw. uiber das Sozialgebilde "Stadt Münster" abgerufen werden.203

201 Vgl. Antonoff, R., Corporate Identity für städte, in: Arbeitsgemeinschaft des Symposiums "Stadtvisionen", v. 2./3. März 1989 in Münster, S. 1 .

202 Aus dem breiten inhaltlichen spektrum räumlicher symbole lassen sich exemplarisch aufzählen: Gebäude und bauliche Wahrzeichen (Kirchen, Schlösser, Brücken, Türme usw.), regionalspezifische Gegenstände des täglichen Gebrauchs, ortstypische Getränke und Speisen, landschaftliche Besonderheiten (Flüsse, Berge, spezifische Vegetationsformen usw.), lokalhistorische Begebenheiten, Persönlichkeiten und Mythen (z.B. Tünnes und Schäl, Till Eulenspiegel), bestimmte Verhaltensweisen bzw. Charaktereigenschaften (Wiener Charme usw.). Ein sehr wichtiges symbol stellt die sprache dar. Weitere Symbole: "In-Lokale", Lokale/regionale Institutionen und Ereignisse wie Festspiele, Sportveranstaltungen oder Festlichkeiten, Lokale Vereine, Institutionen, Bürgerinitiativen, Stadtteil- und StraBenfeste usw.. Vgl. Weichhart, P., Raumbezogene Identität, a.a.0., s. 71 .

203 So ruft bereits der Verweis auf den Namen einer bestimmten stadt oder Region beim Kommunikationspartner ganz bestimmte denotative und konnotative Bedeutungs- 
Gleichermaßen ruft die Konfrontation mit einem Raum-Symbol eine Vorstellung über die ungefähre Lage der stadt hervor.

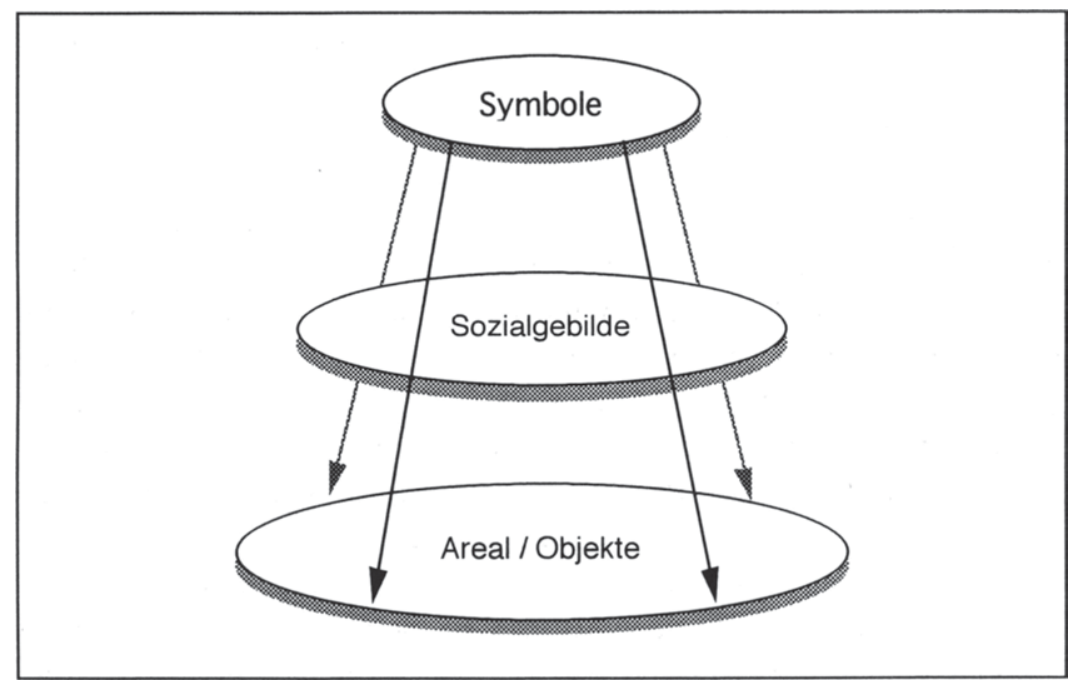

Abb. 9: Systematisierung der Komponenten räumlicher Bezugsgrößen

Damit eine stadt oder Region von innen und außen als eigenständiges Sozialgebilde identifiziert werden kann, das sich von anderen Sozialgebilden unterscheidet (Prinzip von Einheit und Differenz), müssen die Bewohner ein Mindestmaß an sozialer Integration aufweisen. Das Zusammenwachsen eines Konglomerates von Menschen zu einer "Stadt“ oder "Region" setzt deshalb Gemeinsamkeiten voraus, welche die Mitglieder miteinander verbindet. Im ubertragenen sinne ist die suche nach diesen Gemeinsamkeiten gleichbedeutend mit der Frage nach dem "Klebstoff", welcher ein Sozialgebilde zu einen „wir" zusammenwachsen läßt und gleichzeitig die Grenze zu allen übrigen Personenkreisen markiert ( "sie").

zuschreibungen hervor. Vgl. Weichhart, P., Raumbezogene Identität, a.a.0., s. 48 . 
Die Abgrenzung einer räumlichen Bezugsgröße ist eindeutig möglich, sofern sich das Sozialgebilde präzise innerhalb räumlich definierter Grenzen fixieren läßt. In diesem Fall existiert ein räumlich abgrenzbares sozialsystem, welches durch eine Binnenorientierung sozialer Interaktionen und Netzwerke gekennzeichnet ist, und gleichsam als primärgruppe das Bezugsobjekt räumlicher Identität darstellt. 204 Dieses Ideal einer gleichsam "organisch-ganzheitlichen" oder "natürlichen" sozialräumlichen Einheit wird in der klassischen Gemeindesoziologie mit dem Begriff der Gemeinde205 verbunden, und findet sich im amerikanischen Sprachraum in Begriffen und Konzepten wie community oder natural area206 wider. Es handelt sich hierbei uberein-

204 Primärgruppen sind Gruppen im engeren Sinne. Wenn das Wort Gruppe ohne weitere Zusätze gebraucht wird, ist im allgemeinen die Primärgruppe gemeint. Man versteht darunter kleine und informelle Gruppen, in denen die Mitglieder in persönliche (face-to-face) Interaktion treten. Sie haben relativ häufig engen und emotional fundierten Kontakt sowie ein ausgeprägtes Wir-Gefühl. Vgl. Kroeber-Riel, W., Konsumentenverhalten, a.a.0., S. 450 .

205 Vgl. König, R., Grundformen der Gesellschaft: Die Gemeinde, Hamburg 1958.

206 Unter "natural area" verstand man in der klassischen Sozialökologie kleine, mehr oder weniger deutlich in sich geschlossene soziale Welten, z.B. relativ kleine Subgebiete einer stadt mit homogener Bevölkerung, die nicht bewußt als solche wahrgenommen worden waren. Die in diesen Gebieten lebenden Bewohner zeichneten sich durch die Ähnlichkeit ihrer Verhaltensmuster und folglich durch die Gemeinsamkeit von Verhaltenserwartungen, aus gemeinsamen Institutionen wie Nachbarschaft, Schule, Verkehrskreis, Versorgungseinrichtungen, Vereinen etc., aber auch aus der Gemeinsamkeit der räumlichen orientierung an Symbolen und der jeweils spezifischen sprache und den Begriffen, mit denen diese Symbole belegt werden. Begrenzt wurden sie durch natürliche - topographische Niveauunterschiede, Flussläufe etc. - oder künstliche Hindernisse - etwa zum Beispiel Durchfahrtsstraßen - die sich sozial als Kommunikationsschranken und wahrnehmbare symbole auswirkten. Vgl. Hamm, B., Die Organisation der städtischen Umwelt, Frauenfeld, Stuttgart 1977, S. 223. 
stimmend um kleine räumliche Einheiten, welche meist durch „den bloßen Augenschein" erfaßt werden können.207

Die klassische, überwiegend auf Klein- und Kleinsträume bezogene Idee vom Raum als organische Einheit ist vereinzelt auch auf der Ebene größerer Maßstabsbereiche diskutiert worden. So wird beispielsweise seitens der Geographie die Frage aufgeworfen, ob Regionen objektiv abgegrenzt werden können.208 Die "Region als Individuum", in welchem ihr "Totalcharakter zum Ausdruck kommt", die "Eigenart und Selbständigkeit" einer Region und ein "in seinem Charakter als Region zu erkennende[r] Raum", der begrenzt wird durch "eine neue, anders geprägte Raumindividualität”, die sich als nachbarliche Region zu erkennen gibt, 209 lassen sich als typische Formulierungen in diesem Kontext anführen.

Diese durch die interaktive Vernetzung der Gruppenmitglieder über face-to-face Kontakte entstehende Gruppenkohärenz

$207 \mathrm{Vgl}$. Linde, H., Sachdominanz in Sozialstrukturen, Tübingen 1972 , S. 25.

208 In einigen wenigen Einzelbeispielen konnte die Existenz derartiger ortsbezogener Gemeinschaften empirisch nachgewiesen werden. Es wird jedoch nicht ernsthaft bezweifelt, daß die Verkehrskreise der Bevölkerung und das räumliche Muster ihrer sozialen Interaktionen sowie der Versorgungs-, Konsum- und Freizeitaktivitäten keineswegs innerhalb der Grenzen eines bestimmten Areals verläuft. Somit muß die Existenz einer Primärgruppe als Bezugsgröße räumlicher Identität bereits auf Ebene der kleinen Gemeinde, Nachbarschaft, oder dem Stadtviertel bestenfalls als „utopisches Konzept" betrachtet werden. Vgl. Weichhart, P., Raumbezogene Identität, a.a.0., s. $56 f$.

$209 \mathrm{Vgl}$. Boesch, M., Engagierte Geographie, Stuttgart 1989, S. 65. In diesem Punkt werden Parallelen zur betriebswirtschaftlichen Diskussion uber Unternehmensidentität und Corporate Identity (CI) deutlich. Auch dort wird der Frage nachgegangen, ob es zulässig ist, Unternehmen einen Individualcharakter oder eine Identität zuzuweisen. Vgl. Kap. C2.21. 
läßt sich selbst auf einer kleinräumigen Maßstabsebene empirisch nicht nachweisen.210 In der wissenschaftlichen Diskussion besteht deshalb Konsens darüber, daß die Vorstellung von einer "wahren Region" oder einer "Universalregion" im Sinne einer natürlich vorgegebenen, organischen Einheit kein angemessenes Bild zur Beschreibung der Wirklichkeit darstellt. 211

Vor diesem Hintergrund muß die Kongruenz von Sozialgebilde und Areal als empirisch nachweisbares Phänomen aufgegeben werden. Trotzdem besteht kein Zweifel darüber, daß ein lockerer aber durchaus effizienter Gruppenzusammenhalt auf der Basis räumlich-sozialer Bezugseinheiten wie des Stadtviertels, der Gesamtstadt, größerer Regionen oder sogar nationaler Gebilde und Staaten im Bewußtsein der Angehörigen solcher Einheiten belegt werden kann.212 Es liegt somit die paradoxe situation vor, daß eine Gruppenbindung besteht, ohne daß gleichzeitig eine als Bezugsobjekt wirk-

$210 \mathrm{Vgl}$. Weichhart, P., Raumbezogene Identität, a.a.0., s. 67. Wichtige Ursache für die mangelnde Kongruenz sozialer und räumlicher (i.s.v. physischer) strukturen sind grenzüberschreitende Beziehungen: "Ungezählte Menschen wohnen heute in einer Gemeinde $A$, arbeiten in $B$, decken ihren Bedarf an waren in den Gemeinden $A$ und $B$ sowie C, wo ihre Kinder die weiterführende Schule besuchen, während sich ihr persönlicher Verkehrskreis (vermittelt etwa durch den Wassersportclub in C) auch noch auf die Gemeinden D, E und F erstreckt."Vgl. Linde, H., Sachdominanz in Sozialstrukturen, a.a.o., S. $24 \mathrm{f}$.

211 Aus Sicht der Geographie sind derartige Auffassungen "eine Fiktion, für die praxis belanglos, als wissenschaftliche Fragestellung (zumindest in empirischen Kontexten) untauglich, und damit auch als Begriff der Objektsprache überflüssig."Vgl. Boesch, M., Engagierte Geographie, a.a.0., s. 64 .

$212 \mathrm{Vgl}$. Weichhart, s. Raumbezogene Identität, a.a.o., s. 67 . 
same soziale (Primär-)gruppe tatsächlich nachweisbar ist. 213

Dieser Widerspruch läßt sich auflösen, indem städte und Regionen als symbolische Gruppen oder symbolische Gemeinschaften aufgefaßt werden. 214 Die Bindung an die Stadt oder Region kommt zustande, indem die Mitglieder die symbolisch übermittelten Werte und Normen des betreffenden Sozialsystems internalisieren. Je ganzheitlicher, positiver und einheitlicher die werte und Normen geteilt werden, desto mehr kommt ein zusammenhalt zustande, d.h. es entsteht ein räumliches Verbundenheits- und Zugehörigkeitsgefühl. In diesem Zusammenhang ist es unerheblich, ob ein weitreichender Interaktionszusammenhang unter den Mitgliedern existiert oder nicht. Es ist sogar möglich, daß sich die Werte und Normen gewissermaßen "verselbständigt" haben, und das betreffende sozialgebilde gar nicht (mehr) existiert. 215

$213 \mathrm{Vgl}$. Weichhart, s. Raumbezogene Identität, a.a.o., s. 70

214 Am Beispiel ethnischer Gruppierungen kann gezeigt werden, daß es zwei unterschiedliche Wirkungszusammenhänge gibt, welche zu einer Einbindung des Individuums in eine bestimmte ethnische Gruppierung führen können. Die eine Möglichkeit besteht darin, durch die interaktive Vernetzung und durch aktive Teilnahme am Gruppenleben eine Kohäsionswirkung herbeizuführen. Ethnische Identität kann darüber hinaus dadurch entstehen, daß sich das Individuum die spezifischen Wertvorstellungen und symbole des betreffenden Sozialsystems zu eigen macht. Vgl. Weichhart, P., Raumbezogene Identität, a.a.o., s. $68 \mathrm{f}$.

215 vgl. Weichhart, P., Raumbezogene Identität, a.a.o., s. 69. Im Grenzfall ist räumliche Identität eine Chimäre oder eine "Phantom-Identität", was jedoch nicht ausschließt, daß einem solchen Sozialgebilde gegenüber heftige und loyale Zugehörigkeitsgefühle empfunden werden können. Vgl. Hard, G., "Bewusstseinsräume”, a.a.O., s. 140 . 
Die Zugriffsmöglichkeit auf die Werte und Normen beantwortet die Frage nach der Grenze zwischen "innen" und "außen"216: Räumliche Identität muß in diesem Zusammenhang als spielart einer räumlich konstituierten Gruppenidentität aufgefaßt werden, indem die Mitglieder die Möglichkeit haben, auf ein "Wir" Bezug nehmen zu können. Dies deutet gleichermaßen an, in welchem Sinne räumliche Identität die Funktion der Abgrenzung beinhaltet: Wer nicht an diesem Wissen teilhat, bzw. die zentralen Normen und Werte nicht mitträgt, der ist "anders" und kann sich nicht mit dem "Wir" als Gruppenmitglied ausgeben. 217

\subsection{Abgrenzung räumlicher Bezugsgrößen als Grundlage für die Gestaltung räumlicher Identität}

Räumliche Bezugsgrößen sind nicht allein aus der Individualsicht bedeutsam. So setzt die Planung und Umsetzung eines SRM-Konzeptes eine Übereinkunft der verantwortlichen Entscheidungsträger uber die Abgrenzung des Areals voraus, auf das sich die Programme beziehen sollen. Diese Frage ist besonders im Vorfeld eines Regionenmarketingkonzepts von großer Bedeutung. Häufig werden verschiedene selbständige Teilräume - z.B. Städte und Kreise - zum Zwecke gemeinsamer Marketingbemühungen in eine $\mathrm{Zweckregion} \mathrm{zusam-}$ mengefaßt. 218 Dabei ist zu klären, ob die aus der Kooperation verschiedener Entscheidungsträger entstandene "neue" Region nach Maßgabe administrativer Grenzen oder auf Basis

216 Vgl. dazu noch einmal Abbildung 8.

$217 \mathrm{Vgl}$. Weber, J., Unternehmensidentität und unternehmenspolitische Rahmenplanung, a.a.0., S. 125.

218 So wurden z.B. zur Erarbeitung eines Marketingkonzepts "Regionenmarketing Münsterland" die Kreise Borken, Coesfeld, Steinfurt, Warendorf sowie die Stadt Münster zur Region Münsterland zusammengefaßt. 
anderer kriterien (z.B. traditioneller oder landmannschaftlicher Grenzen) gebildet werden soll.219

Häufig ist eine pragmatische Vorgehensweise unumgänglich. Dies setzt voraus, die jeweilige Einheitlichkeit und Ganzheit einer räumlichen Bezugsgröße nicht auf Grundlage objektiv vorgegebener Merkmale zu betrachten. Es ist vielmehr erforderlich, spezifische klassifikationskriterien zu formulieren, anhand der die Abgrenzung vorgenommen wird. Ansatzpunkte $z$ u dieser Vorgehensweise lassen sich der Raumplanung entnehmen, die zwischen deskriptiven und normativen Regionen unterscheidet: 220

Während deskriptive Regionen221 als Ergebnis einer Regionsabgrenzung auf der Grundlage eines oder mehrerer beschreibender Merkmale (z.B. Höhe über Meeresspiegel) aufzufassen sind, sind normative Regionen funktionale Einheiten, für die durch politische Willensäußerungen für die

219 Für die Abgrenzung sollte eine möglichst hohe übereinstimmung zwischen Areal und Sozialgebilde angestrebt werden. Akzeptanzprobleme des SRM sind wahrscheinlich, wenn beispielsweise tradierte Regionsabgrenzungen durchschnitten werden.

220 Vgl. Gehrig, R., Leibundgut, H., Grundlagen zur Abgrenzung und Typisierung von Planungsregionen, Zürich 1971 , S. 3 ff..

221 Die deskriptive Region läßt sich in eine Strukturregion und in eine funktionale Region unterteilen: Eine Strukturregion ist dadurch gekennzeichnet, daß ihre Teilelemente sich in bestimmten Strukturmerkmalen ähnlich sind. Hauptcharakteristikum dieser Abgrenzung ist die einheitliche Problemlage in einem zusammenhängendem Raum. Dabei handelt es sich meist um unausgewogene Räume bzw. um die Dominanz eines einzelnen Wirtschaftssektors. Funktionale Regionen ("Nodalregionen") werden dergestalt abgegrenzt, daß ihre Orte im Hinblick auf eine oder mehrere Austauschbeziehungen enger als mit anderen Orten verknüpft sind. Vgl. Landwehr, R., Die Gliederung des Raumes; Typisierung, Regionsabgrenzung und Regionierung, Beiträge zum Siedlungs- und Wohnungswesen und zur Raumplanung, Bd.22, Ernst, W., Thoss, R., (Hrsg.), Münster 1975, S. 56-66. 
ganze Region relevante Maßnahmen getroffen bzw. koordiniert werden. Normative Regionen sind explizit auf das spezifische Bezugsgebiet und die hier ablaufenden oder vorgesehenen Prozesse abgestimmt. Der Gestaltungswille und die Ziele der Planungsträger bestimmen Umfang und struktur der Region.

Regionen lassen sich demgemäß als Gestaltungseinheiten auffassen, die es nicht von Natur aus gibt. Sie stützen sich auf bestimmte Areale, jedoch ist die zielsetzung und der Gestaltungswille der Entscheidungsträger gegenüber dem Bestehenden das entscheidende Charakteristikum. Regionen sind - objektiv - als organisch gewachsene Ganzheiten unvollkommen, streben aber - subjektiv - eine gewisse regionale Identität an. 222

Mit Blick auf die Gestaltung räumlicher Identität bietet es sich vor dem Hintergrund der raumplanerischen Ansätze zur Regionsabgrenzung an, städte und Regionen generell als Gestaltungseinheiten aufzufassen, welche nach Maßgabe von Entscheidungen als Basis für ein SRM-Konzept gebildet werden.

\subsection{Inhalte räumlicher Identität}

Räumliche Identität ist nicht auf Flächen und physische Grenzen, "sondern gemeinhin auf Inhaltliches, vor allem auf inhaltliche Besonderheiten" 223 bezogen. Die beispielsweise einer stadt oder Region gegenüber bekundete Zugehörigkeit (oder Aversion) ist auf symbole oder auf einen

222 Vgl. Schuler, M, Ein Verfahrensvorschlag zur Messung der regionalen Identität, Georgi 1981, S. 33 ff., zit. in Boesch, M., Engagierte Geographie, a.a.0., S. 6, FN 49.

223 Hard, G., "Bewußtseinsräume", a.a.o., s. 139. 
"räumlichen Kode" ausgerichtet, welcher auf Sachverhalte verweist, die z.B. mit dem Raumnamen assoziiert werden.

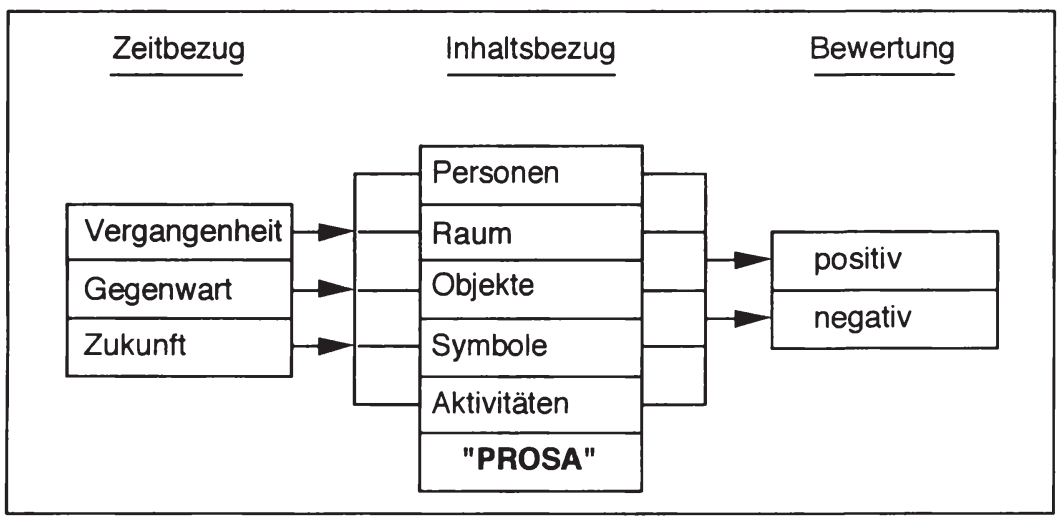

Abb.10: Inhalte räumlicher Identität

In der Abbildung 10 wird zur systematisierung möglicher Inhalte eine Dreiteilung zugrunde gelegt, indem zwischen dem zeit- und Inhaltsbezug räumlicher Identität unterschieden wird. Darüber hinaus kann räumliche Identität positiv oder negativ ausgeprägt sein. Wenn ein Raumausschnitt von einer Mehrzahl von Menschen positiv bewertet wird, läßt sich von einem Emblem sprechen, welches die Identitätsträger ausgewählt haben, um sich anderen gegenüber darzustellen und sich von ihnen zu unterscheiden. 224 Die negative Bewertung wird als stigma bezeichnet.225 Das Stigma beinhaltet die Abwertung oder bewußte Negierung eines Raumes (z.B. das beharrliche Festhalten am "Kohlenpott"-Klischee). Das Stigma wird meist von Auswärtigen geschaffen und ist häufig bestimmender als das Emblem. Zahlreiche Praxisbeispiele verdeutlichen, daß ein

$224 \mathrm{Vgl}$. Bassand, M., Hainard, F. Regionale sozio-kulturelle Dynamik, Bern, Stuttgart 1985, S. 103.

$225 \mathrm{Vgl}$. Bassand, M., Hainard, F. Regionale sozio-kulturelle Dynamik, a.a.0., s. 103. 
Stigma, zumindest aber ein Verkennen der Qualitäten eines Raumes häufig zur Initiierung des SRM Anlaß gibt.

Beim Zeitbezug läßt sich grundsätzlich zwischen einem Vergangenheits-, Gegenwart- und einem Zukunftsbezug unterscheiden.226 Damit wird zum Ausdruck gebracht, daß die Identifizierung von und die Identifikation mit einem lokalen, regionalen, überregionalen, nationalen oder übernationalen Rahmen zwar relativ zeitunabhängig, aber in bestimmten zeit-, Geschehens- oder Erlebnisabschnitten verankert erfolgt 227 :

- Vergangenheitsbezug:

Dieser auch als „historische oder ererbte Identität“ bezeichnete Identitätsinhalt ist auf vergangenen Ereignissen aufgebaut, die für ein Sozialgebilde wichtig waren oder basiert auf einem spezifischen kulturellen, naturräumlichen oder sozio-ökonomischen Erbe.

\section{- zukunftsbezug:}

Diese "projektive Identität" ist mehr oder weniger stark auf eine Vorstellung von der zukunft der stadt oder Region hin ausgerichtet. So kommt beispielsweise in der Formulierung von Leitbildern, Stadtvisionen oder langjährigen stadt- und Regionentwicklungsplänen der Zukunftsentwurf einer wünschenswerten Identität des Referenzraumes zum Ausdruck.

226 Zur Differenzierung räumlicher bzw. regionaler Identität nach dem Zeitbezug vgl. Bassand, M., Hainard, F. Regionale sozio-kulturelle Dynamik, a.a.o., S. 103., Hettlage, R., Regionalkultur ohne Region: Zur Bedeutung regionaler Identitäten in der Schweiz, in: Lipp, W. (Hrsg.), Industriegesellschaft und Regionalkultur, Köln u.a. 1984, S. 209.; Meier-Dallach, H.-P., Regionalbewußtsein und Empirie. Der quantitative, qualitative und typologische Weg, in: Berichte zur deutschen Landeskunde, Bd. 61, H.1, 1987, S. 10 .

227 Vgl. Meier-Dallach, H.-P., Räumliche Identität, a.a.0., s. 303 . 


\section{- Gegenwartsbezug:}

Insbesondere für die Bewohner einer stadt oder Region kommt der gelebten Identität eine Schlüsselrolle zu, welche als spiegel des alltäglichen Lebens die gegenwärtig in der Region vorherrschende Lebensweise ausdrückt.

Dieser Inhaltsbezug räumlicher Identität läßt sich auf Grundlage eines „PROSA-Schemas“ detailliert systematisieren, indem mit Personen, dem Raum, objekten, symbolen und Aktivitäten einige grundsätzlich zu unterscheidende Kategorien möglicher Inhalte räumlicher Identität einander gegenübergestellt werden. 228

So bringt räumliche Identität beispielsweise die Zugehörigkeitserfahrung zu Personen bzw. sozialen Gruppierungen (z.B. Familien- und Bekanntenkreis, Schicht- und Gruppenzugehörigkeit) zum Ausdruck.229 oder aber räumliche Identität spiegelt die Bindung an gesellschaftliche Institutionen und organisationen ("institutionelle Identität“) wider. Dazu gehören beispielsweise "freiwillige Bindungen" wie die Kirche, Parteien, Heimatvereine usw.230

Möglicherweise fungiert der Raum selbst als "Klebstoff“, indem er die Entstehung räumlicher Bindungen beeinflußt. So vermuten einige Autoren, daß bereits durch Kontextualisierung eine raumbezogene Gruppenbindung entstehen könne,

228 Vgl. Pieper, R., Die neue Sozialphysik, Frankfurt 1985, S. 125.

229 Vgl. Hettlage, R., Regionalkultur ohne Region, a.a.o., S. 209.; Schmied, W., Ortsverbundenheit - eine Triebkraft für die Entwicklung ländlicher Räume?, a.a.0., S. 138.; Treinen, H., Symbolische Ortsbezogenheit, a.a.0., S. 238 .

$230 \mathrm{Vgl}$. Hettlage, R., Regionalkultur ohne Region, a.a.o., S. 209.; Meier-Dallach, H.-P., Räumliche Identität, a.a.0., s. 303 . 
indem eine Gruppe von Menschen beispielsweise in ein und derselben stadt wohnt und auf diese weise uiber eine gemeinsame Basis ortsspezifischer Informationen verfüge, die eine Art unbewußter Solidarität hervorrufe.231 Die Relevanz des physischen Raumes als Auslöser räumlicher Identität wird insgesamt jedoch eher als gering eingestuft. 232

In engem zusammenhang mit dem Raum als Katalysator zur Herausbildung räumlicher Identität sind objekte $z u$ betrachten, welche mit dem Raum entweder fest verbunden sind (z.B. landschaftliche Besonderheiten, Bauwerke usw.) oder auf assoziativem Wege in Beziehung gebracht werden. So tragen beispielsweise regionale Produkte zur Entstehung eines „Wir-Bewußtseins" bei.

Eine besondere Bedeutung zur Herausbildung räumlicher Identität kommt symbolen $z u$. So erlangt ein Raum insbesondere dann Identität, wenn eindeutige kulturelle Unterschiede z.B. zwischen einer Region und ihrer Umwelt existieren. 233 Die Kultur wird dabei durch eine vielzahl unterschiedlicher symbole repräsentiert: Die Sprache (z.B. ein ortsspezifischer Dialekt), ortstypische Sitten und Gebräuche, Eßgewohnheiten, usw. stellen einige Beispiele für Konkretisierung von Kultur dar. Schließlich lassen sich Aktivitäten als eine weitere Kategorie möglicher Katalysatoren räumlicher Identität auffassen.

$231 \mathrm{Vgl}$. Weichhart, P. Raumbezogene Identität, a.a.o., s. 52 ff..

232 Vgl. Pohl, J., Regionalbewußtsein im Friaul, a.a.o..

233 "Von Regionalkultur soll dann gesprochen werden, wenn sich habituell verfestigte Orientierungen des Denkens, Fühlens und Handelns im geschichtlichen Prozeß regionalspezifisch so verdichtet haben, daß zwischen einer Region und ihrer Umwelt eindeutige kulturelle Unterschiede existieren, wie schwierig es auch immer sein mag, sie empirisch exakt zu erfassen."Vgl. Rohe, K., Regionalkultur, regionale Identität und Regionalismus im Ruhrgebiet, a.a.0., s. 123. 
Die verschiedenen Kategorien des Zeit- und Inhaltsbezuges sind nicht in jedem Fall überschneidungsfrei. Dies wird am Beispiel der Kultur als wichtiger Repräsentant der symbolischen Ebene zu. So ist Kultur einerseits eine geschichtliche Tatsache, welche wesentliches Element der historischen Identität darstellt. Andrerseits werden durch die Kultur "künstliche" Festlegungen vorgenommen, welche das alltägliche Leben der Bewohner programmieren und regulieren. Insofern ist die historische Identität wesentliche Voraussetzung für die "gelebte Identität".

3 .

Ansatzpunkte zur Operationalisierung räumlicher Identität

3.1 Methodische Prämissen für die Operationalisierung räumlicher Identität

Ein Meßkonzept zur Erklärung räumlicher Identität kann nicht losgelöst von der theoretischen Fundierung des Identitätsbegriffes betrachtet werden. Ausgehend von der Zweiseitigkeit des Begriffsverständnisses räumlicher Identität ist festzulegen, ob sie als oberflächenphänomen oder als Tiefenphänomen betrachtet wird. Identität als oberflächenphänomen ist als intersubjektiv nachprüfbares und meßbares Konstrukt grundsätzlich mit den gängigen Methoden der empirischen Sozialforschung abfragbar. In der zweiten Sichtweise ist räumliche Identität der unmittelbaren Beobachtung und überprüfung nicht zugänglich, da sie durch das Alltagshandeln und -erleben bestimmt wird, und dem Einzelnen kaum oder gar nicht bewußt ist. 234

234 Wenn räumliche Identität als Tiefenphänomen aufgefaßt wird, bedarf es eines fühlbaren Anlasses für den Einzelnen, sein Verhältnis zum Raum zu reflektieren. Erst auf diese Weise gelangt der Bewußtseinsinhalt räumlicher Identität gewissermaßen an die oberfläche. Ge- 
Dies ist insofern von zentraler Bedeutung für die Untersuchung räumlicher Identität, weil damit gleichzeitig eine Vorentscheidung über die methodische vorgehensweise getroffen wird:

In einem Verständnis räumlicher Identität als oberflächenphänomen wird der Referenzraum mit der Einstellung eines externen Beobachters wahrgenommen. Räumliche Identität ist in diesem Verständnis durch ein wissen gekennzeichnet, daß dem Betreffenden selbst zwar nicht in jedem Augenblick präsent ist, welches aber grundsätzlich als „abfragbar" gilt. Dieses Wissen über Oberflächenstrukturen ist sowohl Bewohnern, Entscheidern, als auch Auswärtigen grundsätzlich zugänglich. Wird demgegenüber räumliche Identität als Tiefenphänomen konzipiert, ist eine induktive Forschungsmethodik erforderlich, welche auf Intuition und Interpretation begründet ist.

Abbildung 11 faßt die verschiedenen wissenschaftlichen Grundannahmen, welche mit einem positivistischen und einem funktionalistischem Forschungsparadigma grundsätzlich verknüpft sind, zusammen. In diesem zusammenhang läßt sich ein Verständnis räumlicher Identität als oberflächenphänomen grundsätzlich dem funktionalistischen Paradigma zuordnen. Räumliche Identität als Tiefenphänomen basiert demgegenuiber auf dem interpretativen Paradigma.

Räumliche Identität als oberflächenphänomen ermöglicht die Anwendung des gängigen methodischen Instrumentariums der empirischen Sozialforschung (z.B. Befragungen). Dieses in der Betriebswirtschaftslehre und speziell in der Marketingwissenschaft besonders häufig unterstellte sogenannte funktionalistische Paradigma geht von der Prämisse

plante Maßnahmen im Bereich sogenannter "Sperriger Infrastruktur" aber auch Veränderungen in der privaten Lebenssituation (z.B. ein bevorstehender Umzug) können als Auslöser für die Bewußtwerdung räumlicher Identität bedeutsam werden. 
aus, daß Forscher und Forschungsgegenstand unabhängig voneinander sind. Dem funktionalistischen Paradigma liegt eine Wirklichkeitsauffassung zugrunde, welche durch die Vorstellung eines Kausalzusammenhanges zwischen Größen geprägt ist. Auf diese Weise ist es überhaupt erst möglich, ein Variablendenken im Sinne von abhängigen und unabhängigen Größen theoretisch zu fundieren und empirisch zu überprüfen.

\begin{tabular}{|l|l|l|}
\hline \multicolumn{1}{|c|}{$\begin{array}{l}\text { Grundannahmen } \\
\text { über }\end{array}$} & $\begin{array}{l}\text { positivistisches } \\
\text { Paradigma }\end{array}$ & $\begin{array}{l}\text { naturalistisches } \\
\text { Paradigma }\end{array}$ \\
\hline $\begin{array}{l}\text { das Wesen der sozialen } \\
\text { Wirklichkeit }\end{array}$ & $\begin{array}{l}\text { Es gibt nur eine soziale } \\
\text { Wirklichkeit. Sie ist } \\
\text { objektiv vorgegeben und } \\
\text { in beliebiger Einteilung } \\
\text { analysierbar. }\end{array}$ & $\begin{array}{l}\text { Es gibt viele soziale } \\
\text { Wirklichkeiten. Sie sind } \\
\text { sozial konstruiert und nur } \\
\text { als Ganzheiten } \\
\text { verstehbar. }\end{array}$ \\
\hline $\begin{array}{l}\text { die Beziehung des } \\
\text { Forschers zu seinem }\end{array}$ & $\begin{array}{l}\text { Forscher und Forschungs- } \\
\text { gegenstand sind unab- } \\
\text { hängig voneinander }\end{array}$ & $\begin{array}{l}\text { Forscher und Forschungs- } \\
\text { gegenstand stehen in } \\
\text { Interaktion, sind untrenn- } \\
\text { bar. }\end{array}$ \\
\hline $\begin{array}{l}\text { die Möglichkeit kausaler } \\
\text { Beziehungen }\end{array}$ & $\begin{array}{l}\text { Es gibt realeUrsachen, } \\
\text { die ihrer Wirkung zeitlich } \\
\text { vorangehen oder gleich- } \\
\text { zeitig mit ihr auftreten. }\end{array}$ & $\begin{array}{l}\text { Alle Einheiten prägen sich } \\
\text { zu jedem Zeitpunkt } \\
\text { wechselseitig, so daß } \\
\text { Ursachen und Wirkungen } \\
\text { nicht unterscheidbar sind. }\end{array}$ \\
\hline $\begin{array}{l}\text { die Rolle von } \\
\text { Werten }\end{array}$ & $\begin{array}{l}\text { Wissenschaftliche } \\
\text { Forschung } \\
\text { ist wertfrei }\end{array}$ & $\begin{array}{l}\text { Forschung ist in } \\
\text { mehrfacher Hinsicht } \\
\text { wertgebunden. }\end{array}$ \\
\hline
\end{tabular}

Abb.11: Gegenüberstellung positivistischer und naturalistischer Grundannahmen

Quelle: nach Lincoln/Guba 1985, S. 37, zitiert nach: A. Kieser (Hrsg.) Organisationstheorien, Köln 1993, S. 280.

Im interpretativen Forschungsparadigma stehen Forscher und Forschungsgegenstand in Interaktion, und sind somit untrennbar miteinander verbunden. Die empirische Forschungsarbeit im Rahmen interpretativer Ansätze steht deshalb im deutlichen Gegensatz zu den am naturwissenschaftlichen Forschungsproze $\beta$ orientierten positivisti- 
schen Forschungsweisen. Verwendung finden generell Formen der qualitativen sozialforschung (z.B. hermeneutische Textinterpretationen, teilnehmende Beobachtung, qualitative Inhaltsanalyse usw.). Die Ausrichtung des Untersuchungsdesigns räumlicher Identität am interpretativen Forschungsparadigma ist sinnvoll, wenn räumliche Identität als ein durch den Alltag geprägtes, mehr oder weniger bewußt gewordenes Phänomen aufgefaßt wird. 235

In Abbildung 12 wird zusammenfassend ein Analyseraster räumlicher Identität aufgezeigt, welches einerseits zwischen oberflächen- oder Tiefenphänomenen und andererseits zwischen Innen- und Außenperspektive unterscheidet.236 Dabei wird die Interpretation räumlicher Identität als Tiefenphänomen ausschließlich Prozessen im Rahmen der Innenperspektive vorbehalten. Die Ausgrenzung der Außenperspektive ist damit $z u$ begründen, daß ein Auswärtiger bestenfalls rudimentär am "Tiefenwissen" des

235 Beide methodischen Vorgehensweisen führen möglicherweise $\mathrm{zu}$ unterschiedlichen Ergebnissen, wie sich am Beispiel von zwei Arbeiten aus der Regionalbewußtseinsforschung aufzeigen läßt: Esser, der eine deduktive Vorgehensweise wählt, fällt "die hohe Verbundenheit mit dem Ruhrgebiet bei den Einheimischen auf." Darüber hinaus konstatiert er eine stetige Abnahme der Verbundenheit beim übergang zu kleinräumigeren Einheiten als Identifikationsobjekten. Aring, Butzin u.a., legen 2 Jahre später eine Untersuchung vor, in der gleichermaßen Aspekte von Regionalbewußtsein am Beispiel des Ruhrgebietes untersucht werden. Die Autoren wählen eine induktive Vorgehensweise unter Verwendung narrativer Interviews, und stellen zusammenfassend fest, daß das Ruhrgebiet als Ganzes für den Alltag seiner Bewohner kein relevanter Bezugsraum zu sein scheint. Die Bewohner sind vielmehr auf den Mikromaßstab ihres unmittelbaren räumlichen Umfeldes als Projektionsfläche ihres zugehörigkeitsgefühls hin orientiert. Vgl. Esser, H., Lokale Identifikation im Ruhrgebiet, a.a.O., 1987, S. 114.; Aring, J., Butzin, B., u.a., "... daß die Wahrnehmung wichtiger ist als die Realität“?, a.a.O., S. 524 .

236 Zur Unterscheidung zwischen Innen- und Außenperspektive vgl. Kap. B.1.11 
Referenzraums partizipiert. So ist beispielsweise in Zweifel zu ziehen, ob die im Referenzraum vorherrschenden Werte und Normen von Auswärtigen (z.B. Kurzurlaubern) internalisiert werden können. Es ist vielmehr plausibel anzunehmen, daß die Zugriffsmöglichkeit auf diesen Wissensvorrat eine langjährige Involvierung in die räumlich gebundenen Sozialzusammenhänge und Sachbezüge (z.B. Beruf, Schule, Kirche, Heimatvereine usw.) erforderlich macht. Vor diesem Hintergrund ist anzunehmen, daß der Zugang zu diesem Wissensvorat vornehmlich langjährigen Bewohnern vorbehalten ist. Die Identifizierung von und die Identifikation mit (räumlicher Umwelt) durch Auswärtige ist somit auf oberflächenmerkmale beschränkt.

\begin{tabular}{|l|l|l|}
\hline \multicolumn{1}{|c|}{ Perspektive } & \multicolumn{1}{c|}{ innen } & außen \\
\hline $\begin{array}{l}\text { Räumliche Identität } \\
\text { als } \\
\text { Oberflächenphänomen }\end{array}$ & $\begin{array}{l}\text { Identifizierung von } \\
\text { Identifikation mit } \\
\text { (Bewohner, ortsbe- } \\
\text { zogene Entscheider) }\end{array}$ & $\begin{array}{l}\text { Identifizierung von } \\
\text { Identifikation mit } \\
\text { (Auswärtige) }\end{array}$ \\
\hline $\begin{array}{l}\text { Räumliche Identität } \\
\text { als } \\
\text { Tiefenphänomen }\end{array}$ & $\begin{array}{l}\text { Identifikation mit als } \\
\text { Bestandteil der } \\
\text { persönlichen Identität, } \\
\text { Gruppenidentität }\end{array}$ \\
\hline
\end{tabular}

Abb. 12: Analyseraster räumlicher Identität

Im weiteren Verlauf dieser Arbeit wird die Untersuchung räumlicher Identität auf das oberflächenphänomen beschränkt. Diese Vorgehensweise erscheint insbesondere mit Blick auf die empirische Untersuchung von Teilaspekten räumlicher Identität gerechtfertigt. 237

237 Zur empirischen überprüfung von Teilaspekten räumlicher Identität vgl. Kap. C.1. 
Die Schwerpunktlegung auf die intersubjektiv nachprüfbare Ebene bedeutet nicht zwangsläufig eine Ausgrenzung der beispielsweise durch eine spezifische stadt-oder Regionalkultur repräsentierten werte und Normen (Tiefenphänomene). Es ist wahrscheinlich, daß den von der Bevölkerung im Referenzraum internalisierten Werten und Normen eine Filterfunktion zukommt, welche die Wahrnehmungsmuster der Bevölkerung, und damit ihre Identifizierung von und Identifikation mit (räumlicher Identität) maßgeblich beeinflußt.

In vergleichbaren empirischen Untersuchungen sozialwissenschaftlicher Nachbardisziplinen wird meist eine Focussierung auf eine bestimmte räumliche Maßstabsebene vorgenommen. So ist beispielsweise das vorrangige Untersuchungsinteresse von (Umwelt)psychologie und Soziologie insbesondere auf den Mikromaßstab ausgerichtet.238 Bevorzugtes Untersuchungsobjekt sind Nachbarschaften, stadtteile oder "communities".239 Eine Ausnahme bildet die Umweltpsychologie, welche zunehmend auch räumliche Bindungen auf Ebene der Gesamtstadt untersucht. 240

238 Aus der Soziologie ist die klassische Arbeit von Treinen zur "Symbolischen Ortsbezogenheit" zu nennen. Vgl. Treinen, H., Symbolische Ortsbezogenheit, a.a.O.; Hunter, A., a.a.0.; Fischer, C.S, Networks and places, New York 1977.

239 zur Community-Forschung vgl. bspw. Riger, S., Lavrakus, P.J., Community Ties: Patterns of Attachment and Social Interaction in Urban Neighborhoods, in: American Journal of Community Psychology, Vol. 9, No.1, 1981, S. 55 ff.; Vgl. Taylor, R.B., Gottfredson, S.D., Attachment to place: Discriminant Validity and Impacts of Disorder and Diversity, in: American Journal of Community Psychology, Vol 13, No. 5, 1985, S. 525 ff.; Ringel, N.B., Finkelstein, J.C., Differentiating Neighborhood Satisfaction and Neighborhood Attachment Among Urban Residents, in: Basic and Applied Social Psychology, 1991, 12(2), S. $177 \mathrm{ff}$.

$240 \mathrm{Vgl}$. Schneider, G., Psychological Identity of and Identification with Urban Neighborhoods, in: The Quality of Urban Life, Berlin 1986, S. 203 ff.; Schnei- 
Die geographische Arbeiten sind bevorzugt auf den Mesomaßstab und damit auf die Region als objektbereich ausgerichtet. 241 Mitunter wird die Nachbarschaft als Untersuchungsobjekt berücksichtigt.242 In den empirischen Arbeiten der Regionalbewußtseinsforschung geht es meis $t \quad u m$ unterschiedliche Ausprägungen, Inhalte und Intensitäten des Regionalbewußtseins in der Bewohnerschaft einer Region. Ein besonderer stellenwert kommt dem Bewußtsein von Regionsgrenzen im Wahrnehmungsbild der dortigen Bevölkerung, der Aufdeckung von Kern-Rand-Gefällen der Regionalbewußtseinsintensität, dem stellenwert von Regionalbewußtsein für das persönliche Erleben, der Bewußtwerdung von Regionalbewußtsein auf Grund von "Fremdbestimmung" (z.B. Gemeindegebietsreform) sowie Wahrnehmungsunterschieden zwischen Bewohnern und Experten zu.

der, G., Graumann, C.F., Städtische Umwelt: Identität und Identifikation, in: M. Kampen (Hrsg.), Environment and human action, Berlin 1986 (West): Hochschule der Künste, S. 237.; Lalli, M., Stadtbezogene Identität. Theoretische Präzisierung und empirische Operationalisierung, a.a.0..

241 Vgl. dazu bspw. Wolf, K., Otto, G., Böttcher, F., Rümmler, M., Regionalbewußtsein im Hessischen Ried. Ansätze zur Begriffsbestimmung, räumlichen Dimensionierung und Interpretation, MATERIALIEN, Heft 13 , Frankfurt 1989.; Meissner, R., Lebensqualität und Regionalbewußtsein - Objektive Lebensbedingungen und subjektive Raumbewertung im Kreis Leer (Ostfriesland), in: Ber. z. dt. Landeskunde, Bd. $60, \mathrm{H} .2,1986, \mathrm{~S}$. $227 \mathrm{ff.;}$ Haus, U., Lokale Identität im Zeichen der Gemeindegebietsreform in Oberfranken. Drei Fallbeispiele aus dem ländlichen Raum, in: Ber. z. dt. Landeskunde, Bd. 64, Heft 1, 1990, S. 131 ff.; Fichtner, U., Regionale Identität am Südlichen Oberrhein - zur Leistungsfähigkeit eines verhaltenstheoretischen Ansatzes, a.a.0., S. $109 \mathrm{ff.;}$ Esser, H., Lokale Identifikation im Ruhrgebiet, a.a.0., s. 109 ff..

242 Vgl. dazu bspw. Smith, R.L. Activism and social status as determinants of Neighborhood identity, in: The Professional Geographer 37, 1985, S. 421-432. 
Im Gegensatz zu den genannten Forschungsansätzen sozialwissenschaftlicher Nachbardisziplinen, wird in der vorliegenden Untersuchung die gesamte Bandbreite räumlicher Maßstabsebenen, welche sich vom Mikro- über den Mesobis hin zum Makrobereich erstreckt, berücksichtigt.

\subsection{Wahrnehmungsebenen räumlicher Identität}

Für die Entwicklung eines Operationalisierungsansatzes räumlicher Identität ist es erforderlich, mögliche Ausprägungsformen der Identifizierung von und der Identifikation mit (räumlicher Umwelt) $\mathrm{zu}$ unterscheiden. In diesem Zusammenhang sind die folgenden drei Erscheinungsformen aufzuzählen: 243

\section{Mentale Raumrepräsentation ("innere Bilder")}

Räumliche Identität findet zunächst in der Form einer mentalen Raumrepräsentation im Sinne eines wörtlich $\mathrm{zu}$ verstehenden Vorstellungsbildes Ausdruck. Der Vorstellungsinhalt räumlicher Umwelt umfaßt primär die Wegewahl oder -beschreibung. Im Mittelpunkt steht somit die Raumkennt-

243 Vergleichbare systematisierungen finden sich in der geographischen Literatur. Vgl. Tzschaschel, S., Geographische Forschung auf der Individualebene, a.a.0., S. $30 \mathrm{f}$. Vgl. dazu auch Becker und Keim, die am Beispiel der stadt zunächst die stadtgestalt als objektiv vorhandene Umwelt unterscheiden. Das Erscheinungsbild kommt in der Wechselbeziehung zwischen Stadtgestalt und dem Beobachter zustande. Ein Vorstellungsbild entsteht, indem das subjekt "seine stadt" klassifiziert, bewertet, interpretiert, ordnet, sich mit ihr identifiziert und sie mit Symbolen besetzt. Entscheidend ist, daß ein Vorstellungsbild nur über eigene Erfahrung aufgebaut werden kann. Das Image weist demgegenüber den höchsten Verzerrungsgrad auf. Es beinhaltet die Nivellierung der Vorstellungsbilder zu einem "typischen". Vgl. Becker, H., Keim, D., Wahrnehmung in der städtischen Umwelt, a.a.0., s. $111 \mathrm{f}$. 
nis, welche durch "Mental maps" visualisiert wird.244 Diese Vorstellung von Raumstrukturen, das Wissen über die Anordnung von einzelnen Raumelementen, hat für das Individuum orientierungscharakter. 245

Ein besonderer stellenwert kommt in diesem Zusammenhang der klassischen Untersuchung des Stadtplaners Kevin Lynch $z u$, der die Klarheit und Prägnanz städtischer Umwelt am Beispiel amerikanischer Großstädte untersucht hat.246 Dabei kristallisierten sich Wege, Grenzlinien, Bereiche, Brennpunkte sowie Merk- oder Wahrzeichen als besonders einprägsame Hilfsmittel für die orientierung in der stadt heraus. 247 Vom Denkansatz her betrachtet, handelt es sich

244 Die Funktionen einer "mental map" (gedanklicher Lageplan, kognitive Karte, subjektiver stadtplan) lassen sich folgendermaßen zusammenfassen: (1.) Die Wegbeschreibung außer Sichtweite der Route, (2.) das Durchspielen möglicher Routen für die eigene Wegewahl oder (3.) die verortung von Sachverhalten als gedankliches Hilfsmittel, (4), die Vorstellungswelt von Orten, an denen man nicht ist. Aus der Mental-Map Forschung läßt sich ableiten, welche strukturelemente orientierungscharakter haben oder eine emotionale Identitätsbedeutung zukommt. Mitunter wird die Funktion einer mental map auch mit der "Sichtbarmachung" eines Images umschrieben. Tzschaschel, S., Geographische Forschung auf der Individualebene, a.a.0, S. 36, $41 \mathrm{f} .$, Tuan, Y.-F., Place: An Experimental Perspective, Geographical Review 65/1975, S. 210 f.

245 Der Informationsgehalt gedanklicher Lagepläne ist eher gering. Das Vorstellungsbild zeigt lediglich auf, "where places are". Es gibt keine Auskunft darüber, "what places are". Vgl. Canter, D., The psychology of place, a.a.0., s. 105 .

246 Lynchs Interesse galt der strukturierung von städten für das visuelle Vorstellungsbild ("mental image"). Ziel seiner Untersuchung war es herauszufinden, welche Arten von physischen Elementen bevorzugt als orientierungspunkte oder Hilfsmittel im Prozeß des Sichzurechtfindens in einer stadt gewählt werden. Vgl. Lynch, K., Das Bild der Stadt, Braunschweig/Wiesbaden 1989.

247 Bei den "Wegen" handelt es sich um Kanäle, durch die sich der Beobachter gewohnheitsmäßig bewegt. Es kann 
hierbei um Fragestellungen, welche in vergleichbarer weise in der Imageryforschung behandelt werden ("innere Bilder"). 248

\section{Bewertetes Vorstellungsbild (Image)}

Das bewertete Vorstellungsbild oder das Image kommt durch das gesamte spektrum subjektiver Einflußgrößen zustande und schließt das Konzept der mentalen Raumrepräsentation mit ein. Auch einem räumlichen Image wird eine orientierungsfunktion zugesprochen, d.h. es wird als qualitative Entscheidungsgrundlage des Individuums angesehen und tritt

sich dabei um Straßen, Spazierwege, Verbindungswege, Was s e rwege oder Eisenbahnstrecken handeln. "Grenzlinien (Ränder)" markieren die Grenzen zwischen Gebieten. Diese Linearelemente werden vom Beobachter nicht als Wege benutzt oder bewertet. Sie stellen jedoch wesentliche Elemente der Gliederung einer stadt dar. Dabei kann es sich beispielsweise um Küsten, Baugebietsränder, Mauern usw. handeln. "Bereiche” sind die mittleren bis großen Abschnitte einer Stadt, die vom Beobachter als zweidimensionale Gebiete wahrgenommen werden, und in die er "hineingeht". Diese Gebiete weisen einen einheitlichen charakter auf (z.B. Stadtbezirke oder Ortsteile). "Brennpunkte" sind die strategischen Punkte einer Stadt. Es handelt sich um intensiv genutzte Zentralpunkte (Knotenpunkte, Verkehrsunterbrechungen, Kreuzungen oder Treffpunkte von Straßen). "Merk- oder Wahrzeichen" stellen gleichermaßen optische Bezugspunkte dar. In sie kann der Beobachter allerdings nicht "eintreten". Es handelt sich insbesondere um äußere Merkmale wie beispielsweise Gebäude, Schilder, Warenhäuser oder Anhöhen usw.. Vgl. Lynch, K., Das Bild der Stadt, a.a.0., S. $60 \mathrm{ff.}$.

248 Dieser Forschungszweig der Konsumentenforschung beschäftigt sich unter anderem mit der Frage, wie vom Konsumenten aufgenommene Reize (Informationen) in Form von inneren Bildern kodiert werden. Zum Forschungsfeld "innere Bilder" vgl. Kroeber-Riel, W., Neuere Methoden der Marktforschung, in: DBW, 43/1983, H. 2, S. 277 ff.; Ders., Die inneren Bilder der Konsumenten - Messung, Verhaltenswirkung, Konsequenzen für das Marketing, in: MARKETING. ZFP, 6/1986, H. 2, s. 81 ff.; Ders., Strategie und Technik der Werbung - verhaltenswissenschaftliche Ansätze, Edition Marketing, Stuttgart, Berlin 1988, S. 106 ff. 
somit ganzheitlich an die stelle der Realität. Das bewerte Vorstellungsbild (Image) läßt sich weiter aufspalten, wenn zwischen einem Eigenimage und einem Fremdimage unterschieden wird. 249

Wenn eine geographische Kategorie zur Unterscheidung zwischen Eigen- und Fremdimage gewählt wird, ist das Fremdimage auf einen repräsentativen Querschnitt von Personen außerhalb des Referenzraumes bezogen. Das Eigenimage konstituiert sich demgegenüber aus einem repräsentativen Querschnitt der im Referenzraum ansässigen Bewohner. 250 Der Differenzierung liegt im wesentlichen der Gedanke zugrunde, daß mit wachsender Entfernung vom Referenzraum der Verzerrungsgrad des Images steigt und demgemäß Unterschiede zwischen Bewohnern und Auswärtigen auftreten. 251 Dies muß jedoch nicht zwangsläufig der Fall sein. 252

249 Die trennscharfe Abgrenzung der Begriffe Vorstellungsbild und Image ist nicht möglich. Es lassen sich jedoch Tendenzaussagen treffen. Der entscheidende Unterschied besteht darin, daß ein räumliches Image ohne persönliche Erfahrungsgrundlage entstehen kann, während ein Vorstellungsbild meist auf persönlichen Erlebnissen im Raum beruht. Eine vermittelnde Position nimmt Ganser ein, der in seiner Definition des Images einer stadt die Existenz einer persönlichen Erfahrungsgrundlage nicht zwangsläufig ausgrenzt: "Das Image einer stadt resultiert aus den Wechselbeziehungen zwischen Reizen (Informationen), die von der Realsituation eines Raumes, dem Zusammenspiel aller sogenannten "Grunddaseinsfunktionen" (wohnen, arbeiten, bilden, versorgen, sich erholen, ausgehen) und Individuen, die diese wahrnehmen. Vgl. Ganser, K., Image als entwicklungsbestimmendes steuerungsinstrument, in: Stadtbauwelt 1970, S. 107.

$250 \mathrm{Vgl}$. Ganser, K., Image als entwicklungsbestimmendes Steuerungsinstrument, in: Stadtbauwelt 1970, S. 107.

251 In einer Untersuchung des EMNID-Instituts über das Eigen- und Fremdimage im Rhein-Main-Gebiet konnte nachgewiesen werden, daß die mit der Region verbundenen Assoziationen bei Bewohnern und Fremden voneinander abweichen. So verknüpfen Auswärtige mit der RheinMain-Region insbesondere die stadt Frankfurt (23 \%), Industrie und Flughafen (jeweils 16 \%), Erho- 
Im Rahmen imagepolitischer Fragestellungen ist es interessant, die Ursachen für bestimmte Ausprägungsformen räumlicher Vorstellungsbilder (Images) herauszufinden. Dazu mussen bei der Erhebung des Images eine Reihe von Variablen berücksichtigt werden, auf deren Grundlage die verschiedenen Ursachen analysiert werden können.

Als Basis für die Auswahl dieser Variablen lassen sich eine Reihe von imagebildenen Faktoren unterscheiden. 253 Diese Zusammenstellung hat gegenüber vergleichbaren Strukturierungsansätzen den Vorteil, speziell auf städteimages abgestimmt zu sein:

\section{- zeit:}

Die zeit schlägt sich bei der Messung von Images dadurch nieder, weil jede Imagemessung eine Momentauf-

lung/schöne Landschaft (15\%), Wein (13\%). Demgegenüber ist das Wahrnehmungsbild der Regionsbewohner stärker von Alltagserfahrungen geprägt. Genannt wurden insbesondere Verkehrsprobleme und schlechte Luft (19 ६), gute Verkehrsanbindung (11 \%), Wohnungsnot, schöne Landschaft (jeweils 10 \%). Die von Auswärtigen genannten Faktoren Flughafen, Frankfurt und Wein finden bei den Einheimischen deutlich weniger Erwähnung ( 4 \& bzw. 9 \%). Vgl. Engelhard, A., Ein Ballungsraum mit sehr vielen Vorteilen, in: HORIZONT Nr. 40, 2. Oktober 1992, S. 57; O.V., Die Rhein-Main-Region: Unterschiede und Verbindendes, in: Der Städtetag, 12/1992, S. 855 ff..

252 Möglicherweise bilden sich "Identifikationsinseln" und "Identifikationslöcher" aus. "Identifikationsinseln" liegen vor, wenn Rezipienten, die in weiter Entfernung vom Referenzraum ansässig sind, über ein besonders wirklichkeitsnahes (authentisches) Image verfügen. Umgekehrt is $t$ m it der Existenz von "Identifikationslöchern" der Sachverhalt angesprochen, daß beispielsweise im Referenzraum selbst oder im näheren Umland ein sehr verzerrtes Image nachgewiesen werden kann. Vgl. Zimmermann, K., Zur Imageplanung von Städten. Untersuchungen zu einem Teilgebiet kommunaler Entwicklungsplanung, Köln 1975, S. 108 f.

$253 \mathrm{Vgl}$. Zimmermann, K., Zur Imageplanung von städten, a.a.0., s. 85 ff.. 
nahme darstellt. Die Wahl des Zeitpunktes kann somit die das Ergebnis beeinflussen.

- Ort:

Die räumliche Distanz zwischen Person und Imageobjekt kann zu Verzerrungen von Informationen führen, die das Image beeinflussen.

- Informationsbasis:

Der Wahrheitsgrad und die Vollständigkeit der Informationen und damit die Informationsquelle haben Auswirkungen auf das Image.

- Anschaung/Erfahrung:

Informationen, die persönlich gewonnen wurden, können durch ihren Erlebnisgehalt starke subjekte züge tragen und damit verzerrungen herbeiführen.

- Betrachtungsrichtung:

Räumliche Orientierungen wie beispielsweise der Geburtsort oder der derzeitige wohnort können als "Hintergrundvariable" die Ausprägung räumlicher Images beeinflussen.

- Psychische Bindung:

Der Grad der Zustimmung oder Ablehnung, der einer bestimmten stadt entgegengebracht wird, beeinflußt das räumliche Vorstellungsbild.

- Gruppenidentifikation:

Unterschiedliche Gruppenzugehörigkeiten können zu einer Differenzierung von Images führen. 


\section{Klischee}

Dem bewerteten Vorstellungsbild bzw. dem Image vergleichbar, haben auch pauschalisierende, stereotype Raumeinschätzungen (Klischees) einen ganzheitlichen Charakter. Eine Stadt oder Region wird in diesem Verständnis insgesamt abgelehnt oder favorisiert.

Die Kommunikation klischeehafter Inhalte sagt beispielsweise nichts über die Lebensqualität in einer stadt oder Region aus. Trotzdem ist es möglich, daß die übermittelten Inhalte für Momente zugkräftig sind und möglicherweise Wanderungsmotive beeinflussen (z.B. Besuchs- oder Wohnortwunsch). Probleme sind zu erwarten, wenn die reale Lebenssituation im Referenzraum die kommunizierten Vorstellungen nicht angemessen widerspiegelt. 254

Zusammenfassend wird deutlich, daß die Ausprägungsformen räumlicher Identität die objektiv gegebene, intersubjektiv nachprüfbare Realität nicht im Verhältnis 1:1 abbilden. Dabei ist anzunehmen, daß der Verzerrungsgrad bei der mentalen Raumrepräsentation am geringsten und beim Klischee am höchsten ist.

Die aufgezeigten Wahrnehmungsebenen lassen eine große inhaltliche Nähe zwischen dem Identitäts- und dem Imagebegriff deutlich werden. Zur Abgrenzung beider Begriffe wird vorgeschlagen, die Entstehung räumlicher Identität zwingend an die Existenz einer persönlichen Erfahrungsgrundlage zu knüpfen, während das Image gerade durch das Fehlen persönlicher Erfahrungsbezüge gekennzeichnet ist.255 I n

254 Vgl. Becker, H., Keim, D., Wahrnehmung in der städtischen Umwelt, a.a.0., s. $130 \mathrm{f}$.

255 Während lokale Identität durch einen interaktiven, wechselseitigen zusammenhang konstituiert wird, der Raum und Bewohnerschaft notwendig einschließt, drückt das räumliche Image in dieser Auffassung eine gedeu- 
der vorliegenden Untersuchung sind die mentale Raumrepräsentation, das Vorstellungsbild (Image) sowie das Klischee explizit als verschiedene Wahrnehmungsebenen gekennzeichnet worden. Mit dieser Begriffsbildung wird zum Ausdruck gebracht, daß die genannten Begriffe als Teilaspekt räumlicher Identität aufzufassen sind. Dabei darf nicht übersehen werden, daß die Existenz einer mentalen Raumrepräsentation, eines Images oder eines Klischees nicht zwangsläufig dazu führt, daß der Wahrnehmende diese Vorstellungsinhalte als Bestandteil seiner persönlichen Identität wahrnimmt. So ist beispielsweise denkbar, daß eine bestimmte stadt (z.B. München) im Wahrnehmungsbild eines Betrachters über ein hervorragendes Image verfügt. Dies bedeutet jedoch nicht unbedingt, daß sich der Betreffende als "Münchener" fühlt bzw. "München" und die mit der Metropole assozierten Qualitäten als Teil seiner persönlichen Identität auffaßt.

Abschließend läßt sich feststellen, daß räumliche Identität auf eine der drei aufgezeigten Wahrnehmungsebenen beschränkt sein kann. Andererseits ist möglich, daß Inhalte der drei Wahrnehmungsebenen als Bestandteil der persönlichen Identität wahrgenommen werden. 256

tete und bewertete mentale Repräsentation der kommunalen Wirklichkeit aus. Das räumliche Image beinhaltet somit nicht den Aspekt der aktiven Auseinandersetzung mit der räumlichen Umwelt. Vgl. Singer, C., Kommunale Imageplanung, in: AfK II/88, S. 272 ; Becker, H., Keim, D., Wahrnehmung in der städtischen Umwelt, a.a.0., s. 114 .

256 Eine Ausnahme stellt die Wahrnehmungsebene der mentalen Raumrepräsentation dar. Es erscheint zweifelhaft, daß diese als konkret formenhaft aufzufassende Raumvorstellung ("innere Bilder") als Bestandteil der persönlichen Identität einer Person sinnvoll erklärbar ist. Demgegenüber erscheint es jedoch durchaus möglich, daß die einer Stadt/Region zugeschriebenen Attribute wie beispielsweise "heiter" " souverän", "unterkühlt", "leistungsfähig" usw. identifikationsfähig sind, und in die persönliche Identität einer Person einfließen können. In diesem Fall würde gewisser- 
Zur Fundierung der Hypothesenbildung ist es notwendig, das System unterschiedlicher Einflußgrößen und Bestimmungsfaktoren räumlicher Identität zu analysieren. Auf die Ausprägungsformen der Identifizierung von sowie der Identifikation mit (räumlicher Umwelt) wirken eine Fülle von Faktoren, welche z.T. gar nicht oder nur schwer vom SRM kontrollierbar sind. Die Einflußgrößen, welche durch das SRM kontrolliert werden können, sind in der Gruppe angebotsbezogener Einflußgrößen zusammengefaßt.

Eine weitere Gruppe umfaßt diejenigen Größen, die von seiten des Bewohners auf die Ausprägung räumlicher Identität wirken. Diese Größen können vom SRM nicht kontrolliert werden. Die dritte zentrale Gruppe umfaßt die Einflüsse, welche von der Hierarchie räumlicher Maßstabsbereiche ausgeht, die ebenfalls nur zu einem Teil durch das SRM direkt beeinflußt werden können.

Die in der Abbildung 13 dargestellte systematisierung stellt eine idealtypische Trennung von Einflußbereichen dar, die darüber hinaus eine optimale Möglichkeit zur Ableitung von Hypothesen zu Wirkungsbeziehungen räumlicher Identität bietet. Anhand solcher Hypothesen ist eine fundierte Untersuchung räumlicher Identität möglich. In diesem Zusammenhang werden auch Einflußgrößen aufgenommen, die im Rahmen dieser Untersuchung nicht empirisch überprüfbar sind. Auf diese Weise ist eine umfassende Darstellung des komplexen Einflußgrößensystems möglich. $\mathrm{zum}$ anderen können offene Forschungsfelder abgeleitet werden. 


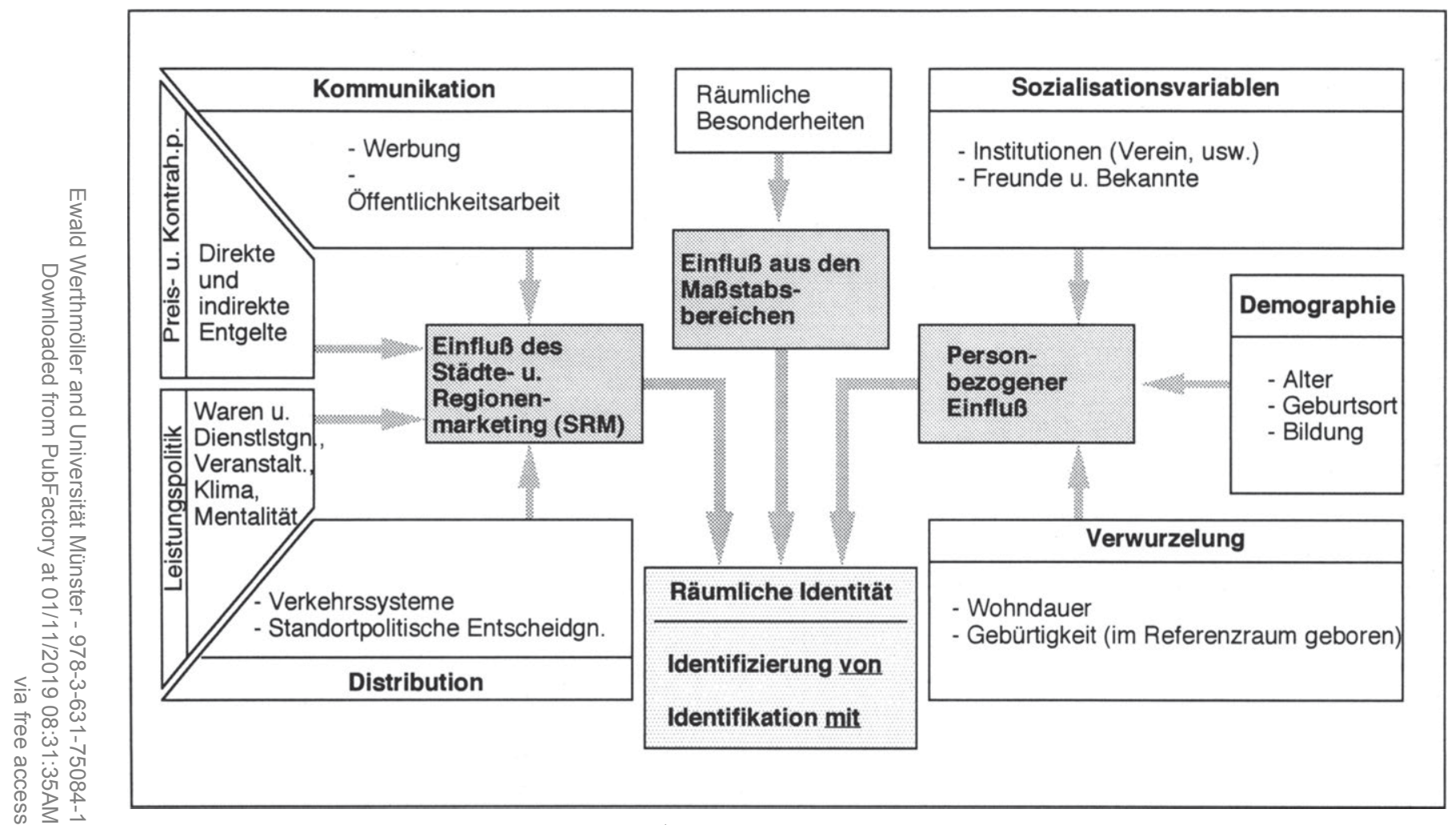

Abb.13: Einflußgrößen räumlicher Identität 
Die idealtypische Trennung der Einflußgrößen bedeutet allerdings keine Unabhängigkeit der drei Faktorengruppen. So bestehen beispielsweise überschneidungen zwischen den angebotsbezogenen Einflußgrößen und den Gegebenheiten auf den verschiedenen räumlichen Maßstabsbereichen.

Ebenso kann die Ausgestaltung angebotsbezogener Faktoren auf die bewohnerbezogenen Einflußgrößen wirken. Wird z.B. ein SRM-Konzept auch auf interne Zielkreise ausgerichtet, kann dies Auswirkungen auf das Mobilitätsverhalten von Bewohnern bzw. Unternehmern haben. So äußert sich beispielsweise ein ausgeprägte Wohnortbindung in einer langen Wohndauer. 257

\subsection{Maßstabsbezogene Einflußgrößen}

Die Gruppe der Einflußgrößen räumlicher Identität von seiten der Hierarchie räumlicher Maßstabsbereiche ist besonders vielfältig und komplex. Daher ist es notwendig, eine problemorientierte Strukturierung der Größen vorzunehmen. Eine Möglichkeit besteht darin, die vom Raum ausgehenden Informationen nach den menschlichen sinnen zu strukturieren. Dieser Vorgehensweise liegt der Gedanke zugrunde, daß die Wahrnehmungsprozesse auf der Mikroebene

257 Ein lange Wohndauer ist aus sicht der Interessenlage einer stadt/Region von Vorteil, weil auf diese Weise für den entsprechenden Zeitraum Steuereinnahmen gewährleistet sind. Die Wohndauer hat darüber hinaus nicht nur eine auf Bewohner im engen Begriffssinn bezogene Bedeutung. Auch Unternehmen zeichnen sich im übertragenen Sinne durch eine - mehr oder weniger lange Wohndauer aus. Die Beeinflussung der "Wohndauer" im Sinne der Gewerbestandspflege wird von vielen Kommunen als wichtiges Aufgabenfeld betrachtet. Angesichts sich verändernder ökonomischer Rahmenbedingungen wird es zunehmend schwieriger, Strukturprobleme durch Neuansiedlungen zu lösen. Vgl. Heuer, H., Instrumente kommunaler Gewerbepolitik, stuttgart u.a. 1985, S. 151 . 
nicht zwangsläufig mit denen auf den räumlich ausgeweiteten Maßstabsbereichen des Meso- oder Makrobereiches vergleichbar sind. Vor diesem Hintergrund erscheint es zweckmäßig, eine systematisierung nach Maßgabe signifikanter und symbolischer stimuli vorzunehmen, die jeden räumli$c h$ e $n$ Maßstabsbereich kennzeichnen.258 Als signifikante Stimuli werden Reize bezeichnet, die vom Raum selbst ausgehen. Die Wahrnehmung dieser Reize setzt voraus, daß sich der Betrachter persönlich im Raum aufhält und ihn mit seinen Sinnesorganen wahrnimmt (Kopräsenz von Mensch und Raum).259 Mit den symbolischen Stimuli sind demgegenüber Worte, Sätze, Bilder usw. gemeint, die in schriftlicher oder mündlicher Form Informationen über einen bestimmten Raumausschnitt (z.B. über eine stadt oder Region) repräsentieren. Anzeigen, Prospekte, Filme und andere Informationsmaterialien uber eine stadt oder Region nutzen diese beispielsweise zur Vermittlung von Botschaften über den Raum. 260

Abbildung 14 verdeutlicht, daß kleine Raumausschnitte überwiegend auf der Grundlage signifikanter Stimuli wahrgenommen werden, während der im Mittelpunkt dieser Untersuchung stehende Mesobereich (Städte und Regionen) durch einen kontinuierlichen Bedeutungszuwachs symbolischer Stimuli gekennzeichnet ist.

$258 \mathrm{Vgl}$. Müller-Hagedorn, L., Das Konsumentenverhalten. Grundlagen für die Marktforschung, a.a.o., S. 70 .

259 Muiller-Hagedorn bezieht signifikante stimuli auf Reize, die von einem Produkt selbst ausgehen - wenn also der Konsument das Produkt im Regal eines Einzelhändlers wahrnimmt. Vgl. Müller-Hagedorn, L., Das Konsumentenverhalten, a.a.0., s. 70 .

$260 \mathrm{Vgl}$. Antonoff, R., Wie man seine Stadt verkauft. Kommunale Werbung und öffentlichkeitsarbeit, Düsseldorf 1971 , S. 124 . 


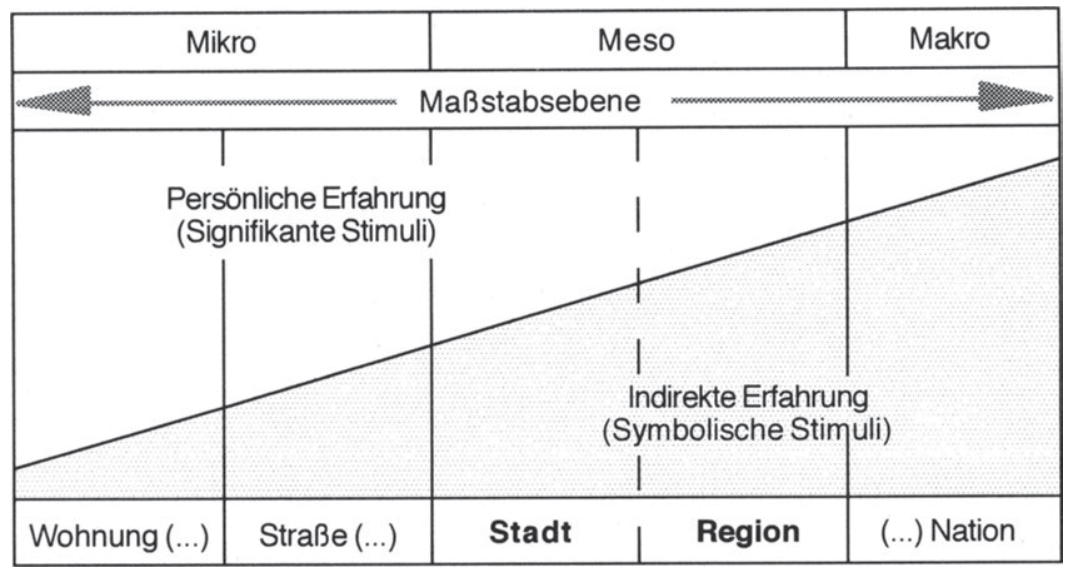

Abb.14: Erfahrungsgrundlagen räumlicher Identität in Abhängigkeit von der räumlichen Maßstabsebene

Auf jeder räumlichen Maßstabsebene treten beide Stimuliarten in unterschiedlicher stärke zusammen auf. Auf der Iinken Seite der Abbildung 14 ist die Relevanz signifikanter Stimuli von oben nach unten aufgetragen, während auf der rechten Seite der Stellenwert symbolischer Stimuli für die Wahrnehmung von unten nach oben deutlich wird. Mit größer werdendem Maßstabsbereich steigt die Bedeutung symbolisch übermittelter Informationen über den Raum ständig an, während der Anteil der Reize, welche vom Referenzraum selbst ausgeht, abnimmt. Insbesondere zeitliche Restriktionen und die mit größer werdender Maßstabsebene wachsende Bedeutung der Distanzüberwindung lassen den Einfluß indirekter Erfahrung im Wahrnehmungsbild der Rezipienten stetig an Bedeutung zunehmen.

Während die durch signifikante stimuli initiierten Wahrnehmungsinhalte durch die Kopräsenz von Mensch und Raum eines besonders hohen Grad an Wirklichkeitsnähe bzw. Authentizität erlangen, ist die symbolische Informationsubermittlung mit einer Reihe von wirkungsproblemen behaftet: 
- Symbolische Informationen können einen Raumausschnitt nur annähernd repräsentieren. Die symbolische Erfahrung eines Raumes ist zwangsläufig unterrepräsentiert, weil die Wahrnehmung einer stadt oder Region nur mit den beiden Sinnen Hören und Sehen erfolgen kann. Es ist plausibel anzunehmen, daß die symbolische Kommunikation insbesondere die atmosphärischen Qualitäten eines Raumes, wozu beispielsweise das Klima, der persönliche Kontakt mit den Bewohnern usw. zählt, nur unvollkommen vermitteln kann. 261

- Darüber hinaus erschwert die symbolische Kommunikation den vergleich verschiedener Räume. Als besonders erschwerend kommt in diesem Zusammenhang hinzu, daß die in vielen Imagekampagnen verwendeten symbolischen stimuli häufig austauschbar sind und dem angesprochenen Raumausschnitt in der Wahrnehmung der angesprochenen zielkreise keine Identität verleihen. 262

- Schließlich wird die Wirkung symbolischer Kommunikation durch semantische probleme eingeschränkt. Es ist beispielsweise nicht auszuschließen, daß die Botschaf-

261 Der Stellenwert persönlicher Erfahrung für die Raumkenntnis und für die Qualität des Raumerlebens wird beispielsweise von dem Geographen Tuan aus einer phänomenologischen Perspektive behandelt. Er unterscheidet $z$ we $i$ Formen von räumlichen Erfahrungen ("experiences" und "sensory modes") : Zunächst die aktive und direkte Erfahrung eines Raumes durch hören und sehen ("active mode of experience") und andererseits die passive Erfahrung ("passive mode of experience" - taste, smell, touch). Nach Auffassung von Tuan stellt neben einem langjährigen Aufenthalt insbesondere die Kontaktaufnahme über die sinne tasten, schmecken und berühren eine wesentliche Voraussetzung zur Entwicklung von Ortskenntnis dar. Vgl. Tuan, Y.F., Place: An Experimental Perspective, a.a.o., S. 161,164 .

$262 \mathrm{Vgl}$. Roth, P., Stiller, R., Stadtkommunikation, in: Werbeforschung \& Praxis, 5/1993, S. 189. 
ten von den Empfängern nicht so verstanden werden, wie von den Absendern beabsichtigt.

Der Bedeutungszuwachs symbolisch übermittelter Informationen auf der Ebene von Städten und Regionen sowie die damit verbundenen Wirkungsprobleme werfen zusammenfassend ein Licht auf die zentrale Bedeutung des SRM zur Beeinflussung räumlicher Identität. Angesichts der Unmöglichkeit, Raumausschnitte dieser Größenordnung durch persönliche Erfahrung bzw. auf der Grundlage signifikanter Stimuli umfassend wahrzunehmen, muß die erfolgreiche Penetration der Einzigartigkeit, Besonderheit und Individualität einer Stadt oder Region in erheblichem Umfang auf symbolisch übermittelten Informationen aufbauen. Das SRM stellt in diesem zusammenhang eine geeignete plattform dar, um bestimmte Informationen über den Referenzraum im Rahmen der Kommunikationspolitik an interne und externe Zielkreise zu ubermitteln.

Im Gegensatz zu den Stimuli, welche unmittelbar vom Raum ausgehen und damit weitgehend als authentisch bezeichnet werden können, sind symbolische stimuli teilweise durch das SRM beeinflussbar. Es ist somit grundsätzlich möglich, eine gewünschte Identitätswirkung bei den internen und externen zielkreisen $z u$ erzeugen. Die von einer prägnanten räumlichen Identität erwünschten Folgewirkungen (beispielsweise ein bestimmtes Mobilitätsverhalten) sind langfristig jedoch nur dann wahrscheinlich, wenn sich die übermittelten Informationen durch einen hohen Authentizitätsgrad auszeichnen. 263

Auf jeder räumlichen Maßstabsebene lassen sich eine Reihe von Besonderheiten nachweisen. Dabei ist $z \mathrm{u}$ vermuten, daß zwischen den Eigenschaften eines Raumes und beispielsweise

263 Zum Authentizitätsgrad als Erfolgsvoraussetzung für das Städte- und Regionenmarketing vgl. Kap. C.2.12. 
der räumlichen Verbundenheit ein zusammenhang besteht. Für die physischen Bestandteile eines Raumes konnte beispielsweise nachgewiesen werden, daß die emotionale Besetzung umso besser gelingt, je unverwechselbarer und eigenständiger sie sind.264 Auch in der Umweltpsychologie wird die Bedeutung der wahrnehmbaren "Einmaligkeit und Besonderheit" von Städten diskutiert.265 Das "Unverwechselbare" und die (positiv besetzte) spezifik einer stadt verleihen auch dem Bewohner das Gefühl einer grundsätzlichen Einmaligkeit. Von diesen überlegungen ausgehend läßt sich die folgende Hypothese formulieren:

HR1 Die wahrgenommenen Besonderheiten eines Raumes haben einen signifikanten Einfluß auf die Höhe der Identifikation, d.h., je positiver die Besonderheiten eines Raumes wahrgenommen werden, umso höher ist der Identifikationsgrad.

Mit Blick auf den zentralen stellenwert des SRM für die zielgerichtete Beeinflussung räumlicher Identität bietet es sich an, daß ursprünglich für kommerzielle Unternehmen entwickelte Marketing-Mix als wichtiges angebotsbezogenes Einflußgrößen-Bündel räumlicher Identität aufzufassen. Das auf eine stadt oder Region zugeschnittene Marketing-Mix läßt sich dabei als eine Konkretisierung signifikanter und symbolischer stimuli auffassen, die grundsätzlich beeinflußbar sind.

$264 \mathrm{Vgl}$. Herlyn, U., Individualisierungsprozesse im Lebenslauf und städtische Lebenswelt, in: J. Friedrichs (Hrsg.), Soziologische Stadtforschung, Opladen 1988, S. 116 .

265 Vgl. Lalli, M., stadtbezogene Identität, a.a.o., s. 22 . 


\subsection{Angebotsbezogene Einflußfaktoren}

Die angebotsbezogenen Einflußfaktoren auf die Ausprägung räumlicher Identität können anhand der vier Marketing-MixBereiche systematisiert werden. 266

Die Leistungspolitik umfaßt in Analogie zur Produkt- und Sortimentspolitik des Konsumgütermarketing alle Erfahrungstatbestände, die sich auf die Ausgestaltung der Leistungen in einer stadt oder Region beziehen. Im Mittelpunkt steht die Ausgestaltung des "Produktes", welches aus einer großen Anzahl einzelner Facetten bzw. Produktbestandteilen zusammengesetzt ist.267 Dies e Facetten umfassen insbesondere die waren und Dienstleistungen, die in einer stadt angeboten werden, die städtischen Einrichtungen, Veranstaltungen, aber auch die Atmosphäre, das Klima und die Mentalität der Bevölkerung.268

Bereits in dieser Aufzählung wird deutlich, daß sich ein großer Anteil der Produktbestandteile einer konsequenten und zielgerichteten Gestaltung entzieht. Die Systematisierung der einzelnen Produktfacetten läßt sich am Beispiel einer Stadt exemplarisch aufzeigen. In diesem zusammenhang ist eine Unterscheidung zwischen Pflichtleistungen und Wahlleistungen sinnvoll:

- Pflichtleistungen werden stets von kommunaler seite getragen und sind Leistungen, zu denen eine stadt gesetzlich verpflichtet ist oder die kein anderer Leistungsträger erbringt. Sie orientieren sich an den Bedürfnissen des einzelnen oder an gesamtgesellschaftlichen zie-

266 Vgl. Meffert, H., Marketing - Grundlagen der Absatzpolitik, 7. Aufl., Wiesbaden 1986, S. 115 ff.

267 Vgl. Meffert, H., Städtemarketing - Pflicht oder Kür?, a.a.0., S. 6 .

268 Ebenda. 
len. Teilweise können diese Leistungen auch von der umliegenden Region oder von Nachbarstädten erbracht werden. Die Stadt kann die Leistungserstellung an Eigenbetriebe bzw. Eigengesellschaften der Städte, sowie Privatunternehmen übertragen, wie dies z.B. häufig bei den Versorgungsbetrieben der Fall ist.

- Als Wahlleistungen lassen sich Leistungen kennzeichnen, die für eine Stadt wünschenswert sind, deren Erbringen jedoch nicht mit einer gesetzlichen verpflichtung verknüpft ist. Einige dieser Leistungen werden zumeist von öffentlicher seite, andere nur von privater seite erbracht. 269 Alle ubrigen in einer stadt angebotenen Leistungen, z.B. der Einzelhandelsgeschäfte und privater sport- und Freizeiteinrichtungen, sind wahlleistungen von privater Seite. Eine Stadt ist aufgefordert, den größtmöglichen Umfang an Wahlleistungen, sei es von privater oder öffentlicher seite, für ihre Bürger bereitzustellen.

Die Nachfrage nach den Leistungen einer stadt ist angebotsinduziert. Bei fehlenden oder nicht genügenden Leistungen, wandern die Nachfrager zur Bedarfsdeckung in andere städte ab. Für das SRM sind die wahlleistungen von besonderem Interesse, weil durch sie die Nachfrager an die Stadt gebunden werden.

Vor dem Hintergrund der Aufteilung städtischer Leistungen in Pflicht- und Wahlleistungen, läßt sich eine Strukturierung de r preis-und Kontrahierungspolitik (Gegenleistungspolitik) vornehmen. Im Bereich der Pflichtleistungen lassen sich direkte Entgelte und indirekte Entgelte unterscheiden. zu den direkten Entgelten zählen bei-

269 Beispiele für öffentliche Leistungen sind städtische Bibliotheken, Schwimmbäder sowie ein Großteil der kulturellen Angebote. 
spielsweise Bearbeitungsgebühren, Abgaben für die Abfallbeseitigung oder Tarife des ÖPNV u.v.a.m. Bei den an Bund, Länder und Gemeinden entrichteten Steuern und Abgaben handelt es sich demgegenüber um indirekte Entgelte. über den Finanzausgleich zwischen Bund und Ländern und Gemeinden fließen diese Gelder als sogenannte Deckungsmittel an die Städte zurück. Sie werden z.B. für den Bau von Straßen, Schulen und anderen öffentlichen Einrichtungen verwendet.

Gegenleistungen für Wahlleistungen werden in Abhängigkeit vom Bereitsteller entweder an private oder öffentliche Seite entrichtet. Die private seite verfolgt in jenem Falle somit erwerbswirtschaftliche $\mathrm{z}$ iele und ist in der Lage, für ihre Waren, Dienstleistungen und sonstigen Leistungen Marktpreise bzw. -gebühren zu verlangen.

Im Rahmen des SRM sind die direkten Entgelte nicht beeinflußbare Gegenleistungen. Ihre Festlegung erfolgt in der Regel durch die Bundes- oder Landesregierung. Gegenleistungen für private Wahlleistungen werden von den unterschiedlichsten Gruppen festgelegt. Hier lassen sich beispielsweise die Mietpreise für Gewerbeflächen oder das Preisniveau des Einzelhandels nennen. Die Festlegung direkter Entgelte sowie der Gegenleistungen für öffentliche wahlleistungen ist relativ einfach $z u$ steuern, da die Stadtverwaltung bzw. ihre Betriebe und Gesellschaften diese größtenteils festlegen.

Die Distributionspolitik beinhaltet alle Entscheidungen, die sich mit dem Austauschprozeß zwischen der Stadt und zielgruppen befassen. Sie unterstüzt die Bereitstellung der einzelnen Leistungen am richtigen ort, zur richtigen zeit im richtigen zustand und in der richtigen Menge. Diese Entscheidungen beziehen sich auf Verkehrssysteme, standortpolitische Entscheidungen und Distributionsorgane. 
Aufgabe der Rommunikationspolitik ist die bewußte Gestaltung zielgruppengerichteter Informationen, die im Rahmen des SRM durch Werbung und/oder Öffentlichkeitsarbeit zum Tragen kommen. Der Kommunikationspolitik kommt eine Sonderstellung $\mathrm{zu}$, da sie einerseits die anderen Instrumente in ihrer wirkung unterstützt und andererseits aber auch die leistungs-, gegenleistungs- und distributionspolitischen Aktivitäten kommunikationspolitische Wirkungen haben.

Die Ausprägung räumlicher Identität wird neben maßstabsund angebotsbezogenen Einflußgrößen durch eine Reihe von personenbezogenen Faktoren beeinflußt, wobei insbesondere ein Zusammenhang zwischen soziodemographischen Merkmalen u und räumlicher Identität $z u$ vermuten ist.

\subsection{Personenbezogene EinfluBfaktoren}

Im Rahmen der vorliegenden Untersuchung zur räumlichen Identität werden die individuellen Merkmale - Wohndauer, Geburtsort, Wohnstatus und sozio-ökonomischer status - im Hinblick auf ihren Beitrag zur Erklärung der Verbundenheit mit einer vorgegebenen räumlichen Bezugsgröße überprüft.

Verfügen die Bewohner eines Referenzraums über eine lange Wohndauer, so sind Auswirkungen auf den Identifikationsgrad $z u$ erwarten. Es ist $z u$ vermuten, daß die wohndauer nicht per se von großer Bedeutung ist, sondern vielmehr eine wichtige Voraussetzung zum Aufbau eines ständigen Verkehrskreises mit nachbarschaftlichen und freundschaftlichen Beziehungen darstellt. Eine lange Wohndauer ist somit als Chance zu verstehen, soziale Kontakte zu knüpfen, raumbezogene soziale Netzwerke aufzubauen, und in den betreffenden Sozialzusammenhang integriert $\mathrm{zu}$ werden. Folgende Tendenzhypothese ist daher im Rahmen der empirischen Analyse räumlicher Identität zu untersuchen: 
HP1 Die Wohndauer hat einen signifikanten Einfluß auf die Höhe der Identifikation.

Im Referenzraum gebürtige Personen unterscheiden sich von Bewohnern, welche erst seit wenigen Jahren im betreffenden Raum ansässig sind. Es ist plausibel anzunehmen, daß Bewohner, welche schon immer im Referenzraum gelebt haben, höhere Identifikationswerte aufweisen als alle übrigen Bewohner. Dies ist möglicherweise darauf zurückzuführen, daß die im Referenzraum gebürtigen Personen zugang zum charakteristischen "Tiefenwissen" haben, welches Auswärtigen weitgehend verschlossen bleibt. Es ist daher zu vermuten:

$\mathrm{HP}_{2}$ Der Geburtsort hat einen signifikanten Einfluß auf die Höhe der Identifikation, d.h., die Identifikation von Personen, die in einem bestimmten ort geboren sind, ist höher als die von Auswärtigen.

Eine identitätssteigernde Wirkung ist darüber hinaus bei Bewohnern zu vermuten, welche uiber Wohneigentum oder Bodenbesitz verfügen. Festansässigkeit und erhöhtes Wohnprestige werden mit diesen Attributen assoziiert. 270 Vereinzelt wird Wohneigentum auch als Indikator für die Existenz eines "emotional investment" in den Referenzraum herangezogen. 271 Daraus ergibt sich die folgende Untersuchungshypothese:

$\mathrm{HP}_{3}$ Der Wohnstatus hat einen signifikanten Einfluß auf die Höhe der Identifikation, d.h. Personen die uiber Wohneigentum verfügen, identifizieren sich mehr mit dem ort in dem sie leben, als Auswärtige.

$270 \mathrm{Vgl}$. Becker, H., Keim, K.D., Wahrnehmung in der städtischen Umwelt, a.a.0., s. 104.

271 Vgl. Taylor, R.B., Gottfredson, S.D., Attachment to place: Discriminant Validity and Impacts of Disorder and Diversity, a.a.0., S. $530 \mathrm{f}$. 
Schließlich lassen sich Unterschiede räumlicher Zugehörigkeiten in Abhängigkeit vom sozio-ökonomischen Status (Bildungsstand) vermuten. Vereinzelt wird der Bildungsstand sogar als die entscheidende Variable zur Erklärung raumbezogener Verbundenheit betrachtet. $272 \mathrm{zu}$ überprüfen ist daher die Hypothese:

$\mathrm{HP}_{4}$ Der sozio-ökonomische Status (Bildungsniveau) hat einen signifikanten Einfluß auf die Höhe der Identifikation, d.h. je niedriger der sozio-ökonomische Status, umso höher ist die Identifikation mit dem ort.

Bevor die verschiedenen Untersuchungshypothesen überprüft werden wird zunächst der Datenrahmen sowie ein überblick über die verwendeten statistischen Auswertungsverfahren aufgezeigt.

272 Vgl. Bassand, M., Hainard, F., Regionale sozio-kulturelle Dynamik, a.a.0., s. 87 . 

men des städte- und Regionenmarketing

Die Hypothesenüberprüfung zu den Einflußgrößen räumlicher Identität geschieht auf der Grundlage einer im Jahre 1990 durch das Meinungsforschungsinstitut EMNID in Bielefeld durchgeführten mündlichen Befragung von Bewohnern des Münsterlandes. Die Erstellung des Fragebogens erfolgte durch das Institut für Marketing der Universität Münster im Auftrag der vier Münsterlandkreise Borken, Coesfeld, Steinfurt und Warendorf sowie der Stadt Münster. Das Ziel der Zusammenarbeit im Projekt „Regionenmarketing Münsterland“ bestand darin, die informatorischen Grundlagen für die Planung eines Marketingkonzeptes zu schaffen.273

273 Mit der Befragung von Bewohnern des Münsterlandes wurde insbesondere das $\mathrm{ziel}$ verfolgt, die Tragfähigkeit des Begriffes "Münsterland" als Basis für ein Regionenmarketing-Konzept Münsterland $\mathrm{zu}$ überprüfen. In weiteren Auswertungsschritten sind Unterschiede und Gemeinsamkeiten der Bewohner des Münsterlandes, d.h. der Bewohner der Stadt Münster und der Kreise Borken, Coesfeld, Steinfurt und Warendorf hinsichtlich ihrer Einstellungen $\mathrm{zu}$ ausgewählten Kriterien analysiert worden (Homogenitätsanalyse). Die Befragung von Bewohnern des Muinsterlandes stellt innerhalb des projektes "Regionenmarketing Münsterland" nur ein Element dar. Darüber hinaus sind Fragebögen für die folgenden zielgruppen ausgearbeitet worden: Bundesbiirger (außerhalb des Münsterlandes), Reisebüros sowie Unternehmen. Der Fragebogenkonzeption sind verschiedene Expertenworkshops mit Entscheidungsträgern des Münsterlandes aus den Bereichen "Kultur/Tourismus" sowie "Wirtschaft" sowie eine studentische Projekt-Arbeitsgemeinschaft vorausgegangen. Die ausfühliche Dokumentation der empirischen Untersuchungsergebnisse sowie die Ergebnisse der im Rahmen der Projekt-Arbeitsgemeinschaft erstellten Situationsanalyse ist nachzulesen in: Mef- 
Die Befragung der Bewohner des Münsterlandes erfolgte als Bestandteil des „EMNID-Omnibus", d.h. in Zusammenhang mit anderen EMNID-Teilbefragungen. Diese Vorgehensweise stellt eine hohe Rücklaufquote der Befragung sicher und gewährleistet schnelle Durchführbarkeit. Der Fragebogen umfaßt 10 Fragenkomplexe, bestehend aus insgesamt 26 Fragen. Die Grundgesamtheit wurde als die Bevölkerung der MünsterlandKreise und der Stadt Münster im Alter von 14 und mehr Jahren definiert. Die Stichprobe wurde entsprechend den Bevölkerungsanteilen im Münsterland vorgenommen und umfaßt insgesamt 1003 Fälle. 274

Mit Blick auf das Untersuchungsinteresse der vorliegenden Arbeit werden die beiden folgenden Fragenkomplexe einer näheren Analyse unterzogen: 275

1. Ausmaß der Verbundenheit bzw. Identifikation mit vorgegebenen räumlichen Bezugsgrößen verschiedener Maßstabsebenen

2. Beurteilung ausgewählter Besonderheiten der Region Münsterland

Die Auswertung erfolgte am Institut für Marketing mit Hilfe des Softwarepaketes sPSS für Windows (Statistical Package for the Social Sciences). Neben den multivariaten Analysemethoden der Faktoren-, Regression-, Cluster- und

fert, H., u.a., Marketing für das Münsterland - Eine Bestandsaufnahme auf der Grundlage sekundärstatistischer Analysen, Münster 1989.; Meffert, H., Regionenmarketing Muinsterland, a.a.o..

274 Die zusammensetzung der stichprobe ergibt sich wie folgt: Stadt Münster 18,2 $8(n=182)$, Kreis Borken 22, 8 \& (228), Kreis Coesfeld 12 \& (120), Kreis Steinfurt 29 o (290), Kreis Warendorf 17,9 \% (179).

275 Darüber hinaus wurden weitere Fragenkomplexe erfaßt, die jedoch für den Untersuchungszweck der vorliegenden Arbeit nicht relevant sind. 
Diskriminanzanalyse wurden Verfahren zur überprüung von Merkmalsunterschieden eingesetzt. 276

1.2 Analyse der Ausprägungsformen räumlicher Identifikationen auf verschiedenen MaBstabsebenen

Die deskriptive Analyse räumlicher Identität verfolgt das Ziel, die räumlichen Zugehörigkeitsgefühle der befragten Regionsbewohner darzustellen, empirisch zu überprüfen und Unterschiede zwischen verschiedenen Bewohnergruppen festzustellen.

Aus Abbildung 15 geht hervor, daß der Mikro-, Meso- und Makromaßstab jeweils durch eine oder mehrere räumliche Bezugsgrößen repräsentiert ist. Während die Mikroebene durch den Wohnort jedes Befragten repräsentiert wird, beinhaltet der Makrobereich die Bundesrepublik Deutschland sowie Europa. Dem Mesomaßstab sind drei Regionen zugeordnet, welche sich hinsichtlich ihrer flächenhaften Ausdehnung in eine aufsteigende Reihenfolge ordnen lassen: Das Münsterland als die kleinste Region, es folgt Westfalen und das ubergeordnete Bundesland Nordrhein-Westfalen.

$276 \mathrm{Zu}$ den einzelnen Prozeduren innerhalb des spss-Programm-Paketes vgl. SPSS GmbH Software, sPSS ${ }^{\circledR}$ für Windows ${ }^{2 m}$. Anwenderbauch für das Basis system, München 1993.; Schubö, W., Uhlinger, H.-M., Perleth, Ch., Schröger, E., Sierwald, W., Handbuch der Programmersionen 4,0 und SPSS-X 3.0, stuttgart und New York 1991, S. $257 \mathrm{ff}$. sowie Zörkendörfer, S., Statistische Datenanalyse mit dem Programmpaket sPSS-X, Softwareinformationen 13 des Rechenzentrums der WestfälischenWilhelms-Universität Münster, 4. Aufl., Münster 1988, S. 1 ff.; Backhaus, K., u.a., Multivariate Analysemethoden, 6. Aufl., Berlin u.a. 1990, s. 1 ff.; zu den Testverfahren vgl. Bauer, F., Datenanalyse mit SPSS, Berlin 1984, S. $84 \mathrm{ff..}$ 


\begin{tabular}{|c|c|c|c|}
\hline $\begin{array}{l}\text { Räumliche } \\
\text { Identität }\end{array}$ & Maßstabsebene & Statement & Auspägungen \\
\hline \multirow{3}{*}{$\begin{array}{l}\text { Identifzierung von } \\
\text { Identifikation mit }\end{array}$} & $\begin{array}{l}\text { Mikro: } \\
\text { - Wohnort }\end{array}$ & \multirow{3}{*}{$\begin{array}{l}\text { "... sagen Sie mir bitte } \\
\text { jeweils wie stark Sie } \\
\text { sich damit verbunden } \\
\text { fühlen." }\end{array}$} & \multirow{3}{*}{$\begin{array}{c}1=\begin{array}{l}\text { Skala } 1 \text { bis } 5 \\
\text { damit fühle ich } \\
\text { mich stark verbun } \\
\text { den/identifiziere } \\
\text { ich mich }\end{array} \\
5=\text { damit fühle ich } \\
\text { mich nicht verbun- } \\
\begin{array}{l}\text { den } / \text { identifiziere } \\
\text { ich mich nicht }\end{array}\end{array}$} \\
\hline & $\begin{array}{l}\text { Meso: } \\
\text { - Münsterland } \\
\text { - Westfalen } \\
\text { - Bundesland NRW }\end{array}$ & & \\
\hline & $\begin{array}{l}\text { Makro: } \\
\text { - Bundesrepublik D } \\
\text { - Europa }\end{array}$ & & \\
\hline
\end{tabular}

Abb.15: Erfassung räumlicher Identität auf verschiedenen räumlichen Maßstabsbereichen

Die Regionen sind nicht hinreichend durch die Größe ihrer Areale beschrieben. Wesentliche Unterschiede bestehen hinsichtlich der traditionellen Bedeutung. Beim Bundesland Nordrhein-Westfalen handelt es sich um einen Administrativraum, der als Ergebnis hoheitlicher Entscheidungen gebildet worden ist und rechtliche und verwaltungstechnische Geltungsbereiche abgrenzt. Die Regionen Münsterland und Westfalen sind demgegenüber weitgehend historisch gewachsene Gebiete, welche sich nicht trennscharf auf der Grundlage administrativer Grenzverläufe beschreiben und abgrenzen lassen.

1.21 Ableitung genereller Muster räumlicher Identifikationen

Anhand einer Fünfer-Notenskala wurden die räumlichen Identifikationen 277 der befragten Bewohner des Münsterlandes

277 Für die Darstellung der empirischen Untersuchungsergebnisse werden in übereinstimmung mit der Formulierung der Statements die Begriffe "Verbundenheit", "Verbundenheitsgefüh l ", "zugehörigkeit(en)", 
direkt erfaßt. Abbildung 16 stellt die Ergebnisse nach den abgefragten räumlichen Maßstabsbereichen zusammen.

Aus Sicht der befragten Bewohner des Münsterlandes bietet die Wohngemeinde die stärkste Identifikationsbasis. Das Müsterland besitzt nach der Bundesrepublik Deutschland die drittstärkste Identifikationskraft. Demgegenüber ist die Identifikation mit westfalen signifikant geringer ausgeprägt. Die schwächste Identifikationsbasis bilden das Bundesland Nordrhein-Westfalen und Europa.

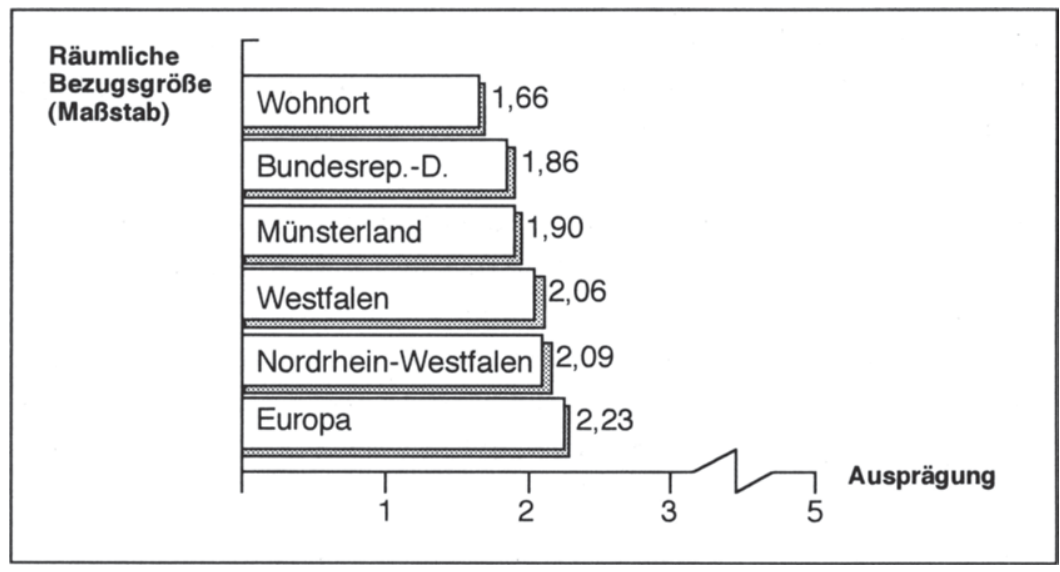

Abb.16:Identifikationsanker der Bürger des Münsterlandes

Quelle: Meffert, H., Regionenmarketing Münsterland, a.a.0., s. 38 .

Die Untersuchungsergebnisse zeigen auf, daß die Identifikation mit allen vorgegebenen Maßstabsbereichen durchweg sehr hoch ist. Dessen ungeachtet wird deutlich, daß in übereinstimmung mit den Ergebnissen sozialwissenschaftlicher Nachbardisziplinen der unmittelbaren Wohnumgebung als maßgeblicher Referenzraum räumlicher Zugehörigkeiten der zentrale Stellenwert zukommt. 278 Das Beispiel Münsterland

"Zugehörigkeitsgefühl" sowie "Identifikation(en)" synonym verwendet. 
läßt darüber hinaus die Tendenzaussage zu, daß Administrativräumen als Bezugsgröße räumlicher Identifikationen eine vergleichsweise nachrangige Bedeutung zukommt.

Angesichts der geringen Unterschiede in der Ausprägung räumlicher zugehörigkeiten $\mathrm{zu}$ den vorgegebenen Maßstabsbereichen ergibt sich die Frage, inwiefern sich Beziehungen zwischen den räumlichen Zugehörigkeiten auf den verschiedenen räumlichen Maßstabsebenen ableiten lassen. Hierzu wurde anhand einer explorativen Faktorenanalyse 279 eine Verd $i c h$ t ung der raumbezogenen Identifikationen vorgenommen. Die Abbildung 17 zeigt das aufbereitete Ergebnis einer nach dem Kaiser-Kriterium ermittelten zwei faktoriellen Lösung. 280

Die hohen Faktorladungen des ersten Faktors auf die traditionsreichen Regionen Münsterland und Westfalen sowie auf den Wohnort kennzeichnen deutlich eine räumliche orientierung, welche als Heimatorientierung umschrieben werden kann. Diese Bezeichnung erscheint zutreffend, obwohl der Administrativraum Nordrhein-Westfalen gleicherma-

279 Vgl. zur Faktorenanalyse z.B. Backhaus, K., u.a., Multivariate Analysemethoden, a.a.0., s. $67 \mathrm{ff} .$, Meffert, H., Marketingforschung und Käuferverhalten, a.a.O., S. $257 \mathrm{ff.;}$ Meffert, H., Marktforschung, Wiesbaden 1986, S. 83 ff.; Bleymüller, J., Faktorenanalyse, Münster 1978 .; Überla, K., Faktorenanalyse, Berlin, u.a. 1972.; Revensdorf, D., Lehrbuch der Faktorenanalyse, Stuttgart 1976.; Ost, F., (Hrsg.), Multivariate statistische Verfahren, Berlin 1984, S. 575 ff.; Weiber, R., Faktorenanalyse, St. Gallen 1984 .

280 Nach dem Kaiser-Kriterium werden nur Faktoren mit einem Eigenwert größer als 1 generiert. Der Eigenwert eines Faktors erklärt dessen Anteil an der Varianz aller Einzelvariablen. Als Schätzverfahren kam in der vorliegenden Analyse die Hauptkomponentenmethode zur Anwendung. Zur besseren Interpretation der Faktorenstruktur wurde eine varimax-Rotation durchgeführt. Vgl. zum Verfahren der Faktorenanalyse Backhaus, K., u.a., Multivariate Analysemethoden, a.a.0., S. 67 ff.; Meffert, H., Marketingforschung und Käuferverhalten, a.a.0., s. 264 . 
Ben diesem Faktor zugerechnet werden muß. Seine Faktorladung ist jedoch vergleichsweise am geringsten.

Der zweite Faktor zeichnet sich durch besonders hohe Faktorladungen bei den räumlichen Bezugsgrößen Bundesrepublik Deutschland und Europa aus. Aufgrund der sehr geringen Faktorladungen bei den Variablen des Mikro- und Mesobereiches läßt sich der zweite Faktor als überregionale orientierung interpretieren. Allerdings ist auch die Identifikation mit Nordrhein-Westfalen mit diesem Faktor verbunden. Interessant erscheint weiterhin, daß dieser Faktor maßgeblich mit administrativen räumlichen Einheiten in engem Zusammenhang steht.

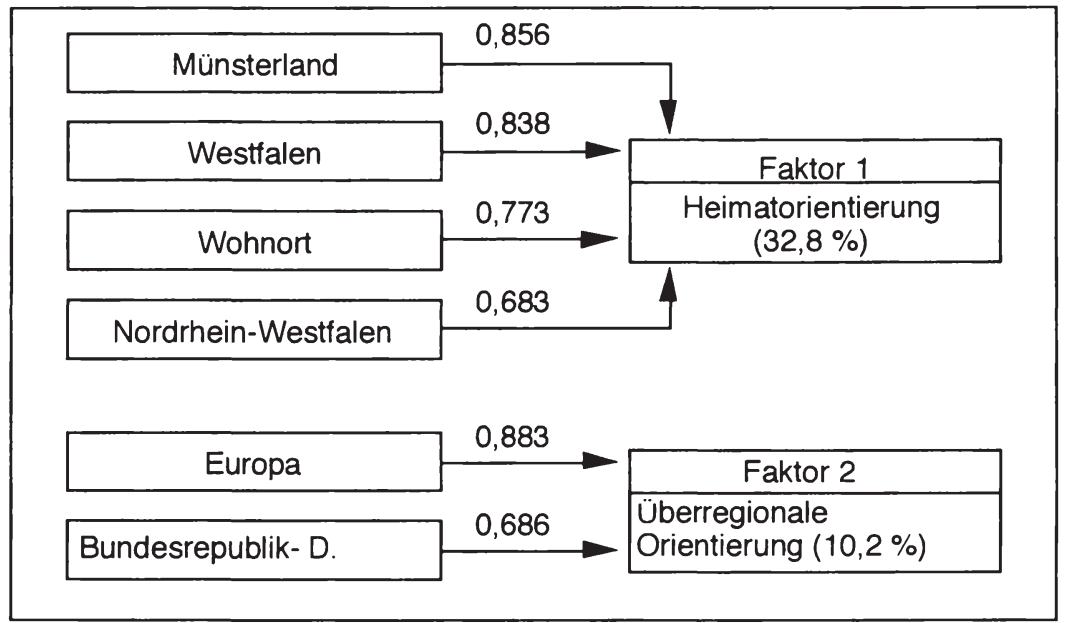

Abb.17: Faktoranalytisch verdichtete räumliche Zugehörigkeitsgefühle

Zusammenfassend läßt sich feststellen, daß sich die räumlichen Identifikationen der befragten Bewohner des Münsterlandes durch eine Schwerpunktsetzung auf eine

- Heimatorientierung und eine

- überregionale orientierung 
kennzeichnen lassen. Ausgehend von diesem Analyseergebnis ist der Frage nachzugehen, inwiefern sich Identifikationstypen ableiten lassen, die sich durch ähnliche Muster ihrer räumlichen Verbundenheits- oder Identifikationsgefüle charakterisieren lassen.

1.22 Typologie räumlicher Identifikationen

Unter Verwendung des Clusteranalyseverfahrens 281 können die befragten Bewohner des Münsterlandes in Gruppen aufgeteilt werden, die sich im Hinblick auf ihre räumlichen orientierungen möglichst ähnlich und untereinander möglichst unähnlich sind.

Entsprechend der Strukturierung der einzelnen Identifikationen nach den zuvor ermittelten räumlichen orientierungen 282 zeigt die Abbildung 18 die clusterspezifischen Unterschiede der einzelnen Identifikationstypen. Die Abbildung verdeutlicht, daß die Cluster wesentliche Unterschiede aufweisen, die sich wie folgt beschreiben lassen:

281 In der vorliegenden Untersuchung wurde im Rahmen der Clusteranalyse die Ward-Methode als Algorithmus zur Gruppenbildung verwendet. Die ermittelte Anzahl der Cluster wurde anhand des Elbow-Kriterium festgelegt. Die optimale clusteranzahl ist dann erreicht, wenn eine weitere Verringerung der Clusteranzahl einen relativ starken Heterogenitätszuwachs nach sich ziehen wïrde. Vgl. zur Clusteranalyse Backhaus, K., u.a., Multivariate Analysemethoden, a.a.0., S. 115 ff.; Meffert, H., Marketingforschung und Käuferverhalten, a.a.0., S. 267 ff.; Meffert, H., Marktforschung, a.a.0., S. $91 \mathrm{ff.;}$ Steinhausen, D., Langer, K., Clusteranalyse, Berlin u.a. 1977 .

282 Bei der Interpretation wurden die Identifikationen entsprechend der zugehörigkeit zu den ermittelten Faktoren strukturiert und im Zusammenhang dargestellt. 
cluster 1: Die "Wohnortfans mit überregionaler orientierung" (43 \%)

Die Bewohner des Münsterlandes, welche diesem Cluster zugerechnet werden, zeichnen sich durch stark unterdurchschnittliche Ausprägungen auf jeder Maßstabsebene aus. Sämtliche Identifikationen auf dem Mikro- und Mesomaßstab sind stark unterdurchschnittlich ausgeprägt. Der durch die Bundesrepublik und Europa repräsentierte Makromaßstab ist zwar gleichermaßen unterdurchschnittlich ausgeprägt, jedoch sind die Abweichungen vom Mittelwert geringfügiger als bei den übrigen räumlichen Bezugsgrößen.

\begin{tabular}{|l|c|c|}
\hline Cluster & CL. 1 & CL. 2 \\
\hline Münsterland & -- & ++ \\
Nordrhein-Westfalen & -- & ++ \\
Westfalen & -- & ++ \\
Wohnort & -- & ++ \\
\hline $\begin{array}{l}\text { Bundesrepublik } \\
\text { Europa }\end{array}$ & - & + \\
\hline Clustergröße $(100 \%=1003)$ & $43 \%$ & $57 \%$ \\
\hline
\end{tabular}

$\mathrm{Abb} .18$ : Clusterbildung nach räumlichen Maßstabsbereichen

cluster 2: D i e "Undifferenzierten Enthusiasten" ( $57 \%$ )

In diesem Cluster weisen die räumlichen Bezugsgrößen auf dem Mikro- und Mesomaßstab eine stark überdurchschnittliche Ausprägung auf. Die von den befragten Bewohnern geäuBerten Identifikationen lassen sich als extrem kennzeichnen. Vergleichsweise gering, jedoch auf hohem Niveau, sind 
die räumlichen Identifikationen auf dem Makromaßstab ausgeprägt. Insgesamt wird deutlich, daß die administrativen Räume - Nordrhein-Westfalen, Bundesrepublik, Europa - ein vergleichsweise geringes Identifikationspotential aufweisen.

Eine Diskriminanzanalyse zur überprüfung der Trennschärfe der einzelnen Identifikationstypen wurde auf der Grundlage der räumlichen orientierungen durchgeführt.283 Daraus geht hervor, daß sich beide cluster unterscheiden und zu eindeutigen Klassifikationsergebnissen führen. 284

283 Die Diskriminanzanalyse bietet die Möglichkeit, durch Ermittlung von Diskriminanzkoeffizienten Aussagen über die relative Bedeutung der einzelnen Identifikationen zur Erklärung der unterschiedlichen Identifikationscluster abzuleiten. U.a. gibt der Anteil korrekter Klassifikationen als Gütemaß an, inwieweit die auf der Grundlage der Diskriminanzwerte prognostizierte Zugehörigkeit von Bewohnern des Münsterlandes mit einer spezifischen räumlichen orientierung mit der tatsächlichen Gruppenstruktur der Clusteranalyse übereinstimmt. Die Trennschärfe der Gruppen steigt mit der Höhe der richtigen Klassifikationen. Vgl. zum Verfahren der Diskriminanzanalyse Backhaus, K., u.a., Multivariate Analysemethoden, a.a.o., S. $116 \mathrm{ff.;}$ Meffert, H., Marketingforschung und Käuferverhalten, a.a.0., s. 279 ff.; Meffert, H., Marktforschung, a.a.o., S. 104 ff..

284 Eine Überprüfung der Güte der Klassifizierung verdeutlicht, daß 90,63\% der befragten Bewohner des Münsterlandes richtig zugeordnet werden konnten, wodurch eine sehr gute Trennschärfe der Identifikationscluster bestätigt wird. Zudem deutet der Wilks-Lambda mit 0,38 bei einem Signifikanzniveau von $\alpha<0,05$ auf eine ausreichend hohe Trennschärfe hin. 


\subsection{Personenbezogene Bestimmungsfaktoren}

\subsection{Einfluß der Wohndauer}

Im Rahmen der Analyse personenbezogener Bestimmungsfaktoren steht zunächst die wohndauer als Einflußfaktor im Mittelpunkt der Betrachtung. Empirische Untersuchungen uber einen (positiven) Zusammenhang zwischen Wohndauer und Identifikation konnten am Beispiel von Nachbarschaften, Städten und Regionen wiederholt belegt werden.285

Um eine einfachere Vergleichbarkeit zwischen verschiedenen Wohndauergruppen herzustellen, wird neben der isolierten Betrachtung ein Index über die Mikro- und Mesoebene sowie über die Makroebene gebildet.

Die Wohndauer wird in der vorliegenden Untersuchung in 3 Klassen unterteilt, wobei zwischen Bewohnern des Münsterlandes unterschieden wird, die bis zu 10 Jahre, zwischen 11 und 20 Jahren und bereits seit 20 Jahren und länger in der Region leben. Betrachtet man zunächst die in Tabelle 1 dargestellten Beziehungen zwischen räumlichen Bezugsgrößen und den Wohndauergruppen auf der Mikro- und Mesoebene, so

285 Ein Überblick über Untersuchungen, welche einen Zusammenhang zwischen der Zufriedenheit mit der Nachbarschaft ("Satisfaction") und der Wohndauer nachweisen, findet sich in: Gerson, K., Attachment to place, a.a.O., S. 152.; Zum Zusammenhang zwischen Wohndauer und Identifikation mit der stadt vgl. Lalli, M., Stadtbezogene Identität, a.a.0., S. $27 \mathrm{f} ., 36,43,46$ ff.; zu Wohndauer und Region vgl. Schulze, H.-J., Regionale Identität Erwachsener, a.a.0., S. 322 f.; Esser, H., Lokale Identifikation im Ruhrgebiet, a.a.o., S. 112.; zu Wohndauer und "place", bzw. zum Zusammenhang zwischen Wohndauer und Identifikationsgrad ohne Bezugnahme auf einen spezifischen räumlichen Maßstabsbereich vgl. beispielsweise Relph, E., Place and Placelessness, a.a.0., S. 29.; Tuan, Y.-F., Place: An Experimental Perspective, a.a.0., S. 164.; Hilgers, W.W., Lebensraum, Sozialisation und Identitätsbildung, a.a.O., s. 66 . 
ist zwischen den bis $\mathrm{zu} 10$ Jahren und den zwischen 11 und 20 Jahren im Münsterland lebenden Personen ein signifikanter Zusammenhang ausschließlich auf der Ebene des Wohnorts nachzuweisen. Die Unterschiede der räumlichen Identifikationen werden jedoch mit steigender Wohndauer mit Bezug auf alle räumlichen Bezugsgrößen des Mikro- und Mesobereiches signifikant. Der über diese räumlichen Bezugsgrößen gebildete Index räumlicher Identifikationen zeigt auf, daß lediglich mit Blick auf die erste Wohndauergruppe $(<11$ Jahre) kein signifikanter Zusammenhang besteht. Dieses Ergebnis ist auf das Fehlen signifikanter Beziehungen zwischen der Identifikation mit dem Münsterland, Westfalen und Nordrhein-Westfalen derjenigen Bewohner zurückzuführen, die weniger als 11 und zwischen 11 und 20 Jahren im Münsterland leben.

\begin{tabular}{|c|c|c|c|c|c|c|}
\hline Identifikationen Wohndauer & $<11$ & $11-20$ & $>20$ & & & \\
\hline Wohnort & 3,93 & 4,24 & 4,5 & ** & $\star \star$ & $* *$ \\
\hline Münsterland & 3,76 & 3,93 & 4,25 & & $\star \star$ & ** \\
\hline Westfalen & 3,67 & 3,62 & 4,09 & & ** & ** \\
\hline Nordrhein-Westfalen & 3,69 & 3,71 & 4,01 & & $\star \star$ & $*$ \\
\hline Bundesrepublik-D. & 3,88 & 4,05 & 4,23 & * & $* \star$ & ** \\
\hline Europa & 3,55 & 3,82 & 3,81 & \# & ** & \\
\hline Index Meso & 3,76 & 3,87 & 4,21 & & * & ** \\
\hline Index Makro & 3,71 & 3,94 & 4,02 & ** & ** & \\
\hline
\end{tabular}

Legende:

Signifikanzniveau $a<=0,10:$ * $a<=0,01:$ *

Tab. 1: Analyse räumlicher Identität differenziert nach Wohndauergruppen

Auf dem Makromaßstab (Bundesrepublik, Europa) lassen sich mit Ausnahme der Europa-Identifikation und Bewohnern, die zwischen 11 und 20 Jahren im Münsterland leben, durchweg signifikante Zusammenhänge feststellen. Der über den Ma- 
kromaßstab gebildete Index ist lediglich für die beiden langen Wohndauergruppen signifikant. Ein Blick auf die Mittelwertausprägungen der Identifikationen auf der Makroebene macht deutlich, daß die Unterschiede im Vergleich zum Mikro- und Mesomaßstab vergleichsweise gering sind. Es läßt sich zwar ein Zuwachs der Identifikation mit steigender Wohndauer feststellen, jedoch muß die Signifikanz der Ergebnisse uberwiegend auf den hohen stichprobenumfang (1003 Fälle) zurückgeführt werden. Darüber hinaus ist unter sachlogischen Gesichtspunkten ein zusammenhang zwischen der Wohndauer in einem spezifischen Wohnort respektive in einer bestimmten Region und dem Ausmaß der Identifikation mit großräumigen Bezugsgrößen in Frage zu stellen. Die über alle Maßstabsebenen hinweg $\mathrm{zu}$ beobachtende Zunahme räumlicher Verbundenheit unterstreicht damit die Vermutung, daß die Wohndauer eine Hintergrundvariable darstellt. So ist anzunehmen, daß weniger die in einem bestimmten ort oder Region verbrachte zeit für die Höhe der Verbundenheit ausschlaggebend ist, sondern die Wohndauer vielmehr als Chance interpretiert werden muß, z.B. soziale Kontakte zu knüpfen.

In einem weiteren Analyseschritt wird der Einfluß der Wohndauer in Abhängigkeit von der Clusterzugehörigkeit analysiert. Aus Tabelle 2 gehen die Ausprägungen der Identifikationen für verschiedene Wohndauergruppen und für die beiden Identifikationstypen hervor. Wenn in cluster 1 ( "Wohnortsfans mit uberregionaler orientierung“) die beiden ersten Wohndauergruppen herausgegriffen werden, kann ein signifikanter zusammenhang ausschließlich auf der Ebene des Wohnortes nachgewiesen werden. Bei einem Signifikanzniveau von $a>=0,10$ ist der Mittelwertunterschied jedoch vergleichsweise gering signifikant.

Alle übrigen Maßstabsbereiche sind nicht signifikant. Das gleiche gilt für die Indices. Erst beim Vergleich zwischen Personen, die weniger als 11 Jahre und mehr als 20 Jahre 


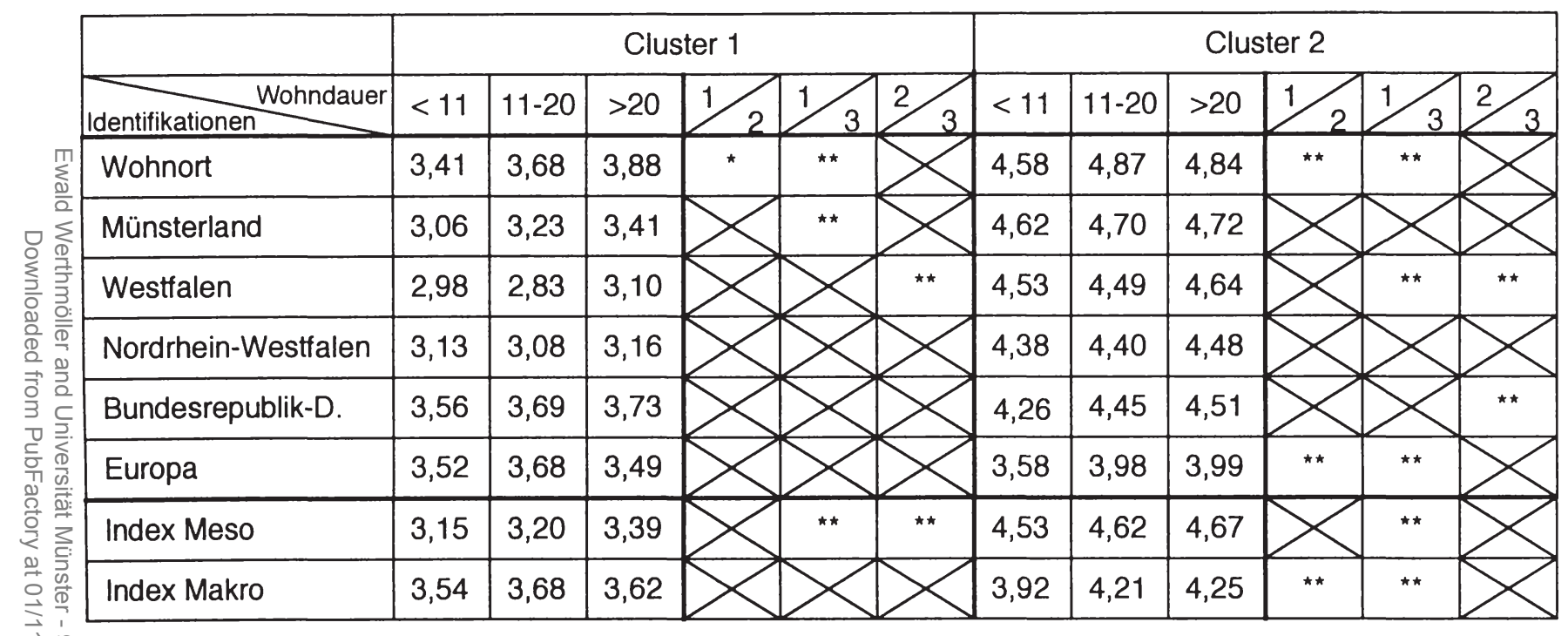

\section{Legende:}

Signifikanzniveau $\alpha<=0,10:$ * $\quad \alpha<=0,01$ : *

Tab. 2: Analyse räumlicher Identität differenziert nach Wohndauergruppen und Clusterzugehörigkeit 
in der Region wohnen, läßt sich ein stark signifikanter Unterschied $(a>=0,01)$ der Identifikationen mit dem Wohnort sowie dem Münsterland nachweisen. Unterschiede hinsichtlich der Identifikation mit Westfalen werden bei Bewohnern deutlich, die zwischen 10 und 20 Jahren und mehr als 20 Jahren in der Region wohnen.

Insgesamt wird für dieses Cluster deutlich, daß die Höhe der Identifikation - unabhängig von der jeweiligen Wohndauerklasse - mit dem Maßstabsbereich ansteigt. Ein Nachweis signifikanter Unterschiede zwischen verschiedenen Wohndauergruppen ist jedoch primär für die kleineren Maßstabsebenen möglich. Die Ergebnisse unterstreichen, daß die Identifikation mit wachsender Maßstabsebene (NRM, Bundesrepublik und Europa) nicht sinnvoll mit der Wohndauer in einem bestimmten ort in Verbindung gebracht werden kann. Die Signifikanz der Ergebnisse auf der Mikroebene (Wohnort) und den traditionsreichen Mesobereichen läßt demgegenüber die Vermutung $\mathrm{zu}$, daß sich die Mensch-UmweltBeziehung auf der Mikro- und Mesoebene in Abhängigkeit von der Wohndauer verändert und für das Individuum bedeutsam ist.

\subsection{EinfluB des Geburtsortes}

Zur überprüfung, inwiefern das Ausmaß räumlicher Verbundenheit auf die berücksichtigten Bezugsgrößen des Mikround Mesomaßstabes vom Geburtsort abhängt, sind die befragten Bewohner des Münsterlandes in zwei Gruppen eingeteilt worden. In der ersten Gruppe sind Personen zusammengefaßt, welche im Münsterland geboren sind. Die zweite Gruppe setzt sich aus Bewohnern der Region zusammen, welche woanders geboren sind.

Mit dem Wohnort, Münsterland und Westfalen werden drei räumliche Bezugsgrößen als Untersuchungseinheiten heraus- 
gegriffen, und die Verbundenheit der Münsterland-Bewohner zu diesen Ebenen exemplarisch untersucht. 286 Der Makromaßstab wird ausgeblendet, weil ein Zusammenhang zwischen Geburtsort und der Identifikation mit einer großräumigen Bezugsgröße nicht plausibel erklärbar ist.

Aus Tabelle 3 geht hervor, daß die Zugehörigkeit der in der Region geborenen Bewohner mit dem Wohnort, dem Münsterland und Westfalen durchweg stärker ausgeprägt ist, als bei den auswärtig Geborenen. Wiederum wird deutlich, daß dem Wohnort als Bezugsobjekt räumlicher Identifikationen der größte stellenwert zukommt, während die geringer ausgeprägte Identifikationsbasis von Münsterland und Westfalen ungefähr gleich stark ausgeprägt ist.

\begin{tabular}{|c|c|c|c|c|c|c|c|}
\hline Identifikationen & \multirow{3}{*}{$\begin{array}{l}\text { MS+ } \\
\text { MSL } \\
4,49\end{array}$} & \multirow{3}{*}{\begin{tabular}{|c} 
ausser- \\
halb
\end{tabular}} & \multirow{3}{*}{$\frac{\text { T-Test }}{\star \star \star}$} & \multicolumn{2}{|c|}{$\begin{array}{l}\text { Kovariate } \\
\text { Wohndauer }\end{array}$} & \multicolumn{2}{|c|}{$\begin{array}{l}\text { Kovariate } \\
\text { Alter }\end{array}$} \\
\hline \multirow{2}{*}{ Wohnort } & & & & Kov. & n.s. & Kov. & n.s. \\
\hline & & & & Haupt & ** & Haupt & $\star \star *$ \\
\hline \multirow{2}{*}{ Münsterland } & \multirow{2}{*}{4,25} & \multirow{2}{*}{3,88} & \multirow{2}{*}{$\star \star \star$} & Kov. & n.s. & Kov. & n.s. \\
\hline & & & & Haupt & ** & Haupt & $\star \star$ \\
\hline \multirow{2}{*}{ Westfalen } & \multirow{2}{*}{4,06} & \multirow{2}{*}{3,73} & \multirow[t]{2}{*}{ ** } & Kov. & n.s. & Kov. & n.s. \\
\hline & & & & Haupt & $\star \star \star$ & Haupt & $\star \star \star$ \\
\hline$n$ & 565 & 438 & & & & & \\
\hline
\end{tabular}

Legende:

Signifikanzniveau: $\alpha<=0,05$ : *

Tab. 3: Analyse räumlicher Identität differenziert nach dem Geburtsort

Der durchgeführte Mittelwertvergleichstest unterstreicht, daß die Unterschiede zwischen in der Region gebürtigen Personen und außerhalb Geborenen für alle ausgewählten

286 Der Makrobereich (Bundesrepublik, Europa) sowie der Administrativraum Nordrhein-Westfalen werden in der Analyse nicht berücksichtigt, weil eine Beziehung zwischen der Gebuirtigkeit und dem Ausmaß der Identifikation zu diesen Makrobereichen sachlich nicht erklärbar ist. 
Maßstabsbereiche signifikant sind, so daß der Hypothese $\mathrm{HS}_{2}$ zugestimmt werden muß.

In einem weiteren Analyseschritt ist der Mittelwertvergleichstest um die Einbeziehung von Kovariaten ergänzt worden.287 Dabei zeigt sich, daß die ergänzende Berücksichtigung von Wohndauer und Alter $z u$ keinen signifikanten Ergebnissen führt. Die Gebürtigkeit stellt somit einen eigenständigen Einflußfaktor auf das Ausmaß der Verbundenheit dar, welche weder durch die Wohndauer noch durch das Alter der Befragten beeinflußt ist. Somit ist die Untersuchungshypothese $\mathrm{HS}_{2}$ auch unter Einbeziehung von Kovariaten $\mathrm{zu}$ bestätigen.

\begin{tabular}{|l|c|c|c|c|c|c|}
\hline \multicolumn{1}{|c|}{ Geburtsort } & \multicolumn{3}{|c|}{ Cluster 1 } & \multicolumn{3}{c|}{ Cluster 2 } \\
\begin{tabular}{|l|c|c|c|c|c|}
\hline MS+ \\
MSL
\end{tabular} & $\begin{array}{l}\text { ausser- } \\
\text { halb }\end{array}$ & T-Test & $\begin{array}{l}\text { MS+ } \\
\text { MSL }\end{array}$ & $\begin{array}{l}\text { ausser- } \\
\text { halb }\end{array}$ & T-Test \\
\hline Wohnort & 3,92 & 3,50 & $* \star$ & 4,83 & 4,76 \\
\hline Münsterland & 3,47 & 3,08 & $* \star$ & 4,72 & 4,67 \\
\hline Westfalen & 3,12 & 2,90 & $\star \star$ & 4,63 & 4,55 \\
\hline$n$ & 212 & 217 & & 353 & 22 & \\
\hline
\end{tabular}

Legende:

Signifikanzniveau: $\alpha<=0,05:$ *

Tab. 4: Analyse räumlicher Identität differenziert nach Geburtsort und clusterzugehörigkeit

Vergleicht man den Einfluß der Gebürtigkeit auf die Identifikationshöhe getrennt nach der clusterzugehörigkeit der befragten Bewohner des Münsterlandes, wird ein differen-

287 Die Einbeziehung von Kovariaten ist formal rechnerisch ein Anwendungsfall der Regressionsanalyse. Kovariate sind metrisch skalierte, unabhängige, d.h. erklärende Variable. Die Einbeziehung von Kovariaten ist im Rahmen einer Varianzanalyse sinnvoll, wenn neben der oder den nominalskalierten unabhängigen Variablen ein Einfluß metrisch skalierter erklärender Variablen vermutet wird. Vgl. Backhaus, K., u.a., Multivariate Analysemethoden, a.a.0., S. $62 \mathrm{f}$. 
zierteres Bild deutlich. Tabelle 4 verdeutlicht, daß sich die "undifferenzierten Enthusiasten" mit allen ausgewählten räumlichen Bezugsgrößen extrem identifizieren. Die Mittelwertunterschiede sind nicht signifikant. Demgegenüber kommt der Mittelwertvergleichstest bei den "Wohnortfans mit überregionaler orientierung" zu einem signifikanten Ergebnis. Unterschiede zwischen in der Region gebürtigen und anderswo gebürtigen Personen lassen sich für jede untersuchte räumliche Bezugsgröße nachweisen. Dieses cluster zeichnet sich insgesamt durch eine schärfere Polarisierung aus. Während bei den „undifferenzierten Enthusiasten" angesichts extremer Identifikationsausprägungen Unterschiede zwischen Untergruppen kaum noch ins Gewicht fallen, werden bei den differenziert urteilenden "Wohnortfans" deutliche Unterschiede der Identifikationshöhe deutlich, welche ursächlich auf die Gebürtigkeit zurückgeführt werden müssen.

\subsection{EinfluB des Wohnstatus}

Die Ausprägung räumlicher Identifikationen differenziert nach dem Wohnstatus zeigt die Tabelle 5. Auf allen 3 berücksichtigten Maßstabsebenen (Wohnort, Münsterland, Westfalen) lassen sich signifikante Unterschiede zwischen dem Verbundenheitsgefühl von Bewohnern feststellen, welche über ein eigenes Haus oder eine Eigentumswohnung verfügen und solchen, welche zur Miete wohnen. Dieses Ergebnis wird auch durch die zusätzliche Berücksichtigung von Kovariaten nicht in Frage gestellt. Weder die Wohndauer noch das Alter der Befragten üben einen signifikanten Einfluß auf die Identifikationshöhe aus. Es ist somit der Hypothese $\mathrm{H}_{2} \mathrm{zu}-$ zustimmen, daß der Wohnstatus einen Einfluß auf die Identifikationshöhe ausübt.

In Tabelle 6 wird eine Differenzierung nach den Clusterzugehörigkeiten vorgenommen. Unabhängig von der clusterzuge- 
hörigkeit gilt, daß sich Personen mit Wohneigentum durchweg stärker identifizieren als "Mieter". Bei den "Wohnortfans" läßt sich ein signifikanter Zusammenhang zwischen Wohnstatus und Identifikationshöhe ausschließlich für den Wohnort nachweisen. Das den beiden Regionen (Münsterland und Westfalen) gegenüber bekundete Ausmaß der Verbundenheit ist durchschnittlich hoch ausgeprägt. Unterschiede zwischen Personen mit und ohne Wohneigentum bestehen gar nicht oder nur geringfügig.

\begin{tabular}{|c|c|c|c|c|c|c|c|}
\hline $\begin{array}{l}\text { Identifike- Wohnstatus } \\
\text { tionen }\end{array}$ & $\begin{array}{l}\text { Eigen- } \\
\text { tum }\end{array}$ & Miete & T-Test & \multicolumn{2}{|c|}{$\begin{array}{l}\text { Kovariate } \\
\text { Wohndauer }\end{array}$} & \multicolumn{2}{|c|}{$\begin{array}{l}\text { Kovariate } \\
\text { Alter }\end{array}$} \\
\hline Wohnort & 4,52 & 4,15 & 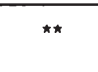 & \begin{tabular}{|l|} 
Kov. \\
Haupt
\end{tabular} & \begin{tabular}{|l|} 
n.s. \\
$* \star$
\end{tabular} & \begin{tabular}{|l} 
Kov. \\
Haupt
\end{tabular} & \begin{tabular}{|l|} 
n.s. \\
$\star \star$
\end{tabular} \\
\hline \multirow{2}{*}{ Münsterland } & \multirow{2}{*}{4,22} & \multirow{2}{*}{3,96} & \multirow{2}{*}{$\star \star \star$} & Kov. & n.s. & Kov. & n.s. \\
\hline & & & & Haupt & $\star \star$ & Haupt & 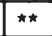 \\
\hline \multirow{2}{*}{ Westfalen } & \multirow{2}{*}{4,06} & \multirow{2}{*}{3,78} & \multirow[t]{2}{*}{ ** } & Kov. & n.s. & Kov. & n.s. \\
\hline & & & & Haupt & ** & Haupt & $\star \star$ \\
\hline$n$ & 495 & 508 & & & & & \\
\hline
\end{tabular}

Legende:

Signifikanzniveau: $\alpha<=0,05:$ *

Tab. 5: Analyse räumlicher Identität differenziert nach Wohnstatus

Mit Blick auf die Signifikanz der Untersuchungsergebnisse zeichnen beide Cluster ein spiegelverkehrtes Bild. Während sich bei den "Wohnortfans" signifikante Mittelwertunterschiede ausschließlich auf der Mikroebene nachweisen lassen, lassen sich bei den "Undifferenzierten Enthusiasten" Unterschiede ausschließlich auf der Ebene des Münsterlandes und westalen feststellen.

Die Untersuchungsergebnisse lassen die Tendenzaussage $z u$, daß ein Einfluß des Wohnstatus insbesondere auf der Mikroebene signifikant gegeben ist. 


\begin{tabular}{|l|c|c|c|c|c|c|}
\hline & \multicolumn{3}{|c|}{ Cluster 1 } & \multicolumn{3}{c|}{ Cluster 2 } \\
\hline Identifikationen Wohnstatus & $\begin{array}{l}\text { Eigen- } \\
\text { tum }\end{array}$ & Miete & T-Test & $\begin{array}{l}\text { Eigen- } \\
\text { tum }\end{array}$ & Miete & T-Test \\
\hline Wohnort & 4,01 & 3,49 & $\star \star$ & 4,82 & 4,78 & \\
\hline Münsterland & 3,29 & 3,26 & $\star \star$ & 4,76 & 4,62 & \\
\hline Westfalen & 3,01 & 3,01 & $* \star$ & 4,68 & 4,50 & \\
\hline $\mathrm{n}$ & 182 & 247 & & 313 & 261 & \\
\hline
\end{tabular}

Legende:

Signifikanzniveau: $\alpha<=0,05:$ **

Tab. 6: Analyse räumlicher Identität differenziert nach Wohnstatus und clusterzugehörigkeit

\subsection{EinfluB des sozio-ökonomischen status}

Der Untersuchung räumlicher Identifikationen in Abhängigkeit vom Bildungsstand liegt die Aufteilung der Befragten in drei Gruppen zugrunde. Volksschulabschluß, der Besuch einer weiterbildenden Schule sowie Abitur oder studium bilden in diesem Zusammenhang die drei Untersuchungsklassen. Der Mittelwertvergleich in Tabelle 7 zeigt auf, daß ein geringwertiger schulabschluß tendenziell eine höhere Verbundenheit nach sich zieht, als dies bei den Absolventen einer weiterbildenden Schule oder Bewohnern mit Abitur oder studium der Fall ist. Diese auf allen Maßstabsbereichen durchgängig zu beobachtenden trifft lediglich für Europa nicht zu. Dort verhält es sich genau umgekehrt: Personen mit Abitur/Studium fülen sich intensiver mit Europa verbunden als alle übrigen Gruppen.

Wenn die Identifikation mit Europa ausgeklammert wird, lassen sich signifikante Unterschiede zwischen Befragten, welche eine Volksschule und solchen, die eine weiterführende schule besucht auf allen Maßstabsebene 


\begin{tabular}{|c|c|c|c|c|c|c|}
\hline Identifikationen & $\begin{array}{l}\text { Volks- } \\
\text { schule }\end{array}$ & $\begin{array}{l}\text { Weiter- } \\
\text { bild. S. }\end{array}$ & $\begin{array}{l}\text { Abi., } \\
\text { Studium }\end{array}$ & & & \\
\hline Wohnort & 4,49 & 4,52 & 3,79 & & ** & \\
\hline Münsterland & 4,24 & 4,14 & 3,67 & & $\star \star$ & * \\
\hline Westfalen & 4,09 & 3,95 & 3,47 & 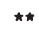 & ** & 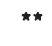 \\
\hline Nordrhein-Westfalen & 4,09 & 3,82 & 3,48 & ** & $\star \star$ & ** \\
\hline Bundesrepublik-D. & 4,26 & 4,18 & 3,76 & & $\star \star$ & 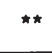 \\
\hline Europa & 3,75 & 3,68 & 3,85 & & & \\
\hline Index Meso & 4,23 & 4,11 & 3,60 & ** & $\star \star \star$ & 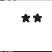 \\
\hline Index Makro & 4,00 & 3,93 & 3,80 & & $\star \star \star$ & \\
\hline
\end{tabular}

Legende:

Signifikanzniveau: $\alpha<=0,05:$ *

Tab.7: Analyse räumlicher Identität differenziert nach Bildungsstand

nachweisen. Das gleiche gilt für Personen, welche eine weiterführende Schule besucht haben und solchen, die über Abitur/Studium verfügen. Allerdings lassen sich keine signifikanten Ergebnisse auf der Mikroebene nachweisen.

Auf der Makroebene lassen sich gleichermaßen keine Unterschiede zwischen den beiden unteren Bildungsgruppen feststellen. Signifikante Unterschiede $\mathrm{zu}$ Personen mit Abitur/Studium werden jedoch im Hinblick auf die Identifikation mit der Bundesrepublik erkennbar. Die Identifikationen der Personen mit Abitur/studium sind signifikant unterschiedlich von allen übrigen Bildungsgruppen. Europa ist nicht ausschließlich durch die hohe zustimmung gut ausgebildeter Person gekennzeichnet. Auffallend ist auch, daß die Verbundenheit mit Europa zwar über alle Bildungskategorien hinweg ein hohes Niveau aufweist. Im Vergleich mit den übrigen räumlichen Bezugsgrößen ist die Verbundenheit jedoch deutlich geringer ausgeprägt. 
Tabelle 8 zeigt die Ausprägung der räumlichen Verbundenheitsgefühle differenziert nach der clusterzugehörigkeit. Tendenziell wird deutlich, daß sich in der Gruppe der "Wohnortfans mit uberregionaler orientierung" die Befragten mit Volksschulbildung von den beiden übrigen Bildungsgruppen signifikant unterscheiden. Eine Ausnahme bildet die Identifikation mit dem Wohnort und Europa, welche zwischen Bewohnern mit Volksschulabschluß und solchen, welche eine weiterbildende schule besucht haben, keinen signifikanten Unterschied erkennen läßt. Noch deutlicher fällt der Unterschied zwischen Volksschulabschluß und Abitur/studium aus. Ein signifikanter Unterschied läßt sich dort ausschließlich für Europa nachweisen, mit dem sich Personen mit höherer schulbildung stärker identifizieren, als alle übrigen Bildungsgruppen. Demgegenüber lassen sich signifikante Unterschiede der Identifikationen zwischen Bewohnern mit weiterbildender schule und Abitur oder Studium nur für Europa nachweisen.

Die Ergebnisse lassen zusammenfassend die Tendenzaussage $z u$, daß sich Personen mit geringwertigem Schulabschluß (a) generell sehr stark mit allen vorgegebenen räumlichen Bezugsgrößen identifizieren und (b) durch eine besondere Verbundenheit gegenüber dem Wohnort und der Bundesrepublik gekennzeichnet sind. Personen mit höherwertigem Bildungsstand identifizieren sich mit allen vorgegebenen räumlichen Bezugsgrößen deutlich geringer als die beiden ubrigen Bildungsklassen. Eine Ausnahme stellt die Identifikation mit Europa dar, welche über alle Bildungsklassen hinweg in dieser Gruppe den höchsten Identifikationswert erhält. Deutlich wird, daß mit steigendem Bildungsstand die Identifikation mit der Bundesrepublik nachläßt, die Verbundenheit zu Europa jedoch steigt.

Personen mit geringem Bildungsstand scheinen durch einen "Kirchturmhorizont" gekennzeichnet zu sein, welcher ein Verlassen des Heimatumfeldes nicht erforderlich erscheinen 
läßt. Demgegenüber lassen sich Personen mit qualifizierter Ausbildung durch eine zwiespältige Grundhaltung charakterisieren. Das ausgeprägte Zugehörigkeitsgefühl gegenüber dem Wohnort und Europa bringt in diesem Zusammenhang eine paradoxe Grundhaltung zum Ausdruck. Offensichtlich stellt die in einer ausgeprägten Wohnortbindung zum Ausdruck kommende "Bodenständigkeit" keinen widerspruch dar zu einer "kosmopolitischen" Haltung. Die europäische Grundorientierung läßt beispielsweise einen modernen, aufgeschlossenen und Grenzen überschreitenden Lebensstil vermuten. Gleichzeitig scheint die große Bedeutung der Mikroebene die bisweilen konstatierte „Wiederentdeckung des Heimatphänomens" auch empirisch zu stützen.

Die „undifferenzierten Enthusiasten” zeichnen sich durch keine signifikanten Mittelwertunterschiede aus. Die Mittelwerte der verschiedenen Identifikationen sind für alle der vorgegebenen räumlichen Bezugsgrößen nahezu maximal, so daß Unterschiede statistisch kaum oder gar nicht ins Gewicht fallen. Diese Schlußfolgerung trifft besonders deutlich auf die Mesoebene $z u$, auf der sich für das Bundesland Nordrhein-Westfalen ein schwach signifikanter Unterschied lediglich zwischen Volksschulabschluß und Abitur oder studium nachweisen läßt. 


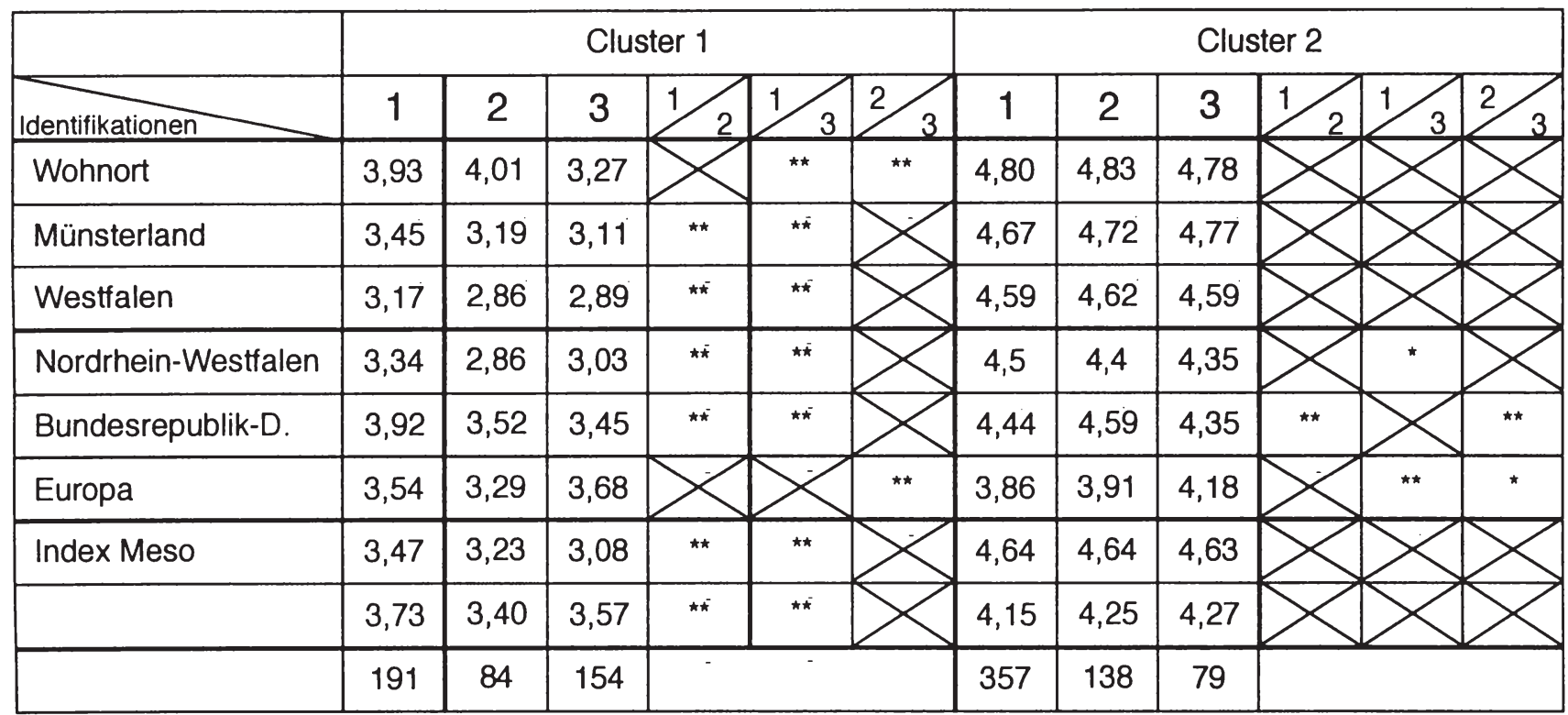

\section{Legende:}

1. Volksschule mit/ohne Abschluß

2. Weiterbildende Schule

Signifikanzniveau: $\alpha<=0,05$ : *

3. Abitur/Studium

Tab. 8: Analyse räumlicher Identität differenziert nach Bildungsstand und Clusterzugehörigkeit 


\subsection{Raumbezogene Bestimmungs faktoren}

Im folgenden steht die Frage im Vordergrund, ob und in welchem Umfang, die Besonderheiten des Münsterlandes die Identifikation mit dem Wohnort oder der Region erklären. Als statistische Methode zur Überprüfung des Erklärungsbeitrages räumlicher Besonderheiten auf Identifikation wird die multiple Regressionsanalyse angewendet.288 Sie ermöglicht die Untersuchung ganzer Ursachenkomplexe auf der Grundlage von Abhängigkeiten zwischen einer metrisch skalierten Variablen und mehreren unabhängigen, metrisch skalierten Variablen. Als Gütemaß der Regressionsfunktion dient das multiple (totale) Bestimmtheitsmaß $\mathrm{r}^{2}$, das mit Werten zwischen 0 und 1 zum Ausdruck bringt, inwieweit die abhängige Variable durch die Gesamtheit der berücksichtigten unabhängigen Variablen bestimmt wird. Die Variablenauswahl wird durch einen Algorithmus derart gesteuert, daß die im Untersuchungsaufbau berücksichtigten Besonderheiten des Münsterlandes jeweils schrittweise nach ihrer statistischen wichtigkeit aufgenommen werden.289 Als Aufnahmekriterium dient dabei der Schwellenwert von $\alpha<=0,05$ für das Signifikanzniveau des F-Wertes. 290

$288 \mathrm{Vgl}$. zur Regressionsanalyse z.B. Backhaus, K., u.a., Multivariate Analysemethoden, a.a.o., s. 1 ff.; Meffert, H., Marketingforschung und Käuferverhalten, a.a.O., S. $247 \mathrm{ff.,} 294 \mathrm{ff}$; Ders., Marktforschung, a.a.0., S. 17 ff.; Bleymïller, J., u.a., Statistik für Wirtschaftswissenschaftler, München 1981, S. 135 ff..

289 In der schrittweisen Regression werden die unabhängigen Variablen einzeln nacheinander in die Regresssionsgleichung einbezogen, wobei jeweils diejenige Variable ausgewählt wird, die ein bestimmtes Gütekriterium maximiert. Aus der Rangfolge der Aufnahme läßt sich die statistische Wichtigkeit der Variablen erkennen. Vgl. Backhaus, K., u.a., Multivariate Analysemethoden, a.a.0., s. 23 .

290 Vgl. zum F-Test bei multipler Regression Bleymüller, J., Gehlert, G., Gülicher, H., Statistik für Wirtschaftswissenschaftler, a.a.o., s. $148 \mathrm{ff}$. 
In den beiden folgenden Abschnitten wird mit dem Wohnort als abhängige Variable zunächst die Identifikation mit dem Mikromaßstab analysiert. In einem weiteren Analyseschritt steht die Mesoebene im Vordergrund. Als Referenzgröße wird dazu exemplarisch das Münsterland als abhängige Variable untersucht. Als unabhängige Variablen gehen jeweils eine Reihe von Besonderheiten in die Untersuchungsaufbau ein, welche im Vorfeld der Fragebogenentwicklung im Rahmen von Expertenworkshops mit Verantwortlichen des Münsterlandes aus den Bereichen Tourismus und Kultur als besonders charakteristisch bezeichnet worden sind. 291

1.41 Wirkung auf die Identifikation mit dem wohnort (Mikromaßstab)

Der Einfluß von Besonderheiten des Münsterlandes auf die Identifikation mit dem wohnort zeigt die Tabelle 9. Die Ergebnisse zeigen, daß die im Untersuchungsaufbau berücksichtigten Charakteristika des Münsterlandes insgesamt einen signifikanten Einfluß auf die Identifikation mit dem Wohnort haben. Es kann somit vermutet werden, daß eine $A b-$ strahlung der für die Region charakteristischen Eigenschaften auf den Wohnort stattfindet. Von daher ist die Hypothese $\mathrm{H}_{\mathrm{B} 1} \mathrm{zu}$ bestätigen. Die multiple Regression der analysierten Besonderheiten des Münsterlandes stellt nach Reihenfolge ihrer statistischen wichtigkeit (Analyseschritt) die Merkmale "regionale Veranstaltungen", "liebenswerte Städte/Orte" sowie "eigener Flughafen (FMO)" als wesentliche Einflußgrößen heraus. Anhand der standardisierten Regressionskoeffizienten läßt sich verdeutlichen, daß die "regionalen Veranstaltungen" sowie die "liebenswerten Städte/Orte" einen fast dreimal so großen Einfluß auf die Identifikation mit dem wohnort ausüben als

$291 \mathrm{Vgl}$. Meffert, H., Regionenmarketing Münsterland, a.a.0., s. 19-27. 
das Kriterium "eigener Flughafen (FMO)“. Das multiple Bestimmtheitsmaß attestiert dabei diesen Besonderheiten einen Erklärungswert von insgesamt $12,1 \%$.

\begin{tabular}{|c|c|c|c|c|}
\hline Identitätsfaktor & $\begin{array}{l}\text { Analyse- } \\
\text { Schritt }\end{array}$ & $\begin{array}{c}\text { Regressions } \\
\text { koeffizient } \\
\text { B }\end{array}$ & $\begin{array}{l}\text { Standardisierter } \\
\text { Regressionskoef- } \\
\text { fizient B }\end{array}$ & $\begin{array}{l}\text { Signifikanz- } \\
\text { niveau } \\
(\alpha<=0,05)\end{array}$ \\
\hline Wasserburgen & & $-0,017780$ & I & $\begin{array}{r}0,2082 \\
\text { n.s. }\end{array}$ \\
\hline Universität Münster & & 0.058198 & 1 & $\begin{array}{r}0,0706 \\
\text { n.s. }\end{array}$ \\
\hline Eigener Flughafen (FMO) & 3 & $-0,057353$ & $-0,069034$ & 0,0260 \\
\hline Hohe Lebensqualität & & $-0,062443$ & 1 & $\begin{array}{r}0,0600 \\
\text { n.s. }\end{array}$ \\
\hline Liebenswerte Städte/Orte & 2 & $-0,223448$ & $-0,187916$ & 0,0000 \\
\hline Sympathische Menschen & & $-0,053190$ & I & $\begin{array}{r}0,1448 \\
\text { n.s. }\end{array}$ \\
\hline Zentrale Lage & & 0,028198 & I & $\begin{array}{r}0,8318 \\
\text { n.s. }\end{array}$ \\
\hline Geringe Kriminalität & & 0,006481 & I & $\begin{array}{r}0,4032 \\
\text { n.s. }\end{array}$ \\
\hline $\begin{array}{l}\text { Bietet Möglichkeiten für } \\
\text { "Ferien auf dem Bauernhof" }\end{array}$ & & $-0,017780$ & 1 & $\begin{array}{r}0,6198 \\
\text { n.s. }\end{array}$ \\
\hline Regionale Veranstaltungen & 1 & $-0,187370$ & $-0,192391$ & 0,0000 \\
\hline Bestimmtheitsmass $r^{2}$ & & & 0,12071 & \\
\hline
\end{tabular}

Tab. 9: Wirkung inhaltlicher Besonderheiten auf die Identifikation mit dem Wohnort

Insgesamt können aus der multiplen Regression drei zentrale Gestaltungsparameter zur Einflußnahme auf die Wohnortidentifikation gewonnen werden, so daß die Hypothese $\mathrm{H}_{\mathrm{B} 1}$ bestätigt wird:

Die Untersuchungsergebnisse belegen generell den zentralen Stellenwert regionaler Veranstaltungen als Handlungsfeld des SRM. Obwohl diese Profilierungsmaßnahmen primär darauf ausgerichtet sind, die regionale Identität zu steigern, wird eine identitätsstiftende Wirkung auch auf dem Mikromaßstab deutlich. Diese Schlußfolgerung ist insbesondere 
mit Blick auf die Effizienz der eingesetzten Kommunikationsbudgets bedeutsam. So müssen beispielsweise die mit der Planung und Durchfürung regionaler Veranstaltungen verbundenen Kosten differenziert beurteilt werden, weil nicht nur die erhoffte Außenwirkung, sondern darüber hinaus eine Innenwirkung erzielt wird.

Die empirischen Ergebnisse dieses Untersuchungsabschnittes belegen darüber hinaus die identitätssteigernde wirkung der "liebenswerten Städte/Orte". Möglicherweise ist dies unter anderem darauf zurückzuführen, daß den vielerorts initiierten Aktivitäten und Wettbewerben zur Dorferneuerung bzw. -verschönerung nicht nur eine vordergründige Kosmetikfunktion zukommt, sondern derartige programme zumindest in gewissem Umfang - eine verstärkte Bindungswirkung zur Folge haben.

Schließlich unterstreichen die vorliegenden Untersuchungsergebnisse, daß die Existenz eines eigenen Flughafens im Wahrnehmungsbild der Bewohner als wichtiger Identitätsfaktor aufgefaßt wird. Wenn alle drei zentralen Identitätsfaktoren im zusammenhang betrachtet werden zeigt sich ein vielschichtiges Bild. So verweisen die regionalen Veranstaltungen und der eigene Flughafen wiederum auf eine grenzüberschreitende, möglicherweise "kosmopolitische" Orientierung hin, während beim kriterium der "liebenswerten Städte/Orte" das Augenmerk mehr auf die Heimatorientierung gelegt wird.

1.42 Wirkung auf die Identifikation mit der Region (Mesomaßstab)

Neben dem Wohnort wurde mit Hilfe der multiplen Regressionsanalyse die Wirkung räumlicher Besonderheiten des Münsterlandes auf die Identifikation mit der Region überprüft. Als abhängige variable ging das Münsterland in die 
Untersuchung ein. Wie aus Tabelle 10 hervorgeht, erreichen insgesamt 6 Besonderheiten das kritische Signifikanzniveau von $\alpha<=0,05$ bezogen auf den F-Wert. Im einzelnen wird deutlich, daß - geordnet nach der statistischen wichtigkeit - eine signifikante Wirkung der Besonderheiten "zentrale Lage”, "hohe Lebensqualität", „Wasserburgen", "eigener Flughafen (FMO), "liebenswerte Städte/Orte" sowie "regionale Veranstaltungen" vorliegt.

\begin{tabular}{|c|c|c|c|c|}
\hline Identitätsfaktor & $\begin{array}{l}\text { Analyse- } \\
\text { Schritt }\end{array}$ & $\begin{array}{c}\text { Regressions } \\
\text { koeffizient } \\
\text { B }\end{array}$ & $\begin{array}{l}\text { Standardisierter } \\
\text { Regressionskoef- } \\
\text { fizient } B\end{array}$ & $\begin{array}{l}\text { Signifikanz- } \\
\text { niveau } \\
(\alpha<=0,05)\end{array}$ \\
\hline Wasserburgen & 3 & $-0,160227$ & 0,048479 & 0,0010 \\
\hline Universität Münster & & 0,034485 & 1 & $\begin{array}{r}0,2767 \\
\text { n.s. }\end{array}$ \\
\hline Eigener Flughafen (FMO) & 4 & $-0,075026$ & 0,028149 & $\overline{0,0078}$ \\
\hline Hohe Lebensqualität & 2 & $-0,109904$ & 0,038744 & 0,0047 \\
\hline Liebenswerte Städte/Orte & 5 & $-0,141139$ & 0,0044522 & 0,0016 \\
\hline Sympathische Menschen & & $-0,046184$ & I & $\begin{array}{r}0,2086 \\
\text { n.s. }\end{array}$ \\
\hline Zentrale Lage & 1 & $-0,91974$ & 0,029755 & 0,0020 \\
\hline Geringe Kriminalität & & 0,032565 & I & $\begin{array}{r}0,2846 \\
\text { n.s. }\end{array}$ \\
\hline $\begin{array}{l}\text { Bietet Möglichkeiten für } \\
\text { "Ferien auf dem Bauernhof" }\end{array}$ & & $-0,047317$ & I & $\begin{array}{r}0,2673 \\
\text { n.s. }\end{array}$ \\
\hline Regionale Veranstaltungen & 6 & $-0,170521$ & 0,038051 & 0,0003 \\
\hline Bestimmtheitsmass $r^{2}$ & & & 0,17477 & \\
\hline
\end{tabular}

Tab. 10: Wirkung inhaltlicher Besonderheiten auf die Identifikation mit der Region

Je ausgeprägter die Identitätsfaktoren als positiv wahrgenommen werden, desto höher ist die Identifikation mit dem Münsterland. Unter Berücksichtigung der standardisierten Regressionskoeffizienten wird die sowohl von den Tourismus-Experten des Münsterlandes als auch im allgemeinen 
Bild der öffentlichkeit bestehende, zentrale Bedeutung der wasserburgen unterstrichen.

Der Blick auf die statistischen Gütekriterien unterstreicht die naheliegende vermutung, daß ein und derselbe Set regionaler Besonderheiten, die Identifikation mit der Region besser erklärt, als die Wohnort-Identifikation. Dies wird beim vergleich der Bestimmtheitsmaße deutlich. während das multiple Bestimmtheitsmaß die Identifikation mit dem Münsterland zu 17,5 \& erklärt, ist dies lediglich zu $12,1 \div$ bei der Identifikation mit dem wohnort möglich.

1.5

Zusammenfassende würdigung der empirischen Ergebnisse

Im Unterschied zur überwiegenden Zahl vergleichbarer Studien sozialwissenschaftlicher Nachbardisziplinen, welche die Analyse einer bestimmten Maßstabsebene (Mikromaßstab) zum Inhalt haben, zeichnet sich die vorliegende empirische Untersuchung durch die Berücksichtigung des gesamten Kontinuums räumlicher Bezugsgrößen aus.292

Die zentrale Bedeutung der Wohndauer, die in empirischen Studien sozialwissenschaftlicher Nachbardisziplinen besonders häufig zum Ausdruck kommt, muß mit Blick auf die vorliegenden Untersuchungsergebnisse differenziert betrachtet werden. Deutlich wird, daß die mit wachsender Wohndauer zu beobachtende Intensivierung des räumlichen Zugehörigkeitsgefühls keineswegs auf den in den meisten untersuchungen im Mittelpunkt stehenden Mikromaßstab begrenzt ist, sondern vielmehr auf allen Maßstabsbereichen gleichermaßen zu beobachten ist. Diese Feststellung ist ein weiterer Hin-

292 Vgl. dazu den überblick über zentrale Forschungsansätze sozialwissenschaftlicher Nachbardisziplinen in Kapa. B. 3.1. 
weis dafür, daß nicht die Wohndauer per se, sondern vielmehr dahinter stehende Einflußfaktoren für die Erklärung räumlicher Identifikationen ausschlaggebend sind. Diese Vermutung erscheint auch insofern plausibel, weil sich die im Zeitablauf intensivierende Identifikation mit räumlichen Bezugsgrößen auf der Makroebene (Bundesrepublik, Europa) nicht mit der Wohndauer in einem bestimmten ort sachlich begründen $1 a ̈ ß t$.

Mit Blick auf die übrigen personenbezogenen Bestimmungsfaktoren räumlicher Identität konnten durchweg die im Vorfeld formulierten Untersuchungshypothesen bestätigt werden. Im einzelnen konnte nachgewiesen werden, daß auf allen Maßstabsebenen

- der Geburtsort

- der Wohnstatus, sowie

- der sozioökonomische Status (Bildungsstand)

jeweils einen signifikanten Einfluß auf die Identifikationshöhe der Befragten ausübt.

Die Untersuchungsergebnisse verdeutlichen darüber hinaus, daß räumliche Besonderheiten einen signifikanten Einfluß auf die Identifikation sowohl mit dem Wohnort als auch mit der Region ausüben. Wenn eine räumliche Bezugsgröße über Merkmale verfügt, welche dem Raum Unverwechselbarkeit und Einzigartigkeit verleihen, können Menschen eine Beziehung nicht nur zu diesen spezifischen Kennzeichen, sondern auch zum Gesamtraum aufbauen. Dabei ist es unerheblich, ob es sich bei einer spezifischen Besonderheit um ein physisches objekt, ein soziales Phänomen ("sympathische Menschen" oder "geringe Kriminalität") oder um speziell zur Attraktivitätssteigerung inszenierte Ereignisse ("regionale veranstaltungen") handelt. 
Unbeantwortet bleibt jedoch die Frage, welche Inhalte die Befragten mit den verschiedenen Identifikationsangeboten verbinden. Zunächst ist zu vermuten, daß physischen Charakteristika eine funktionale Bedeutung zukommt, die sich aus der Zwecksetzung des betreffenden räumlichen Merkmales unmittelbar ableiten läßt. So kommt dem Identitätsfaktor "eigener Flughafen FMO" zunächst die Funktion zu, für die Bewohner des Münsterlandes eine bequeme Reiseplattform zur Verfügung zu stellen, welche einen Transfer beispielsweise zum Düsseldorfer Flughafen überflüssig macht.

In einer groben Zweiteilung lassen sich zwei Funktionen unterscheiden, welche die Identifikation mit räumlichen Bezugsgrößen maßgeblich beeinflussen:

- Personen identifizieren sich möglicherweise bevorzugt mit solchen Räumen, die eine leichte orientierung erlauben ("legibility“). Dies würde erklären, warum eine identitätssteigernde wirkung insbesondere bei besonders prägnanten, visuell auffälligen Besonderheiten nachweisbar ist (z.B. "Wassserburgen", "liebenswerte Städte/Orte“, "Eigener Flughafen").

- Den Besonderheiten kommt darüber hinaus eine Symbolisierungsfunktion $z u$. Insbesondere mit Blick auf die Ausgestaltung von SRM-Konzepten ist die Frage von besonderer Bedeutung, mit welchen Bedeutungen spezifische Besonderheiten des Raumes besetzt sind.

2 . Implikationen für das städte- und Regionenmarketing

Die verschiedenen Bestimmungsfaktoren räumlicher Identität unterscheiden sich hinsichtlich ihrer Beeinflußbarkeit 
durch das SRM.293 So ist beispielsweise eine Einflußnahme auf die bewohnerbezogenen Einflußfaktoren nur indirekt möglich. Der Einsatz des SRM muß deshalb primär bei den angebotsbezogenen Einflußgrößen ansetzen, um im Wahrnehmungsbild interner und externer zielgruppen eine gewünschte Identitätswirkung $z u$ erreichen. In diesem Zusammenhang lassen sich eine Reihe von Erfolgsvoraussetzungen unterscheiden. Dabei ist eine Gruppe von Erfolgsvoraussetzungen auf die Ausgestaltung der organisatorischen Rahmenbedingungen des SRM bezogen. Weitere sind auf die konkrete Ausgestaltung eines SRM-Konzeptes zur Beeinflussung räumlicher Identität ausgerichtet.

2. 1 Stellenwert eines integrierten städte- und Regionenmarketing

Ausgehend von der Zweiseitigkeit des Begriffsverständnisses räumlicher Identität werden mit dem SRM zwei generelle $\mathrm{z}$ ielsetzungen verfolgt:

1. Identifizierung bzw. Identifizierbarkeit des Referenzraums als unverwechselbare Ganzheit durch die $\mathrm{Ziel-}$ $k r e i s$ e ("Identifizierung von").294

2. Förderung der Identifikation der anvisierten Zielkreise mit dem Referenzraum ("Identifikation mit“).295

293 Vgl. dazu noch einmal Kap.B.3.3 sowie Abbildung 13.

294 Angesichts des zunehmenden Wettbewerbs wird die Herausarbeitung eines eigenen Profils als wichtigstes Oberziel für die Durchfürung des SRM aufgefaßt. 56\% der befragten Städte und Regionen gaben an, aus diesem Grunde SRM zu planen und durchzuführen. Vgl. Schückhaus, U., u.a., Stadt- und Regionalmarketing, a.a.0., S. 29 .

295 Die "Verbesserung der Identifikation der Bürger mit dem Standort" wird von $79 \%$ der befragten städte und Regionen als zweitwichtigstes Teilziel des SRM angese- 
Die Identifizierbarkeit einer stadt oder Region als unverwechselbare Ganzheit im Wahrnehmungsbild interner und externer zielgruppen 296 setzt seitens der für den Referenzraum verantwortlichen Entscheider eine ganzheitliche Selbstdarstellung voraus. Eine zersplitterung der kommunikativen Aktivitäten in eine Vielzahl von Einzelmaßnahmen ist demgegenüber mit der Gefahr verbunden, daß ein und dieselbe stadt/Region im Wahrnehmungsbild der Betrachter über eine vielzahl von räumlichen Identitäten verfügt, welche möglicherweise in einem konfliktären Verhältnis zueinander stehen. Aus diesem Grund muß ein integratives SRM-Konzept erstellt werden, welches grundsätzlich alle Leistungsfelder in einem stimmigen Gesamtkonzept einbezieht. Der Kerngedanke derartiger Konzepte besteht darin, die verschiedenen Erfolgs- und Attraktionspotentiale einer Stadt/Region im Zusammenhang $\mathrm{zu}$ sehen. Dies ist erforderlich, weil ein und dieselbe Person gleichzeitig Mitglied verschiedener zielgruppen ist: So wird beispielsweise der Nachfrager nach Industrie- und Gewerbestandorten sein Entscheidungskalkül nicht ausschließlich auf die Beurteilung "harter" ökonomischer Standortfaktoren (Steuern und Abgaben, Fuihlungsvorteile, Infrastruktur usw.) beschränken, sondern darüber hinaus die Attraktivität des Wohn- und Freizeitangebots als Einflußgrößen seiner Standortent-

hen. An der spitze steht mit $83 \%$ die "Erhaltung der Wettbewerbsfähigkeit“. Vgl. Schückhaus, U., u.a., Stadt- und Regionalmarketing, a.a.0., s. 30.

296 Es lassen sich lokale, regionale und überregionale zielgruppen unterscheiden. Bei den lokalen Zielgruppen handelt sich beispielsweise um Bürger, lokale Interessengruppen ( $z \cdot B$. Vereine, Verbände) oder ansässige Wirtschaftsunternehmen. $\mathrm{Zu}$ den regionalen $\mathrm{Zielgruppen}$ $z a ̈ h l e n$ Pendler, Umlandbewohner, ansiedlungswillige Wirtschaftsunternehmen in der Region sowie ansiedlungswillige Arbeitnehmer und Bürger. Überregionale Zielgruppen repräsentieren Touristen, Kongreßreisende, ansiedlungswillige Wirtschaftsunternehmen aus dem Inund Ausland sowie ansiedlungsbereite Arbeitnehmer. Vgl. Schückhaus, U., u.a., stadt- und Regionalmarketing, a.a.0., s. 51 . 
scheidung berücksichtigen. 297 sollte in der betreffenden Stadt/Region jedoch ein standort-, Innenstadt, Tourismus-, Kulturmarketing etc. beziehungslos nebeneinander her betrieben werden, besteht die Gefahr, daß nur bestimmte Teilqualitäten wahrgenommen werden. Möglicherweise wird die betreffende Stadt/Region in Abhängigkeit vom Standpunkt des Betrachters als "Einkaufsstadt", "Kulturstadt" oder "Tourismusparadies" wahrgenommen und nicht als Ganzheit, welche sowohl Möglichkeiten zum einkaufen, zum genießen von kultur als auch zur Erholung usw. gleichzeitig bietet. Die Durchführung von Individualkonzepten ist somit wenig geeignet, Synergien für den Gesamtraum zu nutzen und die Multifunktionalität vieler städte und Regionen herauszustellen.

Die Planung und Umsetzung ganzheitlicher Marketingkonzepte ist kompliziert, weil ein für alle Belange einer stadt oder Region verantwortliches Entscheidungszentrum fehlt. Städte und Regionen sind vielmehr durch ein Neben- und Gegeneinander privater und öffentlicher Akteure gekennzeichnet, welche gemeinsam das Bild der betreffenden Stadt/Region beeinflussen, jedoch in erster Linie ihre individuellen Zielfunktionen optimieren und dabei den "Blick für das Ganze" zwangsläufig zurückstellen.

Vor diesem Hintergrund stellt sich die Frage nach den Voraussetzungen, Merkmalen, und Ausgestaltungsmöglichkeiten einer institutionalisierten zusammenarbeit der verschiedenen Interessens- und Anspruchsgruppen einer Stadt/Region. Dieses "Zweckbündnis" privater und öffentlicher Akteure stellt in diesem Zusammenhang die organisatorische Plattform für die Durchsetzung es SRM dar.

297 Vgl. Hammann, P., Ansätze zu einem Marketing für kommunale Standorte, a.a.0., s. 7 . 
2.2 Erfolgsvoraussetzungen für die Institutionalisierung eines integriertes städte- und Regionenmarketing

Mit Blick auf die organisatorischen Rahmenbedingungen des SRM lassen sich in Anlehnung an die Vorgehensweisen ausgewählter Städte, drei Eckpunkte unterscheiden, welche in Abbildung 19 deutlich werden:

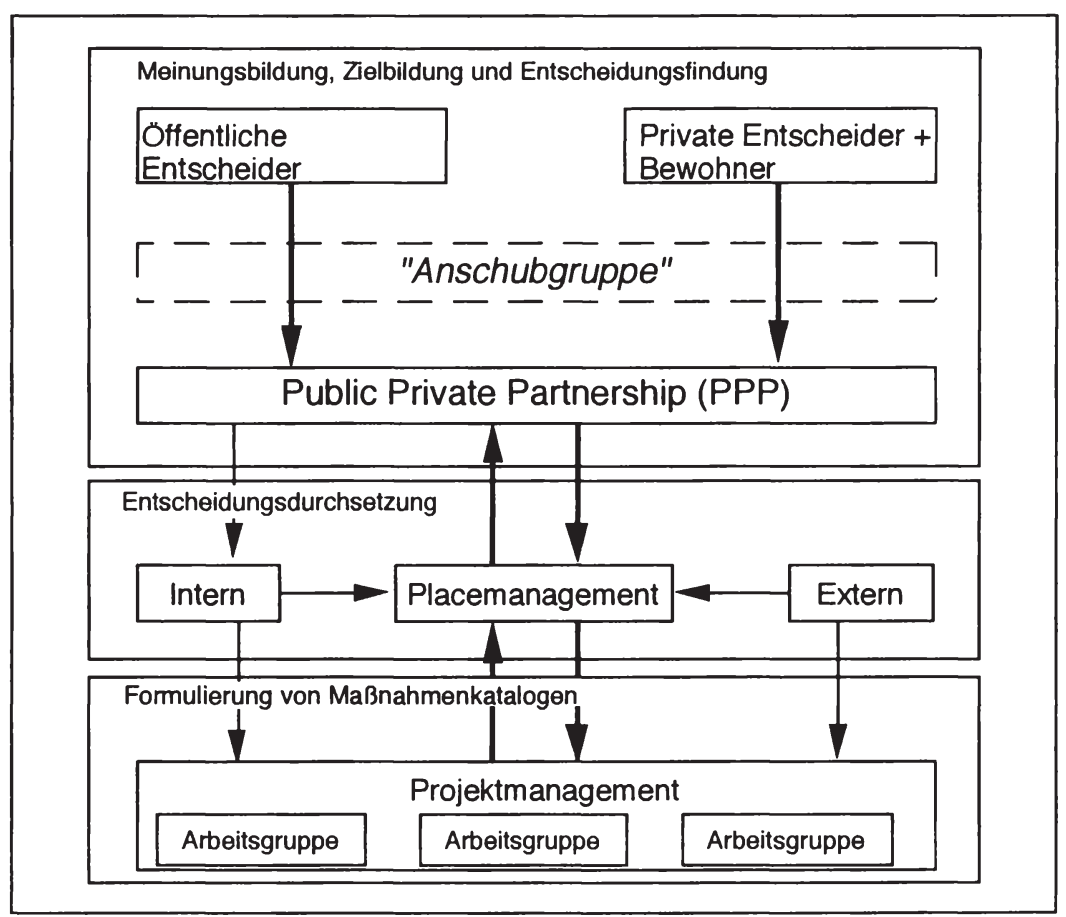

Abb.19: Organisatorische Rahmenbedingungen für das Städte- und Regionenmarketing

Kernstück der Institutionalisierung des SRM ist die Public Private Partnership (PPP) als Kommunikationsforum privater und öffentlicher Interessen mit Meinungsbildungs, Zielbildungs- und Entscheidungsfunktionen. Die PPP setzt sich aus Personen und Gruppen (z.B. Interessenvertreter aus Wirtschaft und Politik) zusammen, welche in regelmäßi- 
gen Zeitabständen eine Koordinierung und Harmonisierung ihrer Interessen "am runden Tisch" suchen. Das Aufgabenspektrum einer PPP ist auf grundsätzlich alle Handlungsfelder ausgerichtet, welche eine Zusammenarbeit privater und öffentlicher Akteure sinnvoll erscheinen lassen. Die Formulierung von raumbezogenen Identitätszielen und die Initiierung eines SRM ist somit als ein mögliches Aufgabenfeld in einem breiten spektrum verschiedenster Bereiche zu betrachten.

Die Maßnahmenplanung sowie die Umsetzung der Programme erfolgt bevorzugt durch ein professionelles placemanagement. Es fungiert als Transferstelle zwischen den in der PPP vertretenen Interessengruppen und als Durchsetzungsorgan für die in der PPP erarbeiteten Marketing-oberziele. Die Einsetzung eines eigenständigen Managementorgans ist erforderlich, um die zur Erreichung der Identitätsziele erforderliche Kontinuität in der kommunikativen Selbstdarstellung sicherzustellen. Im Einzelfall werden unter Federführung des Placemanagements Arbeits-bzw. Projektgruppen zusammengestellt und koordiniert.

2.21 Partnerschaftliche zusammenarbeit privater und öffentlicher Akteure

Ein integratives SRM kann nicht unmittelbar an den beeinflußbaren Produktfacetten 298 ansetzen, weil deren Ausge-

298 Als produktfacetten lassen sich die von privaten und öffentlichen Akteuren im Referenzraum erstellten Waren und Dienstleistungen auffassen. Darüber hinaus setzt sich das "Produkt" aus einer Reihe von Bestandteilen zusammen, welche durch das SRM nicht beeinflußt werden können, aber gleichermaßen mit dem durch den ortsnamen symbolisierten "Produkt" assoziativ verknüpft werden. Dazu zählen beispielsweise Landschaft, Architektur, Klima, Mentalität der Bevölkerung, Geschichte und Tradition, ortstypische Ereignisse (z.B. Wettbewerbe, Großveranstaltungen) usw.. 
staltung in den Zuständigkeitsbereich der entsprechenden privaten oder öffentlichen Akteure fällt. Die Realisierung eines integrativen SRM-Konzeptes ist deshalb an die Konsensbildung und dauerhafte Zusammenarbeit der maßgeblichen gesellschaftlichen Gruppen einer stadt oder Region in der Form einer partnerschaftichen Zusammenarbeit gebunden.

Nach Möglichkeit sollten vertreter aller relevanten geselischaftlichen Gruppen in der PPP vertreten sein. Auf diese Weise ist es möglich, frühzeitig Interessenkonflikte aufzudecken und abzubauen. Die in einer städtischen PPP vertretenen Gruppen lassen sich anschaulich als "PASS" ("Politisch administratives system stadt") umschreiben. Dabei haben die in der Abbildung 20 aufgezeigten Interessenträger nur exemplarische Bedeutung. Die Akquisition geeigneter Personen (bzw. Institutionen) hängt entscheidend von den konkreten Ausgangsbedingungen in der stadt/Region $a b$, so daß auch diesbezüglich nur Tendenzaussagen möglich sind.

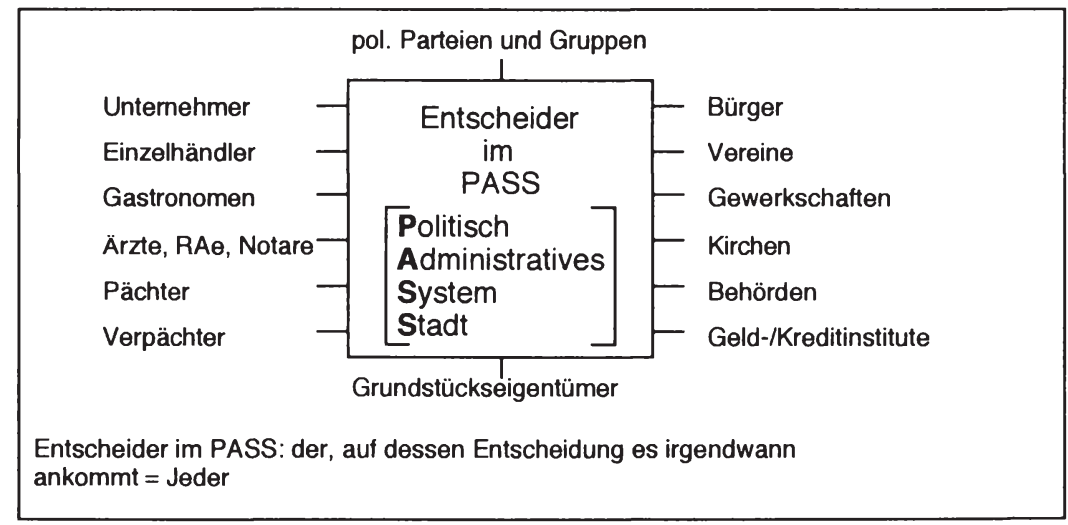

Abb.20: Akteure/Interessen im kommunalen Bereich: das "politisch administrative System Stadt" (PASS)

Quelle: Honert, S. Stadtmarketing und Stadtmanagement, in: Der Städtetag $6 / 1991$, S. 397 . 
Mit Blick auf die Erfahrungen, welche in der Praxis gemacht werden konnten, lassen sich bezüglich der erwünschten Mitgliederstruktur einige Eckpunkte aufzählen. So werden generell größere und bedeutende Unternehmen einbezogen. Darüber hinaus sind Vertreter der Kammern und Verbände zu gewinnen, um die Interessen der kleineren wirtschaftsakteure (Grundstückseigentümer, Kaufleute, Freiberufler, Gewerbetreibende) einzubeziehen. Weitere Interessengruppen sind eher selten. 299

Neben der Mitgliederstruktur sind psychologische Einflüsse zu berücksichtigen:

- Die erfolgreiche Zusammenarbeit setzt voraus, daß private und öffentliche Entscheider die unterschiedliche Kultur des jeweiligen Gegenüber akzeptieren. So hat die öffentliche Hand dafür zu sorgen, daß private Interessen sich entfalten können, und daß diese privaten Interessen auch Teil des Gemeinwohls sind. Die privaten Akteure müssen ihrerseits anerkennen, daß sich ihre Projekte nur im Rahmen eines stimmigen Gesamtkonzeptes entfalten können und das die Einmischung in kommunale Zuständigkeiten möglicherweise die gesamte Zusammenarbeit zum Scheitern verurteilt.

- Darüber hinaus darf die PPP nicht als Plattform für einseitige Forderungen der privaten wirtschaft und der öffentlichen Hand mißbraucht werden. Es muß vielmehr erreicht werden, daß die Interessenvertreter auf ihre jeweiligen Gruppen einwirken und damit Blockaden abbauen.

299 Vgl. Kemming, H., Zur Gestaltung von Stadtmarketing Orientierungen für die Praxis, in: ILS (Hrsg.), Stadtmarketing in der Diskussion, Dortmund 1991, S. 11. 
- Hinsichtlich der Aufgabenverteilung zwischen öffentlicher Hand und privaten Akteuren ist die präzise Abstimmung von Tätigkeitsfeldern gegenseitiger Verantwortlichkeit und eine genaue Definition der partnerschaftlichen Rollen erforderlich.

Neben diesen grundsätzlich zu beachtenden Erfolgsvoraussetzungen, miussen eine Reihe weiterer "Spielregeln“ beachtet werden, welche einen reibungslosen Ablauf der PPP sicherzustellen bezwecken:

- Die PPP sollte jederzeit für neue Mitglieder offen sein, damit alle Interessen im Referenzraum möglichst vollständig vertreten sind. Wenn dies nicht möglich ist, sollten die verschiedenen Interessen zumindest bekannt sein um in den Ausgleichsprozeß einbezogen werden zu können.

- Darüber hinaus muß sichergestellt werden, daß die zur Mitarbeit in der PPP gewonnenen Persönlichkeiten legitimiert sind, für die eigenen Gruppeninteressen $z u$ sprechen.

- Kontinuität in der Zusammenarbeit als Leitziel der PPP setzt die verbindliche Absprache der Beteiligten uber die Grundbedingungen der zusammenarbeit voraus. Insbesondere muß die finanzielle und arbeitsmäßige Belastung für die Mitglieder der PPP aufgezeigt werden. Die PPP muß darüber hinaus über eine angemessene finanzielle Ausstattung verfügen, damit die aus der zusammenarbeit entwickelten Ideen umgesetzt werden können

Die gewählte Kooperationsform sollte als langfristige zusammenarbeit konzipiert sein, welche über einen bloßen Informationsaustausch ( "Debattierclub") hinausgeht und die permanente Initiative und Fortschreibung der Meinungsaustausches gestattet. Für die organisatorische Ausgestaltung 
im einzelnen ist eine ortsspezifische Lösung zu suchen, welche insbesondere von der Größe des Referenzraumes und der sachlichen Schwerpunktsetzung abhängt: 300

- Die Größe des Referenzraumes bestimmt den Abstimmungsbedarf der kommunalen Einrichtungen. Während in kleineren Städten die Aufgaben für Wirtschaftsförderung, Öffentlichkeitsarbeit oder Tourismus vielfach in einer Hand liegen, existieren in Großstädten i.d.R. eigene Ämter für diese Aufgaben.

- Die sachliche Schwerpunktsetzung determiniert die Ausrichtung und die Intensität des SRM (z.B. Schwerpunktlegung auf die Verwaltung, Einzelhandel, Tourismus, Wirtschaftsförderung, Kultur usw.) Verfügt beispielsweise eine stadt oder Region über bedeutende touristische Attraktionen, so ist eine organisatorische Anbindung an vorhandene touristische organisationen sinnvoll. Soll sich der Schwerpunkt des SRM stärker auf regionale und überregionale zielgruppen außerhalb der Tourismus beziehen, so bietet sich eine Integration des SRM in bereits bestehende Wirtschaftsförderungsgesellschaften an. 301

Sofern eine kontinuierliche Zusammenarbeit gewïnscht und durchsetzbar ist, muß eine übereinkunft über die wahl der geeigneten Rechtsform gefunden werden. Die Bandbreite möglicher Rechtsformen reicht von der Bildung eines unverbindlichen Arbeitskreises ohne eigene Rechtspersönlichkeit bis hin zur schaffung einer PPP in der Form eines Entscheidungsvorbereitungs- oder Beschlußorgans in der Rechtsform einer $\mathrm{GmbH}$ oder eines eingetragenen Vereins.

$300 \mathrm{Vgl}$. Schückhaus, U., u.a., Stadt- und Regionalmarketing, a.a.0., s. 77 .

301 Vgl. Schückhaus, U., u.a., stadt- und Regionalmarketing, a.a.0., s. 78 . 
Neben steuerlichen Aspekten ist dabei insbesondere die Frage zu klären, ob sich Dritte, z.B. Unternehmen oder Institutionen der stadt oder des Kreises, in Form von Kapitalanteilen beteiligen sollen.

Eine allgemeingultige Aussage uber die optimale Rechtsform ist nicht möglich. Entscheidend sind die jeweiligen Rahmenbedingungen vor ort, welche angesichts etwaiger Vorbehalte in verschiedenen Interessengruppen nur eine lose Kooperation ermöglichen. In diesem Fall ist die Aufgabe der PPP auf die unverbindliche Meinungsbildung in näher $z u$ bestimmenden Handlungsfeldern begrenzt.

Ermöglicht die Konstellation vor ort eine langfristige $\mathrm{Zu}-$ sammenarbeit und damit die verbindliche Abstimmung der involvierten Interessenträger, fungiert die PPP nicht nur als Forum des Informationsaustausches, sondern als Gremium zur Entscheidungsbildung. Es wird gewissermaßen das Prinzip angewendet, "Betroffene zu Beteiligten“ zu machen und eine hohe Erfolgswahrscheinlichkeit für das gemeinschaftlich verabschiedete Handeln herbeigefürt. Diese Form der zusammenarbeit ist einem sporadisch organisierten Meinungsaustausch vorzuziehen. So ist in zweifel $\mathrm{zu} z$ iehen, ob die gewünschte selbstverpflichtung ("committment") der involvierten Personen und Gruppen in unverbindlichen Gesprächsrunden herstellbar ist.

Mit Blick auf das SRM als mögliches Aufgabenfeld einer PPP sollten deshalb vorab die Realisierungschancen einer aktiven und zielgerichteten zusammenarbeit abgewogen werden. Insbesondere ist die Frage zu klären, ob eine auf Langfristigkeit angelegte institutionalisierte zusammenarbeit wünschenswert bzw. - mit Blick auf mögliche Vorbehalte in den Interessenblöcken - uberhaupt machbar ist.

Die Umorientierung hin $\mathrm{zu}$ einem verstärkten Marketingdenken und -handeln wird von verschiedenen Interessengruppen 
teilweise mit Vorbehalten begegnet. Dabei ähneln die Argumente häufig dem bei Unternehmen mitunter anzutreffenden Ressortegoismus. Als Ursachenbereiche lassen sich im wesentlichen institutionelle Barrieren sowie Interessenkollisionen der involvierten Gruppen nennen:

- Institutionelle Barrieren liegen im jeweiligen Selbstverständnis sowie in inkompatiblen Erwartungshaltungen der öffentlichen und privaten Akteure begründet. Die einer zusammenarbeit grundsätzlich im wege stehenden Ursachen sind häufig psychologisch begründet. Dazu zählt beispielsweise die fehlende gegenseitige Anerkennung, das fehlende Wissen um die konkreten Aufgaben der Verwaltung, der privaten Akteure (z.B. Unternehmen) und der sonstigen Institutionen, die fehlende Bereitschaft zur Zusammenarbeit sowie der Zweifel über den Erfolg des partnerschaftlichen Handelns.

- Weitere Vorbehalte beruhen auf Interessenkollisionen.302 So läuft die Ausschöpfung der Erfolgs- und Attraktionspotentiale der Gesamtstadt mitunter den Interessen stadteigener Institutionen (z.B. IHK, Messe/Kongreß) entgegen, welche primär darin interessiert sind, ihre eigenen Marketingkonzepte durchzusetzen. Auf regionaler Ebene steht der Gründung einer regionalen Wirtschaftsförderungsgesellschaft möglicherweise die Befürchtung einzelner städtischer oder kreisgebundener Wirtschaftsförderungsämter entgegen, ins Hintertreffen zu geraten.

- Die institutionalisierte Zusammenarbeit zwischen privaten Akteuren und öffentlicher Hand wird darüber hinaus seitens der Kommunalpolitik vielfach mit Mißtrauen

$302 \mathrm{Vgl}$. Zentes, J., Marketing für die Stadt, Vortrag vor dem EHV-Essen am 20.01.1988, S. $10 \mathrm{f}$. 
und Skepsis beobachtet. 303 Politische Entscheidungsträger befürchten, daß die Beschlüsse derartiger Gremien parteipolitischen zielen entgegenstehen könnten und damit Konflikte in den eigenen Reihen provozieren. Schließlich steht das der Kommunalpolitik häufig zu eigene Denken in Legislaturperioden einer auf Langfristigkeit angelegten Kooperation entgegen.

- Von besonderer Brisanz ist die Frage der Kompetenzverteilung zwischen öffentlichen und privaten Akteuren. Die kooperative zusammenarbeit privater und öffentlicher Entscheider führt zwangsläufig dazu, daß der kommunale Entscheidungsprozeß um weitere Gruppen erweitert wird. Zwar wird die Kompetenz der politischen Entscheider (z.B. Rat und verwaltung einer stadt) durch eine PPP formal nicht beeinträchtigt. Derartige Kooperationsformen können jedoch einen "informellen push" auf die politische Einflußsphäre ausüben und Handlungsbedarf entstehen lassen.

Unabhängig davon, welche Vorbehalte im Einzelfall artikuliert werden, müssen die Promotoren des Marketingsdenkens Lösungsvorschläge zur Verankerung bzw. Akzeptanzschaffung des SRM erarbeiten. Die Initiierung des SRM läßt sich in diesem Fall als Implementierungsproblem auffassen, wobei die zur Akzeptanzschaffung des SRM erforderliche "Überzeugungsarbeit" mit vergleichbaren Vorgehensweisen zur Strategieimplementierung im Strategischen Management vergleichbar ist.

Das Ziel der Strategieimplementierung besteht darin, eine verabschiedete Strategie in den relevanten Unternehmensbereichen zu verankern ("to carry into effect").304 ES

303 o.v., Stadtmarketing - mehr als Mode?, a.a.o..

$304 \mathrm{z}$ u r Strategieimplementierung als Aufgabenfeld des strategischen Management vgl. beispielsweise Kolks, 
konnte nachgewiesen werden, daß neben Fehlern in der Strategieformulierung die spezifischen Werthaltungen, Denkstrukturen und Verhaltensweisen maßgeblich den Erfolg oder Mißerfolg einer Strategie beeinflussen. Insbesondere Verhaltenswiderstände und die fehlende Akzeptanz konterkarieren vielfach einen erforderlich gewordenen strategischen Wandel. Vor diesem Hintergrund wird zunehmend die Notwendigkeit gesehen, die "Implementierungsumgebung" über die Strategieinhalte in Kenntnis zu setzen um eine hohe Einstellungsakzeptanz und Anwendung der Strategie sicherzustellen.

Wenn dieser am Beispiel von Wirtschaftsunternehmen formulierte Grundgedanke aufgegriffen und auf städte/Regionen ubertragen wird, ist das SRM als "Strategie" zu interpretieren. 305 Die Aufgabe der Marketing-Promotoren besteht darin, das SRM als "Implementierungsobjekt" bei den privaten und öffentlichen Entscheidungsträgern - der PPP - in der betreffenden stadt oder Region $\mathrm{zu}$ verankern.

Bei Vorliegen ausgeprägter Vorbehalte gegenüber dem SRM bei bestimmten Interessengruppen ist eine Kompromißlösung vielfach unumgänglich. Diese könnte in einer stufenlösung bestehen, indem zunächst ein informeller Gedankenaustausch in der Form eines Diskussionskreises angeregt wird, der nach Beendigung einer zeitlich genau festgelegten An-

U., a.a.o.: Meffert, H., Marketing-Management. Analyse

- Strategie - Implementierung, a.a.0., s. $361 \mathrm{ff..}$

305 Die Gleichsetzung von "Strategie“ und "Konzept" ist in diesem Fall zulässig. Es soll lediglich zum Ausdruck gebracht werden, daß die mit der strategieimplementierung verbundenen Kommunikationsaufgaben (z.B. Herstellung strategiebezogener Einstellungsakzeptanz, sowie Durchsetzungsziele wie: "Kennen der Strategie", "Verstehen der Strategie", "Können der Strategie" und "Wollen der Strategie") auf Städte oder Regionen unmittelbar angewendet werden können. Vgl. zu den $\mathrm{zielen}$ der strategieimplementierung Kolks, U., Strategieimplementierung, a.a.0., S. $111 \mathrm{ff.;}$ zur Gleichsetzung von "Strategie" und "Konzept" vgl. ebenda, S. 65. 
laufphase in eine feste organisationsform überführt wird. In diesem Fall bietet sich die Schaffung einer Anschubgruppe an, welche der Gründung einer PPP in einer festen Organisationsform zeitlich vorausgeht. Als Mitglieder dieser Kerngruppe sollte ein ausgewählter Kreis von Meinungsmultiplikatoren aus Verbänden, wirtschaft und Verwaltung gewonnen werden, die als Macht-oder Fachpromotoren für die Idee des SRM werben. In Abhängigkeit vom Kenntnisstand der Beteiligten ist möglicherweise externes MarketingKnow-How ergänzend hinzuziehen. Als inhaltlicher Schwerpunkt dieser startphase ist insbesondere die Frage $z u$ erörtern, wie ein auf die spezifische situation des Referenzraumes abgestimmtes SRM-Konzept ausgestaltet sein könnte.

\subsection{Placemanagement als Durchsetzungsorgan}

Um Interessenkollisionen auszuschließen, werden die Durchsetzungsaufgaben von einem professionellen Placemanagement (PM) wahrgenommen. Aus diesem Grund ist die Beauftragung eines selbstständiges PM erforderlich, das keine Funktion in einer interessegebundenen Gruppe wahrnimmt.306 Das Placemanagement steht somit in einem positiv $\mathrm{zu}$ verstehendem Wortsinn "zwischen den Stühlen“, indem es keiner Gruppe direkt verpflichtet ist. Die Unabhängigkeit des Placemanagements hat darüber hinaus zur Folge, daß bei Interessenkonflikten ein Ausgleich leichter gefunden und akzeptiert wird.

306 Die personelle Trennung zwischen Zielbildung und Entscheidungsdurchsetzung ist schon allein deswegen erforderlich, weil die Teilnehmer der PPP angesichts knapper zeitlicher Ressourcen eine professionelle Entscheidungsdurchsetzung mit ihrer hauptberuflichen Tätigkeit in Wirtschaft, Verwaltung oder in sonstigen Bereichen nur unvollkommen vereinbaren könnten. 
Das Spektrum der Aufgaben des PM läßt sich durch eine Reihe von Funktionen skizzieren, welche in Abbildung 21 im Überblick dargestellt sind. Als wichtigste Aufgabe ist die Koordinierung der privaten und öffentlichen Interessen in der PPP (Koordinations- und Harmonisierungsfunktion) in den Vordergrund zu stellen. Eine weitere Aufgabe besteht darin, die Diskussion zwischen privaten und öffentlichen Akteuren in Gang zu setzen. Das Placemanagement läßt sich anschaulich mit einem "Motor" vergleichen, der den Dialog in der PPP immer wieder anregt (Initiierungsfunktion). Darüber hinaus müssen etwaige Vorbehalte bei einzelnen privaten oder öffentlichen Akteuren abgebaut werden, um die Kontinuität der Kooperation in Zukunft zu gewährleisten (Überzeugungsfunktion).

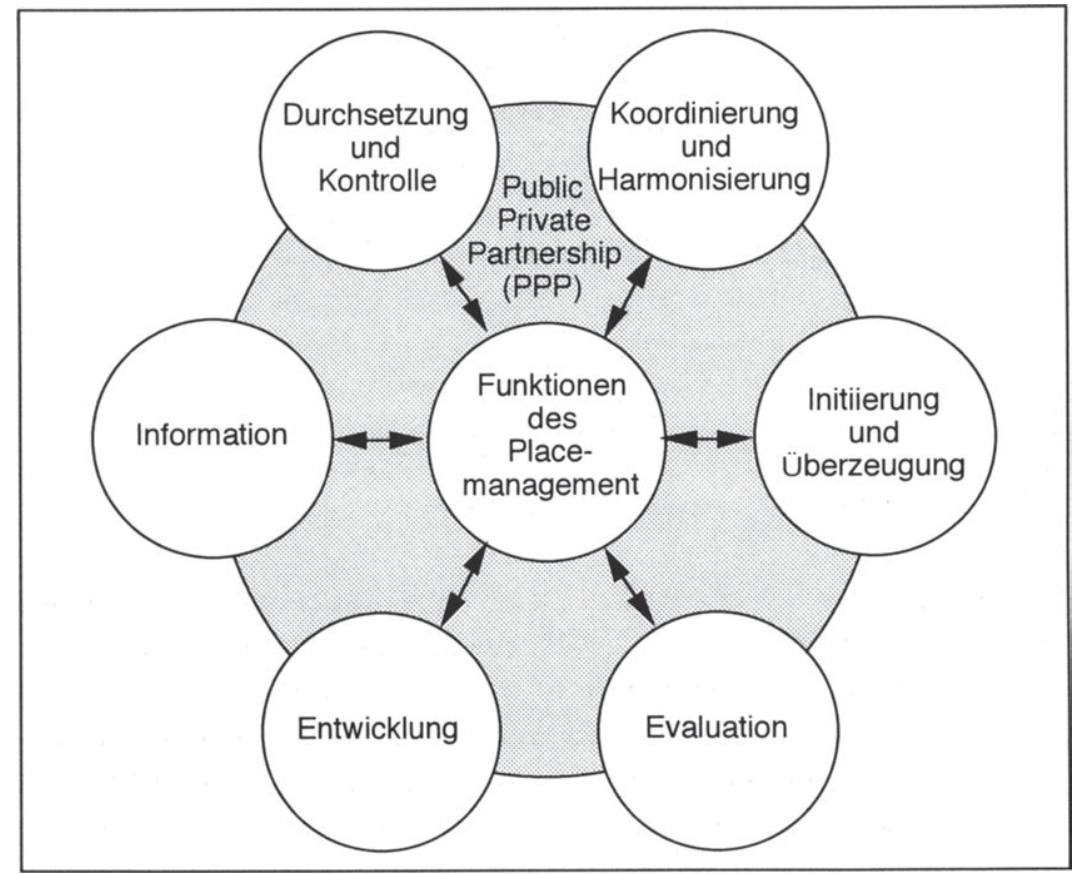

Abb.21: Funktionen des Placemanagement 
Mit Blick auf die Ausgestaltung eines SRM-Konzeptes ist die Festsetzung bedeutsamer Handlungsfelder erforderlich. Hierbei geht es um die Frage, in welchen Bereichen eine Profilierung des Referenzraumes grundsätzlich für die zukunft erfolgversprechend ist. (Evalulationsfunktion). Dazu gehört auch die Entwicklung konkreter innovatorischer aber realistischer Ideen, Projekte und Maßnahmen (Entwicklungsfunktion). Die örtliche Politik sowie die allgemeine öffentlichkeit sind dabei laufend uber den stand des SRM und geplanter Maßnahmen $z u$ informieren (Informationsfunktion) Schließlich ist die Umsetzung und Kontrolle der von der PPP verabschiedeten Zielvorhaben sicherzustellen (Durchsetzungs- und Kontrollfunktion).

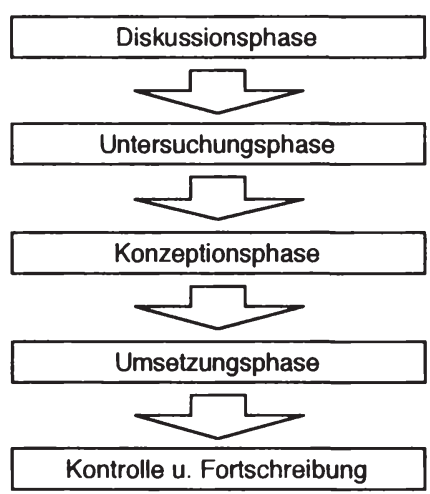

Abb.22: Phasenschema des Placemanagement

In der Praxis wird entweder ein ehrenamtlicher Placemanager bzw. ein interdisziplinär zusammengesetztes Team (z.B. eine Unternehmensberatung) mit der Aufgabe des PM beauftragt. 307 Im Idealfall wird die Aufgabe von einem Generalisten wahrgenommen, der uber Kenntnisse in einer Vielzahl unterschiedlicher Aufgabenfelder verfügt, welche in einer stadt bedeutsam sind oder in der zukunft werden können:

$307 \mathrm{Vgl}$. Heimann, H., City-Management, in: ILS (Hrsg.), Stadtmarketing in der Diskussion, a.a.0., s. 31 . 
Einzelhandel, Verwaltung, Politik, Stadtplanung, Einzelhandelsberatung, Design lassen sich beispielhaft aufzählen. 308

Unabhängig von den verabschiedeten Aufgabenfeldern des SRM lassen sich übereinstimmend eine Reihe von Prozeßphasen unterscheiden. Der in Abbildung 22 aufgezeigte Phasenverlauf ist somit generell anwendbar, unabhängig davon, ob im Einzelfall die zielgerichtete Beeinflussung räumlicher Identität oder ein anderes Handlungsfeld bearbeitet wird. Das Placemanagement ist dabei auf allen Prozeßphasen zumindest koordinierend tätig.

Der SRM-Prozeß beginnt mit der Diskussionsphase. Träger dieser Phase sind die Mitglieder der PPP, welche vor dem Hintergrund der generellen Entwicklungsziele für die betreffende Stadt oder Region, zentrale Handlungsfelder und Basisziele für das SRM festsetzen. Um die Konsensbildung der beteiligten Interessengruppen bestmöglich sicherzustellen, ist der Placemanager als Koordinator und Moderator zwischen den Interessengruppen tätig.

Anschließend wird die Untersuchungsphase eingeleitet. Auf Grundlage der verabschiedeten Handlungsfelder und Basisziele wird eine Situationsanalyse sowie ein zielkatalog erstellt. Weiterhin ist ein Grobplan zu entwickeln, der erste zeit- und Kosteninformationen enthält. Um das ortsbezogene know-how der verschiedenen Interessengruppen effizient zu nutzen und die verabschiedeten Handlungsfelder kompetent zu bearbeiten, werden bei Bedarf ein oder mehrere Arbeitsgruppen eingerichtet. 309

308 Vgl. Heimann, H., City-Management, in: ILS (Hrsg.), Stadtmarketing in der Diskussion, a.a.0., s. 31 .

309 Dabei muß insbesondere Zusammensetzung und Größe der Arbeitsgruppen geklärt werden: Gemischte Arbeitsgruppen aller Betroffenen führen $\mathrm{zu}$ einer besseren Abstimmung; große Arbeitsgruppen ermöglichen einen breiten 
Im Mittelpunkt der Konzeptionsphase steht die Erarbeitung konkreter Maßnahmenvorschläge für die ausgewählten Handlungsfelder. Dabei sollte das spezifische "InsiderWissen" der Arbeitsgruppenteilnehmer flankierend genutzt werden, um etwaige Hindernisse (z.B. in der Durchsetzbarkeit) frühzeitig zu benennen. Mit Blick auf mögliche Vorbehalte in der PPP bezüglich der verabschiedeten Maßnahmenvorschläge und angesichts knapper finanzieller Mittel, sollte ein Pragmatismus die Konzeptionsphase bestimmen. Eine Möglichkeit besteht darin, Maßnahmenvorschläge in der Form zeitlich oder sachlich gestaffelter stufenpläne zu erarbeiten:

- Ein zeitlich gestaffelter stufenplan beinhaltet die vorrangige Umsetzung innengerichteter Maßnahmenvorschläge mit dem Primärziel einer inneren Konsolidierung. Erst im Anschluß daran erfolgt die Ansprache externer zielgruppen. Auf diese Weise wird Akzeptanz im Innenverhältnis geschaffen. Darüber hinaus können mögliche Vorbehalte bei den maßgeblichen Entscheidern abgebaut werden, indem diese von der Leistungsfähigkeit des Marketinginstrumentariums überzeugt werden. 310

- Ein sachlicher Stufenplan legt Maßnahmenprioritäten fest. Um mit relativ geringem Mittelaufwand zu wahrnehmbaren Resultaten zu gelangen, bietet sich beispielsweise die Umsetzung von Vorrangprojekten an. $\mathrm{Zu}$

Konsens. Die Abstimmung ist jedoch schwierig und erfordert lange Entscheidungsprozesse; kleine Projektgruppen ermöglichen einen raschen Kompromiß, ziehen jedoch möglicherweise Durchsetzungschwierigkeiten bei den nicht beteiligten Interessenträger nach sich.

310 Ein zeitlicher stufenplan ist beispielsweise von der stadt Hamm umgesetzt worden, wo das städtemarketing während einer sechs Monate langen Probephase eingeführt worden ist. Vgl. Junker, R., Schulte, W., CityManagement Hamm, Der Städtetag, 9/1992, S. 661. 
diesem Zweck müssen die Maßnahmen in eine Reihenfolge gebracht werden. 311

Während die im Rahmen der Untersuchungs- und Konzeptionsphase erforderlichen Arbeitsschritte autonom durch das Placemanagement - unter Umständen in Zusammenarbeit mit verschiedenen Arbeitsgruppen - vorgenommen werden, geht der Umsetzungsphase möglicherweise zunächst die Rückkopplung mit der PPP voraus.

Ein wichtiger Kontextfaktor stellt in diesem Zusammenhang die Kompetenzausstattung des PM dar. Wenn dem PM ein breiter Entscheidungsspielraum zugewiesen wird, ist die Umsetzung der formulierten Programme im Rahmen der genehmigten Budgetgrenzen in Eigenverantwortung möglich. Andernfalls muß jeweils die Zustimmung der PPP eingeholt werden, was unter Umständen langwierige Bewilligungsverfahren zur Folge hat. Die Zeit wird jedoch angesichts des zunehmenden interkommunalen Wettbewerbsdruckes auch für städte und Regionen ein an Bedeutung zunehmender Erfolgsfaktor. Aus diesem Grund stellt die großzügige Ausstattung des PM mit weitreichenden Handlungsvollmachten eine wichtige Voraussetzung dar, um eine größtmögliche Reaktionsschnelligkeit auf den anvisierten Zielmärkten herzustellen.

311 Eine Möglichkeit besteht darin, zunächst die Maßnahmen durchzuführen, welche einfach, schnell und preiswert sind. Im Anschluß daran, Maßnahmen, welche kompliziert, langwierig oder teuer sind. Vgl. Honert, S., Stadtmarketing und stadtmanagement, a.a.o., s. 398 . Der Maßnahmenkatalog läßt sich darüber hinaus nach der Wirkungsrichtung (z.B. in die stadt/Region, außerhalb der Stadt/Region), der Bedeutung (hoch, mittel, gering oder kurz-, mittel-, langfristig), der Wirkungswahrscheinlichkeit (sehr wirksam, weniger wirksam oder schnelle Wirkung, langsame Wirkung), der Tragfähigkeit (Zustimmung groß, gering, Ablehnung) und der Widerspruchsfreiheit (in sich konsistent, stimmt mit anderem uiberein, ergänzt sich mit anderem) systematisieren. Vgl. Haedeke, G., Meilensteine auf dem Weg zum Stadtmarketing, in: Stadtmarketing Symposium v. 18.19. März '92 in Kassel. 
Die Ergebnisanalyse erfolgt in der Kontroll- und Fort-

schreibungsphase. Die Inhalte hängen dabei wiederum von dem gewählten Handlungsfeld des SRM ab.

\subsection{Prozeßschema zur Identitätsentwicklung}

Im Mittelpunkt der Identitätsenwicklung steht die Idee, die betreffende Stadt/Region als Raumeinheit zu betrachten und ist damit grundsätzlich auf alle Attraktionspotentiale bzw. Handlungsfelder ausgerichtet, welche eine Abstimmung privater und öffentlicher Personen und Gruppen sinnvoll erscheinen lassen. Wenn eine Beschränkung auf die wesentlichen Prozeßschritte der Identitätsentwicklung vorgenommen wird, lassen die in der Abbildung 23 aufgezeigten Phasen unterscheiden.

Die zielgerichtete Beeinflussung räumlicher Identität setzt einen Konsens über die Identität des Referenzraumes voraus. Der Prozeß der Identitätsentwicklung wird dabei durch die Bewußtwerdung räumlicher Identität eingeleitet, indem Antworten auf Fragestellungen gesucht werden wie: "Wer sind wir?", "Wer wollen wir sein?", "Wie werden wir von anderen gesehen?" (Teilschritt 1).

Die Bewußtwerdungsphase mündet in die Formulierung eines Leitbildes (Teilschritt 2). Darunter ist die schriftliche Ausarbeitung all jener Zukunftsvorstellungen $\mathrm{zu}$ verstehen, welche die Identität der stadt oder Region bestimmen sollen. 312 Die explizite Formulierung ist wichtig, um den von der stadt oder Region verfolgten Ideen und ziele einen

312 Vgl. Antonoff, R., CI für Städte, a.a.o., S. 4.; Erlebach, D., Schückhaus, U., Rüstzeug. Stadtmarketing und die Zukunft der Kommunen, a.a.0., S. 17 . 
normativen Charakter $\mathrm{zu}$ verleihen. 313 Gerade Städte und Regionen, welche über eine vielzahl selbständig agierender privater und öffentlicher Interessenträger verfügen, bedürfen eines "roten Fadens", der allen Beteiligten einen in sich geschlossenen, langfristigen orientierungsrahmen zur verfügung stellt.

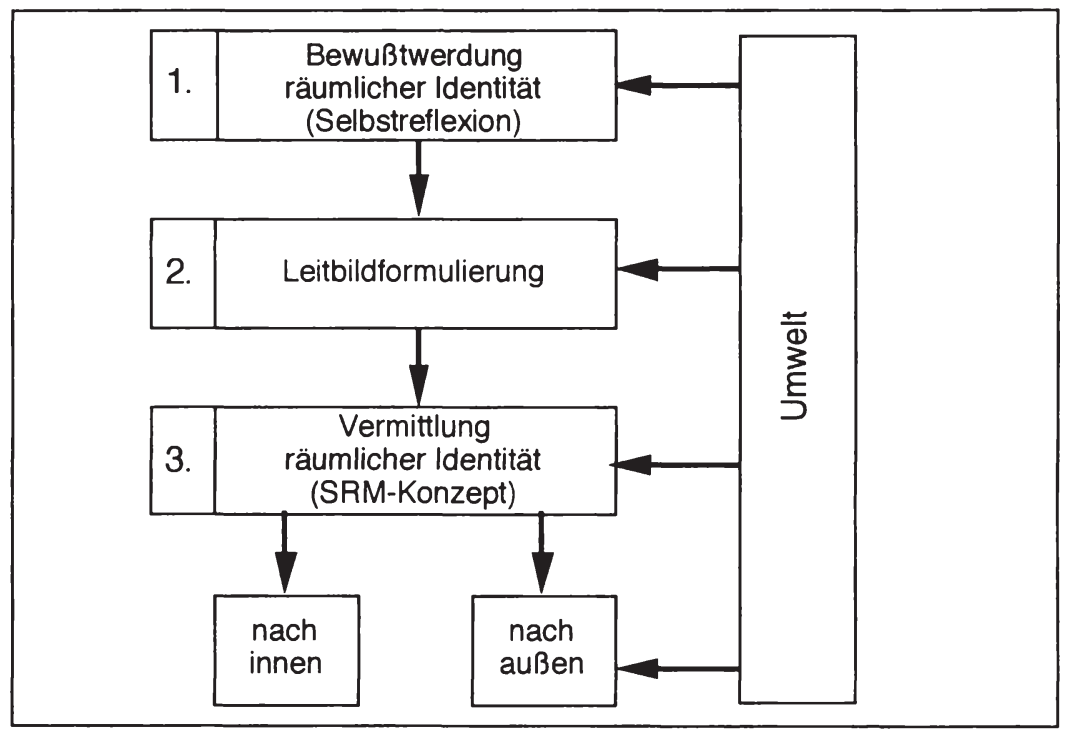

Abb.23: Allgemeines Prozeßschema zur Identitätsentwicklung

Angesichts der Vielfältigkeit der Aufgabenfelder, welche eine Stadt oder Region zu bewältigen hat, müssen Leitbilder inhaltlich differenziert werden. Je nach Handlungsfeld kann ein Leitbild

313 vgl. Dill, P., Hügler, G., Unternehmenskultur und Führung betriebswirtschaftlicher Organisationen - Ansatzpunkte für ein kulturbewußtes Management, in: Heinen, E., (Hrsg.): Unternehmenskultur, München 1987, S. 165. 
- auf die Stadt- oder Regionalentwicklung als Ganzes (z.B. Förderung des endogenen Entwicklungspotentials einer Region),

- auf Ortsteile (z.B. Attraktivierung der City als Einzelhandelszentrum),

- auf die bauliche Gestalt (z.B. die Wiederherstellung historischer Innenstadtfassaden),

- auf die infrastrukturelle Ausstattung (z.B. Förderung eines vielseitigen Branchenmixes, "Stadt Münster: Zentrum für intelligente Dienstleistungen"),

- das kulturelle Angebot (z.B. Profilierung als Festspielstadt), oder die

- kommunikative Selbstdarstellung usw.

ausgerichtet sein. 314

Schließlich muß die im Leitbild zum Ausdruck kommende, erwïnschte räumliche Identität in der Phase der Identitätsvermittlung an die interne und externe öffentlichkeit kommuniziert werden (Teilschritt 3 ). Die Identifizierung der betreffenden stadt oder Region als unverwechselbare Ganzheit und die Identifizkation mit dem Referenzraum umschreiben wesentliche Identitätsziele bzw. -wirkungen der Identitätsentwicklung. Diese ziele stellen keinen selbstzweck dar, sondern müssen als wesentliche Voraussetzungen aufgefaßt werden, um gewïnschte Austauschbeziehungen zwischen den zielkreisen und dem Referenzraum sicherzustellen. In Analogie zu unternehmensbezogenen Identitätskonzepten lassen sich interne und externe wirkungsebenen der Identitätsvermittlung unterscheiden: 315

314 Vgl. Tietz, B., Rothhaar, P., City Studie, a.a.o., s. 22 .

$315 \mathrm{Vgl}$. dazu beispielsweise Heinen, E., Identität, a.a.0., s. 129 . 
Einerseits soll die Vermittlung räumlicher Identität eine positive Profilierung des Referenzraumes im Wettbewerbsumfeld ermöglichen. 316 Identität kommt in diesem zusammenhang eine selektionsfunktion $z u$, indem die Kommunikation des Selbstverständnisses die relevanten Umweltsegmente zur Vornahme erwünschter Austauschbeziehungen stimuliert. Im Innenverhältnis ist die Koordinations- und Integrationsfunktion von Bedeutung. Die Koordinationsfunktion findet beispielsweise in der orientierung der verschiedenen Interessenträger an einem Leitbild Ausdruck und gewährleistet die Ausrichtung der Einzelaktivitäten öffentlicher und privater Entscheider auf eine Gesamtlinie. Die Integrationsfunktion erleichtert das "Zurechtfinden“ innerhalb des Referenzraums, indem die verschiedenen Interessenträger einem abgestimmten Gesamtkonzept gegenüberstehen. Insbesondere bei einem Regionenmarketingkonzept, das möglicherweise von einer Mehrzahl angeschlossener städte und Kreise getragen wird, ist es wünschenswert, ein wahrnehmbares ganzheitliches Bild vom Referenzraum entstehen $\mathrm{zu}$ lassen. Auf diese Weise ist mit einer hohen Identifikation der Beteiligten zu rechnen.

2.4

Erfolgsvoraussetzungen für die Identitätsvermittlung

Um eine hohe Erfolgswahrscheinlichkeit der formulierten Identitätszielsetzungen herbeizuführen, sind bei der Ausgestaltung der Maßnahmenkataloge im Rahmen der Identitätsvermittlung eine Reihe von Voraussetzungen $\mathrm{zu}$ beachten. Im wesentlichen lassen sich dabei zwei Aufgabenschwerpunkte unterscheiden:

316 Unter Profilierung läßt sich die Heraushebung aus der Anonymität, Identifizierbarkeit und Unverwechselbarkeit verstehen. Vgl. Heinen, E., Identität, a.a.o., S. 129 . 
1. Ein erstes Aufgabenfeld des SRM besteht darin, Identitätsfaktoren zu selektieren und kommunikativ herauszustellen, welche die Individualität und Besonderheit des Referenzraumes maßgeblich prägen und von konkurrierenden städten und Regionen nicht ohne weiteres kopiert werden können (Singularität der Identitätsfaktoren).

2. Eine weitere generelle Erfolgsvoraussetzung knüpft an die konkrete Ausgestaltung eines SRM-Konzeptes an. Damit eine stadt oder Region in der Wahrnehmung aktueller und potentieller zielgruppen langfristig als unverwechselbare Ganzheit wahrgenommen wird, ist eine Ausrichtung der Kommunikationsinhalte an den tatsächlich gegebenen Realitäten des Referenzraums erforderlich. Die Erweckung eines "falschen Scheins" im kommunikativen Auftritt ist $z u$ vermeiden (Authentizität der Identitätsvermittlung).

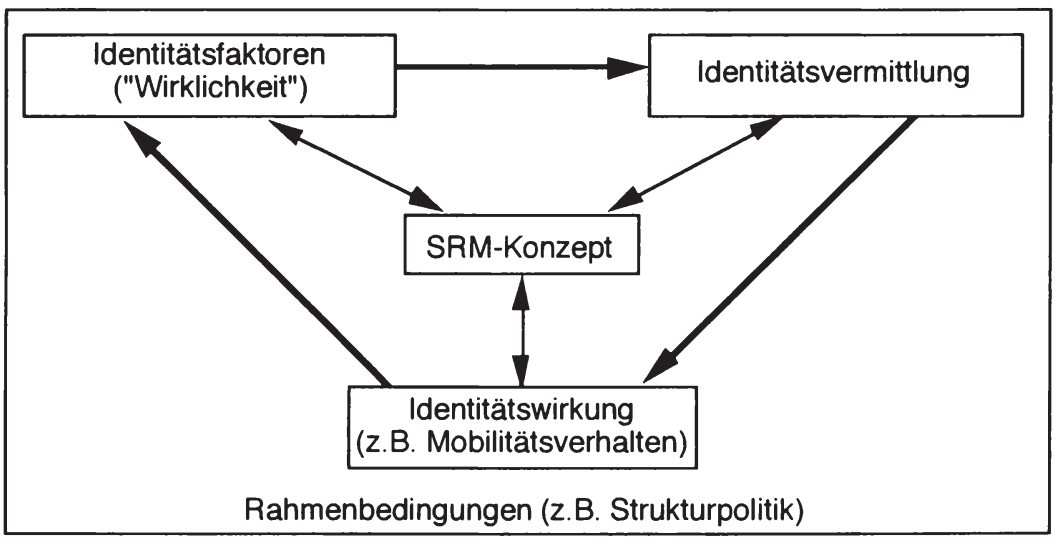

Abb.24: Spannungsfeld der Identitätsentwicklung

In Abbildung 24 wird ein Dreieck aufgespannt, welches aus den drei Identitätskomponenten Identitätsfaktoren, 
-vermittlung und -wirkung zusammengesetzt ist. $317 \mathrm{Am} \mathrm{An-}$ fang des Dreiecks sind die Identitätsfaktoren angesiedelt, welche als "Substanz der Identität" die Identität einer Stadt oder Region bestimmen. 318 Der Identitätsvermittlung kommt in diesem Dreieck eine Scharnierfunktion $z u$, weil die Kommunikation der zentralen Identitätsfaktoren an die internen und externen Zielkreise Gegenstand dieses Handlungsfeldes des SRM darstellt. Die Identitätswirkung strahlt wiederum auf die Identitätsfaktoren $a b$. So ist es beispielsweise denkbar, daß aus einer bestimmten Ausprägung der "Identifizierung von" und der "Identifikation mit" ein spezifisches Verhalten resultiert. Wenn es beispielsweise gelingt, durch eine glaubwürdige Vermittlung räumlicher Identität die angesprochenen zielkreise zur Vornahme bestimmter Austauschbeziehungen $\mathrm{zu}$ veranlassen, verändern sich langfristig auch die Realitäten in der betrachteten stadt oder Region.

317 Es muß stets berücksichtigt werden, daß räumliche Identität sowohl eine auf Personen als auch eine auf den Referenzraum selbst bezogene Bedeutung hat. In der erstgenannten Bedeutungsrichtung hat eine Person (oder eine Gruppe) räumliche Identität; andernfalls ist ein Raum eine räumliche Identität. Ausgangspunkt des aus Identitätsfaktoren, -vermittlung und -wirkung gebildeten Dreiecks, welches auch als "Spannungsfeld des SRM“ aufgefaßt werden kann, ist der zweite Bedeutungskontext räumlicher Identität: Der Raum ist eine räumliche Identität (im Sinne von Individualität, Unverwechselbarkeit, Einzigartigkeit usw.), welche durch den geeigneten Einsatz des SRM an interne und externe zielkreise vermittelt wird. Ausgehend von dieser Unterscheidung läßt sich die "Identifizierung von" sowie die "Identifikation mit" als Wirkungsaspekt des SRM interpretieren.

$318 \mathrm{Vgl}$. Antonoff, R., Corporate Identity für städte, a.a.O., S. 2 . 


\subsection{Singularität der Identitätsbausteine}

Basis der Bewußtwerdung räumlicher Identität sowie der Leitbildformulierung sind die Identitätsfaktoren einer Stadt/Region. Grundsätzlich macht es keinen Unterschied, die Identität einer Person oder die Identität eines Gegenstandes oder einer stadt oder Region auf Grundlage einer Reihe von Merkmalen $\mathrm{zu}$ beschreiben. Identitätsfaktoren lassen sich grundsätzlich als "Bausteine der Identität” oder als Elemente bezeichnen, die zu Identität werden können. 319

Bei der Ermittlung der Identitätsfaktoren einer stadt oder Region geht es um die Frage, wodurch sich ein bestimmter Raum von anderen Räumen unterscheidet. Manchmal sind es einzelne Merkmale, welche die Besonderheit und Einzigartigkeit eines bestimmten Raumes maßgeblich bestimmen. Häufig treffen jedoch einzelne Merkmale ganz oder teilweise auf andere städte und Regionen gleichermaßen zu (Universitätsstadt, Beamtenstadt usw.). In diesem Fall ist die Kombination der Merkmale entscheidend, um einem Raum Identität $\mathrm{zu}$ verleihen.

Die Gestaltung räumlicher Identität setzt deshalb im Vorfeld voraus, jene Merkmale zu entdecken und später gegebenenfalls zu entwickeln, welche einem Raum im Wahrnehmungsbild der internen und externen öffentlichkeit, eine räumliche Identität im Sinne von Individualität und Einzigartigkeit verleihen. Dabei muß einerseits vermieden werden, zu wenige Identitätsfaktoren herauszugreifen und andererseits dürfen nicht zu viele Merkmale selektiert werden.

Die Focussierung auf $\mathrm{zu}$ wenige Identitätsfaktoren birgt eine Reihe von Gefahren. So muß beispielsweise eine über-

319 Vgl. Conzen, P., E. H. Erikson und die Psychoanalyse. a.a.o., s. $77 \mathrm{f}$. 
nutzung der räumlichen Ressourcen vermieden werden. Insbesondere Tourismusregionen sehen sich der Gefahr ausgesetzt, durch Überbeanspruchung nicht regenerierbarer Ressourcen langfristig ihre regionsspezifische Vorteile zu verlieren (z.B. Skigebiete). 320 Darüber hinaus birgt die Spezialisierung auf die aussichtsreichsten Entwicklungsansätze die Gefahr der Ausprägung wirtschaftlicher Monostrukturen. Auf diese Weise wird die Abhängigkeit von externen Nachfrageströmen erhöht. 321 Es sollte deshalb eine Beschränkung auf einige wenige Identitätsfaktoren vorgenommen werden, welche die Grundlage der Gestaltung räumlicher Identität bilden sollen. 322 Dabei sind die spezifischen örtlichen Voraussetzungen entscheidend, um im Einzelfall eine Aussage darüber treffen zu können, ob die selektierte Anzahl von Identitätsfaktoren „zu gering“ , "zu viel" oder "genau richtig" ist. Aus diesem Grund muß die Merkmalsauswahl unter Berücksichtigung langfristiger zielsetzungen und einer fundierten Konkurrenzanalyse erfolgen.

In Abbildung 25 wird eine Matrix aufgezeigt, welche zwischen vier verschiedenen, grundsätzlich zu unterscheidenden Gruppen von Identitätsfaktoren unterscheidet.

Eine Typologisierung von Identitätsfaktoren ergibt sich, indem zunächst zwischen herkunftsspezifischen und -indifferenten Merkmalen unterschieden wird. Mit Blick auf das von vielen städten und Regionen formulierte ziel, singularität (Unverwechselbarkeit und Einzigartigkeit) im

$320 \mathrm{Vgl}$. Hahne, U., Das Regionstypische als Entwicklungschance? Zur Identifizierbarkeit und Vermarktung regionaler Produkte, in: IzR, H. 7/8, 1987, S. 470 .

$321 \mathrm{Vgl}$. Hahne, U., Das Regionstypische als Entwicklungschance?, a.a.0., s. 470 .

$322 \mathrm{Vgl}$. Ostermann, M., Die Imagepolitik von städten dargestellt am Beispiel der Stadt Köln, Diplomarbeit im Fach Handel und Absatz, Universität zu Köln, 1989, S. 107. 
Wahrnehmungsbild interner und externer zielgruppen $\mathrm{zu}$ erlangen, ist darüber hinaus $z u$ unterscheiden, ob die Identitätsfaktoren von konkurrierenden städten/Regionen imitierbar sind oder nicht.

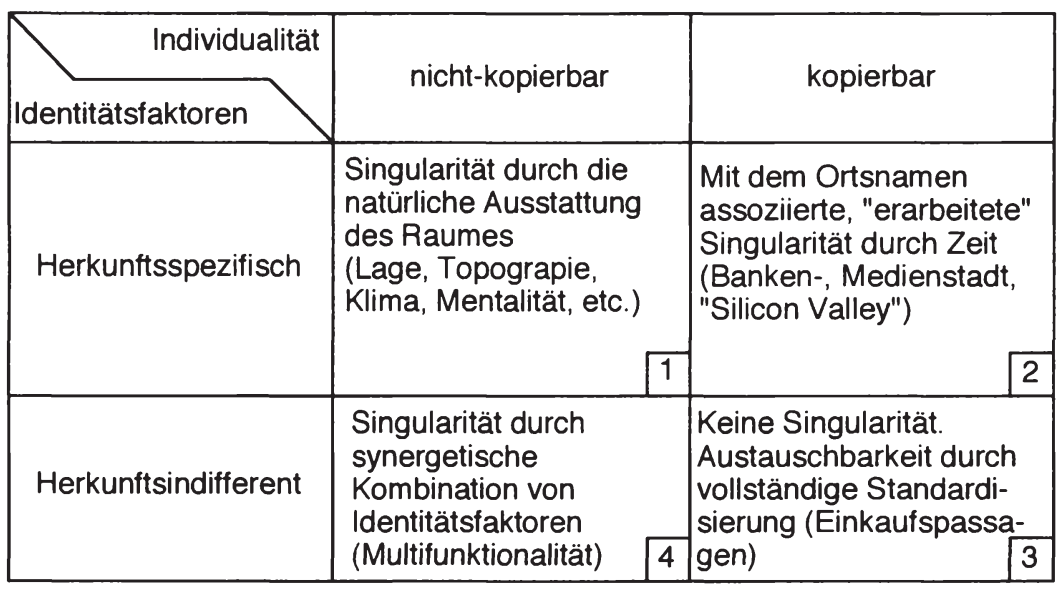

Abb.25: Typologie räumlicher Identitätsfaktoren

Mit der Unterscheidung zwischen herkunftsspezifischen und herkunftsindifferenten Identitätsfaktoren wird zum Ausdruck gebracht, ob das betreffende Merkmal mit dem Referenzraum fest verbunden ist, oder aber keinen unmittelbaren räumlichen Bezug aufweist:

- Ein herkunftsspezifischer Bezug ist einerseits gegeben, wenn das Merkmal unlösbar mit dem Referenzraum verbunden ist. Gegebene Identitätsfaktoren 323 wie Lage, Topographie, Klima aber auch sprachliche Besonderheiten (z.B. Dialekt) usw. haben gemeinsam, auf die natürliche

323 Im übertragenen sinne läßt sich auf die systematisierung der Identitätsfaktoren von de Levita aufbauen, der zwischen zugeschriebenen, erworbenen und übernommenen Identitätsfaktoren unterscheidet. Vgl. Kap. $\mathrm{B} 1.12$. 
Ausstattung eines Raumes $z u$ verweisen. Sie entziehen sich einer Beeinflussung und sind weder frei wählbar noch imitierbar (Feld 1).

- Von diesen zufällig entstandenen Spezifika eines Raumes sind Identitätsfaktoren $\mathrm{zu}$ unterscheiden, welche durch bewußtes Handeln neu entstehen. Diese spielart herkunftsspezifischer Identitätsfaktoren ist mit dem Raum zwar nicht auf natürliche Weise untrennbar verbunden, im Laufe der zeit werden diese Merkmale jedoch mehr oder weniger stark mit dem Raum assoziativ verknüpt (Feld 2).324 Im übertragenen sinne läßt sich in diesem Zusammenhang $v$ on erworbenen Identitätsfaktoren sprechen, weil die Assoziation des ortsnamens mit diesen Eigenschaften nicht kurzfristig möglich ist, sondern Resultat langjähriger Entwicklungen und gewissermaßen „erarbeitet" werden mußte. Weil die mit dem betreffenden Raum assoziierten Eigenschaften nicht auf die natürliche Ausstattung eines Raumes bezogen sind, handelt es sich jedoch grundsätzlich um kopierbare Merkmale.

Besonders leicht kopierbar sind herkunftsindifferente Identitätsfaktoren, welche in gleicher oder ähnlicher Form grundsätzlich für jede stadt oder Region zutreffend sein könnten (Feld 3). Diesen Identitätsfaktoren fehlt entweder der unauflösliche Bezug zum Raum (z.B. als naturräumliche Besonderheit) oder eine langfristig gewachsene Verknüpfung mit dem Referenzraum (z.B. die Assoziation der stadt Stuttgart mit der Automobilindustrie). Gerade für städte und Regionen, welche eine Besserstellung im Wettbewerbsumfeld durch die Bekanntmachung und Etablierung neuer Iden-

324 So wïrde beispielsweise aller wahrscheinlichkeit jeder versuch einer Stadt sich als Bankenstadt zu profilieren mißlingen, weil Frankfurt dieses Merkmal seit Jahren als wesentlichen Bestandteil seines städtischen Identitätsprofils verankert hat. 
titätsfaktoren anstreben, ist diese situation zunächst charakteristisch. So bemühen sich seit den 80 er Jahren gleich mehrere deutsche städte darum, ihr profil als "Kunstmetropole" oder "Medienzentrum" herauszustellen (z.B. Frankfurt und Köln). Die vergleichsweise Neuartigkeit dieser Attribute führt jedoch dazu, daß bislang keine Stadt eines diese Attribute eindeutig für sich reklamieren konnte. Erst durch Kontinuität im Handeln gelingt es, eine wie in Feld 2 aufgezeigte assoziative Verknüpfung zwischen Raum und Merkmal herzustellen.

Herkunftsindifferente Identitätsfaktoren müssen jedoch nicht zwangsläufig leicht imitierbar sein. Dies setzt eine ganzheitliche sichtweise voraus, indem die isolierte Betrachtung einzelner Merkmale überwunden wird und stattdessen die Kombination der verschiedenen Merkmale in den Vordergrund rückt (Feld 4 ). Die Individualität und Besonderheit des Raumes resultiert dann nicht auf den Eigenschaften einzelner, spezifischer Merkmale, sondern auf dem synergetischen Effekt verschiedener Merkmale, welche sich gegenseitig verstärken.

Zusammenfassend wird deutlich, daß die isolierte Betrachtung von Identitätsfaktoren nicht hilfreich ist. Jedes Merkmal für sich wird ganz oder teilweise auch von anderen Städten und Regionen erfüllt. Entscheidend ist die Kombination der Merkmale, die das Besondere und Einzigartige einer Stadt/Region entstehen läßt.

\subsection{Authentizität der Identitätsvermittlung}

Das wesentliche Aufgabenfeld der Identitätsvermittlung besteht darin, die ausgewählten Identitätsfaktoren in die zielkreise der internen und externen öffentlichkeit glaubhaft $z u$ vermitteln, um die gewünschte Identitätswirkung (z.B Neuakquisition) herbeizuführen. Dabei darf die Aus- 
wahl der Identitätsfaktoren nicht vorschnell an den vermeintlichen Präferenzen der Zielgruppen ausgerichtet sein. Neben der Singularität der ausgewählten Identitätsfaktoren muß sichergestellt sein, daß die Selbstdarstellung des Referenzraumes mit den tatsächlich vorhandenen Gegebenheiten übereinstimmt. Dieser Realitätsbezug findet in der Forder u n $\mathrm{n} \mathrm{a} \mathrm{c} \mathrm{h} \mathrm{ortsbezogener} \mathrm{Authentizität} \mathrm{o} \mathrm{d} \mathrm{e} \mathrm{r}$ "Wahrhaftigkeit" in der Identitätsvermittlung Ausdruck.

Ein Indiz für die mangelnde Beachtung dieser Forderung ist immer dann $\mathrm{zu}$ vermuten, wenn im kommunikativen Auftritt einer Stadt oder Region austauschbare Botschaftsinhalte Verwendung finden, welche in ihrer Allgemeingültigkeit für nahezu jede beliebige Stadt oder Region gleichermaßen zutreffend sind. 325 Für die glaubwürdige und prägnante Herausstellung der räumlichen Identität einer stadt oder Region sind deshalb insbesondere solche Identitätsfaktoren kommunikativ herauszustellen, welche für den Referenzraum authentisch, einzigartig und nicht kopierbar sind. Auf diese Weise ist es möglich, eine entscheidende Differenz gegenüber anderen Städten oder Regionen glaubhaft zum Ausdruck zu bringen ( Unterschiede, die einen Unterschied machen.") .

In der Abbildung 26 werden mit $I_{1}$ und $I_{2}$ exemplarisch zwei alternative Vorgehensweisen zur Vermittlung räumlicher Identität einander gegenübergestellt (SRM-Strategien), die sich hinsichtlich ihres Authentizitätsgrads unterscheiden. I1 weist einen zutreffenden, "wahren" Wirklichkeitsbezug auf, während $I_{2}$ ein unwahres Bild vermittelt. Die Wirkungsseite räumlicher Identität verdeutlicht, daß unabhängig von der Authentizität der übermittelten Informationen die Wirkung räumlicher Identität - z.B. das räumliche Vorstellungsbild oder ein erwünschten Mobilitätsverhalten

$325 \mathrm{Vgl}$. Singer, Chr., Kommunale Imageplanung, a.a.0., s. $274 \mathrm{f}$. 
(Bestandspflege, Neuakquisition) - sowohl positiv als auch negativ bewertet werden kann.

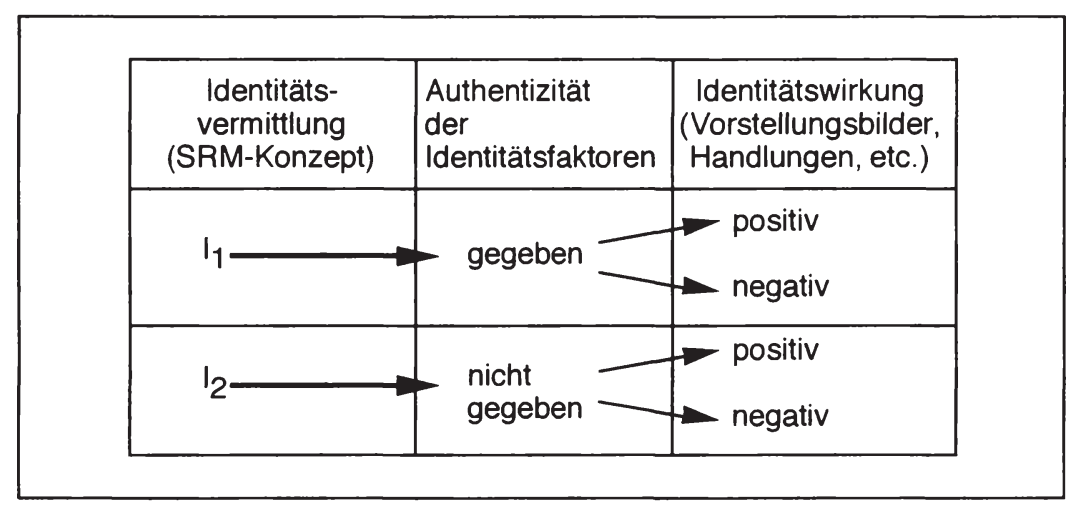

Abb.26: Wirkung räumlicher Identität in Abhängigkeit vom Authentizitätsgrad der übermittelten Kommunikationsinhalte

Zunächst wird unterstellt, daß ein zutreffendes Bild der tatsächlich gegebenen Realität übermittelt wird (I 1 ). Dies ist gleichbedeutend damit, daß die kommunikativ herausgestellten Identitätsfaktoren der Wirklichkeit im Referenzraum entsprechen und seine tatsächliche Besonderheit und Einzigartigkeit widerspiegeln:

- Der Idealfall ist gegeben, wenn mit der Vermittlung eines authentischen Inhaltes ein positive wirkung in der internen und externen öffentlichkeit erzeugt und aufrecht erhalten wird. Damit sind die besten Voraussetzungen gegeben, um auch langfristig im interkommunalen Wettbewerb bestehen zu können.

- Wenn trotz gegebenen Wirklichkeitsbezuges ein negatives Bild in der öffentlichkeit erzeugt wird, liegen die Ursachen entweder in einer qualitativ schlechten SRMStrategie begründet. In diesem Fall ist eine überarbeitung des Marketingkonzeptes erforderlich, um den wün- 
schenswerten Ausgleich zwischen Identitätsbausteinen, -entwicklung und -wirkung sicherzustellen. Im anderen Fall ist die Beschaffenheit der ortsbezogenen Identitätsbausteine möglicherweise derart nachteilig ausgebildet, daß jedwede Kommunikation versagen muß. Hieraus ergeben sich Fragestellungen, welche durch den Einsatz von Stadt- und Regionenmarketing nicht lösbar sind. Es ist vielmehr erforderlich, im Rahmen der strukturpolitik zunächst die Voraussetzungen zu schaffen, ehe eine Zielgruppenansprache sinnvoll wird.

Von dieser wirklichkeitsnahen Vorgehensweise der Identitätsvermittlung ist die bewußte übermittlung eines unwahren, zumindest eines "geschönten" Wirklichkeitsbezuges zu unterscheiden ( $\left.I_{2}\right)$. D i e übermittlung derartiger "Scheininhalte" wird beispielsweise in der verwendung von slogans deutlich, welche die - wie auch immer definierte zentrale Lage innerhalb Deutschlands oder Europas herausstellen, oder sich dazu bekennen, ein ort "mit Herz" zu sein. Möglicherweise werden auch Inhalte vermittelt, welche auf den Referenzraum nicht zutreffend sind. Es ist $z u$ vermuten, daß derartige, vordergründige selbstdarstellungen, im Wahrnehmungsbild der angesprochenen Zielgruppen keinen entscheidenden Unterschied gegenüber konkurrierenden Städten und Regionen bewirken. 326

Wenn die ergriffenen Maßnahmen im Bereich der Identitätsvermittlung trotz fehlenden Wirklichkeitsbezuges eine positive wirkung bewirken, ist eine geringe zeitliche stabilität des übermittelten Bildes wahrscheinlich. Es ist zumindest fraglich, ob die übermittlung eines "falschen" Bildes langfristig mit einer positiven Zielgruppenreaktion verbunden ist. Möglicherweise finden mit der zeit Informationen über die tatsächlichen Gegebenheiten im Referenz-

326 Vgl. Singer, Chr., Kommunale Imageplanung, a.a.o., s. $274 \mathrm{f}$. 
raum über informelle Kommunikationskanäle zugang zur internen und externen öffentlichkeit.

Der letztgenannte Fall - fehlende Authentizität bei negativer Reproduktion - hat seine Ursache gleichermaßen in der übermittlung von "Scheininhalten". Vielleicht sind aber auch enttäuschte Hoffnungen der betroffenen Bewohner ausschlaggebend, wenn anspruchsvolle Entwicklungsperspektiven für die stadt oder Region nicht in die Tat umgesetzt werden konnten. Ursache für derartige Fehlentwicklungen liegen möglicherweise darin begründet, daß die strukturpolitik nicht an die Erfordernisse interner und externer Bedürfnisse angepaßt werden konnte. 327

Die Forderung nach Authentizität oder Wirklichkeitsnähe macht zusammenfassend deutlich, daß das SRM nicht unabhängig von der strukturpolitik betrachtet werden darf. So ist die Ausgestaltung der Identitätsfaktoren - sofern sie überhaupt beeinflussbar sind - kein primäres Aufgabengebiet des Marketing. Eine Region läßt sich beispielsweise nur dann glaubhaft als Technologieregion profilieren, wenn die infrastrukturellen Voraussetzungen im Bereich der "harten“ standortfaktoren durch die strukturpolitik verfügbar gemacht worden sind. Das SRM baut auf diesen Voraussetzungen auf, indem es geeignete Identitätsfaktoren auswählt und in die zielkreise der internen und externen Öffentlichkeit vermittelt, um die gewünschte Identitätswirkung (z.B. Neuakquisition) herbeizuführen.

327 An diesem Beispiel wird noch einmal deutlich, daß Marketing kein Allheilmittel sein kann, sondern letztlich auf der Basis der gegebenen strukturen aufbauen muß. Vor diesem Hintergrund fehlt auch den an das Placemarketing gerichtete Vorwurf, ein "Nebenparlament" etablieren $\mathrm{zu}$ wollen, die Grundlage. Zu diesen Vorwürfen vgl. beispielsweise o.v., stadtmarketing - mehr als Mode?, in: Der Städtetag, 1/1992, S. 1 (Leitartikel). 


\section{D . \\ Schlußbetrachtung \\ 1 . \\ zusammenfassende wïrdigung der Untersu- chungsergebnisse}

Im zuge des wachsenden interkommunalen Wettbewerbs gewinnt die Profilierung im Wettbewerbsumfeld sowie die Identifikation interner und externer zielkreise für städte und Regionen zunehmend an Bedeutung. Unter diesem Eindruck sollte in der vorliegenden Untersuchung der stellenwert räumlicher Identität als Aufgabenfeld des Städte- und Regionenmarketing herausgearbeitet werden. Angesichts der Neuartigkeit des Forschungsfeldes für die Marketingwissenschaft und des Fehlens einer allgemein akzeptierten Definition wurde in der vorliegenden Untersuchung zunächst der versuch unternommen, eine tragfähige Definition des Städte- und Regionenmarketing $\mathrm{zu}$ entwickeln. Dazu wurden die in Theorie und Praxis gängigen Begriffsverwendungen aufgegriffen und einander gegenübergestellt. Auf dieser Grundlage sollte räumliche Identität als Aufgabenfeld des Städte- und Regionenmarketing aufgearbeitet werden.

Unter Bezugsnahme auf diese zielsetzungen sind die vorliegenden konzeptionellen Ansatzpunkte, empirischen Ergebnisse und auch die Implikationen für das städte- und Regionenmarketing $\mathrm{zu}$ würdigen:

- Zur Präzisierung des Begriffsverständnisses räumlicher Identität konnte nicht auf betriebswirtschaftliche Arbeiten $z u$ vergleichbaren Fragestellungen zurückgegriffen werden. Aus diesem Grunde wurden zunächst sozialwissenschaft 1 iche Identitätsaufassungen analysiert, welche auf Grundlage der Differenzierung zwischen Innen- und Außenperspektive im wesentlichen drei verschiedene Begriffsverwendungen erkennen lassen. Dabei zeigte sich, daß räumliche Identität unmittelbar als ein Bestandteil des sozialwissenschaftlichen Iden- 
titätsverständnisses und damit als ein Bestandteil der Identität einer Person aufgefaßt werden kann.

- Ausgehend von den generellen Verwendungsweisen des Identitätsbegriffes in den Sozialwissenschaften und unter dem Eindruck der alltagssprachlichen Begriffsverwendung kristallisierten sich zwei Verwendungsweisen räumlicher Identität heraus. Dabei wurde die erstgenannte Verwendungsrichtung für die weitere Untersuchung herausgegriffen:

1. In einem ersten Bedeutungskontext läßt sich räumliche Identität als Teilidentität bzw. als Substruktur der persönlichen Identität einer Person oder als Bestandteil des "Wir-Gefühls" einer Gruppe auffassen: Die Person hat eine räumliche Identität.

Unter Rückgriff auf umweltpsychologische Forschungen wird räumliche Identität noch weiter aufgeteilt in die:

- Identifizierung von (räumlicher Umwelt) im Sinne einer psychologischen Raumrepräsentation, sowie in die

- Identifikation mit (räumlicher Umwelt) im Sinne eines räumlichen zugehörigkeits- oder Verbundenheitsgefühls.

2. Zum Verständnis der zweiten Bedeutungsrichtung räumlicher Identität wird die Perspektive verändert. Der Identitätsbegriff wird nicht auf Person, sondern auf einen Raum bezogen, der als Identität aufgefaßt wird: Die Stadt oder Region ist eine räumliche Identität. 
Im weiteren Verlauf der Untersuchung wurde eine Schwerpunktsetzung auf die erstgenannte Verwendungsrichtung vorgenommen.

- Angesichts des Fehlens betriebswirtschaftlicher Untersuchungen zum Themenfeld räumliche Identität wurden Ansatzpunkte sozialwissenschaftlicher Nachbardisziplinen mit dem $\mathrm{Ziel}$ aufgegriffen, das Verständnis räumlicher Identität aus Marketingsicht $\mathrm{zu}$ vertiefen. Mit dem Heimatbegriff und der geographischen Regionalbewußtseinsforschung wurden exemplarisch zwei Forschungsfelder herausgegriffen, welche die inhaltliche Nähe zum Zentralbegriff der vorliegenden Arbeit kennzeichnet. Impulse für das eigene Begriffsverständnis lieferte insbesondere die innergeographischen Diskussion, welche die Sinnfälligkeit der Erforschung räumlichen Bewußtseins in Frage stellt. Der Gedanke, die einem bestimmten Raum gegenüber geäußerte Zugehörigkeit (oder Aversion) als räumlichen kode aufzufassen, welche nicht auf einem bestimmten Raum, sondern auf "andere“ Sachverhalte ausgerichtet ist, erwies sich als interessanter Aspekt für die weiterführenden überlegungen.

- Mit Bewohnern, ortsansässigen Entscheidern und Auswärtigen wurden drei Gruppen von Trägern räumlicher Identität (Identitätsträger) unterschieden. Auf der Grundlage von Plausibilitätsüberlegungen wurden

Angesichts ihrer theoretischen Anlage kommt der vorliegenden Arbeit der Charakter einer Basisuntersuchung $z u$, die das generelle Verständnis räumlicher Identität als Gegenstand des städte- und Regionenmarketing aufzeigt und zur Präzisierung des Begriffsverständnisses Ansätze verschiedener sozialwissenschaftlicher Nachbardisziplinen berück- 
sichtigt. Die Beantwortung tiefergehender Fragestellungen muß weiteren, darauf aufbauenden Untersuchungen vorbehalten bleiben. Ausgehend von dieser Einschätzung zeichnen sich verschiedene Ansatzpunkte für detailliertere Analysen $\mathrm{ab}$ :

Mit Blick auf die empirische überprüfung räumlicher Identität lassen sich die folgende Feststellungen treffen:

- Die durch die Berücksichtigung verschiedener räumlicher Hierarchieebenen erzielte Breite des Forschungsdesigns der vorliegenden Untersuchung konnte nicht durch eine entsprechende Tiefe ergänzt werden. So fehlt eine angemessene Berücksichtigung des mehrdimensionalen charakters räumlicher Identität, indem beispielsweise zwischen emotional neutralen und affektiven Bindungen an die stadt oder Region unterschieden wird.

- Die empirische Analyse ist überwiegend auf Bestimmungsfaktoren ausgerichtet, welche durch das städte- und Regionenmarketing nicht direkt beeinflußbar sind. Es erscheint jedoch notwendig, das aufgezeigte Beziehungsgefüge zwischen angebots-, maßstabs- und personenbezogenen Einflußgrößen und räumlicher Identität umfassend aufzuarbeiten. Dabei ist ein besonderes Augenmerk auf diejenigen Einflußgrößen $\mathrm{zu}$ legen, welche durch das Städte- und Regionenmarketing beeinflußt werden können. Dazu lassen sich insbesondere die angebotsbezogene Einflußgrößen rechnen.

- Für die Entwicklung von Meßkonzepten und mit Blick auf die empirischen Vorgehensweisen sozialwissenschaftlicher Nachbardisziplinen ist die Frage aufzuwerfen, ob räumliche Identität als oberflächen- oder Tiefenphänomen aufgefaßt wird. Beide Vorgehensweisen erfordern ein unterschiedliches meßtechnisches Instrumentarium. 
Mit Blick auf weiterführende konzeptionelle und empirische Forschungen scheint die orientierung an der Hierarchie räumlicher Maßstabsebenen ein geeigneter Ansatzpunkt $\mathrm{zu}$ sein. Ausgehend von der Unterteilung zwischen einem Mikro- und einem Mesomaßstab bietet sich eine interdisziplinäre Vorgehensweise an:

- Auf der Mikroebene stellt die Nachbarschaftsforschung ein breites Feld verschiedener konzeptioneller und empirischer Ansätze zu verschieden Aspekten räumlicher Bindungen bereit ( "Satisfaction-with-Neighborhood; "Attachment-to-Neighborhood"). Im einzelnen ist dabei zu überprüfen, inwiefern die vergleichbarkeit der Bindungsarten und -wirkungen von Mikro- und Mesomaßstab gegeben ist.

- Darüber hinaus sollten Forschungsansätze aus der Regionalplanung und -politik einbezogen werden, welche vornehmlich die Mesoebene als Untersuchungsobjekt behandeln. Ein möglicher Ansatzpunkt stellt beispielsweise die regionalpolitische Diskussion uber Möglichkeiten zur Berücksichtigung "endogener Potentiale” als Strategieelement der Regionalpolitik dar.

Die systematisierung des Raums in Maßstabsbereiche ist darüber hinaus bedeutsam, weil in Abhängigkeit von der Position des Referenzraums in der Hierarchie unmittelbare Auswirkungen auf die Ausgestaltung des städte- und Regionenmarketing verbunden sind. So ist beispielsweise $\mathrm{zu}$ erwarten, daß mit größer werdendem Maßstabsbereich die internen Abstimmungsprozesse an Komplexität gewinnen.

Von genereller Bedeutung ist die Beobachtung der Entwicklungsperspektiven des städte- und Regionenmarketing in der Zukunft. Einerseits wird durch die Ausweitung der Märkte die Initiierung eines städte- und Regionenmarketing geradezu herausgefordert und andererseits stellen enger wer- 
dende Finanzspielräume Konzeptentwürfe wieder in Frage. Im Rahmen der Diskussion partnerschaftlicher Kooperationsformen sollte aus diesem Grund die Realisierbarkeit von Marketingkonzepten Beachtung finden.

Um eine kontinuierliche Selbstdarstellung der Stadt/Region in zeiten angespannter Haushaltskassen zu gewährleisten, sind Möglichkeiten zu diskutieren, inwiefern Marketingkonzepte durch die ortsansässige Wirtschaft getragen und finanziert werden können. Die Diskussion der Vor- und Nachteile muß insbesondere vor dem Hintergrund möglicher Vorbehalte politische Entscheidungsträger gegen eine privatwirtschaftliche Federführung betrachtet werden.

Gerade die von politischen Entscheidern geäußerte Befürchtung, der Einsatz von Marketing bezwecke eine Aushöhlung ihrer Kompetenzen muß dabei besonders ernst genommen werden ("Nebenregierung"-Argument). Zahlreiche Praxisbeispiele im Bereich des städtemarketing unterstreichen, daß Initiativen zur Etablierung des Marketingdenkens vielfach erheblichen Zündstoff in sich bergen. Der Ausgestaltung eines Marketing-Konzeptes muß deshalb in vielen Fällen überzeugungsarbeit bei den politischen Entscheidungsträgern über die Sinnfälligkeit derartiger Konzepte vorangehen. Das Marketing ist in diesem Fall gefordert, geeignete Implementierungskonzepte $z u$ formulieren.

Insgesamt wird die Erforschung räumlicher Identität als Aufgabenfeld des städte- und Regionenmarketing an Bedeutung gewinnen, wenn es gelingt, einerseits die unterschiedlichen Forschungsschwerpunkte umfassend aufzuarbeiten. Dabei ist eine interdisziplinäre Vorgehensweise anzustreben. Andererseits muß es der Forschung aber auch gelingen, pragmatische Methoden zu entwickeln und plausible Ergebnisse zu erzielen, die eine unmittelbare Anwendbarkeit im Rahmen des Städte- und Regionenmarketing ermöglichen. 


\section{Literaturverzeichnis}

Achterholt, G.

Afheldt, $\mathrm{H}$.

Akademie für Raumforschung und Landesplanung

Antonoff, R.

Antonoff, R.

Aring, J.,

Butzin, B., Danielzyk, R., Helbrecht, I.

Aring, J. Butzin, B., Danielzyk, R., Helbrecht, I.

Aschauer, W.

Ashworth, G.J., Voogd, $\mathrm{H}$.
Corporate Identity: in $10 \mathrm{Ar}-$ beitsschritten die eigene Identität finden und umsetzen, Wiesbaden 1988 .

Städte im Wettbewerb, in: Stadtbauwelt 1970, S. 100-103.

Aktuelle Probleme der Raumordnung. Raumbewußtsein, Verrechtlichung, Raumordnungsverfahren, Arbeitsmaterialien Nr.66, Hannover 1983.

Wie man seine stadt verkauft. Kommunale Werbung und Öffentlichkeitsarbeit, Düsseldorf 1971 .

Corporate Identity für städte, in: Arbeitsgemeinschaft des Symposiums "stadtvisionen", v. 2./3. März" 1989 in Muinster, s. $1-7$.

„... daß die Wahrnehmung wichtiger ist als die Realität?" Zur Krisenbewältigung und Regionalentwicklung im Ruhrgebiet, in: Ber. z. dt. Landeskunde, $63 / 1989$, s. 513-536.

Krisenregion Ruhrgebiet, in: Wahrnehmungsgeographische stud i e $n \quad z$ u r Regionalentwicklung Nr.8, oldenburg 1989.

Zum Nutzen von "Ethnizität" und "Regional-" oder "Heimatbewußtsein" als Erklärungsansatz geographischer Theoriebildung, Ôsterreichische Assoziation Kritischer Geographen (Hrsg.), Kritische Geographie Bd.7, Wien 1990 , S. 3-27.

Selling the city. Marketing approaches in public sector urban planning, London, New York 1990. 
Backhaus, K., Erichson, B., Plinke, W., Weiber, R.

Bahrenberg, G.

Bartels, D.

Bassand, M.

Bassand, $M$. Hainard, G.

Bauer, F.

Becker, H., Keim, K.D.

Benzing, A.

Bergler, $\mathrm{R}$.

Birkenhauer, J.

Birkigt, K., Stadler, M.M., Funck, H.J.

Bleymüller, J., Gehlert, $\mathrm{H}$.

Bleymuiller, J.
Multivariate Analysemethoden, Eine anwendungsorientierte Einführung, Berlin u.a. 1990.

Unsinn oder Sinn des Regionalismus in der Geographie, in: Gz, $\mathrm{Jg} .75, \mathrm{H} .3,1987$, S. 149-160.

Schwierigkeiten mit dem Raumbegriff in der Geographie, in: Geographica Helvetica 1974, Beiheft zu Nr.2/3, S. 7-21.

Lidentité régionale. Regionale Identität, Saint-Saphorin 1981.

Regionale sozio-kulturelle Dynamik, Publikationen des Schweizerischen Nationalfonds aus den nationalen Forschungsprogrammen Bd.34,5, Bern, Stuttgart 1985.

Datenanalyse mit spSS, Berlin u.a. 1984 .

Wahrnehmung in der städtischen Umwelt - möglicher Impuls für kollektives Handeln, 4.Aufl., Berlin 1978.

Verwaltungsgeographie, Köln 1978.

Der standort als Imagefaktor, unveröffentlichtes Manuskript, o.0., 1991.

Die Daseinsgrundfunktionen und die Frage einer "curricularen Plattform" für das Schulfach Geographie, in: Geographische Rundschau, 26/1974, S. 499-503.

Corporate Identity. Grundlagen Funktionen Fallbeispiele, 4., aktualisierte und erweiterte Auflage, Verlag Moderne Industrie, Landsberg am Lech, 1988.

Statistik für wirtschaftswissenschaftler, 5. Aufl., München 1981 .

Faktorenanalyse, Münster 1978. 
Blotevogel, H.H., Heinritz, G.,

Popp, $\mathrm{H}$.

Blotevogel, H.H., Heinritz, G.,

Popp, $\mathrm{H}$.

Blotevogel, H.H., Heinritz, G.,

Popp, $\mathrm{H}$.

Böhm, B.

Böltz, C.

Boesch, M.

Braun, G.E. ,

Töpfer, A. (Hrsg.)

Cadosch, W.

Campillo-Lundbeck, S.

Canter, D.

Conzen, P.

Danielzyk, R.,

Wiegandt, C.-C.

De Levita, D.J.
Regionalbewußtsein. Bemerkungen zum Leitbegriff einer Tagung, in: Ber. z. dt. Landeskunde, H.1, 1986, S. 103-114.

Regionalbewußtsein - Überlegungen zu einer geographisch landeskundlichen-Forschungsinitiative, in: IzR, H.7/8, 1987, S. 409-418.

"Regionalbewußtsein". Zum Stand der Diskussion um einen stein des Anstosses, in: GZ, Jg.77, H.2, 1989, 65 ff.

Identität und Identifikation. Z u r Persistenz physikalischer Gegenstände, Frankfurt/Mn . u.a. 1989 .

City-Marketing. Eine stadt wird verkauft, in: Bauwelt, H.24, 1988, S. 996-997.

Engagierte Geographie, Stuttgart 1989 .

Marketing im kommunalen Bereich - Der Bürger als "Kunde" seiner Gemeinde, Verlag Bonn Aktuell, Stuttgart 1989.

Marketingstrategien für öffent$1 \mathrm{ich}$ e Energieversorgungsunternehmen, Berlin, Stuttgart 1982.

Standortmarketing gegen Imagedefizite, in: HORIZONT Nr. $46 \mathrm{v}$. 19.11.1993, S. 89 .

The psychology of place, New York 1977.

E. H. Erikson und die Psychoanalyse. Systematische Gesamtdarstellung seiner theoretischen und klinischen Positionen, Heidelberg 1989.

Regionales Alltagsbewußtsein als Faktor der Regionalentwicklung? Untersuchungen im Emsland, in: IzR, H.7/8, 1987, S. 441-449.

Der Begriff der Identität, Frankfurt am Main 1971. 
De u t s cher Industrieund Handelstag (Hrsg.)

Deysson, C.

Dill, $P$. Hügler, G.

Drinkmann, E.

Eichhorn, P., Buchholz, W.

Eick, G.

Eimer, E.

Eiteneyer, $\mathrm{H}$.

Eiteneyer, H., Meissner, H.G.

Endruweit, G.

Engelhard, A.
Modernes Stadtmarketing. Attraktive Innenstadt, Bonn 1989.

USA: Licht ausknipsen, in: WiWo $\mathrm{Nr} .12$ v. 18.3.1994, S. 36-39.

Unternehmenskultur und Führung betriebswirtschaftlicher organisationen - Ansatzpunkte für ein kulturbewußtes Management, in: Heinen, E., (Hrsg.): Unternehmenskultur, München 1987.

Mobilität und Raumbewußtsein. Untersuchungen am Beispiel der Pfarrerschaft der Evangelisch Lutherischen Kirche in Bayern, München 1991.

Marketing in öffentlichen Verwaltungen, in: BFuP, $35 . \mathrm{Jg}$., Nr.3, 1983, S. 209-221.

Der Rhein-Main-Region fehlen bisher noch gemeinsame ziele und ein politisches Dach, in: HB Nr. 233 v. 02.12.1993, S. B11.

Varianzanalyse, stuttgart u.a. 1979.

Social Marketing-Unternehmensphilosophie öffentlicher Unternehmen, in: ZfbF, H.5, 1977, S. 303-311.

Marketing öffentlicher Unternehmungen, Schriftenreihe des Lehrstuhls für Marketing der Universität Dortmund, Dortmund 1978 .

Raumbewußtsein bei Bürgern und Öffentlichkeit als Planungsbedingung, in: ARL (Hrsg.), Aktuelle Probleme der Raumordnung. Raumbewußtsein, Verrechtlichung, Raumordnungsverfahren, Arbeitsmaterialien Nr.66, Hannover 1983, S. 19-55.

Ein Ballungsraum mit sehr vielen Vorteilen. EMNID-Studie zum Eigen- und Fremdimage des Wirtschaftsraumes Rhein-Main, in: HORIZONT Nr.40 v. 02. 10.1992, S. 57 . 


\author{
Erlebach, D., Schück- \\ haus, U. \\ Esser, H.
}

Fichtner, U.

Fischer, C.S.

Flemming, $\mathrm{M}$.

Frey, H.P.,

Haußer, K.

Ganser, G.

Gehrig, R.,

Leibundgut, $\mathrm{H}$.

Geipel, R.

Gerdes, D.
Rüstzeug. Stadtmarketing und die Zukunft der Kommunen, in: Der Gemeinderat, 2/1994, S. 16-17.

Lokale Identifikation im Ruhrgebiet. Zur allgemeinen Erklärung einer speziellen Angelegenheit, in: IzR, 3/1987, S. 109-118.

Regionale Identität am Südlichen Oberrhein - zur Leistungsfähigkeit eines verhaltenstheoretischen Ansatzes, in: Ber. z. dt. Landeskunde, Bd.62, H.1, 1988, S. 109-139.

Networks and places. Social Relations in the Urban setting, New York, London 1977,

Regionalbewußtsein und regionale Identität in der Region Franken/Baden-Würtemberg, in : Arbeitsmaterialien zur Raumordnung, H.43, Regionales Bewußtsein und regionale Identität als Voraussetzung der Regionalpolitik, Bayreuth 1985, S. 5-14.

Entwicklungslinien sozialwissenschaft 1 icher Identitätsforschung, in: H.-P. Frey, K. HauBer (Hrsg.), Identität. Entwicklungslinien psychologischer und soziologischer Forschung, stuttgart 1987, s. 3-26.

Image als entwicklungsbestimmendes steuerungsinstrument, in: Stadtbauwelt 1970, S. 104-108.

Grundlagen zur Abgrenzung und Typisierung von Planungsregionen, Zürich 1971 .

Regionale Fremdbestimmtheit als Auslöser territorialer Bewußtwerdungsprozesse, in: Ber. z. dt. Landeskunde, Bd.58, H.1, 1984 , S. 37 ff.

Regionalismus und Politikwissenschaft. Zur Wiederentdeckung von "Territorialität" als innenpolitischer Konfliktdimension, in: GR 39，H. 10，1987，S. 526-531. 
Gerson, K. , Stueve, C.A., Fischer, C.S.

Glaser, H.

Gloor, R.

Göschel, A.

Goffmann, E.

Greverus, I.M.

Habermas, J.

Haedeke, G.

Hagen, D. , Hasse, J., Krüger, $\mathrm{R}$.

Hänni, H.D.

Hahne, U.
Attachment to place, in: Fischer, C.S., Networks and places. Social Relations in the Urban setting, New York, London 1977, S. 139-161.

Die Kulturstat und die zukunft der Industriegesellschaft, Wien 1991

Die Rolle der Metapher in der Betriebswirtschaftslehre, Bern 1987.

Lokale Identität als Element der Stadtentwicklung. Forschungsbericht, Informationszentrum Raum u n d Bau. Fraunhofer-Gesellschaft, Stuttgart 1984 .

Stigma. Über Techniken der Bewältigung beschädigter Identität, Frankfurt 1967 .

Auf der Suche nach Heimat, München 1979.

Moderne und postmoderne Architektur, in: Theorie des kommunikativen Handelns, Bd.2, Frankfurt 1981. S. 11-29.

Meilensteine auf dem Weg zum Stadtmarketing, in: Dokumentation des Stadtmarketing Symposiums v. 18.-19. März -92 in Kassel.

Bestand und Veränderungstendenz e n r äu m i ch er Identität (Heimatbewußtsein) angesichts bevorstehender Umweltveränderungen durch den Neubau eines seedeiches, Wahrnehmungsgeographische studien zur Regionalentwicklung 2, Oldenburg 1984.

Regionales Tourismus- Marketing, Bern 1984 .

Das Regionstypische als Entwicklungschance? Zur Identifizierbarkeit und Vermarktung regionaler Produkte, in: IzR, H.7/8, 1987, S. 465-473. 
Hamm, B.

Hammann, P.

Hard, G.

Hard, G.

Hartzfeld, U., Junker, R.

Hartzfeld, U., Reetz, C.

Hasitschka, W. , Hruschka, H.

Hasse, J.

Hasse, J., Krüger, R.

Haus, U.
Die Organisation der städtischen Umwelt, Frauenfeld, Stuttgart 1977 .

Ansätze zu einem Marketing für kommunale standorte, in: Arbeitspapiere zum Marketing $\mathrm{Nr}$. 15, Ruhr-Universität Bochum, Seminar für angewandte Wirtschaftslehre, Bochum 1986.

"Bewußtseinsräume" . Interpretationen zu geographischen Versuchen, regionales Bewußtsein zu erforschen, in: GZ, Bd.75, 1987, S. 127-148.

Das Regionalbewußtsein im spiegel der regionalistischen Utopie, in: IzR, H.7/8, 1987, S. 419-440.

City-Management - Anything goes?, in: Raumplanung, H.45, 1989, S. 116-119.

City-Management - Anything goes?, in: Raumplanung, H.50, 1990 , S. 175-177.

Nonprofit-Marketing, München 1982 .

"Regionale Identität" : Zur Reichweite verschiedener wissenschaftstheoretischer Zugriffe auf ein zwiespältiges Phänomen, in: Mitteilungen des Arbeitskreises für Neue Methoden in der Regionalforschung (AMR-Info), $18 / 1988$, S. 30-38.

Raumentwicklung und Identitätsbildung in der nordwestdeutschen Küstenregion, Wahrnehmungsgeographische studien zur Regionalentwicklung, H. 1, Oldenburg 1984 .

Lokale Identität im Zeichen der Gemeindegebietsreform in oberfranken. Drei Fallbeispiele aus dem ländlichen Raum, in: Ber. $z$. dt. Landeskunde, Bd.64, H.1, 1990 , S. 131-156. 
Heimann, $\mathrm{H}$.

Heinacher, P.

Heinemann, G.

Heinen, E.

Heinz, w.

Helbrecht, I., Danielzyk, R., Butzin, B.

Helms . V.

Hennicke, H., Tengler, $\mathrm{H}$.

Herlyn, U •
City-Management - eine neue Strategie für Stadtzentren - am Beispiel der Innenstadt Solingen, in: stadtmarketing in der Diskussion, ILS (Hrsg.), ILSSchriften Nr.56, Duisburg 1991, S. 63-67.

NRW: Wettbewerb zwischen den Regionen deutlich spürbar, in: $\mathrm{HB}$ Nr.55 v. 19.3.1991.

Betriebstypenprofilierung und Erlebnishandel, Wiesbaden 1989.

Identität: Ein bisher vernachlässigtes Element des zielsystems der Unternehmung?, in: Wirtschaftstheorie und Wirtschaftspolitik, Gedenkschrift für E. Preiser, hrsg. v. Mückl, W., Ott, A. E., Passau 1981, S. $125 \mathrm{ff}$.

Partnerschaftsprojekte für die stadtentwicklung - Lehren und Thesen, in: Der städtetag, 3/1993, S. 210-213.

Wahrnehmungsmuster und Bewußtseinsformen als qualitative Faktoren der Regionalentwicklung: Fallstudie Ruhrgebiet, in: Raumforschung und Raumordnung, H.4, 1991, S. 229-236.

Public Private Partnership heißt das neue stichwort, in: HB Nr. 222 v. 16.11.1993, S. B3.

Industrie- und Gewerbepark als Instrument der kommunalen wirtschaf tsförderung, Stuttgart 1986.

Individualisierungsprozesse im Lebenslauf und städtische Lebenswelt, in: J. Friedrichs (Hrsg.), Soziologische Stadtforschung, Opladen 1988, S. 111131 . 
Hesse, J.

Hettlage, $\mathrm{R}$.

Heuer, $\mathrm{H}$.

Heuer, $\mathrm{H}$.

Hilgers, W.W.

Homann, $\mathrm{K}$.

Homann, $\mathrm{K}$.

Honert, S.

Honert, S.

Hunter, A.
Zum Marketingverständnis öffentlicher Unternehmen, in: Jahrbuch der Absatz und Verbrauchsforschung, Hrsg.: Gesellschaft für Konsum-, Markt- und Absatzforschung, Berlin 1981.

Regionalkultur ohne Region: zur Bedeutung regionaler Identitäten in der Schweiz, in: Lipp, $W$. (Hrsg.), Industriegesellschaft und Regionalkultur, Köln, Berlin, Bonn, München 1984, S. 197225 .

Imagepflege und Standortmarketing werden wieder $z u$ wichtigen Handlungsfeldern der Kommunen, in: HB Nr. 225 v. 23.11.1988, S. 28 .

Instrumente kommunaler Gewerbepolitik. Ergebnisse empirischer Erhebungen, Stuttgart u.a. 1985.

Lebensraum, Sozialisation und Identitätsbildung. Sozialökologische sowie umweltpsychologische Erklärungsansätze zur symbolischen Ortsbezogenheit, Düsseldorf 1990 .

Mehr Bürgernähe in Kommunalverwaltungen durch Marketing, in: Der Städtetag, 1986, S. 607-610.

Marketing in Kommunalverwaltungen, in: Homann, K., Meissner, H.G. (Hrsg.), Schriftenreihe des Lehrstuhls für Marketing, Universität Dortmund, H.4, Dortmund 1986 , S. $30 \mathrm{ff}$.

stadtmarketing in Langenfeld, stadtmarketing in der Diskussion, ILS (Hrsg.), ILS-Schriften Nr.56, Duisburg 1991, S. 63-67.

Stadtmarketing und stadtmanagement, in: Der Städtetag, 44.Jg., H.6, 1991, S. 394-401.

Symbolic communities: The persistence and change of Chicago's local communities, Chicago 1976. 
Jacobs, S.

Junker, R. ,

Schulte, $\mathrm{W}$.

Kammerer, J.

Kamps , $\mathbf{M}$.

Kemming, $\mathrm{H}$.

Kerscher, U.

Kieser, A. (Hrsg.)

Klemmer, $\mathrm{P}$.

König, R.

Kolks, U.
City-Marketing. Die Anwendung de $r$ Marketing-Technologie zur Erhöhung der Einkaufsattraktivität von Innenstädten, in: Marketing ZFP, H.2, II. Quartal 1991, S. $121-130$.

City-Management Hamm, in: Der Städtetag, 9/1992, S. 659-664.

Beitrag der Produktpolitik zur Corporate Identity, Reihe Produktforschung und Industriedesign, E. Leitherer (Hrsg.), GBIVerlag, München 1988.

Private und öffentliche Partner, in: Der Städtetag, 2/1992, S. $156 \mathrm{f}$.

Zur Gestaltung von Stadtmarketing - Orientierungen für die Praxis, stadtmarketing in der Diskussion, ILS (Hrsg.), ILSSchriften Nr.56, Duisburg 1991, S. 7-14.

Raumabstraktionen und regionale Identität: Eine Analyse des regionalen Identitätsmanagements zwischen Augsburg und München, Kallmünz 1992 .

Organisationstheorien, Köln 1993.

D i e Gemeinschaftsaufgabe "Verbesserung der Regionalen Wirtschaftsstruktur" . Zwischenbilanz einer Erscheinungsform des kooperativen Föderalismus, in: Konrad Adenauer stiftung (Hrsg.), Dezentralisierung des politischen Handelns III. Konzeption und Handlungsfelder, Melle 1987.

Grundformen der Gesellschaft: Die Gemeinde, Hamburg 1958.

Strategieimplementierung. Ein anwenderorientiertes Konzept, Wiesbaden 1990. 
Kolz, H. ,

Essling, $\mathrm{H}$.

Kotler, P.

Kotler, P.

Krafft, A.

Ulrich, G. ,

Kral, F.

Krappmann, L.

Krawinkel, H.

Kroeber-Riel, W.

Kroeber-Riel, W.

Kroeber-Riel, W.

Kroeber-Riel, W.
Standort-Marketing - ein Konzept zur kommunalen Wirtschaftsförderung, in: Der Städtetag, 10/86, S. 677-680.

Marketing für Nonprofit-Organisationen, Stuttgart 1978.

Marketing für den öffentlichen Bereich, in: DBW, 39/1979, S. 421-430.

Chancen und Risiken regionaler selbstorganisation, opladen 1993.

Die Metropole kann ihre Probleme nur gemeinsam mit der gesamten Region lösen, in: HB Nr. $123 \mathrm{v}$. 29./30.06.1990, s. 27 .

Soziologische Dimensionen der Identität, 5. Aufl., stuttgart 1978 .

Bremen: Eine "Nordwest, Gemeinschaft" soll jetzt dem stadtstaat das überleben sichern, in: HB v. 19./20.01.1991.

Konsumentenverhalten, 4. Aufl., München 1990 .

Neuere Methoden der Marktforschung, in: DBW, 43/1983, H.2, S. $277 \mathrm{ff}$.

Die inneren Bilder der Konsumenten - Messung, Verhaltenswirkung, Konsequenzen für das Marketing, in: Marketing. ZFP, $6 / 1986$, H.2, S. 81 ff.

Strategie und Technik der Werbung - verhaltenswissenschaftliche Ansätze, Edition Marketing, Stuttgart, Berlin 1988. 
Krüger, R. Hasse, $J$.

Krupat, E.

Lackner, W.

Lalli, M.

Lalli, M., Plöger, $W$.

Landwehr, $\mathrm{R}$.

Linde, н.

Lynch, K.

Mai, U.

Maier, J.
Raumentwicklung und Identitätsbildung in der nordwestdeutschen Kuistenregion: Wahrnehmungsgeographische untersuchung zur räumlichen Umweltqualität und ihrer verbesserung, Wahrnehmungsgeographische studien zur Regionalentwicklung $1 / 2$, Oldenburg 1984.

A place for place identity, in: Journal of Environmental Psychology, 3/1983, S. 343-344.

Städte-Ranking: Ein Instrument kommunaler Wirtschaftsförderung, in: Der Städtetag, 6/1992, S. $471 \mathrm{f}$.

Stadtbezogene Identität. Theoretische Präzisierung und empirische Operationalisierung, Darmstadt 1989.

Corporate Identity für städte. Ergebnisse einer bundesweiten Gesamterhebung. Nachdruck des Berichts $\mathrm{Nr} \cdot 90^{-1}$ des Instituts für Psychologie der Technischen Hochschule Darmstadt, 2. Aufl., Oktober 1990.

Die Gliederung des Raumes: Typisierung, Regionsabgrenzung und Regionierung, Beiträge zum Siedlungs - und Wohnungswesen und zur Raumplanung, Bd.22, Ernst, W., Thoss, R. (Hrsg.), Münster 1975.

Sachdominanz in Sozialstrukturen, Tübingen 1972 .

Das Bild der stadt, Braunschweig/Wiesbaden 1989.

Gedanken über räumliche Identität, in: Zeitschrift für Wirtschaftsgeographie, Jg.13, H.1/2, 1989, S. 12-19.

Sozialgeographie, Braunschweig 1977 . 
Maier, J.
Troeger-Weiss, G.

Meffert, $\mathrm{H}$.

Meffert, $\mathrm{H}$.

Meffert, $\mathrm{H}$.

Meffert, $H$.

Meffert, $\mathrm{H}$.

Meffert, $\mathrm{H}$.

Meffert, $\mathrm{H}$.

Meffert, $\mathrm{H}$.

Meffert, $\mathrm{H}$.

Meier-Dallach, H.-P.,

Hohermuth, S.,

Nef, R.
Marketing in der räumlichen Planung. Ansätze und Wege zu einer marktorientierten Regional- und Kommunalplanung/-politik, ARL (Hrsg.), Hannover 1990.

Marketing: Grundlagen der $\mathrm{Ab}-$ satzpolitik, Wiesbaden 1986.

Erfolgreiches Marketing in den neunziger Jahren, in: Atag \& Young (Hrsg.), Marketing im Umbruch, Referate anläßlich der Dolder-Tagung v. 23.05.1991 in Zürich.

Strategische Unternehmensführung u n d Marketing. Beiträge zur marktorientierten Unternehmenspolitik, Wiesbaden 1988.

Städtemarketing - Pflicht oder Kür?, in: Arbeitsgemeinschaft des Symposiums "Stadtvisionen", v. 2./3. März 1989 in Münster, S. 1 .

Marketing für das Münsterland Eine Bestandsaufnahme auf der Grundlage sekundärstatistischer Analysen, Münster 1989.

Regionenmarketing Münsterland. Ansatzpunkte auf der Grundlage einer empirischen Untersuchung, Münster 1991.

Marktforschung, Wiesbaden 1986.

Marketingforschung und Käuferverhalten, Wiesbaden 1992.

Marketing-Management. Analyse Strategie - Implementierung, Wiesbaden 1994.

Regionalbewu $\beta$ tsein, soziale Schichtung und politische KulturForschungsergebnisse und methodolgische Aspekte, in: IzR, H.7, 1987, S. 377-392. 
Meier-Dallach, H.-P.

Meier-Dallach, H.-P.

Meier-Dallach, H.-P.

Meier-Dallach, H.-P.

Meier-Dallach, H.-P.

Meissner, H.-G.

Meissner, R.

Ministerium für Wirtschaft, Mittelstand und Technologie des Landes Nordrhein-Westfalen

Mombaur, P.M.

Müller-Hagedorn, L.
Regionalbewußtsein und Empirie. De r quantitative, qualitative und typologische Weg, in: Ber. $z$. dt. Landeskunde, Bd.61, H.1, 1987, S. 5-29.

Räumliche Identität - Regionalistische Bewegung und Politik, in: IzR, H.5, 1980, S. 301-313.

Regionalbewußtsein, soziale Schichtung und politische Kultur. Forschungsergebnisse und methodologische Aspekte, in: IzR, H.7, 1987, S. 377-392.

Soziale Strukturen und räumliches Bewußtsein, Bern, Stuttgart 1985 .

Was macht die Identität einer Stadt aus?, Zürich 1990.

Grundprobleme eines regionalen Marketing der Industrieregion Ruhr, Vortrag im Rahmen des wissenschaftlichen Kolloquiums aus Anlaß des 60. Geburtstages von Prof. Dr. H.-G. Meissner am 6.10 .1989 .

Lebensqualität und Regionalbewußtsein - Objektive Lebensbedingungen und subjektive Raumbewertung im Kreis Leer (Ostfriesland), in: Ber. $z$. dt. Landeskunde 69, 1986 , S . 227247.

Handlungsempfehlungen regionale Entwicklungskonzepte

(26.11.1990)

Europäischer Binnenmarkt: Kommunalpolitik und Wirtschaftspolitik im Wettbewerb der standort, in: Städte- und Gemeinderat. Sonderdruck 4, 1989, S. 7-25.

Das Konsumentenverhalten. Grundlagen fur die Marktforschung, Wiesbaden 1986. 
Nieland, $\mathrm{M}$.

Onkelbach, H.

Ost, F. (Hrsg.)

Ostermann, M.

o.v.

$0 . \mathrm{V}$.

o.V.

$0 . v$.

$0 . V$.

o.V.

o.V.

o.v.

o.V.

o.v.
Standort-Marketing, in: Konzeptionen zur Industrieansiedlung, Hrsg.: Siedlungsverband Ruhrkohlebezirk, Essen 1977, S. 1-92.

Ein Image voller Kohlenstaub, in: Rheinische post $\mathrm{Nr} .93 \mathrm{v}$. 22.04.1994.

Multivariate statistische Verfahren, Berlin 1984

Die Imagepolitik von städten dargestelit am Beispiel der Stadt Köln, Diplomarbeit im Fach Absatz und Lehre, Köln 1989.

Stadtmarketing - mehr als Mode?, in: Der Städtetag, 1/1992, S. 1 .

Kommunales Marketing, in: Der Städtetag, 8/1989, S. 526-527.

Der Binnenmarkt zwingt Deutschlands Regionen zur stärkeren $\mathrm{Zu}-$ s ammenarbeit, in: HB v. $21 . / 22.02 .1992$, s. 6 .

"Neue Hanse Interregio" soll die Anliegen der Nordseeanrainer in Brüssel vertreten, in: $\mathrm{HB} v$. 08.04 .1992 .

Schleswig-Holstein: Wirtschaftliche und technologische Planungen sollen verzahnt werden, in: HB v. 11./12.10.1991, S. 7 .

Kommt Marketing ins Rathaus?, in: asw $8 / 89$, s. $36 \mathrm{ff}$.

Die neuen Stars der alten welt, in: Manager Magazin, 3/1990, S. 204-233.

City-Marketing für eine stadt, in: w\&v, 25.Jg., Nr.44, 1988, S. $30 \mathrm{ff}$.

Kommunen fürchten um die Etats der Imagewerbung, in: HORIZONT Nr.28 v. 16.07.1993, S. 1, 9.

Innenstadt zieht an, in: asw $8 / 87$, S. 26-35. 
o.v.

Pieper, R.

Pieper, R.

Pohl, J.

Proshansky, H.M., Fabian, A.K., Kaminoff, R.

Raffée, H.

Raffee, H.,

Wiedmann, K.-P.

Rammstein, 0 .

Reichhard, C.

Reinhard, W.

Relph, E.

Revensdorf, D.
D i e Rhein-Main-Region: Unterschiede und Gemeinsamkeiten, in: Der Städtetag, 12/1992, S. 855857.

Region und Regionalismus. Zur Wiederentdeckung einer räumlichen Kategorie in der soziologischen Theorie, in: GR, Bd.39, H.10, 1987, S. 534-539.

Die neue Sozialphysik, Frankfurt 1985 .

Regionalbewußtsein im Friaul, Habilitationsschrift im Druck.

Place-identity: Physical world socialization of the self, in: Journal of Environmental Psychology, 3/1983, S. 57-83.

Marketing in öffentlichen Betrieben, in: Marketing im Wandel, Schriftenreihe Unternehmensführung und Marketing, Meffert, H., Steffenhagen, H., Freter, H., (Hrsg.), Bd.13, Wiesbaden 1980 , S. $201 \mathrm{ff}$.

Nicht-kommerzielles Marketing ein Grenzbereich des Marketing, in: BFuP, 35.Jg., Nr.3, 1983, S. 185-208.

Bürgerbeteiligung und Bürgerinitiativen, villingen-Schwenningen 1977.

Kommunales Management im internationalen Vergleich, in: Der Städtetag, 12/1992, S. 843-848.

Die Identität von organisationen, Bonn 1983,

Place and Placelessness, Research in Planning and Design 1, London 1976.

Lehrbuch der Faktorenanalyse, Stuttgart 1976. 
Riger, S.,

Lavrakus, P.J.

Ringel, N.B.,

Finkelstein, J.C.

Ritter, w.

Röber, M.

Rohe, $\mathrm{K}$.

Roth, P.,

Stiller, R.

Ruhl, G.

Russel, J.A.

Ward, L.M.

Scheele, w.
Community Ties: Patterns of Attachment and Social Interaction in Urban Neighborhoods, in: American Journal of Community Psychology, Vol. 9, No.1, 1981, S. $55 \mathrm{ff}$.

Differentiating Neighborhood Satisfaction and Neighborhood Attachment Among Urban Residents, in: Basic and Applied Social Psychology, 1991, 12(2), S. 177193.

Allgemeine Wirtschaftsgeographie. Eine systemtheoretische Einführung, München 1991.

Marketing - ein Konzept für öffentliche Betriebe?, Publikationen der Fachhochschule für Verwaltung und Rechtspflege BerI in, Der Rektor der FHSVR (Hrsg.), Berlin 1988.

Regionalkultur, regionale Identität und Regionalismus im Ruhrgebiet, in: Lipp, W. (Hrsg.), Industriegesellschaft und Regionalkultur, Köln, Berlin, Bonn, München 1984, S. 123-153.

Stadtkommunikation, in: Werbeforschung \& Praxis, 5/1993, S. 187-189.

Das Image von München als Faktor für den zuzug, in: Münchener Geographische Hefte Nr.5, Geipel, R., Haartke, N. (Hrsg.), Kallmünz/Regensburg 1971.

Environmental Psychology, in: Annual Review of Psychology 33/1982, S. 651-688.

Von der städtewerbung zur kommunalen Corporate Identity: ein weiter Weg, in: Jahrbuch der Werbung, Neumann, E., Sprang, W. , Scheele, W. (Hrsg.), 0.0. 1986 , S. 54-59. 
Schneider, G.

Schneider, G. , Graumann, C.F.

Schnoor, $\mathrm{H}$.

Schöller, P.

Schubö, W. ,

Uhlinger, H.-M.,

Perleth, Ch.,

Schröger, E.,

Sierwald, W..

Schückhaus, U. ,

Graf, H.-A.,

Dormeier, $C$.

Schmied, w.

Schuler, M.

Schulze, H.-J.
Psychological identity of an identification with urban neighborhoods, in: Frick, D. (Hrsg.), The quality of urban life, Berlin 1986, S. 204-218.

Städtische Umwelt: Identität und Identifikation, in: $M$. Kampen (Hrsg.), Environment and human action, Berlin 1986 (west): Hochschule der Künste, S. 237240 .

Bürgernähe als Aufgabe von Politik und Verwaltung, in: Marketing in Kommunalverwaltungen, Schriftenreihe des Lehrstuhls für Marketing der Universität Dortmund H. 4, Homann, K., Meissner, H.G. (Hrsg.), Dortmund 1986.

Traditionsbezogene räumliche Verbundenheit als problem der Landeskunde, in: Ber. z. dt. Landeskunde, Bd.58, H.1， 1984 , S. 31-34.

Handbuch der Programmersionen 4.0 und SPSS-X 3.0, stuttgart und New York 1991.

Stadt- und Regionenmarketing. Einsatzmöglichkeiten und Nutzen, $\mathrm{K}$ i e $\mathrm{nb}$ a u $\mathrm{m}$ Unternehmensberatung GmbH, Düsseldorf, Februar 1993.

Ortsverbundenheit - eine Triebkraft für die Entwicklung ländlicher Räume?, in: IzR, H. 3, 1987 , S. 131-139.

Ein Verfahrensvorschlag zur Messung der regionalen Identität, in: Bassand, M. (Hrsg.), Regionale Identität, Saint-Saphorin 1981 .

Regionale Identität Erwachsener. Voraussetzungen und empirische Befunde, in: Raumforschung und Raumplanung, H.5/6, $1989, \mathrm{~S}$. 319-325. 
Singer, C.
Smith, R.L.
spsS $^{\circledR}$ GmbH Software

Staehle, w.

Stauss, B.

Steinhausen, D., Langer, $K$.

Steinmetz, F.

Stilcken, R.

Tafertshofer, A.

Taylor, R.N., Gottfredson, S.D., Brower, S.

Tietz, B.

Tietz, B.,

Rothhaar, P.
Kommunale Imageplanung, in: Archiv für Kommunalwissenschaften (AfK) II/88, S. 271-279.

Activism and social status as determinants of neighborhood identity, in: The Professional Geographer 37, 1985, S. 421-432.

SPSS $^{(1)}$ für Windows ${ }^{m}$. Anwenderbuch $\mathrm{f} \ddot{\mathrm{u}} \mathrm{d}$ das Basis System, München 1993.

Management, 6. Aufl., München 1991.

Grundlagen des Marketing öffentlicher Unternehmen, Baden-Baden 1987.

Clusteranalyse, Berlin u.a. 1977 .

Standortmarketing - aber wie?, in: Der Städtetag, H.3, 1986.

Rationale Argumente verlieren immer mehr an Kraft, in: Blick durch die Wirtschaft Nr.204, v. 20.10.1989, S. 7 .

Corporate Identity. Magische Formel als Unternehmensideologie, in: Die Unternehmung, 36.Jg., Nr.1, 1982, S. 11-25.

Attachment to place: Discriminant validity, and impacts of disorder and diversity, in: American Journal of Community Psychology 1985, 13, 525-542.

Regional- und Kommunalmarketing. Bericht über ein Forschungsprogramm, in: Marketing $\mathrm{ZFP}, \mathrm{H} .2$, Mai 1981, S. 129-132.

City studie - Marktbearbeitung und Management für die stadt Neue Konzepte für Einzelhandels$\mathrm{u} n$ d Dienstleistungsbetriebe, Verlag Moderne Industrie, Landsberg/Lech 1991 . 
Töpfer, A.

Töpfer, A., Braun, G.E.

Treinen, $\mathrm{H}$.

Trommsdorff, v.

Tuan, Y. $-\mathrm{F}$.

Tzschaschel, S.

Überla, K.

Uhlmann, J.

Wagner, G.R.

Weber, J.

Weiber, R.
Stadtmarketing, Eine neue Herausforderung an Kommunen, in: VOP, 6/1991, S. 339-344 (Teil 1); 1/1992, S. 22-26 (Teil 2).

Ansatzpunkte für Marketing im öffentlichen Bereich, in: Braun, G.E., Töpfer, A. (Hrsg.), Marketing im kommunalen Bereich. Der Bürger als "Kunde" seiner Gemeinde, stuttgart 1989.

Symbolische ortsbezogenheit. Eine soziologische Untersuchung zum Heimatproblem, in: Atteslander, P., Hamm, B. (Hrsg.), Materialien zur siedlungssoziologie, 1974, S. 234-259.

Konsumentenverhalten, Stuttgart 1989.

Place: An Experimental Perspective, in: Geographical Review 65/1975, S. 151-165.

Geographische Forschung auf der Individualebene, Münchener Geographische Schriften, 1986 , H. 53 .

Faktorenanalyse, Berlin, u.a. 1972 .

City-Marketing Velbert. Gemeinsame Arbeit mit Beteiligten und Betroffenen, in: Experimenteller Wohnungs- und Städtebau, November 1991, S. 29-31.

Kommunales Marketing, in: Verwaltungsrundschau, $30 . \mathrm{Jg}$., $\mathrm{Nr} .7$, 1984 , S. 225 ff.

Unternehmensidentität und unternehmenspolitische Rahmenplanung, Planungs - und Organisationswissenschaftliche Schriften, Nr.42, München 1985 .

Faktorenanalyse, st. Gallen 1984 . 
Weichhart, P.

Wirth, A.

Wittkämper, G.W.

Wolf, K., Otto, G. , Böttcher, F., Rümmler, $M$.

Wolf, K., Otto, G., Böttcher, F., Rümmler, $M$.

Wood, G.

Zentes, J.

Zimmermann, $\mathrm{K}$.
Raumbezogene Identität - Bausteine $z u$ einer Theorie räumlich-sozialer Kognition und Identifikation, Schriftenreihe für Forschung und Praxis, Hrsg. Emil Meynen in Verbindung mit Gerd Kohlhepp und Adolf Leidlmair, Erdkundliches Wissen, H.102, Stuttgart 1990 .

Bewahrung lokalen Bewußtseins $b$ e $i$ Umsiedlungsmaßnahmen im rheinischen Braunkohlerevier, in: IzR, H.10, 1981, S. 157-173.

Die Rolle der städte im neuen Jahrtausend, in: Arbeitsgemein$s$ c h a $t$ des symposiums "Stadtvisionen", v. 2./3. März 1989 in Münster.

Das Hessische Ried. Name und $\mathrm{Ab}-$ grenzung einer hessischen Landschaft im Regionalbewußtsein ihrer Bevölkerung, in: Bericht zur deutschen Landeskunde, Bd. 63, H. 2,1989 , S. 587-623.

Regionalbewußtsein im Hessischen Ried. Ansätze zur Begriffsbestimmung, räumlichen Dimensionierung und Interpretation, in: Materialien H.13, Institut für Kulturgeographie der Universität Frankfurt am Main (Hrsg.), Frankfurt 1989.

Regionalbewußtsein im Ruhrgebiet in der Berichterstattung regionaler Tageszeitungen, in: Ber. z. dt. Landeskunde, Bd.63, H.2, 1989 , S. 537-562.

Marketing für die Stadt, Vortrag vor dem EHV-Essen am 20.01.1988.

Zur Imageplanung von Städten. Untersuchungen zu einem Teilgebiet kommunaler Entwicklungsplanung, Kölner Wirtschafts- und Sozialwissenschaftliche Abhandlungen, Bd.5, Köln 1975. 
Zimmermann, $\mathrm{K}$.

Zörkendörfer, s.
Wirtschaftsförderung als Aufgabe des kommunalen Marketing, in: Die Kommunalwirtschaft, Nr.11, 1976 , S. $341 \mathrm{ff}$.

Statistische Datenanalyse mit dem Programmpaket SPSS-X, Softwareinformationen 13 des Rechenzentrums der Westfälischen wilhe $1 \mathrm{~ms}-\mathrm{Un}$ iversität Münster, 4.Aufl., Münster 1988 . 


\section{SCHRIFTEN ZUM MARKETING}

Band 1 Friedrich Wehrle: Strategische Marketingplanung in Warenhäusern. Anwendung der Portfolio-Methode. 1981. 2. Auflage. 1984.

Band 2 Jürgen Althans: Die Übertragbarkeit von Werbekonzeptionen auf internationale Märkte. Analyse und Exploration auf der Grundlage einer Befragung bei europaweit tätigen Werbeagenturen. 1982.

Band 3 Günter Kimmeskamp: Die Rollenbeurteilung von Handelsvertretungen. Eine empirische Untersuchung zur Einschätzung des Dienstleistungsangebotes durch Industrie und Handel. 1982.

Band 4 Manfred Bruhn: Konsumentenzufriedenheit und Beschwerden. Erklärungsansätze und Ergebnisse einer empirischen Untersuchung in ausgewählten Konsumbereichen. 1982.

Band 5 Heribert Meffert (Hrsg.): Kundendienst-Management. Entwicklungsstand und Entscheidungsprobleme der Kundendienstpolitik. 1982.

Band 6 Ralf Becker: Die Beurteilung von Handelsvertretern und Reisenden durch Hersteller und Kunden. Eine empirische Untersuchung zum Vergleich der Funktionen und Leistungen. 1982.

Band

7 Gerd Schnetkamp: Einstellungen und Involvement als Bestimmungsfaktoren des sozialen Verhaltens. Eine empirische Analyse am Beispiel der Organspendebereitschaft in der Bundesrepublik Deutschland. 1982.

Band 8 Stephan Bentz: Kennzahlensysteme zur Erfolgskontrolle des Verkaufs und der MarketingLogistik. Entwicklung und Anwendung in der Konsumgüterindustrie. 1983.

Band 9 Jan Honsel: Das Kaufverhalten im Antiquitätenmarkt. Eine empirische Analyse der Kaufmotive, ihrer Bestimmungsfaktoren und Verhaltenswirkungen. 1984.

\section{SCHRIFTEN ZU MARKETING UND MANAGEMENT}

Band 10 Matthias Krups: Marketing innovativer Dienstleistungen am Beispiel elektronischer Wirtschaftsinformationsdienste. 1985.

Band 11 Bernd Faehsler: Emotionale Grundhaltungen als Einflußfaktoren des Käuferverhaltens. Eine empirische Analyse der Beziehungen zwischen emotionalen Grundhaltungen und ausgewählten Konsumstrukturen. 1986.

Band 12 Ernst-Otto Thiesing: Strategische Marketingplanung in filialisierten Universalbanken. Integrierte Filial- und Kundengruppenstrategien auf der Grundlage erfolgsbeeinflussender Schlüsselfaktoren. 1986.

Band 13 Rainer Landwehr: Standardisierung der internationalen Werbeplanung. Eine Untersuchung der Prozeßstandardisierung am Beispiel der Werbebudgetierung im Automobilmarkt. 1988.

Band 14 Paul-Josef Patt: Strategische Erfolgsfaktoren im Einzelhandel. Eine empirische Analyse am Beispiel des Bekleidungsfachhandels. 1988. 2. Auflage. 1990.

Band 15 Elisabeth Tolle: Der Einfluß ablenkender Tätigkeiten auf die Werbewirkung. Bestimmungsfaktoren der Art und Höhe von Ablenkungseffekten bei Rundfunkspots. 1988.

Band 16 Hanns Ostmeier: Ökologieorientierte Produktinnovationen. Eine empirische Analyse unter besonderer Berücksichtigung ihrer Erfolgseinschätzung. 1990.

Band 17 Bernd Büker: Qualitätsbeurteilung investiver Dienstleistungen. Operationalisierungsansätze an einem empirischen Beispiel zentraler EDV-Dienste. 1991.

Band 18 Kerstin Ch. Monhemius: Umweltbewußtes Kaufverhalten von Konsumenten. Ein Beitrag zur Operationalisierung, Erklärung und Typologie des Verhaltens in der Kaufsituation. 1993. 
Band 19 Uwe Schürmann: Erfolgsfaktoren der Werbung im Produktlebenszyklus. Ein Beitrag zur Werbewirkungsforschung. 1993.

Band 20 Ralf Birkelbach: Qualitätsmanagement in Dienstleistungscentern. Konzeption und typenspezifische Ausgestaltung unter besonderer Berücksichtigung von Verkehrsflughäfen. 1993.

Band 21 Simone Frömbling. Zielgruppenmarketing im Fremdenverkehr von Regionen. Ein Beitrag zur Marktsegmentierung auf der Grundlage von Werten, Motiven und Einstellungen. 1993.

Band 22 Marcus Poggenpohl: Verbundanalyse im Einzelhandel auf der Grundlage von Kundenkarteninformationen. Eine empirische Untersuchung von Verbundbeziehungen zwischen Abteilungen. 1994.

Band 23 Kai Bauche: Segmentierung von Kundendienstleistungen auf investiven Märkten. Dargestellt am Beispiel von Personal Computern. 1994.

Band 24 Ewald Werthmöller: Räumliche Identität als Aufgabenfeld des Städte- und Regionenmarketing. Ein Beitrag zur Fundierung des Placemarketing. 1995. 


\section{Marketing \\ in der kommunalen Wirtschaftsförderung unter besonderer Berücksichtigung der Subventionsvergabe}

Frankfurt/M., Berlin, Bern, New York, Paris, Wien, 1992, XV, 268 S., 7 Abb., Tab. Europäische Hochschulschriften: Reihe 5, Volks- und Betriebswirtschaft. Bd. 1332 ISBN 3-631-45300-0 br. DM 84.--*

In der vorliegenden Schrift wird untersucht, ob und in welchem Maße mit Hilfe des Einsatzes von Marketinginstrumenten die weitverbreitete These widerlegt werden kann, kommunale Wirtschaftsförderung sei überflüssig und arbeite ineffizient. Die These bezieht sich insbesondere auf die kommunale Subventionsvergabe. Nach der einführenden Charakterisierung der kommunalen Wirtschaftsförderung wird die Übertragung von Marketingideen und -instrumenten auf die kommunale Wirtschaftsförderung vorgestellt. Den Schwerpunkt der Untersuchung stellt die Erörterung dar, welchen Beitrag zur effizienteren Subventionsvergabe insbesondere die Preispolitik zu leisten imstande ist. Um praktikable Kriterien einer differenzierten Vergabepolitik sowie Möglichkeiten zu einer verbesserten Subventionskontrolle aufzeigen zu können, werden grundsätzlich drei Fälle der Subventionierung unterschieden: die Neuansiedlung, die Erhaltung und die Erweiterung von Unternehmen und öffentlichen Einrichtungen. Dementsprechend werden abschließend drei Gestaltungsempfehlungen zur künftigen Vergabe von Kommunalsubventionen gegeben.

Aus dem Inhalt: Effizientere Ausgestaltung, d.h. Vergabe und Kontrolle von Kommunalsubventionen zum Zwecke der kommunalen Wirtschaftsförderung durch verstärkten Einsatz marketingpolitischer Instrumente (insbesondere der Preispolitik) - Verknüpfung von Marketing und kommunaler Wirtschaftsförderung

\footnotetext{
Peter Lang

Frankfurt a.M. - Berlin - Bern - New York - Paris - Wien

Auslieferung: Verlag Peter Lang AG, Jupiterstr. 15, CH-3000 Bern 15

Telefon (004131) 9411122, Telefax (004131) 9411131

- Preisănderungen vorbehalten - *inklusive Mehrwertsteuer
} 
Ewald Werthmöller and Universität Münster - 978-3-631-75084-1 Downloaded from PubFactory at 01/11/2019 08:31:35AM via free access 
Ewald Werthmöller and Universität Münster - 978-3-631-75084-1 Downloaded from PubFactory at 01/11/2019 08:31:35AM via free access 
Ewald Werthmöller and Universität Münster - 978-3-631-75084-1 Downloaded from PubFactory at 01/11/2019 08:31:35AM via free access 